\title{
Implementation and Evaluation of the MOVE! Program at Medical Weight Loss Center
}

Kimberly Bird

Follow this and additional works at: https://researchrepository.wvu.edu/etd

\section{Recommended Citation}

Bird, Kimberly, "Implementation and Evaluation of the MOVE! Program at Medical Weight Loss Center" (2015). Graduate Theses, Dissertations, and Problem Reports. 5213.

https://researchrepository.wvu.edu/etd/5213

This Dissertation is protected by copyright and/or related rights. It has been brought to you by the The Research Repository @ WVU with permission from the rights-holder(s). You are free to use this Dissertation in any way that is permitted by the copyright and related rights legislation that applies to your use. For other uses you must obtain permission from the rights-holder(s) directly, unless additional rights are indicated by a Creative Commons license in the record and/ or on the work itself. This Dissertation has been accepted for inclusion in WVU Graduate Theses, Dissertations, and Problem Reports collection by an authorized administrator of The Research Repository @ WVU.

For more information, please contact researchrepository@mail.wvu.edu. 


\title{
Implementation and Evaluation of the MOVE! Program at Medical Weight Loss Center
}

\author{
Kimberly Bird, MSN \\ Capstone Project submitted to the \\ School of Nursing at West Virginia University \\ in partial fulfillment of the requirements for the degree of \\ Doctor of Nursing Practice in \\ Family and Community Health
}
Georgia Narsavage, PhD, ANP-C, FAAN, FNAP, Chair
Emily Barnes, DNP, FNP-C, Co-Chair
Mary Colley, AD, CMIS
Kara Gilreath, RDLD

Department of Family and Community Health

\author{
Morgantown, West Virginia \\ 2015
}

Keywords: obese, weight loss, group sessions, BMI, MOVE!

Copyright 2015 Kimberly Bird 


\section{ABSTRACT \\ Implementation and Evaluation of the MOVE! Program at Medical Weight Loss Center}

Kimberly Bird, MSN

Background: Obesity is an increasing worldwide epidemic that contributes to chronic diseases such as Coronary Artery Disease (CAD), Hypertension (HTN), Hyperlipidemia, Diabetes Mellitus Type 2, some cancers, and even death. West Virginia ranks in the top ten most obese states with over $32 \%$ of the residents being obese. Research has shown that group education $\mid$ programs are more effective in weight loss than individual education programs.

Objective: The purpose of the study was to examine the change in weight, body mass index (BMI), systolic blood pressure, and number of steps of overweight or obese adult participants in a group weight loss program.

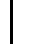

Method: Adult overweight and obese participants participated in a group weight loss program that promoted weight loss by journaling of foods consumed, activities completed, and group discussion or problem solving for a twelve-week period.

Outcomes: Due to the high attrition rate there were inadequate data to assess significance of the findings related to results of weight loss, decreased BMI, decreased systolic blood pressure, or increased number of steps walked daily. Important information was gained regarding individual | pros and cons of the Medical Weight Loss Program.

Discussion/Implications: The trend toward significance with the small sample suggests that the Managing Overweight/Obesity for Veterans Everywhere (MOVE!) Program has a strong potential for success in different venues with modifications to meet the needs of the participants. A modified program is successfully continuing at the center. 


\section{Table of Contents}

Title Page i

Abstract $\quad$ ii

Table of Contents

$\begin{array}{ll}\text { Introduction } & 1\end{array}$

$\begin{array}{lr}\text { Background and Significance } & 2-3\end{array}$

Epidemiology of the problem of obesity 2

Opportunities leading to the proposed project 2-3

$\begin{array}{lr}\text { Problem Statement 3-6 } & \end{array}$

$\begin{array}{ll}\text { Clinical practice guidelines on obesity } & 3-5\end{array}$

PICOT question $\quad 5$

Purpose of the Project 5

Significance of the Project 5-6

Literature Review and Synthesis 6-11

Search of electronic databases

$\begin{array}{ll}\text { Systematic Review } & 8\end{array}$

$\begin{array}{ll}\text { Synthesis } & 8-11\end{array}$

$\begin{array}{lr}\text { Theoretical Framework } & 12-17\end{array}$

$\begin{array}{ll}\text { Self-efficacy Theory } & 12\end{array}$

Enactive Mastery Experience $\quad 13$

$\begin{array}{ll}\text { Vicarious Experience } & 14\end{array}$

$\begin{array}{ll}\text { Verbal Persuasion } & 14\end{array}$ 
Physiological and Affective States 14-15

Transtheoretical Model 15-17

$\begin{array}{lr}\text { Project } & 17-27\end{array}$

Evidence Based Project/Intervention Plan 17-19

$\begin{array}{ll}\text { Feasibility } & 19-23\end{array}$

Resources - Personnel, Technology, Budget 23-24

Congruence of Organization's Strategic Plan to Project 24-25

Evidence of Key Site Support $\quad 25$

Measurable Project Objectives $\quad$ 26-27

$\begin{array}{lr}\text { Evaluation Methods } & \text { 27-28 }\end{array}$

$\begin{array}{lr}\text { Results } & 28-34\end{array}$

$\begin{array}{ll}\text { Statistical Analysis } & 29\end{array}$

Table 1 - Descriptive Results of BMI, Weight, BP, and steps $\quad 30-31$

Table 2 - MOVE! Program Participants Sessions Attended 31-33

Table 3 - Participant Comments 33-34

Discussion and Recommendations 34-38

Table 4 - Comparison of MOVE! Program Topics and the WLC Modified Program 35-38

$\begin{array}{ll}\text { Implications } & 38\end{array}$

Attainment of DNP Essentials $\quad 39-50$

Table 5 - Attainment of DNP Essentials $\quad 42-50$

$\begin{array}{lr}\text { References } & 51-56\end{array}$

$\begin{array}{lr}\text { Appendix A } & \text { 57-83 }\end{array}$ 
Appendix B

84-126

Appendix C

$127-186$

Appendix D

$187-197$

Appendix E

198

Appendix F

199-203

Appendix G

204

Appendix $\mathrm{H}$

205

Appendix I

206 
Implementation and Evaluation of the MOVE! Program at Medical Weight Loss Center

\section{Introduction}

Clinical practice guidelines for the treatment of obesity recommend achieving weight loss through a multi-pronged approach: decreasing caloric intake, increasing physical activity, behavioral therapy, pharmacotherapy, and weight loss surgery (Pi-Sunyer et al., 1998). Treatments vary in both the format of delivery as well as setting. Evidence suggests that weight loss interventions delivered in group format may result in greater weight loss to participants than individual format interventions (Paul-Ebhohimhen \& Avenell, 2009).

The World Health Organization (WHO) (2011) identifies obesity as a major health issue that has continued to increase for several decades. An accumulation of excessive fat that may impair health, obesity results from the taking in of more calories than what is expended through activity. WHO classifies obesity and overweight based on body mass index (BMI), a crude calculation taking the weight in kilograms divided by square of the height in meters. Overweight is a BMI of $25-29.9 \mathrm{~kg} / \mathrm{m}^{2}$, obesity is a BMI of $30-39.9 \mathrm{~kg} / \mathrm{m}^{2}$, and morbid obesity is a BMI greater than or equal to $40 \mathrm{~kg} / \mathrm{m}^{2}$. Obesity, a major health problem, contributes to chronic and debilitating diseases of coronary heart disease, hypertension, Type 2 diabetes, hyperlipidemia, liver and gallbladder disease, sleep apnea, respiratory problems, osteoarthritis, abnormal menses and infertility, cerebral vascular accidents, some cancers, and premature death (Pi-Sunyer et al., 1998). Also, obesity links to social stigmatism, discrimination, and diminished quality of life (Pi-Sunyer et al., 1998). Obesity and the associated co-morbidities have grown to epidemic proportions across the world (World Health Organization [WHO], 2011). 


\section{Background and Significance}

Epidemiology of the problem of obesity. Obesity affected nearly 200 million men and 300 million women worldwide in 2008 (WHO, 2011). By 2015, estimates place the number of obese adults to more than 700 million. The WHO (2011) identifies the incidence of obesity has more than doubled since 1980 , and obesity now ranks as the $10^{\text {th }}$ most preventable health risk.

Over the past ten years, obesity has been recognized as a United States (US) national health threat and a challenge to the public health in general (CDC, 2010). In the US approximately 72.5 million adults were obese in 2007-2008 (CDC, 2010). In 2009, the selfreported prevalence of obesity was $26.7 \%$ in the US (CDC, 2010).

Over the past two decades West Virginia (WV) has had an obesity prevalence that is among the worst in the nation. The prevalence of obesity in WV in 2004 was $27.6 \%$, and by 2005 had increased to $30.6 \%$ (WVBRFSS, 2007). During these years WV had the third highest prevalence of obesity in the United States and its territories (WVBRFSS, 2007). By $2010 \mathrm{WV}$ was identified as one of twelve states with an obesity prevalence rate of greater than $30 \%$ in adults (CDC, 2010). During 2007 the obesity rate in Kanawha County, where the project was implemented, was $29.6 \%$ compared to the WV rate of $31.59 \%$ (Find the Data website, n.d.), and by 2010 the Kanawha County rate had increased to $31.0 \%$ compared to the WV rate of $32.9 \%$ (WVBRFSS, 2012).

Opportunities leading to the proposed project. Several weight loss programs are provided in the city of Charleston (Kanawha County) including Weight Watchers; however, a fee was associated with those providing a group education with a set educational curriculum. Group education similar to that used by Weight Watchers includes a technique of peer support that can lead to successful weight loss efforts due to accountability to others. The Charleston Area 
Medical Center (CAMC) Weight Loss Center (WLC) is a provider of individual weight loss programs for its employees and patients, including bariatric surgery, medical weight loss, and "Healthy Kids". The center had not offered a group weight loss program and was interested in partnering with the project director with the aid of the Charleston Area Medical Center (HR) Resources department to provide a group weight loss program to CAMC employees.

\section{Problem Statement}

The project director identified a desire to change practice at the CAMC Weight Loss Center related to the need for a group weight loss program option for employees. With the director of the CAMC weight loss center, the project director explored the literature to find an evidence-based group weight loss program that could be offered as another weight loss treatment option for the overweight/obese employees of the Charleston Area Medical Center. In evaluating possible programs that could be implemented as a group weight loss program, the availability of clinical practice guidelines on obesity provided an evidence base for a weight loss program.

Clinical practice guidelines on obesity. Clinical practice guidelines (CPG) help guide decisions made by providers regarding diagnosis, management, and treatment in specific areas of healthcare. Three clinical practice guidelines related to overweight and obesity (Moyer, 2012, PiSunyer et al., 1998, Toouli et al., 2009) were critically reviewed in preparation for this project. The Appraisal of Guidelines Research and Evaluation II (AGREE II) form (Brouwers et al., 2010) provided the framework that was used to assess the quality of those guidelines.

The CPGs consistently recommend decreased caloric intake, increased physical activity, behavioral therapy, pharmacotherapy, and surgical intervention for the management of obesity. Each of these CPGs was critically reviewed by the project director and judged to be of high 
quality (Brouwers et al., 2010). According to the CPGs, behavioral therapy can effectively be delivered in either group or individual sessions (Moyer, 2012, Pi-Sunyer et al., 1998, Toouli et al., 2009). The guidelines reviewed are consistent in recommending education of patients regarding goal setting, self-monitoring, obesity, nutrition, physical activity, personal resistances, and preventing relapses (Moyer, 2012, Pi-Sunyer et al., 1998, Toouli et al., 2009).

The United States Preventive Services Task Force (2012) guideline, Screening for and Management of Obesity in Adults, advocates high-intensity behavioral interventions delivered in group or individual sessions of 12 to 26 sessions annually. The World Gastroenterology Organization Global Guideline: Obesity specifically recommends weekly individual or group behavioral treatment sessions for six months to educate patients. Specific recommendations that are consistent include: goal setting, self-monitoring, stimulus control, preventing relapse, and discussion of emotional eating habits ((Moyer, 2012, Pi-Sunyer et al., 1998, Toouli et al., 2009).

A CPG from the National Institute of Health (NIH) (Pi-Sunyer et al., 1998) entitled, Clinical Guidelines on the Identification Evaluation, and Treatment of Overweight and Obesity in Adults was chosen to guide this project. This NIH guideline recommends behavioral therapy modalities, but did not find adequate evidence to recommend any particular methods as superior. Recommended behavior strategies aim to change eating habits and increase physical activity of patients by frequent patient/practitioner contacts during weight loss attempts in promoting weight loss and weight maintenance. These changes, according to the guideline, can be achieved in group settings or individual settings with group settings being advantageous over individual settings due to lower cost (Pi-Sunyer et al., 1998). This NIH guideline is the standard of care for obesity evaluation and treatment in the United States. 
In reviewing CPG's, an article written by Dahn and colleagues (2011) "Weight management for veterans: Examining change in weight before and after MOVE!" noted that the MOVE! exercise and group weight loss program and curricula used in the Veterans' Administration (VA) health systems was based on the recommendations from the NIH guidelines. The MOVE! Program's effectiveness was documented in the VA system and the literature (Garvin, J. T., Marion, L. N. Narsavage, G. L., Finnegan, L., 2015) finding the MOVE! Program implemented at the VAMC in Clarksburg, WV provided an opportunity for the project director to observe the program in action and determine that it could address the problem identified at CAMC. Using the evidence-based components of the MOVE! Program in a new setting would be a feasible practice change.

\section{Population/disease, Intervention or Variable of Interest, Comparison, Outcome,} Time (PICOT) question. Since the CPGs acknowledge the use of group cognitive behavioral therapy to enhance weight loss efforts as an effective format, the PICOT question was: Will a weekly group weight loss program result in weight loss or decreased BMI in overweight or obese participants during a 12-week period? A literature search was performed to find the best evidence relevant to the PICOT question regarding group weight loss intervention and the outcomes.

Purpose of the Project. This capstone project was created as an evaluation of a group weight loss program in the CAMC clinic setting following the evidence-based MOVE! WeightManagement Program for Veterans (VA) curriculum.

Significance of the Project. The project addresses a gap in group-based program offerings to partially meet the critical problem of obesity in West Virginia and the WHO (2011) report on critical health problems. The MOVE! Program's implementation with employees of a 
large health care facility that actively encourages wellness will expand their current individuallyfocused options by incorporating best practices for motivating people and providing peer support. The MOVE! curricula implemented in a non-government setting has a strong evidence base and easily adapted materials for both men and women. Interprofessional teams with nurse practitioners, physicians, and dietitians as members of a MOVE! Program bring their individual areas of expertise into sessions that provide multiple possibilities for effective communication and problem solving. Accessible group weight loss programs could provide evidence of success and influence local and national policies to incentivize attendance. Evaluation of this practice change can be used to identify components that work and do not work in a non-government setting, so that an ongoing group weight loss program can be sustained. Evaluation of the program within a sound theoretical framework can be useful in applying it in other settings. The sections below present how the components of the MOVE! Program fit within the theoretical framework, following a relevant literature review.

\section{Literature Review and Synthesis}

\section{Search of electronic databases.}

To prepare the literature review eight electronic databases were searched to locate the best evidence regarding whether a weekly group weight loss program would result in weight loss or decreased BMI in overweight or obese participants during a 12-week period? Additional evidence was sought through using the "snowball technique for literature review" (Marshall, 1998).

One search was conducted through EbscoHost databases of Academic Search Complete, CINAHL with Full Text, Global Health, Health Source: Nursing Academic Edition, and Medline with the Boolean/Phrase search terms of "group intervention" AND "obese". Search 
limitations included: data published from January 1998 - March 2013, peer reviewed, English language, and human subjects, which resulted in 24 records. After reviewing abstracts, 22 of the articles were excluded because they included children or lacked a group weight loss intervention. Two articles remained (Andersson et al., 2008: Sniehotta et al., 2011).

An additional search was conducted of the databases of the Cochrane Library and PubMed with the Boolean/Phrase search terms of "group intervention" AND "obese". Limitations were added to the search, if available, of data published from January 1998 - March 2013, peer reviewed, English language, and human subjects which resulted in 37 articles in Cochrane Library and 39 in PubMed. All titles from the Cochrane Library and PubMed were reviewed. The search was repeated using The Science Direct database using the search terms of "group intervention" AND "obese" which resulted in 466 hits. Limits were added to search for only journals, the topics of "weight loss" and "intervention group," and year's covering1998 through 2013, which resulted in 27 hits. From the resultant 103 abstracts reviewed, three additional studies were included (Gray et al., 2009; Kennedy et al., 2005; Teixeira et al., 2010). Snowballing technique was used and resulted in six additional articles being selected for inclusion (Ash et al., 2006; Cresci et al., 2007; Jovanovic et al., 2009; Miller et al., 2009; Minniti et al., 2007; Renjilian et al., 2001). A critical appraisal was then performed on the evidence relevant to the research question. During the critical appraisal of the selected evidence, two tools: the 2007 Scottish Intercollegiate Guidelines Network (SIGN) and Larrabee's Literature Review Form (Larrabee, 2009) were used to evaluate articles. The selected studies were individually evaluated for internal validity, reliability, overall assessment, and study description and are included on the evidence table provided in Appendix A for specific study components. 
Systematic Review. The systematic review by Paul-Ebhohimhen \& Avenell (2009) was selected from articles reviewed using the snowballing technique. The article was then critically appraised using the SIGNs Methodology Checklist 1: Systematic reviews and meta-analysis. The systematic review was published in 2009 and included a review of 5 randomized controlled trials comparing the effectiveness of group-based to individual-based interventions for weight loss (Paul-Ebhohimhen \& Avenell, 2009). To prepare the systematic review, seven electronic databases and two obesity journals were searched to locate any additional evidence regarding the effectiveness of group versus individual treatment for adult obesity (Paul-Ebhohimhen \& Avenell, 2009). Four of the studies included just women, while one included only men. The systematic review concluded that group based interventions resulted in statistically greater weight changes of $-1.4 \mathrm{~kg}$ (95\% confidence interval) than individual-based interventions (PaulEbhohimhen \& Avenell, 2009). Sub-analyses found that weight loss was greatest in group(s) led by psychologists and in group(s) which had financial incentives (Paul-Ebhohimhen \& Avenell, 2009). The limitation of this systematic review is that the studies did not have the same type of provider (dietician, physician, nurse practitioner, psychologist, etc.) leading the intervention. Another weakness is that only one trial included men. Strengths of this systematic review included the search criteria and the review of secondary references that led to an overall analysis of 336 participants. The systematic review supported a potential impact of group-based weight loss sessions versus individual-based weight loss sessions in delivering adult obesity treatments.

\section{Synthesis}

When comparing group intervention to individual intervention for weight loss, both formats have resulted in significant weight loss. Although specific results vary, the strength of the evidence for the effectiveness of group intervention in weight loss is acceptable for 
evaluation as a next step (Larrabee, 2009). The selected studies include one systematic review (Paul-Ebhohimhen \& Avenell, 2009) and five randomized control trials (RCT) (Ash et al., 2006; Kennedy et al., 2005; Renjilian et al., 2001; Sniehotta et al., 2011; Teixeira et al., 2009).

Additionally, six quasi-experimental studies were found, which also support the premise that group intervention results in weight loss (Andersson et al., 2008 Cresci et al., 2007; Gray et al., 2009; Jovanic et al., 2008; Miller et al., 2009; Minniti et al., 2007). The mean age of the study participants ranged from 37.6 to 56 years of age with the range of participant ages from 18 to 75 years. Seven of the studies had more women participants than men $(60 \%$ women - $90 \%$ women) (Andersson et al., 2008; Ash et al., 2006; Jovanic et al., 2008; Kennedy et al., 2005, Miller et al., 2009; Renjilian et al., 2001; Sniehotta et al., 2011). However, studies by Cresci et al., 2007 and Minniti et al., 2007 excluded males and two studies included only males (Gray et al., 2009; Teixeira et al., 2009). One study was conducted only on African-Americans (Kennedy et al., 2005).

Eight of the eleven studies were conducted outside of the United States, (Andersson et al., 2008; Ash et al., 2006; Cresci et al., 2007; Gray et al., 2009; Jovanic et al., 2008; Minniti et al., 2007; Sniehotta et al., 2011; Teixeira et al., 2009) attesting to the fact that obesity is a worldwide epidemic. Seven of the studies were considered to have large sample sizes of greater than 100 participants (Andersson et al., 2008; Ash et al., 2006; Cresci et al., 2007; Gray et al., 2009; Jovanic et al., 2008; Minniti et al., 2007; and Teixeira et al., 2009). The length of the studies varied from 12 weeks to two years with one study having follow-up data covering 49 months.

In the majority of the studies reviewed each intervention session lasted from 60 to 90 minutes (Andersson et al., 2008; Ash et al., 2006; Cresci et al., 2007; Gray et al., 2009; Miller et 
al., 2009; Minniti et al., 2007; Renjilian et al., 2001; Sniehotta et al., 2011). The number of group sessions varied according to the length of the studies. Most groups had four to 15 participants assigned to each group session. The general education focus of the studies incorporated knowledge regarding nutrition, food choices, physical activity, stimulus control, behavioral techniques, problem solving techniques, and relapse prevention (Anderson et al., 2008; Ash et al., 2006; Cresci et al., 2007; Gray, et al., 2009; Jovanic, et al., 2008; Miller, et al., 2009; Minniti, et al., 2007; Renjilian, et al., 2001; Sniehotta, et al., 2011; and Teixeira, et al., 2009). All studies had attrition rates ranging from 10\% to 59\% (Andersson, et al., 2008; Ash, et al., 2006; Cresci et al., 2007; Gray et al., 2009; Jovanic et al., 2008; Kennedy et al., 2005 Miller, et al., 2009, Minniti, et al., 2007, Renjilian, et al., 2001, and Sniehotta, et al., 2011, and Teixeira, et al., 2009).

Eight of the studies did identify group versus individual format, but all interventions were not delivered by the same profession or for the same amount of time (Ash et al., 2006; Cresci et al., 2007; Jovanic et al., 2008; Kennedy et al., 2005; Miller et al., 2009; Minniti et al., 2007; Renjilian et al., 2001; and Sniehotta et al., 2011). Consistent with these eight studies, the MOVE! Program described by Dahn and colleagues (2011) documented the effectiveness of the group weight loss program in the VA settings. Three studies incorporated group intervention without an individual intervention and examined the group effect on multiple variables including body weight change and BMI (Andersson et al., 2008; Gray et al., 2009; and Teixeira et al., 2009). Gray et al., (2009) and Andersson et al., (2008) also studied abdominal diameter. Teixeira et al., (2009) examined exercise, eating behavior, and body image, while Andersson et al., (2008) compared data on cholesterol level, triglyceride level, glucose level, as well as systolic and diastolic blood pressure. 
All except two studies (Cresci et al., 2007; Minniti et al., 2007) indicated that an approach to weight loss with participants in groups resulted in greater loss of weight than an individual approach to weight loss (Andersson et al., 2008; Ash et al., 2006; Jovanic et al., 2008; Kennedy et al., 2005; Miller et al., 2009; Renjilian et al., 2001; and Sniehotta et al., 2011). The studies by Cresci et al., (2007) and Minniti et al., (2007) found that both groups lost weight, but no statistically significant weight loss between intervention groups at any time occurred. The study by Garvin et al., 2015 reviewed records of 404 veterans enrolled in MOVE! weight management program and concluded that a five percent weight reduction was achieved by 13 percent of the participants.

After reviewing the evidence, a weight loss model supported in the majority of successful programs used educational interventions that included the recommended content of decreasing caloric intake and increasing physical activity and using behavioral therapy as recommended in the CPGs. Many of the group sessions focused on weight loss related topics of goal setting, selfassessment, social support, stress management, and relapse prevention. Available evidence is not sufficient to state that incentives were important to outcomes. Although interventions were delivered by different professional groups, the resulting improved outcomes might support that "who" delivers the intervention is not as important as the content of the programs and the motivation of the participants, or perhaps the interpretation would be that an interdisciplinary team could be recommended. The evidence base for the MOVE! curricula with multi-faceted components implemented in the VA setting was strong and had not been evaluated in a nongovernment setting. A review of literature related to the theoretical framework was used to examine the applicability of the MOVE! Program evidence-based group weight loss components. 


\section{Theoretical Framework}

The theory of self-efficacy and the transtheoretical model serve as a predictive framework for this project. The self-efficacy theory by Bandura (1997) predicts a person's confidence to exert control over eating habits and to implement an exercise program. The transtheoretical model by Prochaska, Norcross, and DiClemente (1994) explains the stages that individuals must go through to implement a successful behavior change.

Utilizing a sound theoretical framework or model can assist in achievement of improved health outcomes by assessing a patient's readiness to participate in weight loss, targeting intervention to the patient's readiness to change, and providing a structure for the continued promotion of weight loss. Several theories and models provide a framework for weight loss interventions including, but not limited to the following: cognitive behavioral therapy (Cooper et al., 2010), the health belief model (Daddario, 2007), the transtheoretical model (Rosenstock, Strecher \& Becker, 1988; Prochaska et al., 1994), the self-efficacy model (Bandura, 1997), the theory of planned behavior (Ajzen, I., \& Manstead, A. S. R., 2007; Groth \& Morrison-Breedy, 2011), and Pavlovian conditioning (Pavlov, I. P., 2003; Davidson \& Swithers, 2004).

\section{Self-Efficacy Theory}

Bandura's self-efficacy model was chosen because it has previously been used in obesity interventions and literature supports that this framework leads to greater weight loss through enhancing behavioral changes (Bandura, 2006; Linde et al., 2006; and Roach et al., 2003). Although the theory of self-efficacy has been used successfully in obesity interventions for individuals, this theory is particularly suited for an obesity group intervention because the peer relationship is a key concept of the theory, and is predicted to influence individuals' self-efficacy (Bandura, 1997). According to Bandura (1997), a strong self-efficacy enhances personal 
accomplishments and well being, whereas a weak self-efficacy leads people to doubt whether they are capable of accomplishing difficult tasks. Bandura (1997) states the self-belief system asserts that an individual's beliefs in his or her capabilities are not constant but vary according to activity or situation. An individual's beliefs in his or her capabilities are influenced by four sources of information. These information sources are:

- Enactive Mastery Experience

- Vicarious

- Verbal Persuasion

- Physiological and Affective States (Bandura, 1997).

Enactive Mastery Experience. Bandura (1997) stated that the first source identified as enactive mastery experiences represents the most influential source on individual success. If previous successes were obtained easily, then people expect instant results and are easily dissuaded if tasks demand more effort (Bandura, 1997). On the other hand, previous challenges individuals encountered are beneficial in teaching one that sustained efforts promote success (Bandura, 1997). Components of the MOVE! weight loss program incorporates enactive mastery experiences through encouraging participants to increase their physical activity to promote weight loss. All MOVE! sessions include a physical activity in which participants draw on previous successful experiences of participating in physical activity or exercise. In addition, participants are encouraged during the sessions to try new or different physical activities for weight loss successes. Another example of enactive attainment with the MOVE! weight loss program includes the practice of reading food labels. Participants take a food label and practice the skill of reading the nutritional and caloric contents of foods. According to the theoretical framework, providing opportunities to engage in healthy behaviors increase participants' self- 
efficacy belief and confidence in mastering skills of healthy eating and increased physical activity levels.

Vicarious experience. Vicarious experience is the second self-efficacy source and is equated with modeling either through communication or action (Bandura, 1997). Bandura (1997) describes the vicarious experiences as an individual's capabilities compared to others engaged in weight loss endeavors. Bandura (1997) states that seeing others succeed typically encourages one to believe he or she is capable of mastering comparable skills. Modeling inspires and motivates self-development in others and teaches participants more effective ways of engaging in weight loss behaviors (Bandura, 1997). In the MOVE! curriculum vicarious experiences are promoted in each group sessions through participant's discussion of his or her progress and goals since the last class and the discussion of problem solving for the barriers encountered.

Verbal Persuasion. Effective verbal persuasion provides verbal encouragement to each individual participant for his or her efforts and successes (Bandura, 1997). Verbal persuasion promotes skill development and a sense of personal efficacy (Bandura, 1997). For example, verbal persuasion is evident in each MOVE! group session when participants set weekly activity goals to increase their activity levels such as increasing total steps walked or adding weight training or aerobic exercise to their regimen. Bandura (1997) states that part of the verbal persuasion includes constructive criticism that increases aspirations, as well as, upholds and bolsters self-efficacy. Self-efficacy is influenced during each MOVE! session through group discussion, problem solving, and support.

Physiological and Affective States. The last self-efficacy component described by Bandura (1997) is physiological and affective states or sensory experiences. If a person has 
experienced aches, pains, or shortness of breath while exercising, he or she may have a negative self-efficacy source of physiological and affective states. Additionally, if a person encounters a stressful or uncomfortable situation, he or she may make unhealthy food choices or overeat. According to Bandura (1997) physiological and affective states can be altered by an enhanced physical status, reduced stress, and the correction of bodily state misinterpretations. The selfefficacy source of physiological and affective states is promoted in the MOVE! Program through the physical activities practiced in each move session, as well as in the MOVE! sessions that discuss the different types of physical activity, barriers to physical activity, and exercise safety in different types of weather. The MOVE! Program discusses adequate warming up, stretching, and cooling down after physical activity. Participation in the MOVE! sessions educate participants to identify triggers that lead to overeating or decreased physical activity. The MOVE! Program teaches and encourages practice in problem solving techniques and stress management skills that result in increased participant self-efficacy through enhanced management of physiological and affective states.

\section{Transtheoretical Model}

The transtheoretical model (TM) also serves as a theoretical framework for this project. This model predicts how a desired behavior is acquired as people modify problematic behavior. The TM is a guide to be used by practitioners to determine interventions that may be more appropriate or effective in the promotion of exercise and dietary changes (Seals, 2007). Additionally, the TM guides treatment of overweight and obesity due to the recognition that an individual goes through stages of change as he or she tackles a lifelong challenge. The stages that a person moves through during behavior change are as follows: pre-contemplation (not planning on behavior changes within the next 6 months), contemplation (change is planned 
within the next 6 months), preparation (ready to make changes immediately), action (behavior change made within the last 6 months), and maintenance (behavior changed for a least 6 months and trying not to relapse) (Prochaska et al., 1994).

The TM has been used elsewhere in the obesity literature and serves as the framework for the MOVE! Program (Prochaska et al., 1994; MOVE! Weight Management Program Clinical Reference Manual, 2005). In the MOVE! Weight Management Program Clinical Reference Manual (2005) the authors point out that patient-centered counseling most effectively promotes adherence to weight loss through the use of motivational counseling techniques and patient support. In the MOVE! Program at CAMC, TM was used to assess a participant's readiness per the MOVE! 23 questionnaire. The MOVE! Weight Management Program Clinical Reference Manual (2005) identifies specific behavioral handouts and provides these to each participant based on stage of change regarding weight loss efforts as defined by the MOVE! 23 questionnaire results. The following handouts are recommended:

- Precontemplative - So, You're Not Ready Yet?

- Contemplative - So, You're Thinking About It!

- Preparation - Getting Ready to Lose Some Weight?

- Action - Yes... Now You're Doing It!

- Maintenance - You Can Keep That Weight Off! (MOVE!)

In using the MOVE! curriculum and associated handouts the program leader uses communication techniques of expressing empathy, listening reflectively, providing information and assistance, and reinforcing to help the participant move through and overcome barriers to successful weight loss. 
Use of the self-efficacy theory as a framework for this project predicts that using the group format enhances an individual's self-efficacy levels through vicarious experiences, which can lead to behavior change resulting in weight loss. The transtheoretical model framework predicts which individuals are ready to make a behavior change and thus allows the project director to tailor interventions to each individual's unique level of readiness. The two theoretical frameworks can assist in the overall attainment of successful behavioral changes to improve individual health outcomes.

\section{Project}

\section{Evidenced Based Project/Intervention Plan}

Submission to the Internal Review Board (IRB) at Charleston Area Medical Center, Inc. (CAMC) and West Virginia University was completed in September 2013. When the IRB letters of exemption were secured, a 30-day period of advertisement and recruitment of employee was held in October and sessions began on November 4, 2013. This capstone project was created as an evaluation of a weight loss program in a clinic setting to follow the evidence-based MOVE! Weight-Management Program for Veterans curriculum. The MOVE! curriculum was formatted to be delivered in 12 weekly group weight loss educational sessions and may be found on line at http://www.move.va.gov/GrpSessions.asp as well as in Appendix B. The MOVE! curriculum provides detailed guidelines for content topics, participant activity during each session, and practice activities related to key concepts. The project director used the MOVE! curriculum for each educational session and relied on the VA's structure of those educational sessions to run the group sessions efficiently. Most lesson plans recommended allotting 15 to 20 minutes for the introduction section, which left 40 to 45 minutes to spend on physical activities and discussion of the lesson topic for that session. Each lesson plan identified materials such as paper, pencils, 
pens, flip chart, or white board that were needed during the session, and identified the session's applicable handouts (see Appendix C) to reinforce the content discussed. As noted previously, the MOVE! curriculum was designed within an evidence-based theoretical framework to promote behavioral changes and the educational materials within the curriculum are consistent with current evidence for the treatment of overweight and obesity. The MOVE! group sessions were not to be rigidly followed, but allowed for loose structure in order to promote group support and discussion (MOVE! Clinical Reference Manual, 2005).

For this project three groups of 10 to 19 participants were recruited through an advertisement via CAMC email, signs, information booths in the hospital cafeteria, and an article in the hospital newspaper. These recruitment efforts resulted in a list of 40 potential participants. Desired sample size was determined based on the power needed to determine the effect of the intervention such as group sessions (The Joint Commission, 2008). Inclusion criteria for the group educational weight loss sessions included overweight and obese individuals who are CAMC employees or family members of employees and who are at least 18 years of age. An individual was excluded from the group educational weight loss sessions if he or she was currently taking a prescribed weight loss medication such as Phentermine, Qsymia, Belviq, Orlistat, human chorionic gonadotropin (HCG), or any over the counter weight loss supplements. Also excluded were those employees that were pregnant, breastfeeding, or those that could not read, write, or understand the English language. No employees that expressed interest in the MOVE! Program met any of the exclusion criteria, however, one employee did not meet the inclusion criteria of being overweight, but due to her interest in increasing activity, healthy food choices, and having friends that were participating, she was allowed to attend the 
sessions. These recruitment efforts resulted in 25 qualified participants. Data analysis includes only the 25 qualified participants.

\section{Feasibility}

The major internal stakeholders were the overweight and obese CAMC employees with $\mathrm{BMI} \geq 25 \mathrm{~kg} / \mathrm{m}^{2}$, Human Resources department overseeing the Wellness Program, CAMC health insurance company, the CAMC Weight Loss Practice Administrator and employees, and CAMC hospital administration. Public officials, private insurance companies, and public insurance companies could be external stakeholders for the results of this project since they would be interested in the success of the program, because a reduction in obesity within this population could result in cost savings related to co-morbid conditions.

Prior to implementing the project, communication was made to the CAMC Human Resources Department staff to explain the program. The HR staff was educated on all aspects of the project including date and time of the sessions as well as the length of the program. The enrollment period for the program was thirty days. Forty employees signed up via the Wellness portal (an online communication system for employees) or called the project director or wellness director to enroll in the program. The HR staff provided a session roster to the project director at the end of the enrollment period for the three groups with a total of 40 potential participants.

Recruitment of enough participants was an important aspect of this project where initially three group sessions were offered: Mondays at 5:00PM, Tuesdays at 5:30PM and Fridays at 9:00AM. Several interested individuals called for enrollment or to obtain additional information regarding the sessions to determine if the program was what they were interested in attending. Enrollment resulted in 21 potential participants for Mondays, 16 potential participants for Tuesdays, and 3 potential participants for Fridays. Due to the minimal interest in the Friday 
session the potential participants were informed that the session would not be held on Fridays, and they could join either the session on Monday or Tuesday. This decision was made after discussion between the program director and the practice administrator regarding facility availability, travel expenses to the WLC for the program director, and the MOVE! Program suggesting group size of 10 to 15 participants (MOVE! weight management program; Clinical reference manual, 2005). None of the three were able to join another session due to prior work or other commitments, resulting in 37 potential participants.

At the first session held on Mondays, 18 of the potential 21 participants were in attendance. At the first Tuesday session, nine (9) of the potential 16 participants attended the session, resulting in 37 potential participants who began the program. Depending on the topic and patient volume at the CAMC Weight Loss Center (WLC), sessions were held in the waiting room, conference room, and gym as appropriate. At the first session the participants completed the MOVE! 23 questionnaire (Appendix D) via the paper and pencil version. The participants were weighed in light clothing without shoes on the Body Composition Analyzer Model TBF310 Tanita Scale, had height measured by a wall-mounted stadiometer, and blood pressure readings taken by a registered nurse or the project director (also a registered nurse) in the WLC clinical area. The BMI was automatically calculated from the specific employee height, weight, gender, and age entered into the scales' software. The date, weight, BMI, and blood pressure were documented on the data collection tool developed by the project director based on the MOVE! Program parameters (see Appendix E). In keeping with confidentiality of data and Health Insurance Portability and Accountability Act policies, the participant paper and pencil MOVE! 23 questionnaires were stored in a locked cabinet at the WLC, accessible only to the program director. Participant contact information was separated from the data. Participant 
identity was not recorded on any of the evaluation data forms; instead, participant's record numbers were coded in chronological order.

The MOVE! 23 questionnaire is a self-assessment of 23 items covering demographic information, psychiatric history, weight management history, body size perceptions, eating habits, physical activity, self-efficacy and readiness to change lifestyle habits, social support, and barriers to making lifestyle changes (Kinsinger et al., 2009). The MOVE! 23 questionnaire was available to be completed online, but due to the lack of enough computers in the WLC, a paper copy of the MOVE! 23 questionnaire was provided to and completed by each participant at the first session. The questionnaire took approximately 30 minutes to complete (Kinsinger et al., 2009). The project director collected the questionnaires and entered the individual questionnaire responses into the MOVE! 23 online version. Results of the individual responses to the MOVE! 23 questionnaire were printed and given to the individuals to provide individual tailored feedback at the next session. If other health issues were identified through the use of the MOVE! 23 questionnaire or during any of the sessions, the participant was referred to his/her primary care provider for further assessment.

At the first session the participants heard the first MOVE! lecture and were provided with the MOVE! Group Sessions Food and Physical Activity Diary (see Appendix F for blank form and examples for completion). There were no issues identified during the first sessions to explain why several participants did not return for subsequent sessions. In further follow-up, reasons for not returning were identified and can be found in Table 3.

Seventeen (17) women were able to continue to participate in the remaining weekly (60 to 90 minute session) group education sessions to discuss nutrition, physical activity and behavioral modifications. At each session the participants' blood pressure and weight (in light 
clothing with shoes and socks removed) were obtained. Four individuals on the first Tuesday session were weighed on a different scale due to WLC staff attempts to expedite the weigh-in process. Those scales were checked (3 measures) against the Tanita scale and found to be consistently 0.2 pounds heavier. The 4 participant's weights and BMIs were adjusted accordingly for data analysis. The weight, BMI, blood pressure, and pedometer-recorded steps (as available) were recorded on the data collection tool at each session.

The participants asked if they were allowed to exercise in the WLC gym. The project director contacted the WLC practice administrator and asked if the participants could use the gym. They were granted access to the gym for the 12 weeks they were in the session, and 6 participants used it consistently. The physical activity portion of the sessions were modified or eliminated from the sessions because the participants viewed the activities as not being helpful due to their current level of physical fitness.

The participants received a packet of MOVE! handouts and their individual MOVE! 23 questionnaire results at the second group session. They were instructed to bring the packet with them each week to be able to access certain MOVE! handouts for each educational session and to add information applicable to their weight loss efforts. The participants also took part in activities outlined in the MOVE! curricula each week, as well as, reviewed food and activity diaries (if available) along with goal setting relative to the weekly topic. All MOVE! participants were encouraged to engage in peer discussions to support each other in weight loss endeavors as research has shown that the success of individuals is many times dependent on the self-efficacy sources of vicarious experiences and social persuasion (Bandura, 1997).

To encourage proper nutrition and physical activity, the MOVE! participants were urged to access the CAMC WLC website at: http://www.camc.org/weightloss where low fat recipes are 
available and exercises are demonstrated by the exercise physiologist. Two of the participants indicated they had accessed the website for recipes and exercises. At the conclusion of the 12week educational group weight loss sessions, the participants again were asked to complete the MOVE! 23 questionnaire paper and pencil version in order to ascertain changes in self-efficacy and stage of change. However, during the course of the program the VA had changed the questionnaire to 11 questions. Therefore, a problem arose in that 3 of the participants completed a new MOVE! 11 questionnaire online and two participants completed the MOVE! 23 paper version so results were not comparable to the MOVE! 23 for all participants. As a result the data were not available to assess if there had been a change in readiness.

\section{Resources - Personnel, Technology, Budget}

The project director was able to utilize professional contacts within the CAMC organization and garner support for the project from the organization. The CAMC Human Resources department supplied Ariel pedometers that were estimated to cost $\$ 20$ each but were provided at no cost to the participants. Although not a component of the proposed project, the salaries of a scheduler, registration clerk, $\mathrm{RN}$, and a medical assistant, as well as the rent and utilities are included in the budget shown on Appendix $\mathrm{G}$ to aid in the estimated cost of the project. The estimated cost from Kinkos in Charleston, WV for copying the MOVE! 23 Questionnaire, MOVE! handouts, and MOVE! Group Sessions Food and Physical Activity Diary (approximately 3,100 pages) was $\$ 1,650$. However, for this project the copying was provided by the CAMC WLC and paid for through the CAMC WLC budget. The scales, stadiometer, sphygmomanometer, conference room, gym, waiting room, and furniture utilized for this project were already at the CAMC WLC and thus available throughout the project with no additional 
cost for equipment. The benefits to the CAMC WLC and the CAMC organization are discussed in the Congruence of Organization's Strategic Plan to Project section below.

\section{Congruence of Organization's Strategic Plan to Project}

During the beginning stages of the project, permission was obtained from CAMC to perform the project at the WLC. (See letter of support from Mary Colley, Practice

Administrator, WLC; Appendix H). At the WLC the core values of "quality, service with compassion, safety, respect, integrity, and stewardship" are practiced. The MOVE! Program was proposed to provide quality, evidence-based care of value to the participants.

As the project evolved the CAMC Human Resources department was contacted, and they agreed to use the project as a part of the employee wellness program in the upcoming benefit year (See letter of support from Evan Thoman, Director of Wellness, CAMC, Appendix I). CAMC's vision was to be recognized as the "best place to receive patient-centered care, best place to work, best place to practice medicine, best place to learn, and best place to refer patients" (Charleston Area Medical Center, Inc. website, n.d.). Additionally, the 2013 CAMC strategic plan listed a goal to "implement plan to improve the health of our communities" (Charleston Area Medical Center, Inc. website, n.d.). In keeping with CAMC's core values, vision, and strategic plan, the goal of the CAMC Weight Loss Center was "to provide a comprehensive and multidisciplinary approach to assist patients [employees] to achieve longterm weight loss and a healthier life." Therefore, the proposed project based on The MOVE! Weight Loss Program goal of empowering the person to improve his or her health with lifestyle changes was congruent with CAMC's vision, core values, goals, and strategic plan. The proposed project to implement the MOVE! Weight Loss Program was aligned with the CAMC WLC goal to give employees an alternative group-based weight loss solution to help them be 
healthier. Not only did the CAMC Human Resources Department agree to the inclusion of the MOVE! Program as an employee wellness incentive but further supported the program by advertising to potential participants and providing free pedometers to participants.

\section{Evidence of Key Site Support}

As previously identified, letters of formal support from the Practice Administrator of the CAMC WLC and the CAMC Wellness Director were received (Appendices H and I). The CAMC WLC conference room, waiting room, and gym were used for the group education weight loss sessions and were available for the proposed project at times when the WLC was not being used by other patients (Mondays at 5:00PM and Tuesdays at 5:30PM). However, during some of the weight loss sessions, patients were still being seen and another weight loss session "Healthy Kids" was being held, and because the same area was used for taking blood pressures and weights, there was a minimal delay in taking the blood pressures and weighing the participants.

\section{Measurable Project Objectives}

According to the literature, the combination of interventions to increase physical activity, decrease caloric intake, and promote behavioral changes through behavioral therapy was the most successful standard of care for patients with obesity (Pi-Sunyer et al., 1998; Prochaska et al., 1994). The MOVE! Program incorporated all of these obesity management aspects and used the Transtheoretical Model (TM) as a framework to individualize the interventions to the participant's stage of change.

The project examined the effects of the MOVE! Program on weight and BMI of overweight and obese adult employees of Charleston Area Medical Center and was designed to answer the program evaluation question of: Will a weekly group weight loss program result in 
weight loss or decreased BMI in overweight or obese participants during a 12-week period? The objectives of the project were selected based on outcomes noted in the obesity literature with interventions delivered in group format (Andersson et al., 2008; Dahn et al., 2011; Kennedy et al., 2005; Sniehotta et al., 2011). Therefore, participation in the MOVE! Program at the CAMC Weight Loss Center was expected to yield results of weight loss, decreased BMI, decreased systolic blood pressure, and increased activity as indicated by the following objectives for the 12 week program:

1. Participants will decrease weight in pounds by the end of the 12 -week MOVE! Program by a minimum of $5 \%$ from baseline.

2. Participants will decrease BMI in $\mathrm{kg} / \mathrm{m}^{2}$ by the end of the 12 -week MOVE! Program by a minimum of $1 \mathrm{~kg} / \mathrm{m}^{2}$ from BMI baseline.

3. Participants will decrease systolic blood pressure in $\mathrm{mm} / \mathrm{Hg}$ by the end of the 12 -week MOVE! Program by a minimum 5\% from sphygmomanometer baseline.

4. Participants will increase activity level in steps by the end of the 12-week MOVE! Program by a minimum of 2000 steps/day from pedometer baseline.

5. Participants will increase self-efficacy score evidenced by an increased score from question number 10 of the MOVE! 23 questionnaire, found in Appendix D, repeated at the end of the 12-week MOVE! Program.

6. Participants will move to a higher stage of change above baseline evidenced from question number 11 of the MOVE! 23 questionnaire repeated at the end of the 12-week MOVE! Program.

The expected outcomes were based on the outcomes of similar weight loss programs found in the literature. The measures of weight, BMI, systolic blood pressure, and activity (steps 
recorded by pedometer), were not only measured at the beginning and end of the program, but also captured during each session that the participant attended, as consistent tracking was predicated to be influential in participants' successes or relapses. However, many participants did not track their daily steps as requested, many citing that they just forgot.

\section{Evaluation Methods}

A decrease in the participant's weight, BMI, and blood pressure as well as an increase in activity were the anticipated outcomes of this project. Descriptive statistics of age, gender, race, previous weight loss attempts, self-efficacy, and readiness to change are reported and used to describe the participants. Means of the participant's weight, BMI, blood pressure, and height were analyzed using measurements obtained at the first session and throughout the project. Baseline pedometer steps were recorded at the third session for the participants that remembered to bring that information and reported weekly steps at each additional session. During each additional session and at the conclusion of the 12-week program, the weight, BMI, blood pressure, and steps of each participant was recorded. The technique to examine the difference of the two measures of the baseline data and the program end data was a paired t-test on the change from baseline and was to be used to answer the following hypotheses.

1. For participants in the group weight loss education sessions, weight will decrease, on average, by $5 \%$ between baseline and 12 weeks.

2. For participants in the group weight loss education sessions, BMI will decrease, on average, by $1 \mathrm{~kg} / \mathrm{m}^{2}$ between baseline and 12 weeks.

3. For participants in the group weight loss education sessions, systolic blood pressure will decrease, on average, by $5 \%$ between baseline and 12 weeks. 
4. For participants in the group weight loss education sessions, activity will increase based on pedometer steps/day an average addition to baseline of 2000 steps/day between baseline and 12 weeks.

5. For participants in the group weight loss education sessions, self-efficacy will increase between baseline and 12 weeks.

6. For participants in the group weight loss education sessions, stage of change will move to a higher stage from baseline and 12 weeks.

The data were entered into SPSS version 22.0 where the weight, BMI, blood pressure, and pedometer-measured steps were entered as continuous variables. Gender, race, age, and marital status were entered as categorical variables. An important variable of attendance of the participants was recorded to determine if the participants attended a minimum $75 \%$ of the sessions. Because of the high attrition rate $(80 \%)$, additional attempts to contact participants were made to identify barriers to participation.

\section{Results}

The original objectives were not achieved due to the low number of qualified participants. The 24 women and one man (range 41-64 years), who volunteered to participate in the program were employees of Charleston Area Medical Center, Inc. and were offered this program as part of their annual Wellness Program. All of the participants were in the "ready" stage of change according to the answers provided on the MOVE! 23 questionnaire.

Fifteen (60\%) participants suffered from arthritis or joint pain and four (16\%) indicated they had back pain or spinal disc disease. Eleven (44\%) participants had hypertension, nine (36\%) had hyperlipidemia, and four (16\%) had diabetes. Twelve (48\%) said they had too much 
stress and seven (25\%) listed anxiety problems or nervousness in regards to their overall health. Eighteen $(72 \%)$ of the participants were actively trying to lose weight when the program began, while twenty four (96\%) had tried to lose weight in the past.

The participants included in this program started the program November 4 or November 5, 2013 for twelve weeks. The program was approved by the facility Institutional Review Board and then approved by the University's Institutional Review Board. Informed written consent was obtained from all subjects at the first session.

\section{Statistical Analyses}

Beginning and ending weight, BMI, Systolic blood pressure, and steps were analyzed for each subject by paired t-test. Due to the inconsistent tracking and sharing of the number of steps walked per day by the participants it was not possible to determine if there was a daily increase of 2000 or more steps per day. The data points of initial weight, BMI, systolic blood pressure compared to the end weight, BMI, and systolic blood pressure showed a slight difference, but were not statistically significant. The mean age of the participants was 50.73 years with a standard deviation of 6.245. The participants consisted of 25 women and one man. Seventeen of the participants were married, four were single, and four were divorced. There were 23 Caucasians and two African Americans. The information regarding the participants' weight, BMI, systolic blood pressure and steps is described in Table 1. 
Table 1

Descriptive Results of BMI, Weight, Blood Pressure, and Steps

\begin{tabular}{|c|c|c|c|c|c|c|}
\hline Variable & $\mathrm{N}$ & Minimum & Maximum & Mean & Std. Dev. & $\mathrm{P}$ value \\
\hline $\begin{array}{l}\text { Initial } \\
\text { BMI* }\end{array}$ & 25 & 26.70 & 61.82 & 37.8896 & 7.94282 & \multirow{2}{*}{.082} \\
\hline $\begin{array}{l}\text { End } \\
\text { BMI* }\end{array}$ & 25 & 26.80 & 61.82 & 37.5928 & 8.04142 & \\
\hline $\begin{array}{l}\text { Initial } \\
\text { Weight** }\end{array}$ & 25 & 160.0 & 383.00 & 224.740 & 56.4130 & \multirow{2}{*}{.064} \\
\hline $\begin{array}{l}\text { End } \\
\text { Weight** }\end{array}$ & 25 & 153.0 & 383.00 & 222.980 & 57.2597 & \\
\hline $\begin{array}{l}\text { Initial } \\
\text { Systolic } \\
\text { BP*** }\end{array}$ & 25 & 108 & 161 & 134.72 & 13.719 & \multirow{2}{*}{.681} \\
\hline $\begin{array}{l}\text { End } \\
\text { Systolic } \\
\text { BP*** }\end{array}$ & 25 & 114 & 155 & 133.60 & 11.962 & \\
\hline $\begin{array}{l}\text { End } \\
\text { Step } * * * *\end{array}$ & 25 & 2782 & 10422 & 6418.70 & 2091.778 & \\
\hline
\end{tabular}

Note. $*$ Calculated by $\mathrm{kg} / \mathrm{m}^{2} * *$ in pounds $* * *$ in $\mathrm{mmHg} * * * *$ by individual pedometer

The number of sessions completed ranged from one to ten. Only five participants $(20 \%)$ attended nine sessions $(75 \%)$ or more and were considered to have completed the program. 
There were no participants that completed the entire 12 sessions. Three of the five participants that completed the program had a combined weight loss of 35 pounds. Two of them met the stated objectives of a weight loss of 5\% and a BMI change of 5\% at the end of the 12 weeks. The end-of-program self-efficacy and stages of change ratings were unobtainable due to the change in the MOVE! questionnaire from 23 to 11 questions with the system generated report not listing the participant's stage of change. Due to the high attrition rate, there were not enough subjects to have meaning in the statistical analyses. Quantitative data are included to identify the start date, end date, and the number of sessions each participant attended, and the weight gain or loss as shown in Table 2. The variable of attendance of the participants was recorded to determine if the participants attended a minimum $75 \%$ of the sessions, which was important to the HR department for determining if participation in the program could be applied toward the employee wellness incentive.

Table 2

MOVE! Program Participant Sessions Attended

\begin{tabular}{|l|l|l|l|l|}
\hline Participant \# & Start Date & End Date & \# Sessions Attended & $\begin{array}{l}\text { Weight } \\
\text { gain/loss lbs. }\end{array}$ \\
\hline 1 & $11 / 04 / 13$ & $02 / 03 / 2014$ & 10 & +0.5 \\
\hline 2 & $11 / 04 / 13$ & $11 / 04 / 13$ & 1 & 0 \\
\hline 3 & $11 / 04 / 14$ & $12 / 20 / 13$ & 3 & 0 \\
\hline 4 & $11 / 05 / 13$ & $02 / 10 / 14$ & 9 & -9 \\
\hline 5 & $11 / 04 / 13$ & $11 / 04 / 13$ & 1 & 0 \\
\hline 6 & $11 / 04 / 13$ & $11 / 18 / 13$ & 3 & -5 \\
\hline 7 & $11 / 05 / 13$ & $1217 / 13$ & 7 & -7.1 \\
\hline 8 & $11 / 04 / 13$ & $11 / 11 / 13$ & 2 & -2.5 \\
\hline 9 & $11 / 05 / 13$ & $12 / 30 / 13$ & 6 & +2 \\
\hline 10 & $11 / 04 / 13$ & $02 / 13 / 14$ & 9 & +2 \\
\hline
\end{tabular}




\begin{tabular}{|l|l|l|l|l|}
\hline Participant \# & Start Date & End Date & \# Sessions Attended & $\begin{array}{l}\text { Weight } \\
\text { gain/loss lbs. }\end{array}$ \\
\hline 11 & $11 / 4 / 13$ & $11 / 11 / 13$ & 2 & -1.5 \\
\hline 12 & $11 / 04 / 13$ & $11 / 04 / 13$ & 1 & 0 \\
\hline 14 & $11 / 04 / 13$ & $11 / 18 / 13$ & 3 & -2.5 \\
\hline 15 & $11 / 04 / 13$ & $11 / 11 / 13$ & 2 & 0 \\
\hline 16 & $11 / 04 / 13$ & $01 / 28 / 14$ & 7 & +4 \\
\hline 17 & $11 / 05 / 13$ & $12 / 03 / 13$ & 4 & +4 \\
\hline 18 & $11 / 04 / 13$ & $11 / 11 / 13$ & 2 & 0 \\
\hline 19 & $11 / 04 / 13$ & $11 / 25 / 13$ & 4 & +1.5 \\
\hline 20 & $11 / 04 / 13$ & $11 / 18 / 13$ & 2 & -2.5 \\
\hline 21 & $11 / 04 / 13$ & $11 / 04 / 13$ & 1 & 0 \\
\hline 22 & $11 / 05 / 13$ & $02 / 10 / 14$ & 9 & -11 \\
\hline 23 & $11 / 04 / 13$ & $11 / 04 / 13$ & 1 & 0 \\
\hline 24 & $11 / 04 / 13$ & $01 / 20 / 14$ & 9 & -15 \\
\hline 25 & $11 / 04 / 13$ & $11 / 04 / 13$ & 1 & 0 \\
\hline 26 & $11 / 05 / 13$ & $12 / 17 / 13$ & 5 & -2.1 \\
\hline
\end{tabular}

Barriers and unintended consequences to achieving objectives included the high attrition rate, inconsistent attendance, November, December, and January holidays that occurred during the time the sessions were held, the bad winter weather with snow and extreme cold, and a water crisis in the community which resulted in most citizens in the area not having water to drink, bathe, wash dishes, cook with, or wash clothes for almost one week.

One participant had been losing weight prior to the MOVE! Program but joined the program because she had reached a plateau. This participant went on to achieve a 100-pound weight loss, which she stated was due to motivation she received from attending the MOVE! sessions. Another participant had broken her arm and was recovering from having surgery when 
she joined the program and was motivated to lose weight she had gained during her recovery time by increasing her steps walked daily. Also, additional qualitative data consisted of comments made to the project director regarding the MOVE! Program are presented in the Table

3.

Table 3

Participant Comments*

\begin{tabular}{|c|c|}
\hline Participant \# & Comments \\
\hline 1 & $\begin{array}{l}\text { The activities in the MOVE! Program are designed for someone who } \\
\text { has never exercised before. The program is helping me to make } \\
\text { healthier choices }\end{array}$ \\
\hline 6 & $\begin{array}{l}\text { My mother in law became ill and was hospitalized. I wasn't able to } \\
\text { complete the sessions, but am still working to eat better and to MOVE! } \\
\text { more }\end{array}$ \\
\hline 7 & $\begin{array}{l}\text { Chemical leak in the water caused session attendance to lessen because } \\
\text { of when the water was restored there were mountains of dishes and } \\
\text { clothes to be washed }\end{array}$ \\
\hline 9 & $\begin{array}{l}\text { The session that showed examples of the amount of fat in foods was } \\
\text { eye opening. Won't be having those McDonald's fries anymore }\end{array}$ \\
\hline 10 & The weather has been too cold and bad with a lot of snow \\
\hline 14 & $\begin{array}{l}\text { I tripped over my dog at 4:30AM one morning and broke my hip, so } \\
\text { had to have surgery, hospital stay, and physical therapy, so I had to } \\
\text { miss sessions }\end{array}$ \\
\hline 15 & Don't do blood pressure every week \\
\hline 19 & $\begin{array}{l}\text { I know what I need to do, so don't need to come to session since I } \\
\text { already know what to do. I did not get any new information from the } \\
\text { session, so feel like it is not going to help me. }\end{array}$ \\
\hline 22 & $\begin{array}{l}\text { My pipes burst and I am waiting on a plumber to come to fix them, so } \\
\text { will be missing sessions }\end{array}$ \\
\hline
\end{tabular}




\begin{tabular}{|l|l|}
\hline Participant \# & Comments \\
\hline 24 & Having the gym at the WLC is a great motivator \\
\hline 26 & I was ill and had to miss session. I have Crohn's so it is hard to diet \\
\hline
\end{tabular}

*Not all participants commented

\section{Discussion and Recommendations}

As previously discussed Bandura's Self-efficacy Theory and the Transtheoretical Model framed this project because participant-centered counseling has been shown to be effective in adherence to weight loss and that peer relationships influence individual's self-efficacy. In the group sessions the use of these theories was evident in the support provided to each participant through discussion of weight loss efforts, trials, and successes.

Although the findings of weight loss and systolic blood pressure changes were not significant, the trend toward significance with the small sample suggests that the program was effective. Further scheduling of a similar program using lessons learned from this program has a strong potential for success.

Following the completion of this program in February 2014, Mary Colley, Practice Administrator at the WLC, and the projector director discussed the project outcomes, including what facilitators and areas for improvement were needed. Improvements could be made specifically regarding not recording the blood pressure at each session. They also discussed that the MOVE! Program was designed for 12 weeks, but most participants felt that 12 weeks was too long. Additionally, they discussed the different sessions and in paring it down to 8 weeks, could have the different sessions held by different disciplines of dietitian, exercise physiologist, physician, psychologist, and nurse practitioner to provide different perspectives and added emphasis to different session topics as is seen in the Table 4 comparing the original MOVE! Program and the modified WLC sessions. 
Table 4

Comparison of MOVE! Program topics and the WLC modified program

\begin{tabular}{|c|c|}
\hline MOVE! Program Sessions & WLC Sessions \\
\hline $\begin{array}{l}\text { MOVE! Begins Lesson } 1 \\
\text { Orientation } \\
\text { Questionnaire completed } \\
\text { Input in computer by project leader } \\
\text { Learn about MOVE! } \\
\text { Discuss self-management } \\
\text { Set goals for program }\end{array}$ & $\begin{array}{l}\text { Lesson } 1-\text { Dr. Shin presented causes of overweight } \\
\text { and the co-morbidities that could be avoided. } \\
\text { Orientation - participants weighed and pedometer } \\
\text { given }\end{array}$ \\
\hline $\begin{array}{l}\text { MOVE! Lesson } 2 \\
\text { Stepping out with my pedometer } \\
\text { Distribute questionnaire results to individuals } \\
\text { Walking as a physical activity } \\
\text { Learn how to use pedometer } \\
\text { Develop walking plan } \\
\text { Practice stretches, cool down } \\
\text { Review Diaries } \\
\text { Set goals for the week }\end{array}$ & \\
\hline $\begin{array}{l}\text { MOVE! Lesson } 3 \\
\text { What's in Your Food? } \\
\text { Learn about food composition } \\
\text { Discuss healthy food choices } \\
\text { Review diaries } \\
\text { Set goals for the week }\end{array}$ & $\begin{array}{l}\text { Lesson } 2 \text { - Barbara Daye (dietitian) presented } \\
\text { Explained dieting and food choice }\end{array}$ \\
\hline $\begin{array}{l}\text { MOVE! Lesson } 4 \\
\text { Fit for Life } \\
\text { Discuss exercise } \\
\text { Develop activity plan } \\
\text { Review Diaries } \\
\text { Set goals for the week }\end{array}$ & $\begin{array}{l}\text { Lesson } 3 \text { - Witney Thoman (exercise physiologist) } \\
\text { introduced gym and usage of exercise equipment }\end{array}$ \\
\hline $\begin{array}{l}\text { MOVE! Lesson } 5 \\
\text { Trim the fat } \\
\text { Discuss fatty foods in diet } \\
\text { How to eat less fat } \\
\text { Learn why some fats are better than others } \\
\text { Review diaries } \\
\text { Set goals for the week }\end{array}$ & $\begin{array}{l}\text { Lesson } 4 \text { (Dietitian presented) } \\
\text { Discussed food diary and avoiding or limiting of } \\
\text { soft drinks, eating fast food, and making healthier } \\
\text { food choices. }\end{array}$ \\
\hline $\begin{array}{l}\text { MOVE! Lesson } 6 \\
\text { Play it Safe } \\
\text { Discuss when to stop exercising } \\
\text { Discuss how hard to exercise } \\
\text { Personal safety issues }\end{array}$ & \\
\hline MOVE! Lesson 7 & \\
\hline
\end{tabular}




\begin{tabular}{|c|c|}
\hline $\begin{array}{l}\text { Tip the Balance } \\
\text { Discuss energy intake vs. energy output effecting } \\
\text { weight } \\
\text { Look at food labels } \\
\text { Discuss serving size } \\
\text { Discuss Holiday eating } \\
\text { Review diaries } \\
\text { Set goals for the week }\end{array}$ & \\
\hline $\begin{array}{l}\text { MOVE! Lesson } 8 \\
\text { If at First You Don't Succeed...PLAN } \\
\text { Discuss planning ahead to eat healthy and exercise } \\
\text { Discuss eating healthy at home and dining out } \\
\text { Consider time for physical activity } \\
\text { Review diaries } \\
\text { Set goals for the week }\end{array}$ & $\begin{array}{l}\text { Lesson } 5 \text { (Peggy Perdue, psychologist) } \\
\text { Discussed psychology of dieting. Promoted used } \\
\text { of distractors when wanting to indulge in } \\
\text { unhealthy, impulsive eating. }\end{array}$ \\
\hline $\begin{array}{l}\text { MOVE! Lesson } 9 \\
\text { You are the Boss! } \\
\text { Examine environmental influence on food/activity } \\
\text { Discuss making healthy choices } \\
\text { Learn new techniques to prevent overeating } \\
\text { Review Diaries } \\
\text { Set goals for the week }\end{array}$ & $\begin{array}{l}\text { Week } 6 \text { (exercise physiologist) demonstration of } \\
\text { additional exercise and promotion of increasing } \\
\text { steps walked per day }\end{array}$ \\
\hline $\begin{array}{l}\text { MOVE! Lesson } 10 \\
\text { MOVEing Forward } \\
\text { Bariatric Surgery } \\
\text { - Lap band } \\
\text { - Bypass } \\
\text { - Sleeve } \\
\text { Pharmacological aids } \\
\text { Sessions end }\end{array}$ & $\begin{array}{l}\text { Week } 7 \text { (dietitian) Ways to increase metabolism } \\
\text { and diet counseling }\end{array}$ \\
\hline $\begin{array}{l}\text { MOVE! Lesson } 11 \\
\text { Oops, I Did it Again! } \\
\text { Identify slip causes } \\
\text { Practice problem solving } \\
\text { Review Diaries } \\
\text { Set goals for the week } \\
\text { Review diaries } \\
\text { Set goals for the week }\end{array}$ & \\
\hline $\begin{array}{l}\text { MOVE! Lesson } 12 \\
\text { Keep it Going } \\
\text { Review progress } \\
\text { Dealing with weight plateaus } \\
\text { Staying motivated } \\
\text { Maintaining weight outside the group }\end{array}$ & $\begin{array}{l}\text { Week } 8 \text { (physician) discussion of other more } \\
\text { aggressive weight loss strategies including surgery. }\end{array}$ \\
\hline
\end{tabular}


Therefore, improvements were adjusted for length of the program, timing of the sessions, and focusing more on the information provided instead of data collection.

The WLC practice administrator then added the program to the WLC schedule of options with modifications of the length of the program from 12 weeks to eight weeks. The shortened program is intended to increase participant commitment. Only the weight of the participant was measured at the first visit, week five, and at week eight. The blood pressure, pulse, BMI, and steps walked were not measured in the modified program currently offered. Emphasis was made regarding the behavioral changes needed for a lifelong weight loss success and changes that last. The diet presentations included calorie counting, decreasing sugar sweetened beverages, eliminating diet drinks, making healthy food choices from food options offered in the workplace cafeteria, eating out, the amount of fats in fast food, and increasing metabolism. The progress of the participants was tracked on the MyHealth Website for CAMC employees with points toward wellness incentives given if they attended all sessions for a $\$ 100$ gift card.

Mrs. Colley and the WLC employees maintained interest in the MOVE! Program, and have continued it with modifications based on the outcomes of this project; it remains another weight loss program option at the WLC. The CAMC "MyHealth" website enabled employees to register for the group education session. The program was offered again beginning September 30. It is recommended that the WLC communicate with participants to obtain feedback regarding what works and what does not work in the program to remain effective and sustainable and to make changes as indicated in providing another weight loss program option for employees and the community.

Overweight and obesity are known contributors to other comorbid conditions and in that context the MOVE! Program or an adaptation of the program could be implemented in other 
settings. The MOVE! Program could be established in primary care physician offices since overweight and obese patients are prevalent in those practices and because comorbid conditions are exacerbated on this preventable condition. Because of the adaptability of the MOVE! Program, it easily could also be implemented as part of a community outreach service with potential sites at schools, recreation centers, or churches.

In the process of implementing the MOVE! Program the project director noted that attrition rate was very high as was indicated in the literature. An email was sent out to all participants to obtain information as to why they completed or did not complete the project, and two participants gave additional feedback. Those participants suggested that the program was too long in duration (12 weeks), it was held during high stress and high overeating temptation holiday seasons of Thanksgiving, Christmas, and New Year's, and some of the material was already known information.

Implications. The trend toward significance with the small sample suggests that the MOVE! Program has potential for success in different venues with or without modifications to meet the needs of the participants. Due to the established curricula, multitude of educational handouts regarding weight loss, increased activity, healthy eating, and techniques to avoid emotional eating available on the MOVE! website, the program could be implemented in many different settings. The website has been used by the project director in her current position to educate patients that have expressed an interest in weight loss. The variety of information available is suggested to individuals interested in weight loss to provide them more information in winning their fight against obesity. A modified program is successfully continuing at CAMC. Further projects implementing and evaluating the MOVE! Program in diverse settings and with diverse populations are needed. 


\section{Attainment of DNP Essentials}

The American Association of Colleges of Nursing (AACN) publication of "The Essentials of Doctoral Education of Advance Nursing Practice (October, 2006) recommends competency of the foundation of roles in advanced practice nursing. The objective of the Doctor of Nursing Practice (DNP) project is to gain proficiency in quality improvement and practice change. The DNP Essentials are defined and attained as shown in Table 5 titled "Attainment of DNP Essentials". In the implementation of the MOVE! Program in the Medical Weight Loss Center the DNP Essentials were attained in Essential 1 of scientific underpinnings of practice through the integration of nursing science in determining the nature and the significance of the need for an additional weight loss program at CAMC that incorporated the group presentation. In this essential nursing science is integrated "with knowledge from ethics, the biophysical, psychosocial, analytical, and organizational sciences for the highest level of nursing practice" (American Association of Colleges of Nursing, 2006). Theoretical frameworks from other disciplines were studied that supported weight loss and behavioral changes. The addition of that program was to increase options and to enhance health of those participants by imparting education regarding proper eating habits, food choices, and promotion of increased daily activities using nursing science, organizational science, and social science.

In the Essential II which is organizational and systems leadership for quality improvement and systems thinking was attained by recognition of the need for additional weight loss programs by working with multiple departments within the organization as well as utilizing systems and programs already in place. The literature to support the need was reviewed and evaluated. CAMC administration agreed with the need and allowed the project director to 
conduct the project at the WLC. The program director of the WLD and the WLC physiclans then implemented a group weight loss program based on a modified MOVE! Program.

Clinical scholarship and analytical methods for evidence-based practice in Essential III was completed through the entire weight loss project where review of previous research was the platform for directing a weight loss program to disseminate information to affect change in the participants. The evidence supporting a group weight loss program, including previous research and clinical practice guidelines were evaluated and reviewed.

The MOVE! Program was reviewed and evaluated and ultimately selected as the curriculum to follow because it was evidence-based and previously shown to be successful in a group setting. Information technology and research methods were used to appropriately collect the data, analyze the data from the practice and outcomes, to identify the gap in the practice, and disseminate the finding to improve healthcare outcomes.

In the Essential IV that is information systems/technology and patient care technology for the improvement and transformation of healthcare was accomplished through the use of multiple computer programs including electronic resources from the MOVE! Program, Internet searches, library searches, Microsoft Excel, Microsoft PowerPoint, Microsoft Word, SPSS, and others. It was also attained through the utilization of the existing communication system in the CAMC organization. The project director examined existing data from multiple sources including the significance of the overweight and obesity rates for the world, US, WV, and Kanawha County, which was important in articulating the importance of the project.

Health care policy for advocacy in health care of Essential V was achieved through introducing the MOVE! Program to the WLC and implementation of a revised form of the MOVE! Program to their weight loss programs. The HR policy was changed to allow this 
program to count toward the employee wellness incentive. This Essential was important in influencing the change in the delivery of a new health care program to provide a new program format to reach more patients or participants interested in improved health care.

Essential VI is the interprofessional collaboration for improving patient and population health outcomes that was carried out through the collaboration with the WLC and the HR department at CAMC to obtain the place for the program, time for the program, the advertisement, signing up of participants, and rewards to participants to aid in their weight loss success. It was attained through the meeting with the program director, Mary Colley, Mary Caldwell, and Evan Thoman to garner their support for the project. Other collaboration between the dietitian and the exercise physiologist was done to provide them the information regarding the MOVE! Program and to support them as they taught their assigned classes on proper nutrition and increasing activity.

In the Essential VII for clinical prevention and population health for improving the nation's health was fulfilled through the offering of this program to improve the health of overweight and obese individuals as has been identified as a national health goal for any years identified as "Healthy People". Charleston, WV is certainly not the nation, but based on the statistics of WV being tied with Mississippi as the most obese states in the nation, this essential was accomplished in providing another weight loss program option as we know that not all people go through life events the same, this is important as the group format may be more successful for some than others.

The last Essential VIII is identified as advanced practice nursing was concluded through pulling together different disciplines of nursing, medicine, dietetics, exercise physiology, administration, and psychology to accomplish the implementation of another avenue of weight 
loss program that may lead to the successful life changes that need to be made by individuals embarking on weight loss endeavors. There has been a growth of nursing practice specialization of which no one individual can master. Therefore, the specialization is identified as the defining feature of the DNP.

I feel that during the five years of this education, I have grown exponentially, albeit, not always easily. I have been able to identify a health care need of group weight loss and have been able to implement and revise it based on the science of nursing and other sciences. The DNP program has helped me to develop relationships with professors, other professionals, and patients in order to provide them optimal care and to facilitate optimal outcomes. I have enhanced my skills in clinical judgment and systems thinking as well as guiding, mentoring, and supporting other nurses to achieve excellence in nursing. In my current practice working in Gastroenterology I am daily educating and guiding individuals and groups through their complex health issues. It is important in my position to apply analytical skills to continually evaluate the practice, organization, and the population. As I am transitioning to a new role as Nurse Manager of the Outpatient Care Center at CAMC I will be using all of the skills that I have acquired to make relevant, sustainable differences and changes based on sound, proven evidence.

Table 5

Attainment of DNP Essentials

\begin{tabular}{|c|c|}
\hline ESSENTIAL DEFINED & ESSENTIAL ATTAINED \\
\hline $\begin{array}{l}\text { Essential I: Scientific Underpinnings for } \\
\text { Practice }\end{array}$ & \\
\hline $\begin{array}{l}\text { 1. Integrate nursing science with knowledge } \\
\text { from ethics, the biophysical, psychosocial, } \\
\text { analytical, and organizational sciences as the } \\
\text { basis for the highest level of nursing practice. }\end{array}$ & $\begin{array}{l}\text { For the project, nursing science was } \\
\text { integrated with Bandura's Self efficacy } \\
\text { psychosocial theory and Prochaska's } \\
\text { Transtheoretical Model which comes from } \\
\text { behavioral science. They were integrated }\end{array}$ \\
\hline
\end{tabular}




\begin{tabular}{|c|c|}
\hline ESSENTIAL DEFINED & ESSENTIAL ATTAINED \\
\hline & $\begin{array}{l}\text { with biophysical measurements for the } \\
\text { weight loss program, ethics as evidenced by } \\
\text { the IRB approvals, analytics through } \\
\text { statistical analyses, and organizational } \\
\text { science through working with the WLC } \\
\text { department to promote employee health. }\end{array}$ \\
\hline $\begin{array}{l}\text { 2. Use science-based theories and concepts to: } \\
\text { - determine the nature and significance of } \\
\text { health and health care delivery phenomena; }\end{array}$ & $\begin{array}{l}\text { The project incorporated a group weight loss } \\
\text { program to address the significant problem } \\
\text { of obesity. }\end{array}$ \\
\hline $\begin{array}{l}\text { - describe the actions and advanced strategies } \\
\text { to enhance, alleviate, and ameliorate health } \\
\text { and health care delivery phenomena as } \\
\text { appropriate; and }\end{array}$ & $\begin{array}{l}\text { The MOVE! Program was an additional } \\
\text { strategy to increase weight loss options and } \\
\text { enhance health of the CAMC employees that } \\
\text { used multiple professionals and an advanced } \\
\text { practice nurse. }\end{array}$ \\
\hline - evaluate outcomes & $\begin{array}{l}\text { Outcomes of the data collected during the } \\
\text { twelve week program were analyzed using } \\
\text { SPSS and Excel; outcomes were evaluated } \\
\text { and used to modify the program for future } \\
\text { WLC center options. }\end{array}$ \\
\hline $\begin{array}{l}\text { 3. Develop and evaluate new practice } \\
\text { approaches based on nursing theories and } \\
\text { theories from other disciplines. }\end{array}$ & $\begin{array}{l}\text { The EBP MOVE! Program was developed } \\
\text { and evaluated as a new approach to a group } \\
\text { format for CAMC employee weight loss } \\
\text { options; actions and information to promote } \\
\text { weight loss were based on nursing, } \\
\text { biophysical, communication, and } \\
\text { psychosocial theories. }\end{array}$ \\
\hline \multicolumn{2}{|l|}{$\begin{array}{l}\text { Essential II: Organizational and Systems } \\
\text { Leadership for Quality Improvement and } \\
\text { Systems Thinking }\end{array}$} \\
\hline $\begin{array}{l}\text { 1. Develop and evaluate care delivery } \\
\text { approaches that meet current and future needs } \\
\text { of patient populations based on scientific } \\
\text { findings in nursing and other clinical sciences, } \\
\text { as well as organizational, political, and } \\
\text { economic sciences. }\end{array}$ & $\begin{array}{l}\text { For the project, a care delivery approach } \\
\text { provided in groups was developed and } \\
\text { evaluated to meet current and future needs of } \\
\text { the CAMC employee population that were } \\
\text { overweight. It included weekly meetings } \\
\text { with biophysical measurements, economic } \\
\text { incentives for completion, and organizational } \\
\text { science to promote employee health. The } \\
\text { political component included integrating the } \\
\text { work of the HR department and the WLC. }\end{array}$ \\
\hline $\begin{array}{l}\text { 2. Ensure accountability for quality of health } \\
\text { care and patient safety for populations with } \\
\text { whom they work. }\end{array}$ & $\begin{array}{l}\text { Due to the overweight and obese epidemic it } \\
\text { was important for the project director to } \\
\text { choose a program that could improve the }\end{array}$ \\
\hline
\end{tabular}




\begin{tabular}{|c|c|}
\hline ESSENTIAL DEFINED & ESSENTIAL ATTAINED \\
\hline & $\begin{array}{l}\text { quality of health of the participants and } \\
\text { patients/populations with whom they work. } \\
\text { Future improvement and decreased } \\
\text { comorbidities would be expected to lead to } \\
\text { higher quality of life. }\end{array}$ \\
\hline $\begin{array}{l}\text { a. Use advanced communication } \\
\text { skills/processes to lead quality improvement } \\
\text { and patient safety initiatives in health care } \\
\text { systems. }\end{array}$ & $\begin{array}{l}\text { In this project communication skills, } \\
\text { including effective counseling principles, } \\
\text { reflection and tailored messages, were used } \\
\text { to lead the program initiatives as suggested } \\
\text { and defined in the MOVE! Clinical Manual }\end{array}$ \\
\hline $\begin{array}{l}\text { b. Employ principles of business, finance, } \\
\text { economics, and health policy to develop and } \\
\text { implement effective plans for practice-level } \\
\text { and/or system-wide practice initiatives that } \\
\text { will improve the quality of care delivery. }\end{array}$ & $\begin{array}{l}\text { Business, finance and economic principles to } \\
\text { make the program viable for sustainability } \\
\text { and health policy principles to address } \\
\text { wellness incentives in the workplace, were } \\
\text { used to develop, implement and evaluate the } \\
\text { MOVE! Program at CAMC Weight Loss } \\
\text { Center to improve the quality of programs } \\
\text { available for weight loss education. }\end{array}$ \\
\hline $\begin{array}{l}\text { c. Develop and/or monitor budgets for } \\
\text { practice initiatives }\end{array}$ & $\begin{array}{l}\text { A budget was included in program design to } \\
\text { show what a group weight loss program may } \\
\text { potentially cost; cost-effectiveness resulted } \\
\text { in the program being modified prior to } \\
\text { continuation. }\end{array}$ \\
\hline $\begin{array}{l}\text { d. Analyze the cost-effectiveness of practice } \\
\text { initiatives accounting for risk and } \\
\text { improvement of health care outcomes. }\end{array}$ & $\begin{array}{l}\text { According to the literature overweight and } \\
\text { obesity account for a tremendous amount of } \\
\text { health care dollars due to the increased co- } \\
\text { morbidities; group options for weight loss } \\
\text { education are more cost-effective than } \\
\text { individual options. }\end{array}$ \\
\hline $\begin{array}{l}\text { e. Demonstrate sensitivity to diverse } \\
\text { organizational cultures and populations, } \\
\text { including patients and providers. }\end{array}$ & $\begin{array}{l}\text { This was accomplished through the work } \\
\text { with multi-cultural providers and patients, as } \\
\text { well as provider sensitivity to the social } \\
\text { stigma often experienced by overweight and } \\
\text { obese patients in the group. }\end{array}$ \\
\hline $\begin{array}{l}\text { 3. Develop and/or evaluate effective strategies } \\
\text { for managing the ethical dilemmas inherent in } \\
\text { patient care, the health care organization, and } \\
\text { research. }\end{array}$ & $\begin{array}{l}\text { In our facility where Bariatric Surgery is } \\
\text { offered, all employees complete an annual } \\
\text { competency regarding obesity to be more } \\
\text { sensitive to the targeted population. This } \\
\text { Weight Loss Program included a letter to } \\
\text { participants to inform them that the program } \\
\text { was for research and their identities would be } \\
\text { protected. }\end{array}$ \\
\hline $\begin{array}{l}\text { Essential III: Clinical Scholarship and } \\
\text { Analytical Methods for Evidence-Based }\end{array}$ & \\
\hline
\end{tabular}




\begin{tabular}{|c|c|}
\hline ESSENTIAL DEFINED & ESSENTIAL ATTAINED \\
\hline \multicolumn{2}{|l|}{ Practice } \\
\hline $\begin{array}{l}\text { 1. Use analytic methods to critically appraise } \\
\text { existing literature and other evidence } \\
\text { to determine and implement the best evidence } \\
\text { for practice. }\end{array}$ & $\begin{array}{l}\text { Critical appraisal performed using the } 2007 \\
\text { Scottish Intercollegiate Guidelines Network } \\
\text { (SIGN) Larrabee's Literature Review Form, } \\
\text { and AGREE II Form are found in Appendix } \\
\text { A and summarized in the Literature Review } \\
\text { and Synthesis section }\end{array}$ \\
\hline $\begin{array}{l}\text { 2. Design and implement processes to } \\
\text { evaluate outcomes of practice, practice } \\
\text { patterns, and systems of care within a practice } \\
\text { setting, health care organization, or } \\
\text { community against national benchmarks to } \\
\text { determine variances in practice } \\
\text { outcomes and population trends. }\end{array}$ & $\begin{array}{l}\text { The biophysical date were evaluated } \\
\text { outcomes; systolic blood pressure, weight, } \\
\text { BMI, steps walked, were compared to } \\
\text { national benchmarks to identify variances } \\
\text { such as HTN and overweight. }\end{array}$ \\
\hline $\begin{array}{l}\text { 3. Design, direct, and evaluate quality } \\
\text { improvement methodologies to promote safe, } \\
\text { timely, effective, efficient, equitable, and } \\
\text { patient-centered care. }\end{array}$ & $\begin{array}{l}\text { The project was guided by the established } \\
\text { and proven effective MOVE! Program. It } \\
\text { was timely, patient-centered, efficient, } \\
\text { equitable, and safe to provide this program to } \\
\text { employees at the CAMC Weight Loss } \\
\text { Center, and QI methods were used to } \\
\text { improve participation and completion. }\end{array}$ \\
\hline $\begin{array}{l}\text { 4. Apply relevant findings to develop practice } \\
\text { guidelines and improve practice and the } \\
\text { practice environment. }\end{array}$ & $\begin{array}{l}\text { Relevant practice guidelines were used for } \\
\text { the project which was then embraced by the } \\
\text { Weight Loss Center practice administrator } \\
\text { and physicians and a modified program was } \\
\text { implemented and is still being offered at the } \\
\text { facility }\end{array}$ \\
\hline \multicolumn{2}{|l|}{$\begin{array}{l}\text { 5. Use information technology and research } \\
\text { methods appropriately to: }\end{array}$} \\
\hline $\begin{array}{l}\text { - collect appropriate and accurate data to } \\
\text { generate evidence for nursing practice }\end{array}$ & $\begin{array}{l}\text { A tool was developed to collect appropriate } \\
\text { and accurate data that measured weight, } \\
\text { blood pressure, BMI, pulse; data were } \\
\text { compared at each patient contact; } \\
\text { adjustments for scale variance had to be } \\
\text { included in the process. }\end{array}$ \\
\hline $\begin{array}{l}\text { - inform and guide the design of databases } \\
\text { that generate meaningful } \\
\text { evidence for nursing practice }\end{array}$ & $\begin{array}{l}\text { The biophysical data were entered into an } \\
\text { excel spreadsheet along with information } \\
\text { from the MOVE! } 23 \text { questionnaire to allow } \\
\text { quantification of data; data were exported to } \\
\text { SPSS for analysis. }\end{array}$ \\
\hline - analyze data from practice & $\begin{array}{l}\text { SSPS and Excel were used to analyze data } \\
\text { using descriptive and comparative tests along } \\
\text { with qualitative analyses to explain barriers }\end{array}$ \\
\hline
\end{tabular}




\begin{tabular}{|c|c|}
\hline ESSENTIAL DEFINED & ESSENTIAL ATTAINED \\
\hline & $\begin{array}{l}\text { and unintended consequences to achieving } \\
\text { objectives such as inconsistent attendance. }\end{array}$ \\
\hline - design evidence-based interventions & $\begin{array}{l}\text { Evidence-based interventions were defined } \\
\text { in the MOVE! clinical practice guidelines } \\
\text { and the class curricula followed this EBP }\end{array}$ \\
\hline - predict and analyze outcomes & $\begin{array}{l}\text { Analyzed data with the help of chair and co- } \\
\text { chair and Statistician to identify sessions } \\
\text { attended and outcomes related to hypotheses. }\end{array}$ \\
\hline - examine patterns of behavior and outcomes & $\begin{array}{l}\text { Patterns of participation and related } \\
\text { outcomes were expressed in a table for easier } \\
\text { interpretation }\end{array}$ \\
\hline - identify gaps in evidence for practice & $\begin{array}{l}\text { Identified gap of no group weight loss } \\
\text { program at the weight loss center - } \\
\text { evidenced-based program implemented. }\end{array}$ \\
\hline $\begin{array}{l}\text { 6. Function as a practice specialist/consultant } \\
\text { in collaborative knowledge-generating } \\
\text { research. }\end{array}$ & $\begin{array}{l}\text { Functioned as the project leader for the } \\
\text { MOVE! Program project where I was the } \\
\text { practice specialist/consultant at all program } \\
\text { sessions, in collaboration with dietician and } \\
\text { exercise physiologist. }\end{array}$ \\
\hline $\begin{array}{l}\text { 7. Disseminate findings from evidence-based } \\
\text { practice and research to improve } \\
\text { healthcare outcomes }\end{array}$ & $\begin{array}{l}\text { Interpreted findings and communicated those } \\
\text { findings to the Weight Loss Center Practice } \\
\text { Administrator to support the ongoing } \\
\text { inclusion of a group weight loss program }\end{array}$ \\
\hline $\begin{array}{l}\text { Essential IV: Information } \\
\text { Systems/Technology and Patient Care } \\
\text { Technology for the } \\
\text { Improvement and Transformation of Health } \\
\text { Care }\end{array}$ & \\
\hline $\begin{array}{l}\text { 1. Design, select, use, and evaluate programs } \\
\text { that evaluate and monitor outcomes } \\
\text { of care, care systems, and quality } \\
\text { improvement including consumer use of } \\
\text { health care information systems. }\end{array}$ & $\begin{array}{l}\text { Word, Excel, Power Point, and SPSS were } \\
\text { used to track, evaluate, monitor, and } \\
\text { communicate the outcomes of the project. } \\
\text { Program handouts, their BMI analyses, and a } \\
\text { pedometer were examples of materials } \\
\text { supplied to improve self-care. }\end{array}$ \\
\hline $\begin{array}{l}\text { 2. Analyze and communicate critical elements } \\
\text { necessary to the selection, use } \\
\text { and evaluation of health care information } \\
\text { systems and patient care technology. }\end{array}$ & $\begin{array}{l}\text { Critical elements to identify weight loss and } \\
\text { improved health, including BMI \& BP } \\
\text { measurements, were accumulated and project } \\
\text { results were communicated in written and } \\
\text { oral formats. }\end{array}$ \\
\hline $\begin{array}{l}\text { 3. Demonstrate the conceptual ability and } \\
\text { technical skills to develop and execute } \\
\text { an evaluation plan involving data extraction } \\
\text { from practice information }\end{array}$ & $\begin{array}{l}\text { Guided by chair and co-chair, along with the } \\
\text { statistician, developed and executed the } \\
\text { evaluation plan involving data extraction and } \\
\text { interpretation using SPSS and Excel. }\end{array}$ \\
\hline
\end{tabular}




\begin{tabular}{|c|c|}
\hline ESSENTIAL DEFINED & ESSENTIAL ATTAINED \\
\hline \multicolumn{2}{|l|}{ systems and databases. } \\
\hline $\begin{array}{l}\text { 4. Provide leadership in the evaluation and } \\
\text { resolution of ethical and legal issues } \\
\text { within healthcare systems relating to the use } \\
\text { of information, information } \\
\text { technology, communication networks, and } \\
\text { patient care technology. }\end{array}$ & $\begin{array}{l}\text { The necessity of obtaining IRB approval to } \\
\text { conduct the project evaluation was } \\
\text { complicated by the need for dual } \\
\text { submissions to WVU where the project } \\
\text { director was a student and CAMC where the } \\
\text { project was located. These were addressed } \\
\text { and approval was obtained. }\end{array}$ \\
\hline $\begin{array}{l}\text { 5. Evaluate consumer health information } \\
\text { sources for accuracy, timeliness, and } \\
\text { appropriateness. }\end{array}$ & $\begin{array}{l}\text { Consumer health information mainly from } \\
\text { the CDC and NIH were evaluated to explain } \\
\text { the severity of the problem of overweight } \\
\text { and obesity. }\end{array}$ \\
\hline \multicolumn{2}{|l|}{$\begin{array}{l}\text { Essential V: Health Care Policy for } \\
\text { Advocacy in Health Care }\end{array}$} \\
\hline $\begin{array}{l}\text { 1. Critically analyze health policy proposals, } \\
\text { health policies, and related issues from the } \\
\text { perspective of consumers, nursing, other } \\
\text { health professions, and other stakeholders in } \\
\text { policy and public forums. }\end{array}$ & $\begin{array}{l}\text { Analyzed the issue of weight loss program } \\
\text { payment and policies to support consumers; } \\
\text { a resulting paper provided background for } \\
\text { this project. }\end{array}$ \\
\hline $\begin{array}{l}\text { 2. Demonstrate leadership in the development } \\
\text { and implementation of institutional, local, } \\
\text { state, federal, and/or international health } \\
\text { policy }\end{array}$ & $\begin{array}{l}\text { Led the implementation of a group weight } \\
\text { loss program in the CAMC Weight Loss } \\
\text { Center; the program continued to be } \\
\text { implemented because they recognized the } \\
\text { importance of a different weight loss } \\
\text { program format and the HR staff recognized } \\
\text { it as a program that could be added as a } \\
\text { Wellness Incentive for employees. These } \\
\text { were examples of implementing institutional } \\
\text { policy changes. }\end{array}$ \\
\hline $\begin{array}{l}\text { 3. Influence policy makers through active } \\
\text { participation on committees, boards, or task } \\
\text { forces at the institutional, local, state, } \\
\text { regional, national, and/or international levels } \\
\text { to improve health care delivery and outcomes. }\end{array}$ & $\begin{array}{l}\text { Influenced the Medical Director at the WLC } \\
\text { through active meetings and worked with the } \\
\text { CAMC Human Resources department and } \\
\text { the Weight Loss Center to add the Weight } \\
\text { Loss Program to improve the health of the } \\
\text { employees; no opportunity for direct } \\
\text { participation in task forces as a DNP student. }\end{array}$ \\
\hline $\begin{array}{l}\text { 4. Educate others, including policy makers at } \\
\text { all levels, regarding nursing, health policy, } \\
\text { and patient care outcomes. }\end{array}$ & $\begin{array}{l}\text { Advocated the implementation of a group } \\
\text { weight loss program where policy was } \\
\text { changed to allow attendees participation to } \\
\text { count toward their wellness incentive }\end{array}$ \\
\hline $\begin{array}{l}\text { 5. Advocate for the nursing profession within } \\
\text { the policy and healthcare communities. }\end{array}$ & $\begin{array}{l}\text { Advocated through personal contacts that the } \\
\text { advanced practice registered nurse can make } \\
\text { positive changes for the participant and the }\end{array}$ \\
\hline
\end{tabular}




\begin{tabular}{|c|c|}
\hline ESSENTIAL DEFINED & ESSENTIAL ATTAINED \\
\hline & community \\
\hline $\begin{array}{l}\text { 6. Develop, evaluate, and provide leadership } \\
\text { for health care policy that shapes health } \\
\text { care financing, regulation, and delivery. }\end{array}$ & $\begin{array}{l}\text { Provided the leadership for change in the } \\
\text { health care delivery of a weight loss program } \\
\text { that included financial incentives for } \\
\text { participation. }\end{array}$ \\
\hline $\begin{array}{l}\text { 7. Advocate for social justice, equity, and } \\
\text { ethical policies within all healthcare arenas. }\end{array}$ & $\begin{array}{l}\text { Overweight and obese individuals are often } \\
\text { subject to social stigmatism, discrimination, } \\
\text { and diminished quality of life. Offering } \\
\text { program sensitive to the needs of this } \\
\text { population advocates for social justice, } \\
\text { equity, and ethical policy change within the } \\
\text { facility environment and the community. }\end{array}$ \\
\hline \multicolumn{2}{|l|}{$\begin{array}{l}\text { Essential VI: Interprofessional } \\
\text { Collaboration for Improving Patient and } \\
\text { Population Health Outcomes1 }\end{array}$} \\
\hline $\begin{array}{l}\text { 1. Employ effective communication and } \\
\text { collaborative skills in the development and } \\
\text { implementation of practice models, peer } \\
\text { review, practice guidelines, health policy, } \\
\text { standards of care, and/or other scholarly } \\
\text { products. }\end{array}$ & $\begin{array}{l}\text { The Move! Program was premised on the } \\
\text { strong communication skills of the leader in } \\
\text { instructing, encouraging, counseling, and } \\
\text { persuading the participants toward better } \\
\text { health and the administration of CAMC } \\
\text { towards program continuation.. } \\
\text { Collaborative skills were used in promoting } \\
\text { multiple professionals to address the group } \\
\text { weight loss program }\end{array}$ \\
\hline $\begin{array}{l}\text { 2. Lead interprofessional teams in the analysis } \\
\text { of complex practice and organizational issues. }\end{array}$ & $\begin{array}{l}\text { The inclusion of the Weight Loss Center, } \\
\text { Human Resources, and Administration in the } \\
\text { analysis of the weight loss problem resulted } \\
\text { in realization of the need for this weight loss } \\
\text { option for employees; multiple professionals } \\
\text { were included in offering program sessions. }\end{array}$ \\
\hline $\begin{array}{l}\text { 3. Employ consultative and leadership skills } \\
\text { with intraprofessional and interprofessional } \\
\text { teams to create change in health care and } \\
\text { complex healthcare delivery systems. }\end{array}$ & $\begin{array}{l}\text { Consulted with HR representatives and } \\
\text { Weight Loss Center staff to create and } \\
\text { change health care program and policy } \\
\text { within the CAMC health system. } \\
\text { During the course of the program, } \\
\text { successfully advocated to the WLC practice } \\
\text { administrator to allow the participants access } \\
\text { to the gym for the length of the program. }\end{array}$ \\
\hline \multicolumn{2}{|l|}{$\begin{array}{l}\text { Essential VII: Clinical Prevention and } \\
\text { Population Health for Improving the } \\
\text { Nation's } \\
\text { Health }\end{array}$} \\
\hline 1. Analyze epidemiological, biostatistical, & Analyzed epidemiologic data on the problem \\
\hline
\end{tabular}




\begin{tabular}{|c|c|}
\hline ESSENTIAL DEFINED & ESSENTIAL ATTAINED \\
\hline $\begin{array}{l}\text { environmental, and other appropriate } \\
\text { scientific data related to individual, aggregate, } \\
\text { and population health. }\end{array}$ & $\begin{array}{l}\text { of obesity in the world, US, WV, and the } \\
\text { county to support the need for the program; } \\
\text { qualitative and quantitative data were } \\
\text { accumulated and analyzed related to the } \\
\text { individuals participating in the program. }\end{array}$ \\
\hline $\begin{array}{l}\text { 2. Synthesize concepts, including } \\
\text { psychosocial dimensions and cultural } \\
\text { diversity, related to clinical prevention and } \\
\text { population health in developing, } \\
\text { implementing, and evaluating interventions to } \\
\text { address health promotion/disease prevention } \\
\text { efforts, improve health status/access patterns, } \\
\text { and/or address gaps in care of individuals, } \\
\text { aggregates, or populations. }\end{array}$ & $\begin{array}{l}\text { Determined that there was a gap in the } \\
\text { facility where a group weight loss program } \\
\text { did not exist. Researched possible weight } \\
\text { loss programs, synthesized the information, } \\
\text { and determined that the established and } \\
\text { clinically proven MOVE! group weight loss } \\
\text { program could be modified to meet the need } \\
\text { for a group weight loss program at CAMC to } \\
\text { improve health status. }\end{array}$ \\
\hline $\begin{array}{l}\text { 3. Evaluate care delivery models and/or } \\
\text { strategies using concepts related to } \\
\text { community, environmental and occupational } \\
\text { health, and cultural and socioeconomic } \\
\text { dimensions of health. }\end{array}$ & $\begin{array}{l}\text { Evaluated strategies to impart health } \\
\text { information regarding overweight and } \\
\text { obesity related to inactivity, overeating, poor } \\
\text { food choices, etc. to aid in the improved } \\
\text { health of the participant. The problem of } \\
\text { obesity included concepts related to } \\
\text { community (CAMC employees), } \\
\text { environmental and occupational health } \\
\text { (obesity in WV), and cultural and } \\
\text { socioeconomic dimensions of health } \\
\text { (Appalachian culture). }\end{array}$ \\
\hline \multicolumn{2}{|l|}{ Essential VIII: Advanced Nursing Practice } \\
\hline $\begin{array}{l}\text { 1. Conduct a comprehensive and systematic } \\
\text { assessment of health and illness parameters in } \\
\text { complex situations, incorporating diverse and } \\
\text { culturally sensitive approaches. }\end{array}$ & $\begin{array}{l}\text { Reviewed the literature, evaluated the } \\
\text { problem of weight loss programs. Reviewed } \\
\text { established weight loss program and } \\
\text { determined the MOVE! Program met the } \\
\text { need of the program director in having an } \\
\text { established curricula which would make it } \\
\text { feasible to implement; comprehensive and } \\
\text { systematic assessment skills were used to } \\
\text { individualize the participants program. }\end{array}$ \\
\hline $\begin{array}{l}\text { 2. Design, implement, and evaluate } \\
\text { therapeutic interventions based on nursing } \\
\text { science and other sciences. }\end{array}$ & $\begin{array}{l}\text { The established program had a curriculum } \\
\text { that was modifiable by the program director } \\
\text { to match the needs of the participants. Social } \\
\text { science and organizational science along } \\
\text { with nursing science was utilized to } \\
\text { implement the program. The MOVE! } \\
\text { Program was adapted to a non-governmental }\end{array}$ \\
\hline
\end{tabular}




\begin{tabular}{|c|c|}
\hline ESSENTIAL DEFINED & ESSENTIAL ATTAINED \\
\hline & setting based on the participants needs. \\
\hline $\begin{array}{l}\text { 3. Develop and sustain therapeutic } \\
\text { relationships and partnerships with patients } \\
\text { (individual, family or group) and other } \\
\text { professionals to facilitate optimal care and } \\
\text { patient outcomes. }\end{array}$ & $\begin{array}{l}\text { Relationships with the participants were } \\
\text { forged within the program on a weekly basis. } \\
\text { Relationships with other professionals in HR } \\
\text { and the Weight Loss program were solidified } \\
\text { to facilitate the Weight Loss Program }\end{array}$ \\
\hline $\begin{array}{l}\text { 4. Demonstrate advanced levels of clinical } \\
\text { judgment, systems thinking, and } \\
\text { accountability in designing, delivering, and } \\
\text { evaluating evidence-based care to improve } \\
\text { patient outcomes. }\end{array}$ & $\begin{array}{l}\text { Demonstrated advanced levels of systems } \\
\text { thinking, clinical judgment, and } \\
\text { accountability in adapting the MOVE! } \\
\text { Program to the Weight Loss Center to } \\
\text { deliver a group weight loss program to } \\
\text { improve the health of the participants }\end{array}$ \\
\hline $\begin{array}{l}\text { 5. Guide, mentor, and support other nurses to } \\
\text { achieve excellence in nursing practice. }\end{array}$ & $\begin{array}{l}\text { In my student role I guided other advanced } \\
\text { practice nurses, and in my new position I } \\
\text { support LPNs, RNs, and APRNs, where I can } \\
\text { demonstrate and communicate my path to the } \\
\text { DNP and other paths to professional growth }\end{array}$ \\
\hline $\begin{array}{l}\text { 6. Educate and guide individuals and groups } \\
\text { through complex health and situational } \\
\text { transitions. }\end{array}$ & $\begin{array}{l}\text { Education as well as guiding of individuals } \\
\text { and groups was accomplished in each } \\
\text { MOVE! class through the explanation and } \\
\text { then group discussion of the topics and } \\
\text { transitions to future health. }\end{array}$ \\
\hline $\begin{array}{l}\text { 7. Use conceptual and analytical skills in } \\
\text { evaluating the links among practice, } \\
\text { organizational, population, fiscal, and policy } \\
\text { issues }\end{array}$ & $\begin{array}{l}\text { Used concept analysis skills to link the } \\
\text { weight loss program to meeting the } \\
\text { organizational need to improve the health of } \\
\text { the population; this may lead to decreased } \\
\text { fiscal load to the hospital system, and policy } \\
\text { changes related to adding a program to be } \\
\text { included in the wellness incentives of the } \\
\text { facility. }\end{array}$ \\
\hline
\end{tabular}




\section{References}

2009 - 2010 West Virginia Behavioral Risk Factor Survey Report WV Health Statistics Center, 2012.

Ajzen, I., \&Manstead, A. S. R. (2007) Changing health-related behaviors: An approach based on the theory of planned behavior. In K. van den Bos, M. Hewstone. J. de Wit, H. Schut \& M. Stroebe (Eds.), The scope of social psychology: Theory and applications (pp. 43-63). New York: Psychology Press.

American Association of Colleges of Nursing (2006). The essentials of doctoral education for advanced nursing practice. Washington, DC: Author.3

Andersson, K., Karlstrom, B., Freden, S., Petersson, H., Ohrvall, M., \& Zethelius, B. (2008). A two-year clinical lifestyle intervention program for weight loss in obesity. Food \& Nutrition Research.

Appraisal of Guidelines Research \& Evaluation. Retrieved May 18, 2012, from http://www.agreetrust.org/wpcontent/uploads/2013/06/AGREE_II_Users_Manual_and_23item_Instrument_ENGLISH.pdf

Ash, S., Reeves, M., Bauer, J., Dover, T., Vivanti, A., Leong, C., ... Capra, S. (2006, March 14). A randomised control trial comparing lifestyle groups, individual counselling and written information in the management of weight and health outcomes over 12 months. International Journal of Obesity, 30, 1557-1564. http://dx.doi.org/10.1038/sj.ijo.0803263

Bandura, A. (1997). Self-efficacy: The exercise of control. New York: W. H. Freeman and Company. 
Bates, T. L., Burdick, M. B., Crotty, K., Del Monte, P., Harvey, R. T., Jones, K. R.,...Yevich, S. (2005). MOVE! Weight management program clinical reference manual. : VA National Center for Health Promotion and Disease Prevention.

Beck, Aaron T. (1991). Cognitive Therapy A 30-year retrospective. American Psychologist, 46, 4, 368-375.

Brouwers, M., Kho, M. E., Browman, G. P., Burgers, J. S., Cluzeau, F., Feder, G., ... Zitzelsberger, L. (2010, December). AGREE II: Advancing guideline development, reporting and evaluation in healthcare. Canadian Medical Association Journal, 182, E839-842.

Centers for disease control and prevention (Report Early Release/Vol. 59). (2010, August 3). Retrieved from CDC Morbidity and Mortality Weekly Report: www.cdc.gov/mmwr Cooper, Z., Doll, H. A., Hawker, D. M., Byrne, S., Bonner, G., Eeley, E., ... Fairburn, C. G. (2010). Testing a new cognitive behavioural treatment for obesity: A randomized controlled trial with three-year followup. Behavior Research and Therapy, 48, 706-713.

Cresci, B., Tesi, F., La Ferlita, T., Ricca, V., Ravaldi, C., Rotelia, C. M., \& Mannucci, E. (2007). Group versus individual cognitive-behavioral treatment for obesity: results after 36 months. Eating Weight Disorders, 12, 147-153.

Daddario, D. K. (2007, December). A review of the use of the health belief model for weight management. MedSurg Nursing, 16(6), 363-366.

Davidson, T. L., \& Swithers, S. E. (2004). A pavlovian approach to the problem of obesity. International Journal of Obesity, 28, 933-935.

Find the Data website. (n.d.). retrieved from http://diabetes-obesity.findthedata.org/ 
Garvin, J. T., Marion, L. N., Narsavage, G. L., \& Finnegan, L. (2015). Characteristics influencing weight reduction among veterans in the MOVE!@ Program. Western Journal of Nursing Research. 37(1) 50-65. doi; 10.1177/0193945914534323. Epub 2014 May.

Gray, C. M., Anderson, A. S., Clarke, A. M., Dalziel, A., Hunt, K., Leishman, J., \& Wyke, S. (2009). Addressing male obesity an evaluation of a group-based weight management intervention for scottish men. Journal of Men's Health, 6, 70-81.

Groth, S. W. \& Morrison-Breedy, D. (2011). Obesity risk in urban adolescent girls: nutritional intentions and health behavior correlates. Journal of the New York State Nurses Association, 42(1-2), 15-20.

Jovanovic, Z., Crncevic-Orlic, Z., Stimac, D., Kokic, S., Persic, V., Ruzic, T., \& Goll-Baric, S. (2009). Effects of obesity reduction on cardiovascular risk factors: comparison of individual and group treatment - substudy of the croatian healthy weight loss programme. Coll. Antropol, 33, 751-757.

Kennedy, B. M., Paeratakul, S., Champagne, C. M., Ryan, D. H., Harsha, D. W., McGee, B., ... Bogle, M. L. (2005, Summer). A pilot church-based weight loss program for africanamerican adults using church members as health educators: a comparison of individual and group intervention. Ethnicity \& Disease, 15, 373-378.

Larrabee, J. H. (2009). Nurse to nurse: evidence-based practice. New York, NY: McGraw-Hill.

Linde, J. A., Rothman, A. J., Baldwin, A. S., \& Jeffery, R. W. (2006). The impact of selfefficacy on behavior change and weight change among overweight participants in a weight loss trial. Health Psychology, 25(3), 282-291.

MOVE! weight management program; Clinical reference manual. (2005). In MOVE! clinical reference manual (Version 2.0, pp. 1-229). 
Marshall, G. (1998). A dictionary of sociology. Retrieved from http://www.encyclopediaA.com/doc/1088-snowballingtechnique.html

Miller, W. M., Franklin, B. A., Janosz, K. E., Vial, C., Kaitner, R., \& McCullough, P. A. (2009). Advantages of group treatment and structured exercise in promoting short-term weight loss and cardiovascular risk reduction in adults with central obesity. METABOLIC SYNDROME AND RELATED DISORDERS, 7, 441-446.

Minniti, A., Bissoli, L., Di Francesco, V., Fantin, F., Mandragona, R., Olivieri, M., ... Zamboni, M. (2007, December). Individual versus group therapy for obesity: comparison of attrition rate and treatment outcome. Eating Weight Disorders, 12, 161-167.

Moyer, V. A. (2012, September 4). Screening for and management of obesity in adults: u.s. preventive services task force recommendation statement . Annals of Internal Medicine, $157,373-378$.

Paul-Ebhohimhen, V. \& Avenell, A. (2009). A systematic review of the effectiveness of group versus individual treatments for adult obesity. Obesity Facts, 2, 17-24.

Pavlov, I. P. (2003). Conditioned Reflexes. New York Dover Publications.

Piaget, J. (1983). “Piaget's Theory”. In P. Mussen (Ed.) Handbook of child psychology. Wiley. Pi-Sunyer, F. X., Becker, D. M., Bouchard, C., Carleton, R. A., Colditz, G. A., Dietz, W. H., ... Wilson, G. T. (1998). Clinical guidelines on the identification, evaluation, and treatment of overweight and obesity in adults (NIH Publication No. 98-4083). National Institutes of Health.

Prochaska, J. O., Norcross, J. C., \& DiClemente, C. C. (1994). Changing for good. New York: HarperCollins. 
Renjilian, D. A., Perri, M. G., Nezu, A. M., McKelvey, W. F., Shermer, R. L., \& Anton, S. D. (2001). Individual versus group therapy for obesity: effects of matching participants to their treatment preferences. Journal of Consulting and Clinical Psychology, 69, 717-721. http://dx.doi.org/10.1037//0022-006X.69.4.717

Roach, J. B., Adrick, M. K., Johnson, J. T., Boudreaux, L. J., Forsythe, W. A., \& Billon, W. (2003). Using self-efficacy to predict weight loss among young adults. Journal of the American Dietetic Association, 103, 1357-1359.

Rosenstock, I. M., Strecher, V. J., \& Becker, M. H. (1988). Social learning theory and the health belief model. Health Education Quarterly, 15 (4), 175-183.

Scottish Intercollegiate Guidelines Network. Retrieved May 18, 2012, from http://www.sign.ac.uk/methodology/checklists.html

Seals, J. G. (2007). Integrating the transtheoretical model into the management of overweight and obese adults. Journal of the American Academy of Nurse Practitioners, 19(), 63-71.

Sniehotta, F. F., Dombrowski, S. U., Avenell, A., Johnston, M., McDonald, S., Murchie, P., ... Araujo-Soares, V. (2011). Randomised controlled feasibility trial of an evidenceinformed behavioural intervention for obese adults with additional risk factors. Plos ONE, 6, e23040. http://dx.doi.org/10.1371/journal.pone.0023040

Teixeira, P. J., Silva, M. N., Coutinho, S. R., Palmeira, A. L., Mata, J., Vieira, P. N., ... Sardinha, L. B. (2010, April). Mediators of weight loss and weight loss maintenance in middleaged women. Obesity, 18, 725-736. http://dx.doi.org/10.1038/oby.2009.281

The Joint Commission. Comprehensive Accreditation Manual for Hospitals: The Official Handbook. (2008). Oakbrook Terrace, IL: The Joint Commission. 
Toouli, J., Fried, M., Khan, A. G., Garish, J., Hunt, R., Fedall, S., ... Krabshuis, J. (2009). World gastroenterology organization global guideline: obesity. Retrieved from National Guideline Clearinghouse: http://guideline.gov/popups/printView.aspx?id=15230

WV behavioral risk factor surveillance system report (Report). (2007-2011). Retrieved from WV behavioral risk factor surveillance system 2014: http://www.dhhr.wv.gov/bhhf/Sections/programs/ProgramsPartnerships/AlcoholismandD rugAbuse/Research/Documents/County\%20Profiles/Kanawha\%20County\%202014.pdf WV behavioral risk factor surveillance system 2004-2005 report (Report). (2004-2005).

Retrieved from WV behavioral risk factor surveillance system 2004-2005: http//www.wvdhhr.org/bph/hsc/pubs/brfss/2004_2005/ObesityandOverweight.pdf World Health Organization. (2011). [Fact Sheet 311]. Retrieved from World Health Organization website: http://www.who.int/mediacentre/factsheets/fs311/en/index.html 


\begin{tabular}{|c|c|c|c|c|c|c|c|c|c|}
\hline Reference & Design/Demographics & $\begin{array}{l}\text { Group Description } \\
\text { (N) and Baseline Data }\end{array}$ & Length & Intervention & $\begin{array}{l}\text { Drop-out } \\
\text { Total }\end{array}$ & Tools & Findings & Follow-up & Comments \\
\hline $\begin{array}{l}\text { Ash et al., } \\
2006\end{array}$ & $\begin{array}{l}\text { Australia } \\
\text { Two tertiary hospitals } \\
\text { (public and private) } \\
\text { Randomized Control } \\
\text { Trial } \\
\text { Independent variables: } \\
\text { Group based cognitive } \\
\text { behavior therapy } \\
\text { lifestyle intervention } \\
\text { Dependent variables: } \\
\text { Weight change } \\
\text { Percent body fat } \\
\text { Waist circumference } \\
\text { Physical activity } \\
\text { Health status, self- } \\
\text { efficacy, life satisfaction } \\
\text { Inclusion: } \\
\text { BMI } \geq 27 \mathrm{~kg} / \mathrm{m}^{2} \\
\text { Exclusion: }\end{array}$ & $\begin{array}{l}\mathrm{N}=191 \\
\text { 1. Fat Booters } \\
\text { Incorporated }(\mathrm{FBI})= \\
57 \\
\text { With } 10-12 \text { participants per } \\
\text { group } \\
\text { 2. Individualized dietetic } \\
\text { treatment (IDT) }=65 \\
\text { 3. Control group } \\
\quad \text { information booklet } \\
\text { only (BO) }=54 \\
\text { Mean Age: } 48 \\
\text { Females: } 129 / 176 \\
\text { Mean weight: } \\
\text { FBI = 94.6kgs. } \\
\text { IDT = 95.4kgs. } \\
\text { BO = 101.6kgs. } \\
\text { All participants required to } \\
\text { purchase nutrition resource } \\
\text { booklet on cognitive }\end{array}$ & 12 mos. & $\begin{array}{l}\text { FBI attended an } 8 \text { - } \\
\text { week ( } 1 \frac{1 / 2 \mathrm{~h} \text { per week }}{\text { for } 6 \text { weeks with }} \\
\text { follow-up at } 8 \text { weeks }) \\
\text { lifestyle behavior } \\
\text { management group. } \\
\text { Tri-phasic design } \\
\text { involving knowledge } \\
\text { and skill } \\
\text { development, } \\
\text { cognitive behavior } \\
\text { therapy and relapse } \\
\text { prevention with focus } \\
\text { on self-concept, self- } \\
\text { efficacy, and skills } \\
\text { mastery improvement. } \\
\text { Information about diet } \\
\text { and exercise } \\
\text { available, but up to } \\
\text { individual to act on it. } \\
\text { End of program } \\
\text { attended follow up } \\
\text { visit at week } 8 \text { and } \\
\text { monthly until } 6 \\
\text { months, with follow }\end{array}$ & $\begin{array}{l}\text { FBI drop out } \\
\text { at baseline = 5 } \\
\text { FBI lost to } \\
\text { follow up =5 } \\
\text { withdrew } \\
\text { consent and } \\
16 \text { dropped } \\
\text { out } \\
\text { IDT drop out } \\
\text { at baseline = } 1 \\
\text { IDT lost to } \\
\text { follow up = } 1 \\
\text { withdrew } \\
\text { consent and } \\
11 \text { dropped } \\
\text { out } \\
\text { BO drop out at } \\
\text { baseline = 9 } \\
\text { BO lost to } \\
\text { follow up = 9 } \\
\text { withdrew }\end{array}$ & $\begin{array}{l}\text { 1. General Self } \\
\text { Efficacy } \\
\text { Scale with } \\
\text { internal } \\
\text { consistency } \\
\text { of } 0.82 \text { to } \\
0.86 \\
\text { 2. General } \\
\text { Health } \\
\text { Questionnair } \\
\text { e (GHQ-12) } \\
\text { r=0.67, r=0.45 - } \\
0.49 \\
\text { 3. Satisfaction } \\
\text { with Life } \\
\text { Scale with } \\
\text { internal } \\
\text { consistency } \\
\text { of } 0.82 \\
\text { month test- } \\
\text { retest and } \\
\text { low to } \\
\text { moderate } \\
\text { concurrent } \\
\text { validity }\end{array}$ & $\begin{array}{l}\text { Baseline } \\
\text { characteristics not } \\
\text { significantly } \\
\text { different between } \\
\text { groups } \\
\text { Significantly more } \\
\text { females were } \\
\text { attrition > than } \\
\text { expected. } \\
\text { Dropouts younger } \\
\text { than completers } \\
\text { Dropouts had } \\
\text { higher BMIs } \\
\text { Weight change } \\
\text { between groups } \\
\text { significant } \\
(\mathrm{P}=0.05) \\
\text { FBI }>\text { BO at } 3 \text { and } \\
12 \text { months }-2.8 \pm \\
0.7 \text { vs. }-1.0 \pm 6 \\
\text { kgs. (p=0.05) and }\end{array}$ & $\begin{array}{l}3 \text { months } \\
6 \text { months } \\
12 \text { months }\end{array}$ & $\begin{array}{l}\text { Strengths: } \\
\text { Randomize } \\
\text { d } \\
\text { Large } \\
\text { Study } \\
\text { Limitations } \\
: \\
\text { Large } \\
\text { attrition } \\
\text { rate } \\
\text { Short study } \\
\text { time period } \\
\text { Clinical } \\
\text { end points } \\
\text { of blood } \\
\text { sugars, } \\
\text { lipids, or } \\
\text { other } \\
\text { markers of } \\
\text { disease } \\
\text { were not } \\
\text { measured. } \\
\text { More } \\
\text { women } \\
\text { than men }\end{array}$ \\
\hline
\end{tabular}


Appendix A Evidence Tables

\begin{tabular}{|c|c|c|c|c|c|c|c|c|c|}
\hline Reference & Design/Demographics & $\begin{array}{l}\text { Group Description } \\
(\mathrm{N}) \text { and Baseline Data }\end{array}$ & Length & Intervention & $\begin{array}{l}\text { Drop-out } \\
\text { Total }\end{array}$ & Tools & Findings & Follow-up & Comments \\
\hline & $\begin{array}{l}\text { BMI }<27 \mathrm{~kg} / \mathrm{m}^{2} \\
<18 \text { years of age } \\
\text { non-English speaking } \\
\text { background requiring } \\
\text { interpreter } \\
\text { cognitive impairment } \\
\text { NOT excluded based on } \\
\text { medical conditions or } \\
\text { medications. }\end{array}$ & behavior therapy principles & & $\begin{array}{l}\text { up at } 12 \text { months } \\
\text { IDT group had } \\
\text { individualized weekly } \\
\text { contact with dietitian } \\
\text { for } 8 \text { weeks. } \\
\text { Included initial } \\
\text { nutrition assessment, } \\
\text { individual diet } \\
\text { prescription, and an } \\
\text { exercise prescription. } \\
\text { Monthly follow up } \\
\text { visits from week } 8 \text { to } \\
6 \text { months, and } 12 \\
\text { months. } \\
\text { BO group was control } \\
\text { group and was } \\
\text { provided only the } \\
\text { nutrition resource } \\
\text { booklet. } \\
\text { Follow up at } 3,6, \& \\
12 \text { months }\end{array}$ & $\begin{array}{l}\text { consent and } \\
20 \text { dropped } \\
\text { out }\end{array}$ & & $\begin{array}{l}-2.9 \pm 0.9 \text { vs. }+0.5 \\
\pm 0.9 \text { kgs } \\
(\mathrm{p}<0.005) \\
\text { respectively } \\
\\
\text { Waist } \\
\text { circumference } \\
\text { significantly less } \\
\text { than baseline at all } \\
\text { time points } \\
\text { (p<0.001) } \\
\text { Change in weight } \\
\text { between IDT and } \\
\text { FBI did not differ } \\
\text { at any time } \\
\text { Change in per cent } \\
\text { body fat and waist } \\
\text { circumference } \\
\text { between } 3 \text { groups } \\
\text { over } 12 \text { months } \\
\text { did not differ. } \\
\text { Physical activity } \\
\text { levels changed } \\
\text { over time but were } \\
\text { not statistically }\end{array}$ & & \\
\hline
\end{tabular}


Appendix A Evidence Tables

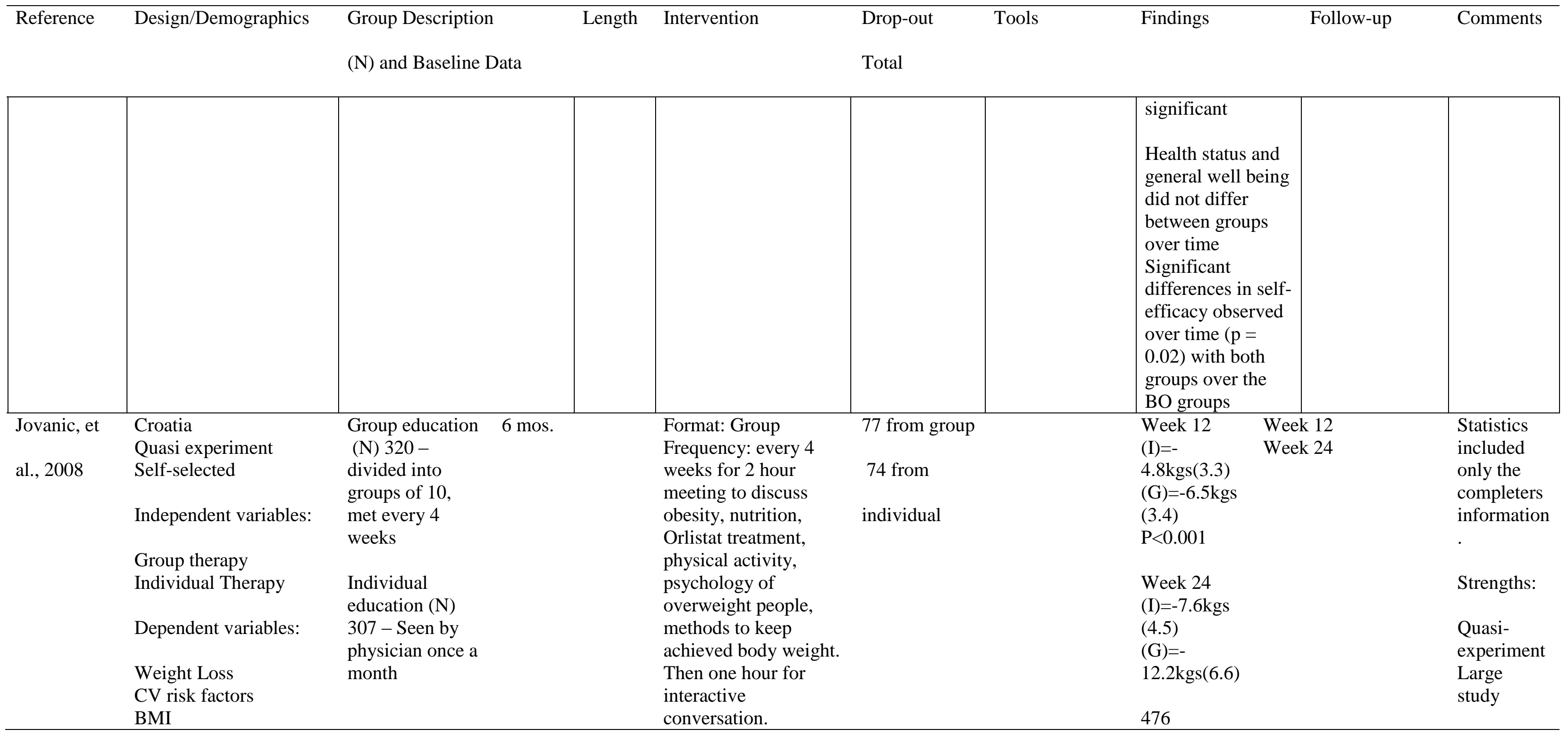


Appendix A Evidence Tables

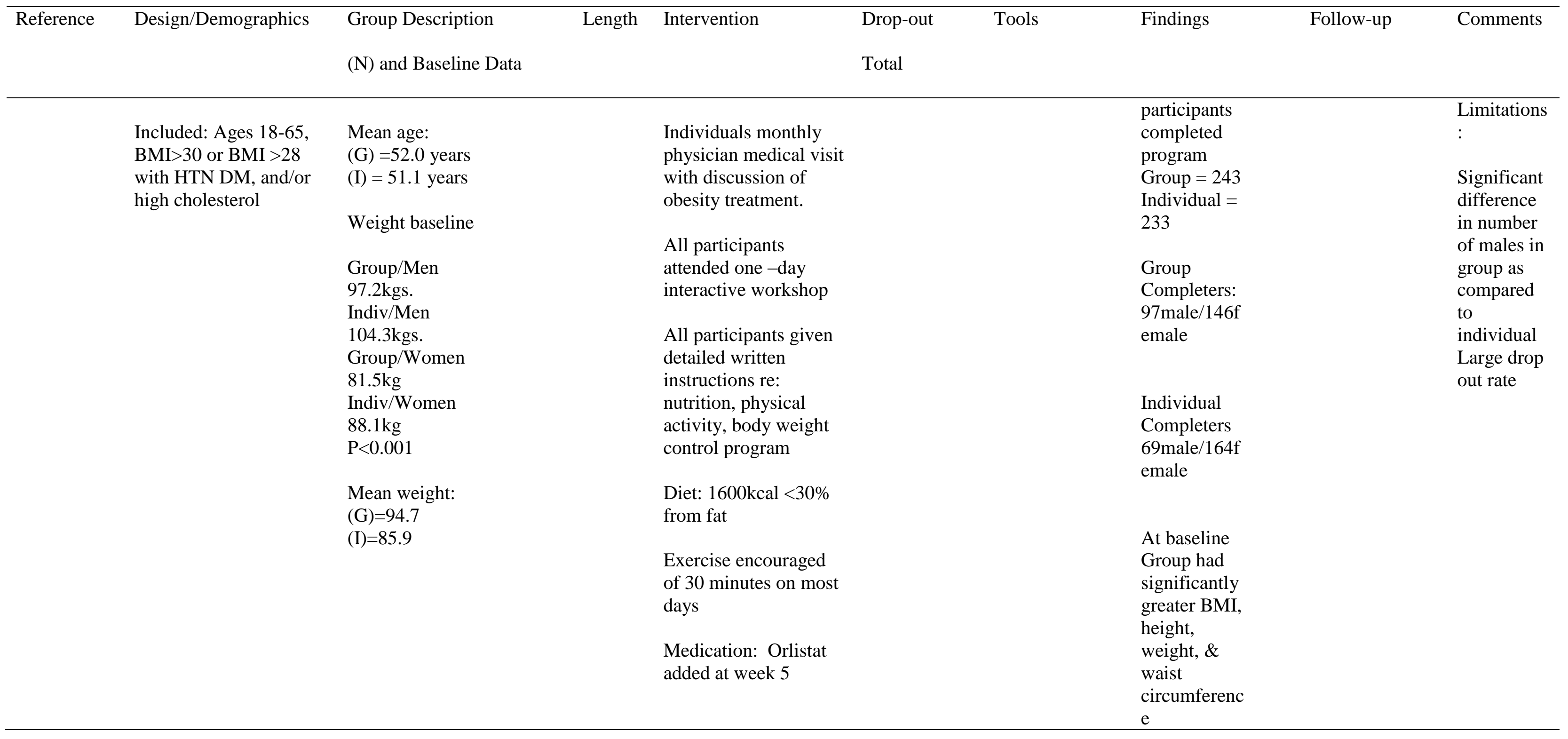


Appendix A Evidence Tables

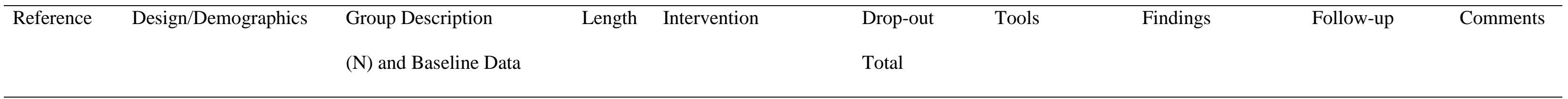

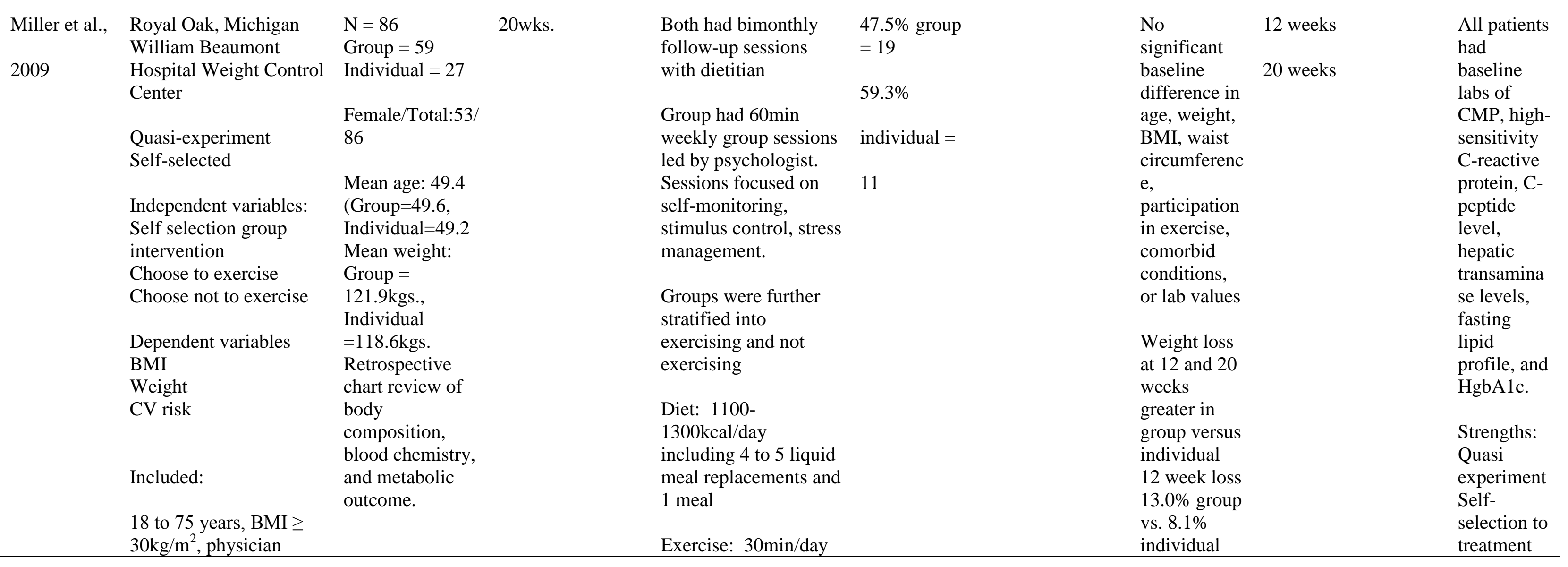


Appendix A Evidence Tables

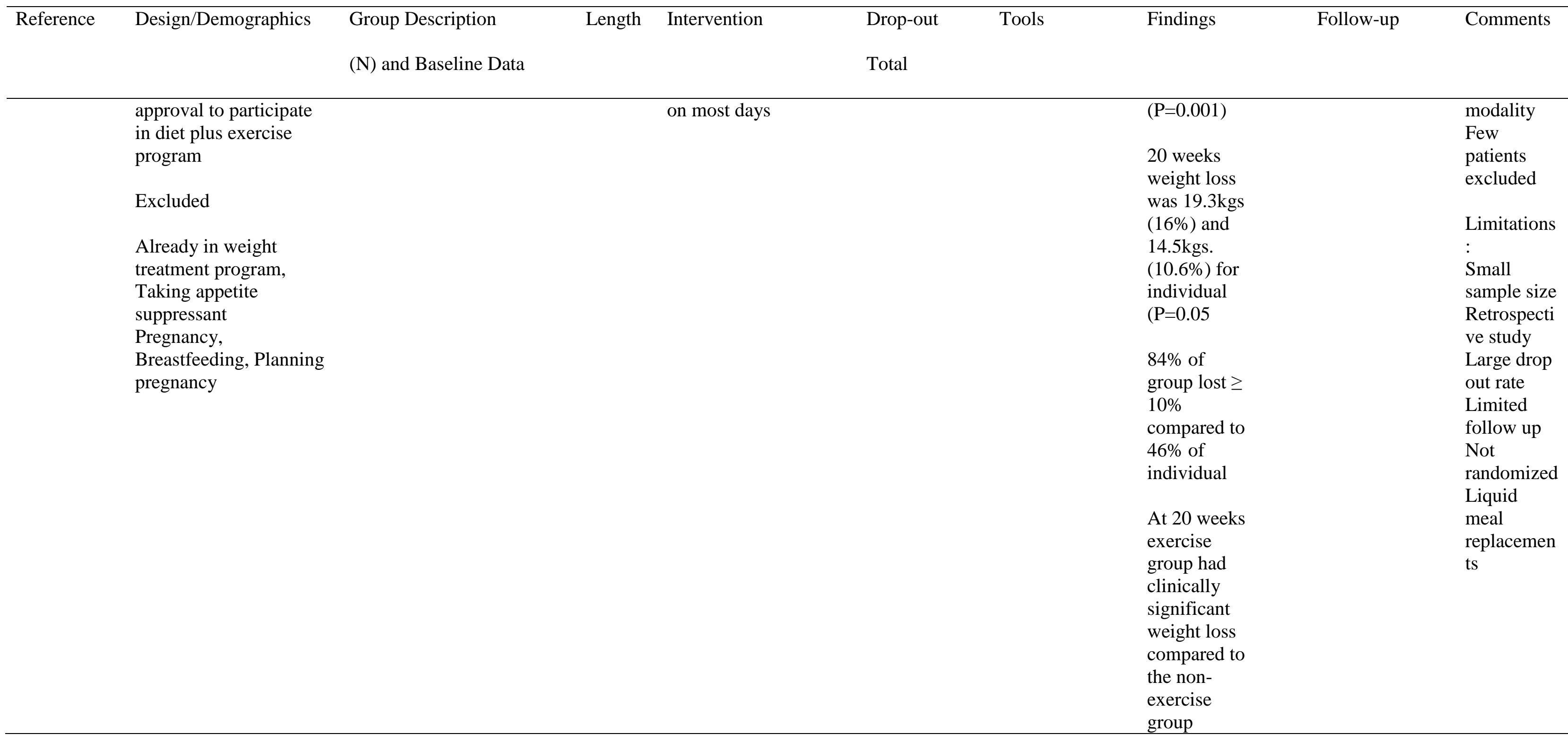


Appendix A Evidence Tables

\begin{tabular}{|c|c|c|c|c|c|c|c|c|c|}
\hline Reference & Design/Demographics & $\begin{array}{l}\text { Group Description } \\
(\mathrm{N}) \text { and Baseline Data }\end{array}$ & Length & Intervention & $\begin{array}{l}\text { Drop-out } \\
\text { Total }\end{array}$ & Tools & Findings & Follow-up & Comments \\
\hline & 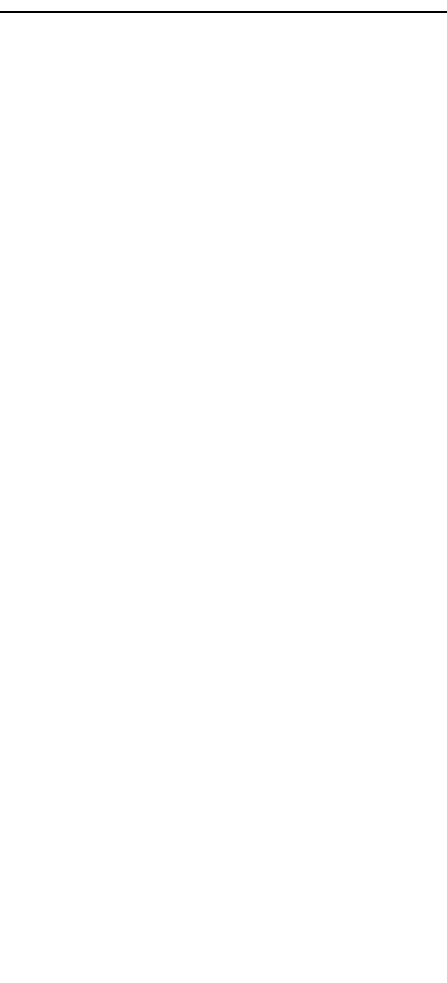 & & & 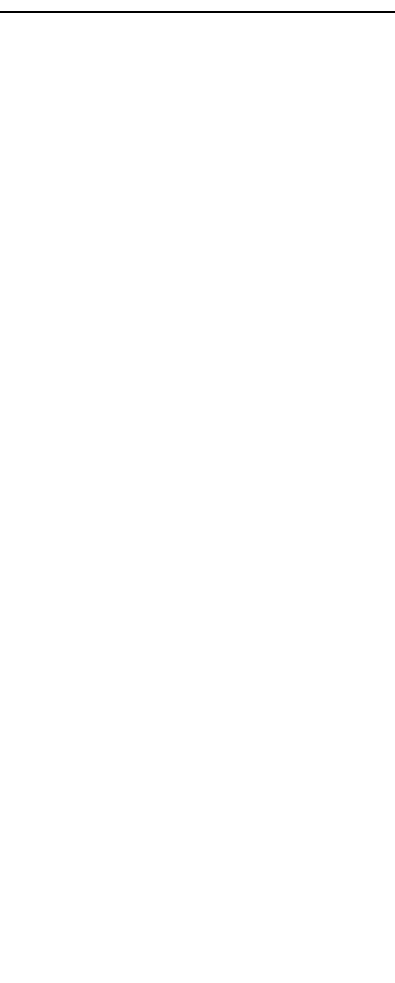 & & & $\begin{array}{l}\text { (82\%vs.38\% } \\
\text { lost weight) } \\
\mathrm{p}=0.02 \\
\text { Higher } \\
\text { percentage } \\
\text { of group } \\
\text { plus exercise } \\
\text { had } \\
\text { significant } \\
\text { weight loss } \\
\text { at } 20 \text { weeks } \\
\text { vs. } \\
\text { individual } \\
\text { without } \\
\text { exercise } \\
\text { (89\% } \\
\text { compared to } \\
0 \%, P \\
=0.006)\end{array}$ & 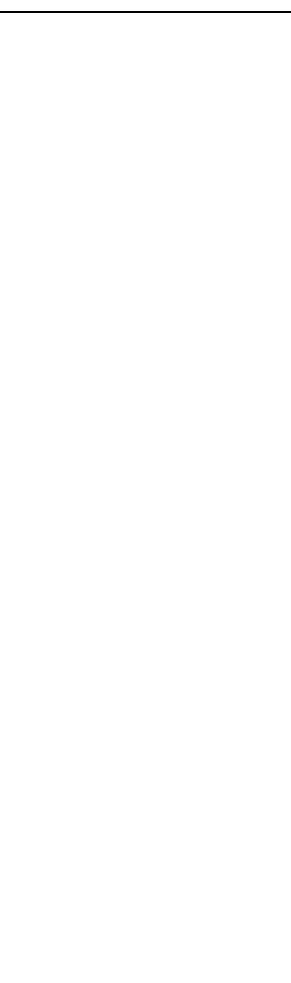 & \\
\hline $\begin{array}{l}\text { Renjilian et } \\
\text { al., } 2001\end{array}$ & $\begin{array}{l}\text { Fairleigh Dickinson } \\
\text { University, Teaneck, NJ, } \\
\text { University of Florida, } \\
\text { Gainesville, FL } \\
\text { Randomized Control }\end{array}$ & $\begin{array}{l}N=75 \\
58 \text { completed } \\
M=14 \\
F=61\end{array}$ & & $\begin{array}{l}26 \text { weekly sessions of } \\
\text { training re: self- } \\
\text { monitoring, goal } \\
\text { setting, stimulus } \\
\text { control. }\end{array}$ & 17 & $\begin{array}{l}\text { General } \\
\text { Severity Index } \\
\text { of Symptoms } \\
\text { checklist test- } \\
\text { retest reliability } \\
\text { of } 0.80 \text { to } 0.90\end{array}$ & $\begin{array}{l}\text { No } \\
\text { significant } \\
\text { differences } \\
\text { of baseline } \\
\text { measures of } \\
\text { age, weight, }\end{array}$ & 24 weeks & $\begin{array}{l}\text { Strengths: } \\
\text { RCT } \\
\text { Limitations } \\
:\end{array}$ \\
\hline
\end{tabular}


Appendix A Evidence Tables

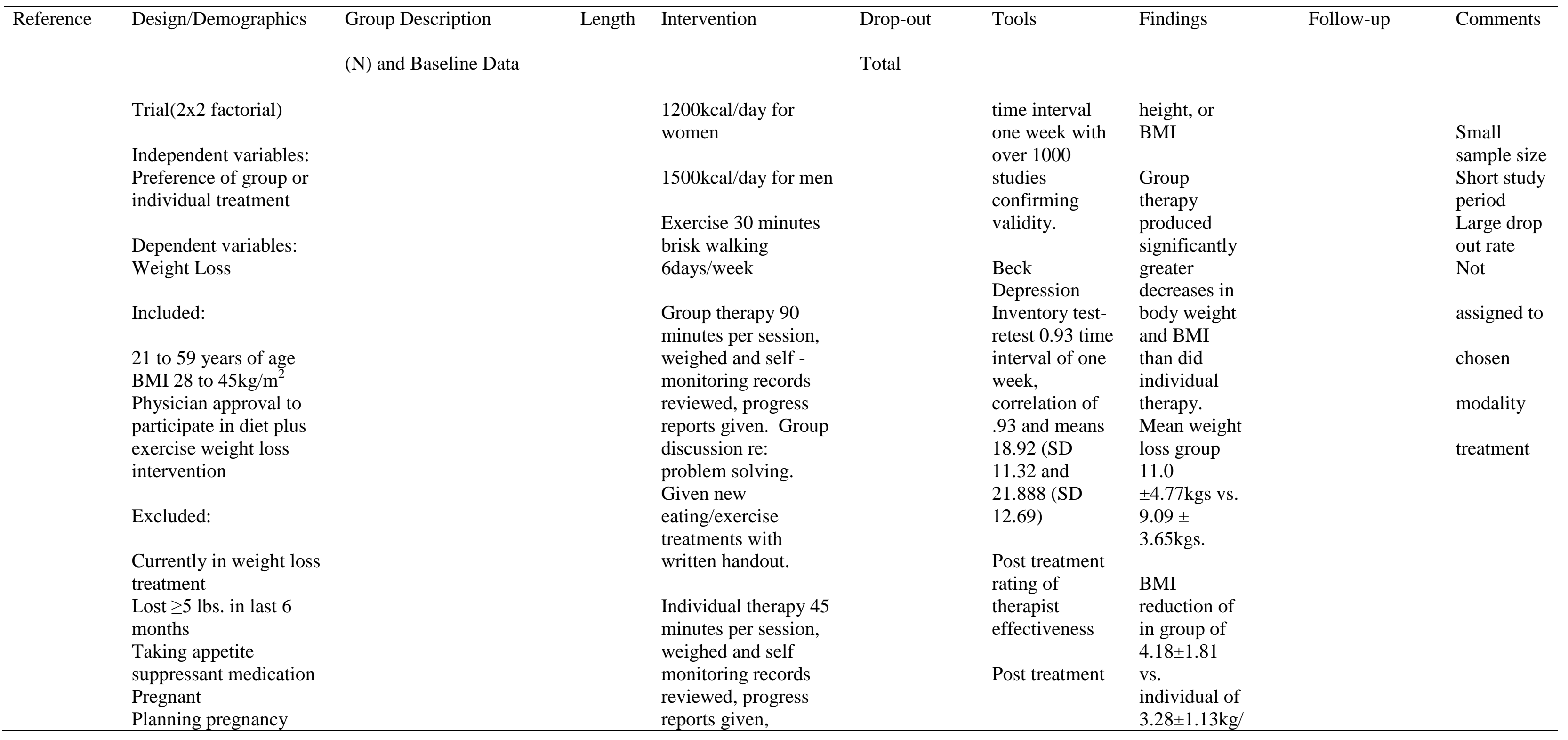


Appendix A Evidence Tables

\begin{tabular}{|c|c|c|c|c|c|c|c|c|c|}
\hline Reference & Design/Demographics & $\begin{array}{l}\text { Group Description } \\
(\mathrm{N}) \text { and Baseline Data }\end{array}$ & Length & Intervention & $\begin{array}{l}\text { Drop-out } \\
\text { Total }\end{array}$ & Tools & Findings & Follow-up & Comments \\
\hline & $\begin{array}{l}\text { Unwilling to accept } \\
\text { random assignment }\end{array}$ & & & $\begin{array}{l}\text { discussion re: } \\
\text { problem solving. } \\
\text { Given new } \\
\text { eating/exercise } \\
\text { treatments with } \\
\text { written handout. }\end{array}$ & & $\begin{array}{l}\text { of therapist } \\
\text { effective }\end{array}$ & $\begin{array}{l}\mathrm{m}^{2} \text { effect } \\
\text { size } \eta \tau= \\
.14, \\
\text { moderately } \\
\text { large } \\
\text { Clinically } \\
\text { significant } \\
\text { losses by } 18 \\
\text { of } 40 \text { in } \\
\text { group } \\
\text { therapy } \\
\text { condition } \\
\text { (45\%) and } \\
10 \text { of 35 } \\
\text { participants } \\
\text { in individual } \\
\text { therapy } \\
\text { condition } \\
\text { (29\%). } \\
\text { Participants } \\
\text { in all } \\
\text { conditions } \\
\text { showed } \\
\text { significant } \\
\text { improvemen } \\
\text { ts in }\end{array}$ & 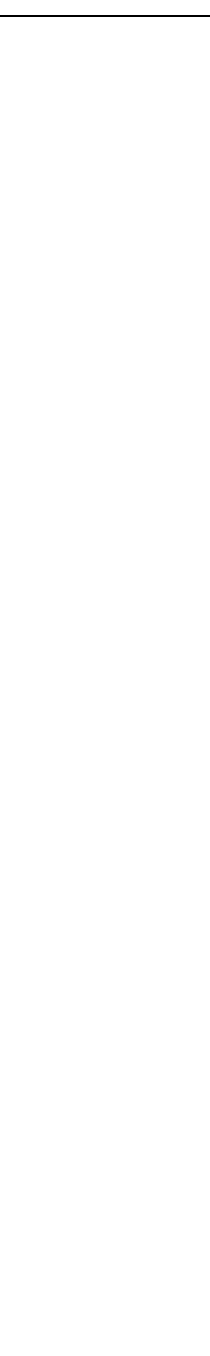 & - \\
\hline
\end{tabular}


Appendix A Evidence Tables

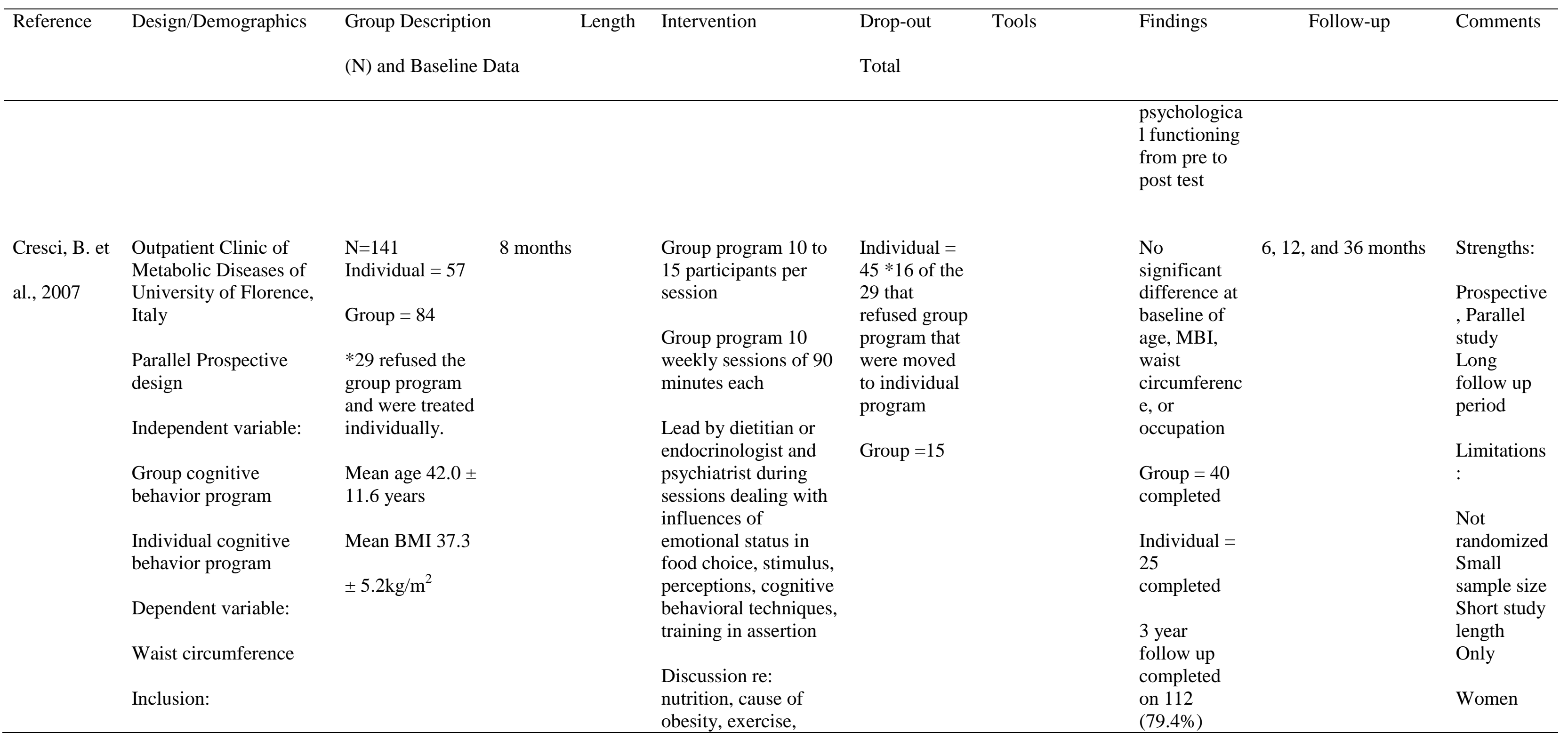


Appendix A Evidence Tables

\begin{tabular}{|c|c|c|c|c|c|c|c|}
\hline Reference & Design/Demographics & $\begin{array}{l}\text { Group Description } \\
\text { (N) and Baseline Data }\end{array}$ & Intervention & $\begin{array}{l}\text { Drop-out Tools } \\
\text { Total }\end{array}$ & Findings & Follow-up & Comments \\
\hline & $\begin{array}{l}\text { BMI } \geq 30 \mathrm{~kg} / \mathrm{m}^{2} \\
\text { Live within } 40 \mathrm{~km} \text { from } \\
\text { the clinic } \\
\text { Informed consent } \\
\text { Exclusion: } \\
\text { Males } \\
\text { Live more than } 40 \mathrm{~km} \\
\text { from the clinic } \\
\text { Uncontrolled hypo or } \\
\text { hyperthyroid } \\
\text { Insulin treated diabetes } \\
\text { Conditions that prohibit } \\
\text { exercise } \\
\text { Mental disorders } \\
\text { Current diagnosis of } \\
\text { bulimia or binge eating }\end{array}$ & 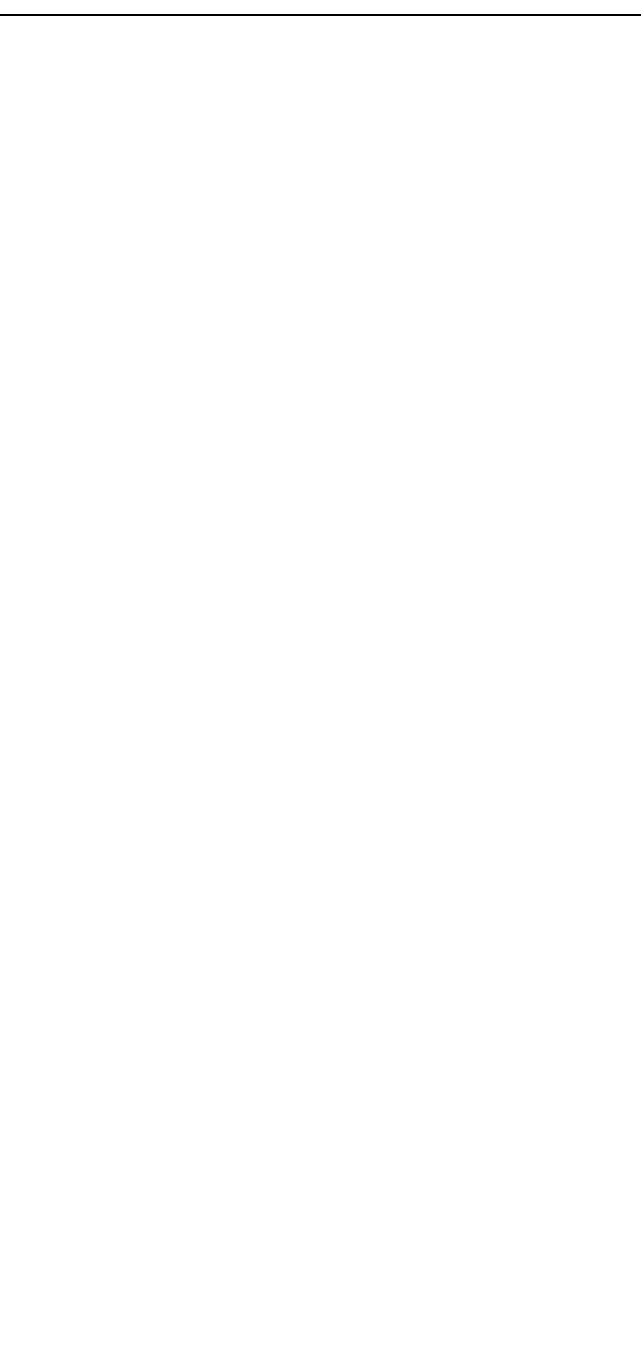 & $\begin{array}{l}\text { phases of change } \\
\text { (Prochaska), stimulus } \\
\text { control, problem } \\
\text { solving techniques, } \\
\text { and relapse prevention } \\
\text { Exercise encouraged } \\
\text { (minimum of } 45 \\
\text { minutes brisk walking } \\
\text { or } 30 \text { minutes cycling. } \\
\text { Individual: } \\
\text { Similar to group, Self- } \\
\text { monitoring of food } \\
\text { intake, physical } \\
\text { exercise, behavioral } \\
\text { techniques, and } \\
\text { problem solving } \\
\text { techniques discussed } \\
\text { and tolls for } \\
\text { preventing relapse. } \\
\text { All patients seen by } \\
\text { physician every } 3 \\
\text { months to verify }\end{array}$ & 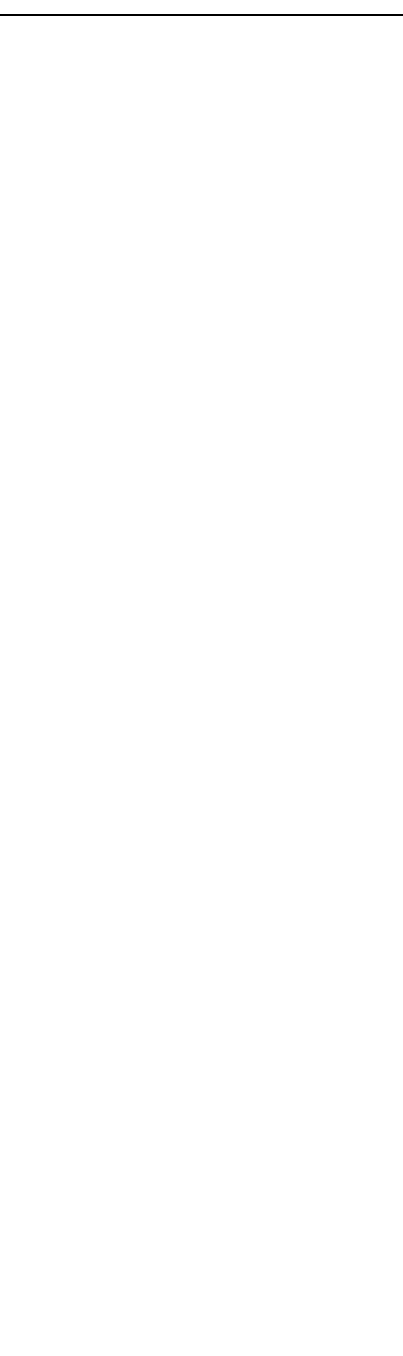 & $\begin{array}{l}27 \text { lost to } \\
\text { follow up } \\
\text { and } 2 \\
\text { refused } \\
\text { collaboration } \\
\text { Proportion } \\
\text { patients lost } \\
\text { to follow up } \\
\text { similar } \\
\text { (22.8\% in } \\
\text { individual, } \\
\text { and } 19 \% \text { in } \\
\text { group) } \\
\text { Significant } \\
\text { decrease in } \\
\text { group waist } \\
\text { circumferenc } \\
\text { e at } 6 \\
\text { months } \\
\text { (p<0.05). } \\
\text { Individual } \\
=102.9 \pm 2.4 \\
\text { vs. group } \\
=97.4 \pm\end{array}$ & 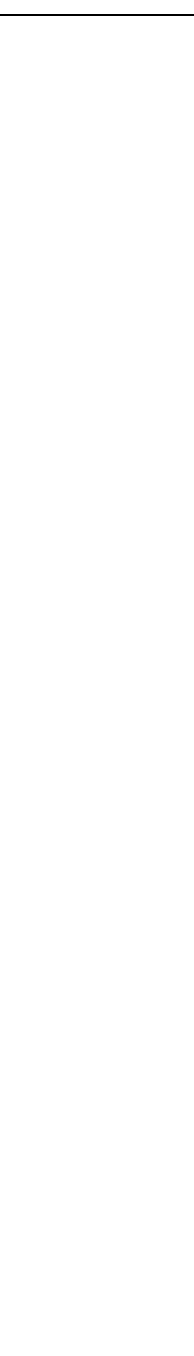 & 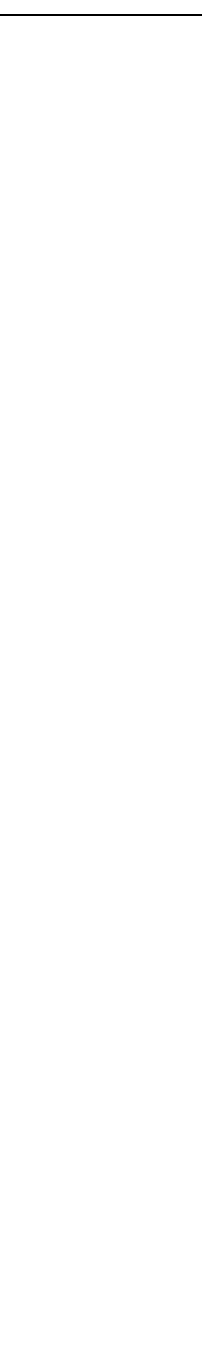 \\
\hline
\end{tabular}


Appendix A Evidence Tables

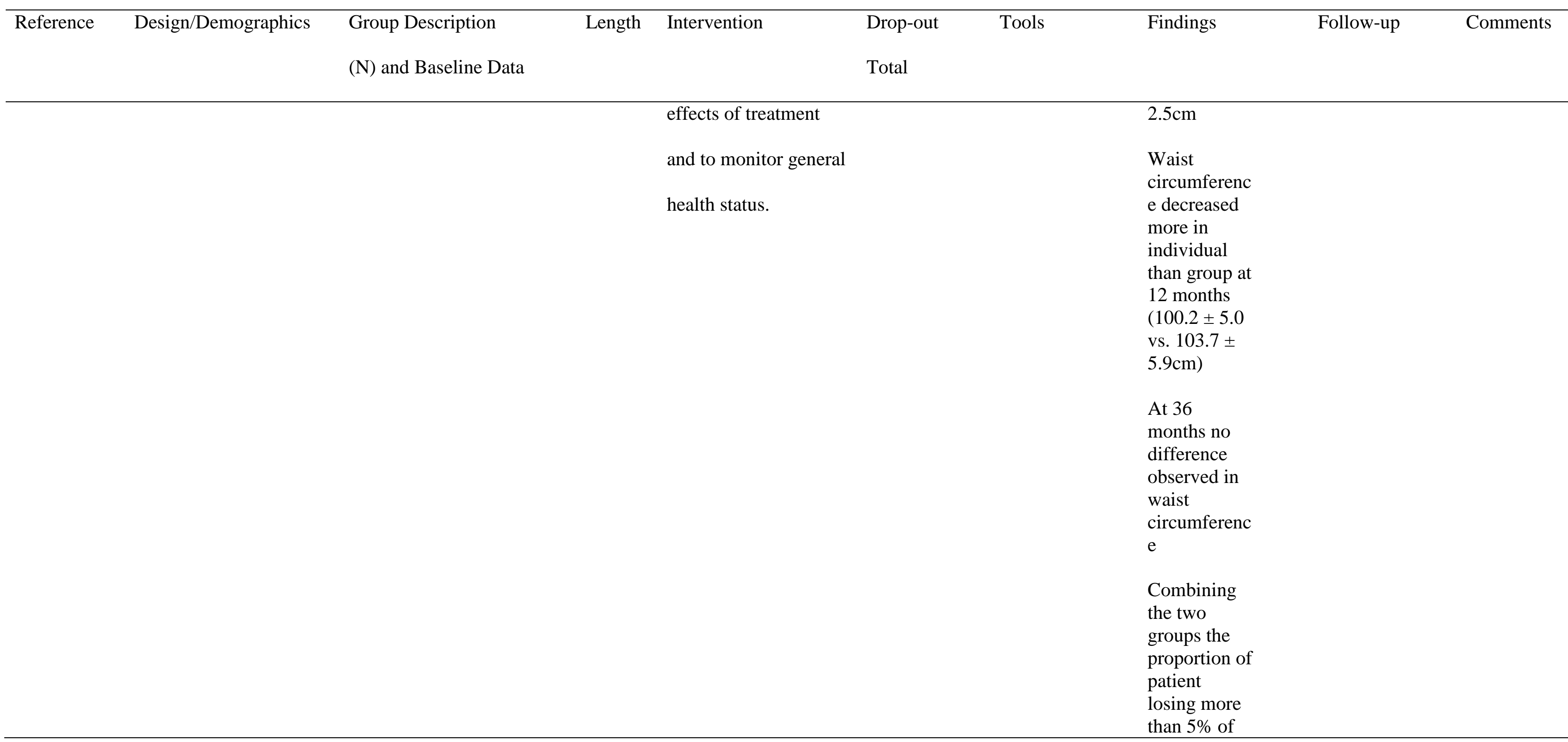


Appendix A Evidence Tables

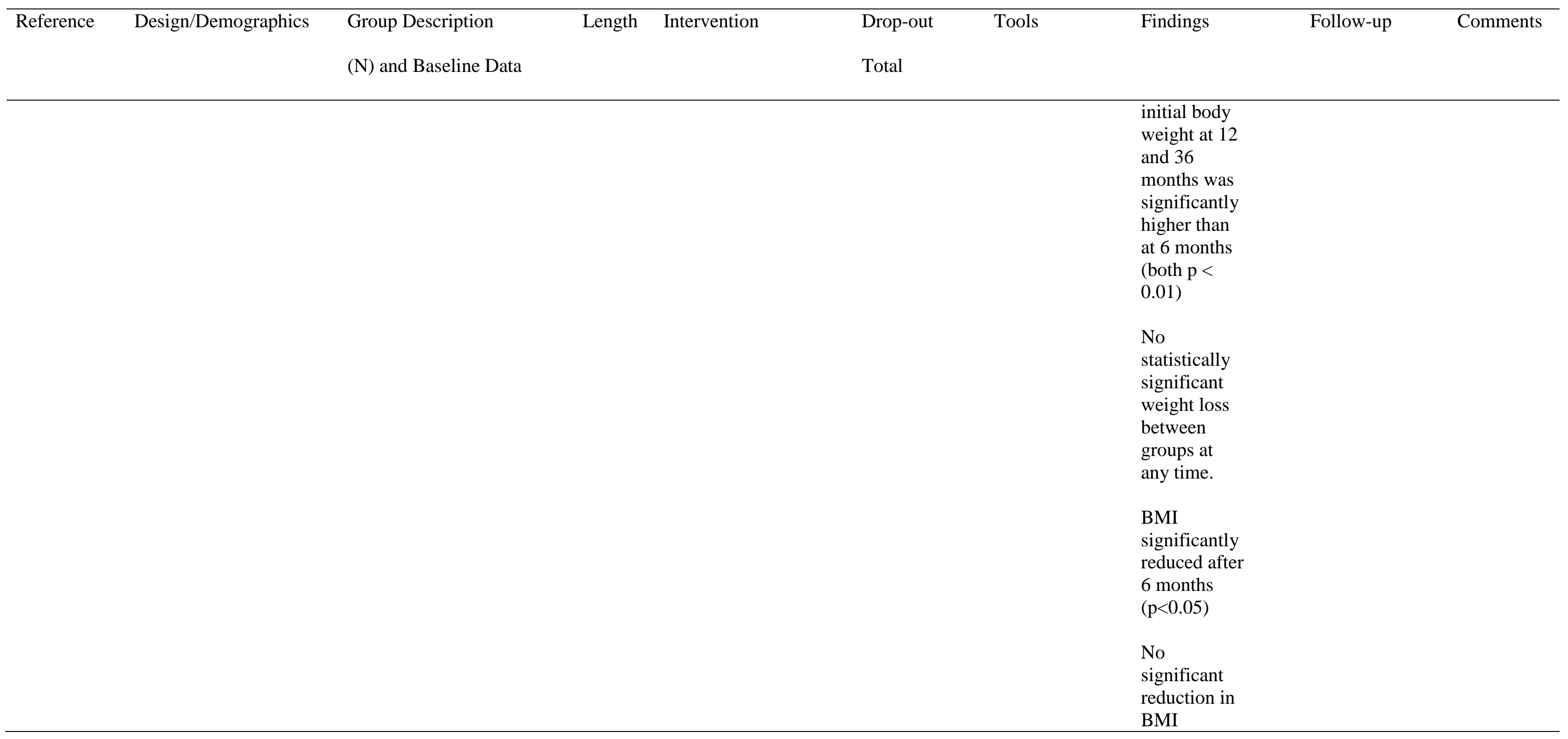


Appendix A Evidence Tables

\begin{tabular}{|c|c|c|c|c|c|c|c|c|c|}
\hline Reference & Design/Demographics & $\begin{array}{l}\text { Group Description } \\
(\mathrm{N}) \text { and Baseline Data }\end{array}$ & Length & Intervention & $\begin{array}{l}\text { Drop-out } \\
\text { Total }\end{array}$ & Tools & Findings & Follow-up & Comments \\
\hline & & . & & . & & & $\begin{array}{l}\text { between } 6 \\
\text { and } 12 \\
\text { months. } \\
\text { Significantly } \\
\text { lower BMI } \\
\text { in both } \\
\text { groups at } 36 \\
\text { months, both } \\
\text { p }<0.05 \\
\text { After } 3 \text { years } \\
35 \% \text { of } \\
\text { patients lost } \\
>5 \% \text { and } \\
12 \% \text { had lost } \\
\text { more than } \\
10 \% \text { of body } \\
\text { weight }\end{array}$ & 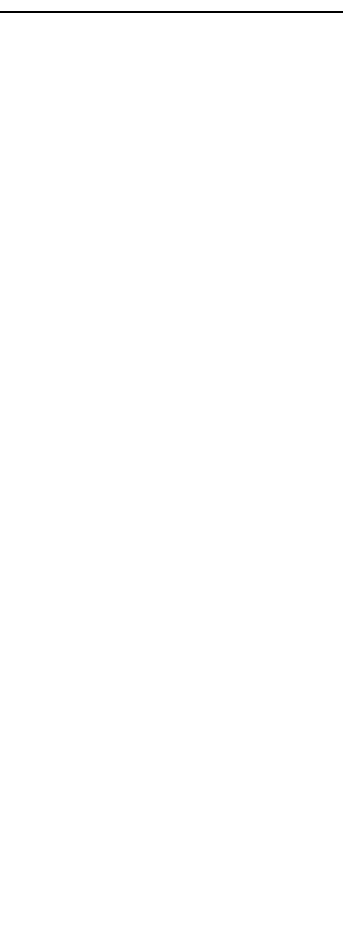 & \\
\hline $\begin{array}{l}\text { Sniehotta, } \\
\text { F., et al., } \\
(2011\end{array}$ & $\begin{array}{l}\text { Clinical Research } \\
\text { Facility of University of } \\
\text { Aberdeen in Aberdeen, } \\
\text { Scotland, UK } \\
\text { Single Center }\end{array}$ & $\begin{array}{l}\mathrm{N}=81 \\
\text { Face to face } \\
\text { group }=53 \\
\text { Control group = }\end{array}$ & & $\begin{array}{l}\text { Face to face } \\
\text { participants allocated } \\
\text { to one of seven groups } \\
\text { ranging from } 4 \text { to } 9 \\
\text { participants. }\end{array}$ & $\begin{array}{l}\text { Face to face } \\
\text { group }=21 \\
\text { Control }=3\end{array}$ & $\begin{array}{l}\text { Theory of } \\
\text { Planned } \\
\text { Behavior (TPB) } \\
\text { questionnaire } \\
\text { Action Planning }\end{array}$ & $\begin{array}{l}\text { Face to face } \\
\text { group } \\
\text { participants }\end{array}$ & $\begin{array}{l}\text { Time } 2-3 \text { months } \\
\text { following } \\
\text { randomization } \\
\text { Time } 3-6 \text { months }\end{array}$ & $\begin{array}{l}\text { Strengths: } \\
\text { RCT } \\
\text { Blinded } \\
\text { assessor }\end{array}$ \\
\hline
\end{tabular}


Appendix A Evidence Tables

\begin{tabular}{|c|c|c|c|c|c|c|c|c|}
\hline Reference & Design/Demographics & $\begin{array}{l}\text { Group Description } \\
\text { (N) and Baseline Data }\end{array}$ & Intervention & $\begin{array}{l}\text { Drop-out } \\
\text { Total }\end{array}$ & Tools & Findings & Follow-up & Comments \\
\hline & $\begin{array}{l}\text { Random Controlled } \\
\text { Trial (parallel group } \\
\text { study with imbalanced } \\
\text { randomization. } \\
\text { Outcome assessor } \\
\text { blinded } \\
\text { Independent variables: } \\
\text { Face to face group } \\
\text { intervention } \\
\text { Control group } \\
\text { Dependent variables: } \\
\text { Weight Loss } \\
\text { Inclusion: } \\
\text { Adults } \geq 18 \text { years old } \\
\text { BMI } \geq 30 \mathrm{~kg} / \mathrm{m}^{2} \text { with at } \\
\text { least one comorbid } \\
\text { condition of HTN, heart } \\
\text { disease, COPD, Type } 1 \\
\text { or Type } 2 \text { diabetes } \\
\text { mellitus, impaired } \\
\text { glucose tolerance (IGT), }\end{array}$ & $\begin{array}{l}28 \\
\text { Pre- } \\
\text { randomization } \\
\text { baseline } \\
\text { characteristics } \\
\text { were } 56.6 \text { years } \\
\text { old (SD =11.4) } \\
51(63 \% \text { females } \\
\text { BMI } 36.73 \mathrm{~kb} / \mathrm{m}^{2} \\
\text { Diagnosed with } \\
2.4 \text { (SD=1.5) } \\
\text { risk } \\
\text { factors } / \text { comorbid } \\
\text { ities } \\
\text { Baseline more } \\
\text { female in control } \\
\text { group: } 71.4 \% \\
\text { vs. } 58.5 \% \text {, older } \\
61.0 \text { vs. } 54.4 \text {, } \\
\text { shorter } 164.6 \mathrm{~cm}\end{array}$ & $\begin{array}{l}\text { Provided pedometer } \\
\text { Behavioral change } \\
\text { techniques at sessions } \\
\text { included intention } \\
\text { formation/goal setting, } \\
\text { self-monitoring of } \\
\text { behavior, action } \\
\text { planning, barrier } \\
\text { identification/coping } \\
\text { planning, review of } \\
\text { behavioral goals, } \\
\text { prompting practice, } \\
\text { planning contingent }\end{array}$ & 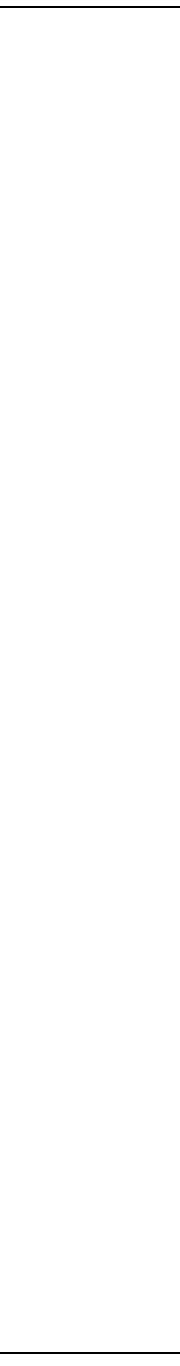 & $\begin{array}{l}\text { ENRICHd } \\
\text { Social Support } \\
\text { Scale } \\
\text { Illness } \\
\text { Perception }\end{array}$ & $\begin{array}{l}\text { weight at } 6 \\
\text { months } \\
(\mathrm{p}=.258) \text { and } \\
4.24 \mathrm{~cm} \\
\text { waist } \\
\text { circumferenc } \\
\text { e. }(\mathrm{p}=.047)\end{array}$ & $\begin{array}{l}\text { following } \\
\text { randomization }\end{array}$ & $\begin{array}{l}\text { Limitations } \\
: \\
\text { Small } \\
\text { sample size } \\
\text { Large drop } \\
\text { out rate }\end{array}$ \\
\hline
\end{tabular}


Appendix A Evidence Tables

\begin{tabular}{|c|c|c|c|c|c|c|c|c|c|}
\hline Reference & Design/Demographics & $\begin{array}{l}\text { Group Description } \\
\text { (N) and Baseline Data }\end{array}$ & Length & 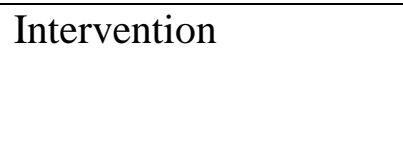 & $\begin{array}{l}\text { Drop-out } \\
\text { Total }\end{array}$ & Tools & Findings & Follow-up & Comments \\
\hline & $\begin{array}{l}\text { cerebrovascular disease } \\
\text { and arthritis } \\
\text { Exclusion: } \\
\text { Current treatment for } \\
\text { cancer, dementia, or } \\
\text { significant psychiatric } \\
\text { illness, inability to give } \\
\text { informed consent, } \\
\text { inability to comply with } \\
\text { trial protocol and } \\
\text { insufficient language } \\
\text { skills to complete } \\
\text { consent procedures }\end{array}$ & $\begin{array}{l}\text { vs. } 166.0 \mathrm{~cm} \text {, } \\
\text { lighter } 93.8 \mathrm{~kg} \\
\text { vs. } 104.8 \mathrm{~kg} \text {, and } \\
\text { smaller waist } \\
\text { circumference } \\
111.1 \mathrm{~cm} \text { vs. } \\
115.9 \mathrm{~cm}\end{array}$ & 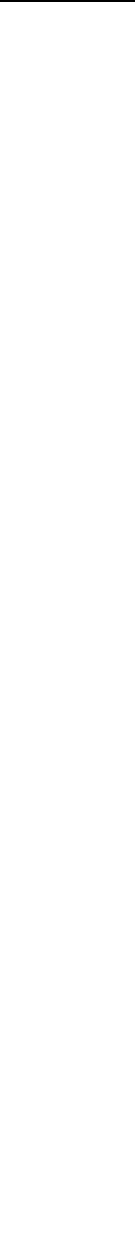 & $\begin{array}{l}\text { rewards and relapse } \\
\text { prevention } \\
\text { Received British Heart } \\
\text { Foundation booklets, } \\
\text { "So you want to lose } \\
\text { weight for good" and } \\
\text { "Get Active" } \\
\text { including info on } \\
\text { portion sizes, daily } \\
\text { eating plan, types of } \\
\text { physical activity, etc. } \\
\text { Control group } \\
\text { received standard care } \\
\text { (which was not } \\
\text { described) and the two } \\
\text { British Heart } \\
\text { Foundation booklets } \\
\text { that the face to face }\end{array}$ & & & & & \\
\hline
\end{tabular}


Appendix A Evidence Tables

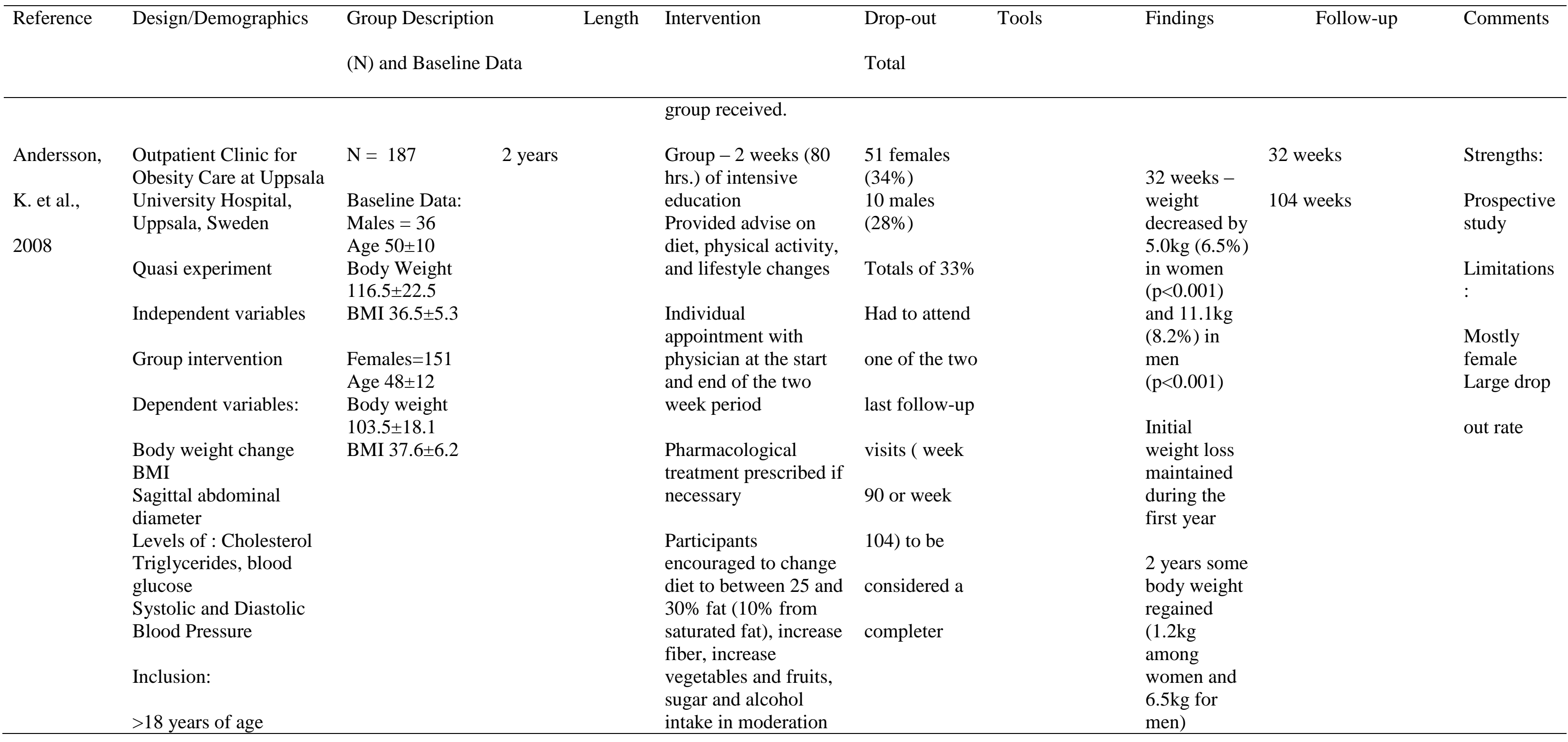


Appendix A Evidence Tables

\begin{tabular}{|c|c|c|c|c|c|c|c|c|c|}
\hline Reference & Design/Demographics & $\begin{array}{l}\text { Group Description } \\
\text { (N) and Baseline Data }\end{array}$ & Length & Intervention & $\begin{array}{l}\text { Drop-out } \\
\text { Total }\end{array}$ & Tools & Findings & Follow-up & Comments \\
\hline & $\begin{array}{l}\text { BMI > } 30 \mathrm{~kg} / \mathrm{m}^{2} \text { or } \\
\text { BMI }>28 \mathrm{~kg} / \mathrm{m}^{2} \text { with } \\
\text { concomitant metabolic } \\
\text { disorders. } \\
\text { Exclusion: } \\
\text { Inability to follow spoke } \\
\text { or written instructions } \\
\text { Refusing group } \\
\text { treatment } \\
\text { Not able to participate in } \\
\text { water gymnastics } \\
\text { Sever heart failure, } \\
\text { COPD or other } \\
\text { conditions precluding } \\
\text { participation in exercise }\end{array}$ & & & $\begin{array}{l}\text { Water gymnastics } \\
\text { each day during the } \\
\text { two weeks } \\
14 \text { more visits during } \\
\text { the two years } \\
\text { were held and usually } \\
60 \text { minutes in duration } \\
\text { ( } 2 \text { visits involved } \\
\text { cooking) } \\
\text { Week } 32 \text {, the structure } \\
\text { of the initial } 2 \text { weeks } \\
\text { was repeated for } 2 \\
\text { days at the clinic. }\end{array}$ & 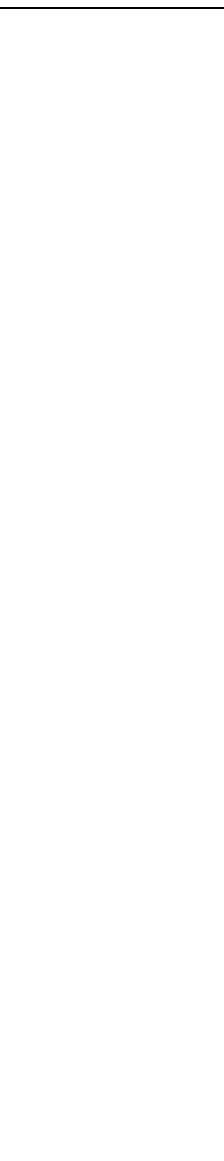 & 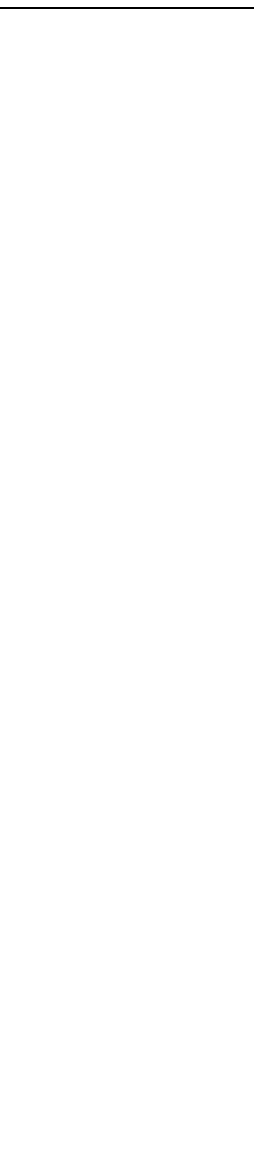 & $\begin{array}{l}2 \text { years } \\
\text { weight still } \\
\text { significantly } \\
\text { decreased by } \\
\text { almost } 4 \% \\
\text { for both } \\
\text { sexes } \\
\text { At } 2 \text { years } \\
\text { weight } \\
\text { reduction of } \\
-3.8 \mathrm{~kg} \text { in } \\
\text { women and } \\
-4.4 \mathrm{~kg} \text { in } \\
\text { men ( } 3.5 \text { and } \\
3.7 \%)\end{array}$ & 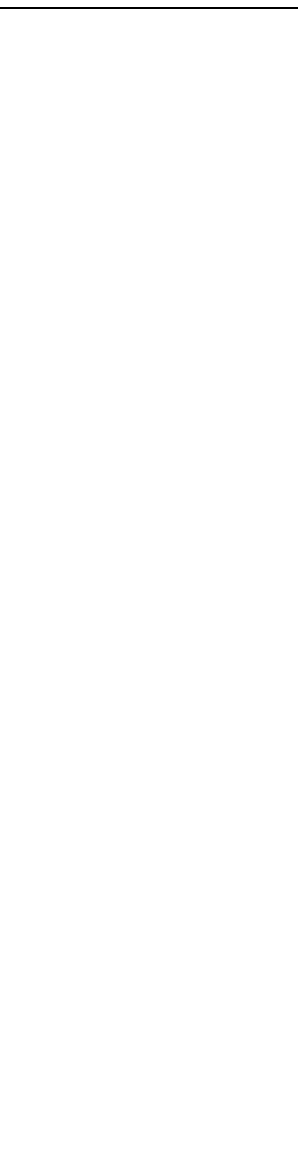 & 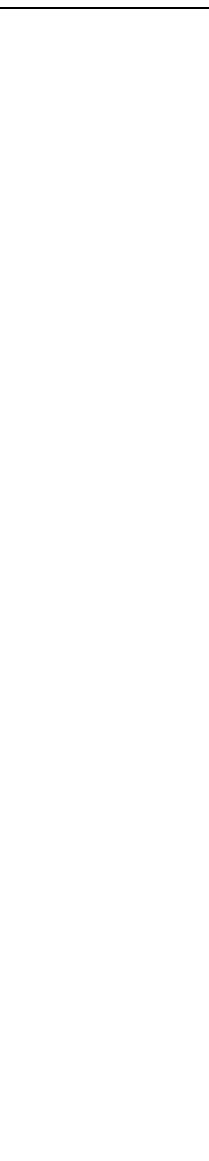 \\
\hline Minniti, A, & $\begin{array}{l}\text { University of Verona } \\
\text { Verona, Italy }\end{array}$ & $\begin{array}{l}\mathrm{N}=129 \\
\text { Group }=\end{array}$ & & $\begin{array}{l}\text { Format: Group } \\
10 \text { weekly meetings }\end{array}$ & $\begin{array}{l}48(37.2 \%) \\
39 \text { from the }\end{array}$ & $\begin{array}{l}\text { ORWELL } 97 \\
\text { Symptom }\end{array}$ & $\begin{array}{l}\text { No } \\
\text { significant } \\
\text { differences }\end{array}$ & 6 months & $\begin{array}{l}\text { Strengths: } \\
\text { Comparabl }\end{array}$ \\
\hline
\end{tabular}


Appendix A Evidence Tables

\begin{tabular}{|c|c|c|c|c|c|c|c|c|}
\hline Reference & Design/Demographics & $\begin{array}{l}\text { Group Description } \\
\text { (N) and Baseline Data }\end{array}$ & Length & Intervention & $\begin{array}{l}\text { Drop-out } \\
\text { Total }\end{array}$ & Tools & Findings & Comments \\
\hline et al., 2007 & $\begin{array}{l}\text { Quasi experiment } \\
\text { Partial randomization } \\
\text { If refused group } \\
\text { randomization could be } \\
\text { individual group, but } \\
\text { results not included in } \\
\text { research } \\
\text { Independent variables: } \\
\text { Group Therapy } \\
\text { Individual Therapy } \\
\text { Dependent variables: }\end{array}$ & $\begin{array}{l}57 \\
\text { Individual }=72\end{array}$ & & $\begin{array}{l}\text { One control medical } \\
\text { visit with physician at } \\
3^{\text {rd }} \text { month } \\
\text { Two booster sessions } \\
\text { at } 4^{\text {th }} \text { and } 6^{\text {th }} \text { month } \\
\text { focused on } \\
\text { maintenance of weight } \\
\text { loss and preventing } \\
\text { relapse } \\
\text { Meetings } 90 \text { minutes } \\
\text { conducted by } \\
\text { psychologist and } \\
\text { dietitian } \\
\text { Discussion re: } \\
\text { successes and group } \\
\text { problem solving of } \\
\text { difficulties, emotional } \\
\text { eating, exercise related } \\
\text { subjects, stimulus } \\
\text { control, physical } \\
\text { activity, motivation, } \\
\text { and assertivity } \\
\text { Individual }\end{array}$ & $\begin{array}{l}\text { initial therapy } \\
\text { group }(54.2 \%) \\
9 \text { from the } \\
\text { group therapy } \\
(15.8 \%)\end{array}$ & $\begin{array}{l}\text { Check List } 90 \\
\text { Binge Eating } \\
\text { Scale } \\
\text { Body } \\
\text { Uneasiness Test }\end{array}$ & $\begin{array}{l}\text { at baseline } \\
\text { Completers } \\
\text { were older } \\
(\mathrm{p}<0.03) \\
\text { Completers } \\
\text { had worse } \\
\text { Body } \\
\text { Uneasiness } \\
\text { Test General } \\
\text { Severity } \\
\text { Index score } \\
\text { (p<0.04) } \\
\text { than non- } \\
\text { completers. }\end{array}$ & $\begin{array}{l}\text { e results to } \\
\text { other } \\
\text { studies } \\
\text { Limitations } \\
\text { : } \\
\text { Small } \\
\text { sample size } \\
\text { Only } \\
\text { Women } \\
\text { Study } \\
\text { design not } \\
\text { completely } \\
\text { randomized } \\
\text { Large drop } \\
\text { out rate }\end{array}$ \\
\hline
\end{tabular}


Appendix A Evidence Tables

\begin{tabular}{|c|c|c|c|c|c|c|c|}
\hline Reference & Design/Demographics & $\begin{array}{l}\text { Group Description } \\
\text { (N) and Baseline Data }\end{array}$ & Intervention & $\begin{array}{l}\text { Drop-out Tools } \\
\text { Total }\end{array}$ & Findings & Follow-up & Comments \\
\hline & 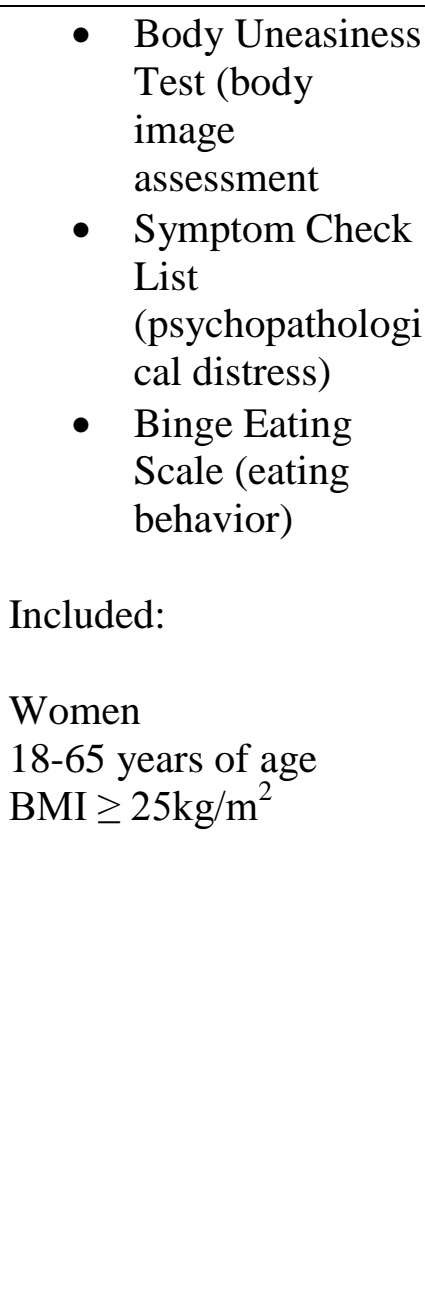 & 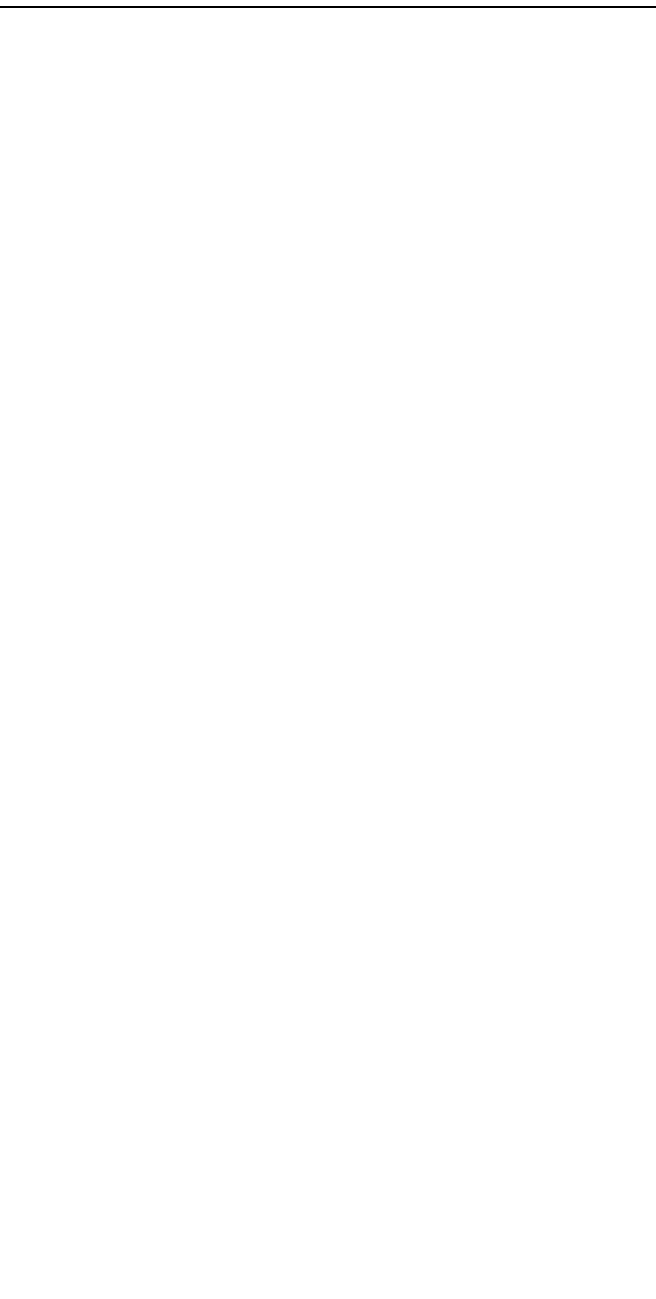 & $\begin{array}{l}\text { Meeting with dietitian } \\
\text { every } 14 \text { days ( } 20 \\
\text { minutes each) } \\
\text { One control medical } \\
\text { visit with a physician } \\
\text { at } 3^{\text {rd }} \text { month } \\
\text { Totaling } 12 \text { meetings } \\
\text { during first } 6 \text { months } \\
\text { of therapy } \\
\text { Discussion re: } \\
\text { obesity, nutrition } \\
\text { counseling, regular } \\
\text { moderate physical } \\
\text { activity } 20-30 \text { minutes } \\
3 \text { days per week, } \\
\text { progress or } \\
\text { difficulties, eating and } \\
\text { exercise-related } \\
\text { strategies }\end{array}$ & 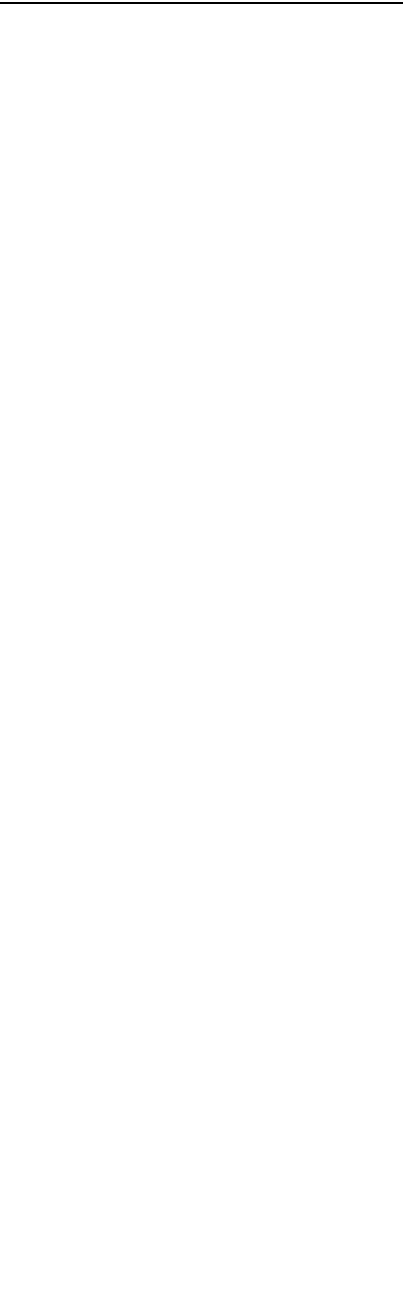 & $\begin{array}{l}\text { obtained } \\
\text { improvemen } \\
\text { ts in all } \\
\text { variables } \\
\text { except the } \\
\text { Body } \\
\text { Uneasiness } \\
\text { Test and } \\
\text { Symptom } \\
\text { Check List } \\
\text { No } \\
\text { significant } \\
\text { difference } \\
\text { between } \\
\text { therapies } \\
\text { regarding } \\
\text { weight } \\
\text { reduction } \\
49 \text { of the } 81 \\
\text { completers } \\
\text { (60.5\%) } \\
\text { reduced }\end{array}$ & 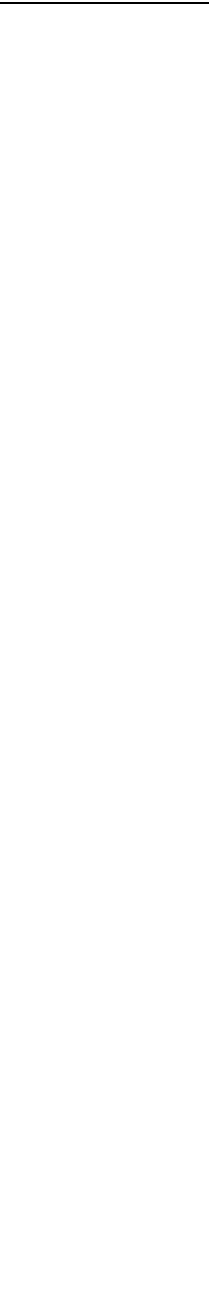 & 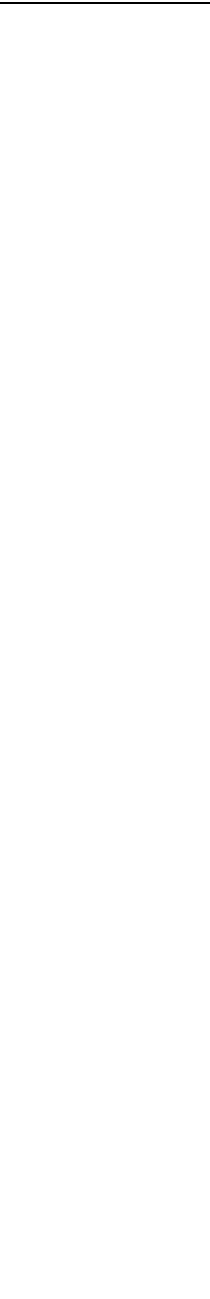 \\
\hline
\end{tabular}


Appendix A Evidence Tables

\begin{tabular}{|c|c|c|c|c|c|c|c|c|}
\hline Reference & Design/Demographics & $\begin{array}{l}\text { Group Description Length } \\
\text { (N) and Baseline Data }\end{array}$ & Intervention & $\begin{array}{l}\text { Drop-out } \\
\text { Total }\end{array}$ & Tools & Findings & Follow-up & Comments \\
\hline & & & & & & $\begin{array}{l}\text { body weight } \\
\text { by } 5-10 \% \text { or } \\
\text { more }\end{array}$ & & \\
\hline $\begin{array}{l}\text { Teixeira, A., } \\
\text { et al., } 2009\end{array}$ & $\begin{array}{l}\text { Lisbon, Portugal } \\
\text { RCT } \\
\text { Independent variable: } \\
\text { Group intervention } \\
\text { Dependent variables: } \\
\text { Exercise } \\
\text { Eating behavior } \\
\text { Body image } \\
\text { Body Weight } \\
\text { Included: } \\
\text { Female } \\
25 \text { to } 50 \text { years old } \\
\text { Premenopausal } \\
\text { BMI between } 25 \text { and } \\
\text { atolm² }\end{array}$ & $\begin{array}{l}\mathrm{N}=225 \\
\text { Did not identify } \\
\text { initial } \\
\text { breakdown of } \\
\text { intervention vs. } \\
\text { control } \\
3 \text { annual cohorts } \\
\text { with each cohort } \\
\text { split into two } \\
\text { randomly } \\
\text { assigned groups } \\
\text { (intervention vs. } \\
\text { control) } \\
\text { Mean age: } 37.6 \\
\pm 7.0 \text { years of } \\
\text { age } \\
\text { Mean BMI: } 31.3\end{array}$ & $\begin{array}{l}\text { Format: } \\
\text { Intervention attended } \\
30 \text { group sessions } ~ 1 \\
\text { year. } \\
\text { Increased physical } \\
\text { activity } \\
\text { Energy expenditure } \\
\text { Adopting diet } \\
\text { consistent with } \\
\text { moderate energy } \\
\text { deficit } \\
\text { Personal resistances } \\
\text { Overcoming lapses } \\
\text { Establish goals } \\
\text { Self-monitoring } \\
\text { Program based on } \\
\text { Self-Determination } \\
\text { Theory }\end{array}$ & $\begin{array}{l}12 \text { months } \\
7 \% \text { for } \\
\text { intervention } \\
\text { and } 21 \% \text { for } \\
\text { control } \\
24 \text { months } \\
10 \% \text { for } \\
\text { intervention } \\
\text { and } 28 \% \text { for } \\
\text { control }\end{array}$ & $\begin{array}{l}\text { Three-Factor } \\
\text { Eating } \\
\text { Questionnaire } \\
\text { Dutch Eating } \\
\text { Behavior } \\
\text { Questionnaire } \\
\text { Weight } \\
\text { Management } \\
\text { Efficacy } \\
\text { Questionnaire } \\
\text { Intrinsic } \\
\text { Motivation } \\
\text { Inventory } \\
\text { Body Shape } \\
\text { Questionnaire } \\
\text { Body Image }\end{array}$ & $\begin{array}{l}\text { Baseline no } \\
\text { differences } \\
\text { between } \\
\text { intervention } \\
\text { and control } \\
\text { groups } \\
\text { except for } \\
\text { exercise } \\
\text { intrinsic } \\
\text { motivation } \\
\text { slightly } \\
\text { higher in } \\
\text { intervention } \\
\text { group } \\
\text { Average } \\
\text { weight loss } \\
\text { and the } \\
\text { percentage } \\
\text { of } \\
\text { participants }\end{array}$ & $\begin{array}{l}12 \text { months } \\
24 \text { months }\end{array}$ & $\begin{array}{l}\text { Limitations } \\
: \\
\text { Drop out } \\
\text { rate } \\
\text { Only } \\
\text { women }\end{array}$ \\
\hline
\end{tabular}


Appendix A Evidence Tables

\begin{tabular}{|c|c|c|c|c|c|c|c|c|c|}
\hline Reference & Design/Demographics & $\begin{array}{l}\text { Group Description } \\
\text { (N) and Baseline Data }\end{array}$ & Length & Intervention & $\begin{array}{l}\text { Drop-out } \\
\text { Total }\end{array}$ & Tools & Findings & Follow-up & Comments \\
\hline & $\begin{array}{l}\text { No major illnesses } \\
\text { No medications known } \\
\text { to interfere with body } \\
\text { weight regulation } \\
\text { Excluded: } \\
\text { Taking medications } \\
\text { susceptible to affect } \\
\text { weight } \\
\text { Serious chronic illness } \\
\text { Or injury } \\
\text { Pregnancy } \\
\text { Menopause }\end{array}$ & $\pm 4.1 \mathrm{~kg} / \mathrm{m}^{2}$ & & $\begin{array}{l}\text { Control: } \\
\text { Received general } \\
\text { health education } \\
\text { curriculum based on } \\
\text { educational courses on } \\
\text { various topics (e.g. } \\
\text { stress management, } \\
\text { self-care, effective } \\
\text { communication skills }\end{array}$ & 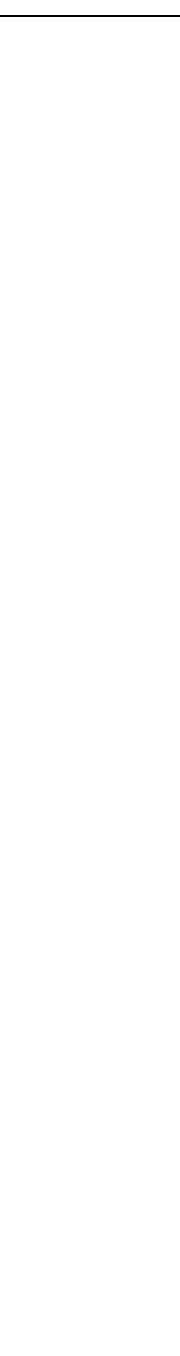 & $\begin{array}{l}\text { Physical Self- } \\
\text { Perception } \\
\text { Profile }\end{array}$ & $\begin{array}{l}\text { than the } \\
\text { accepted } \\
\text { success } \\
\text { criteria of } 5 \\
\text { and } 10 \% \text { of } \\
\text { initial weight } \\
\text { higher in } \\
\text { intervention } \\
\text { group at } 12 \\
\text { and } 24 \\
\text { months (p }< \\
0.001) \mathrm{n}= \\
106 \\
(12 \mathrm{mos} .) \\
\text { Mean } \\
\text { change }=- \\
7.3 \pm 5.9 \% \\
\mathrm{n}=103(24 \\
\text { mos.) Mean } \\
\text { change }=- \\
1.7 \pm 5.0 \% \\
\text { Control } \\
\text { group } \\
\text { completers } \\
\mathrm{n}=88(12 \\
\text { mos.) Mean } \\
\text { change }=-\end{array}$ & & \\
\hline
\end{tabular}


Appendix A Evidence Tables

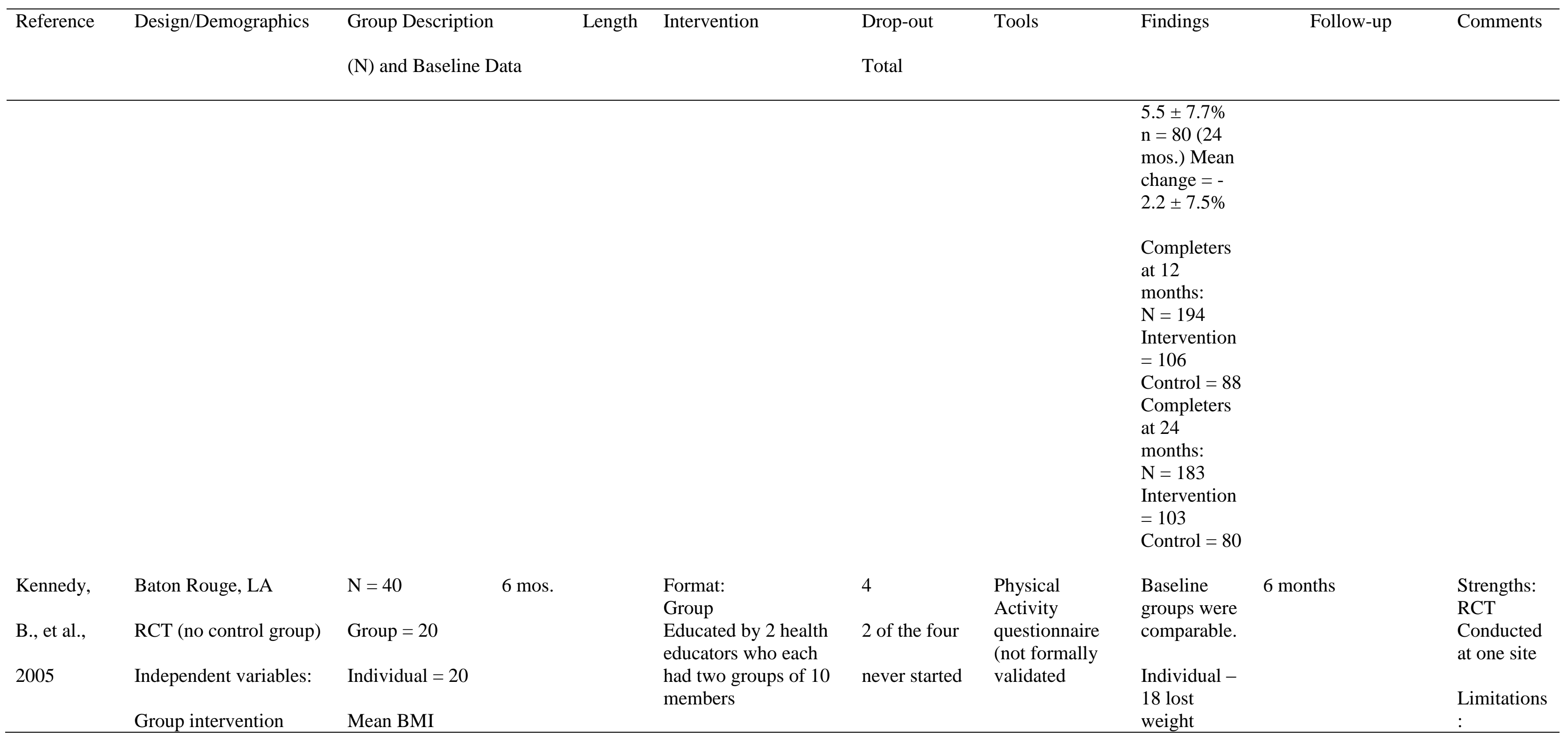


Appendix A Evidence Tables

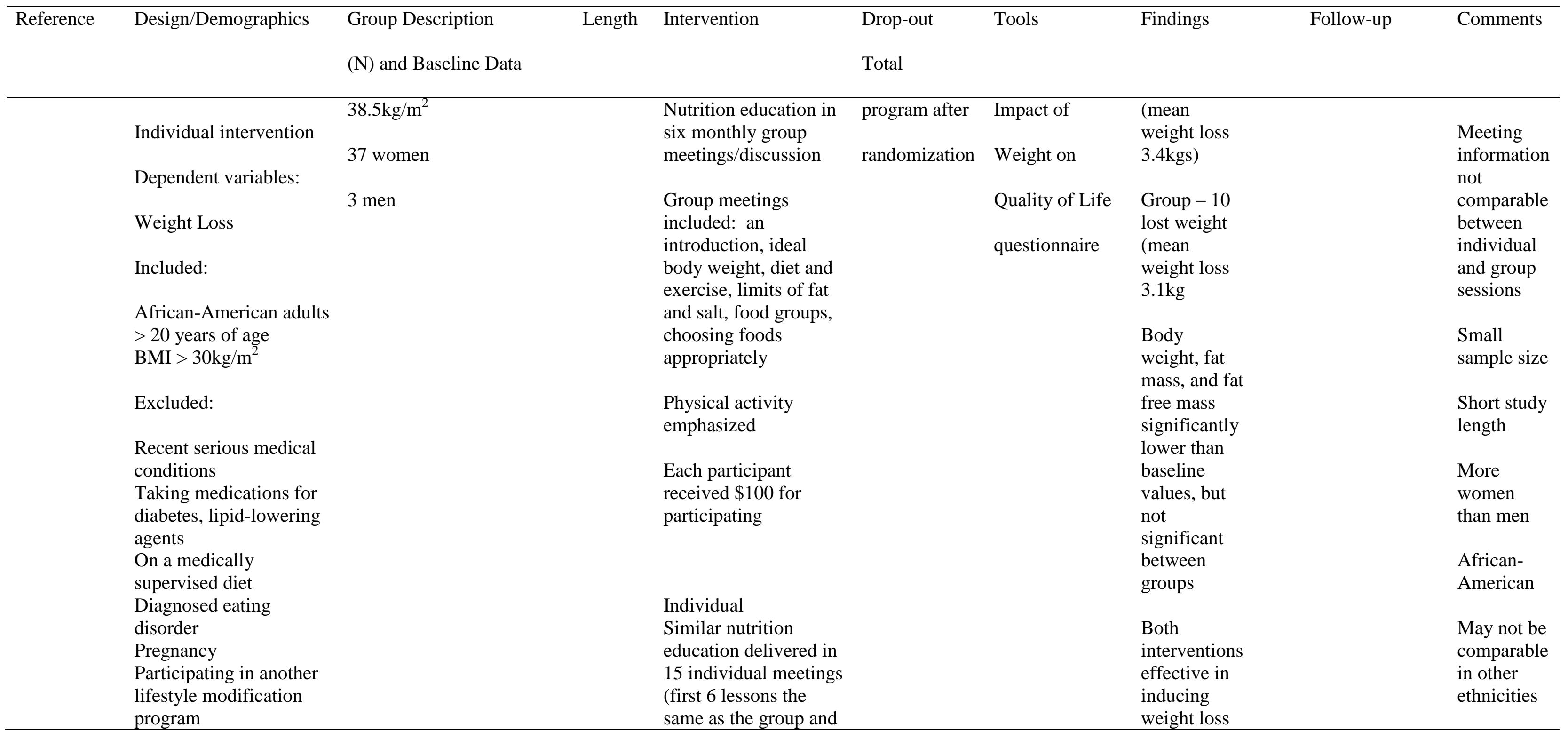


Appendix A Evidence Tables

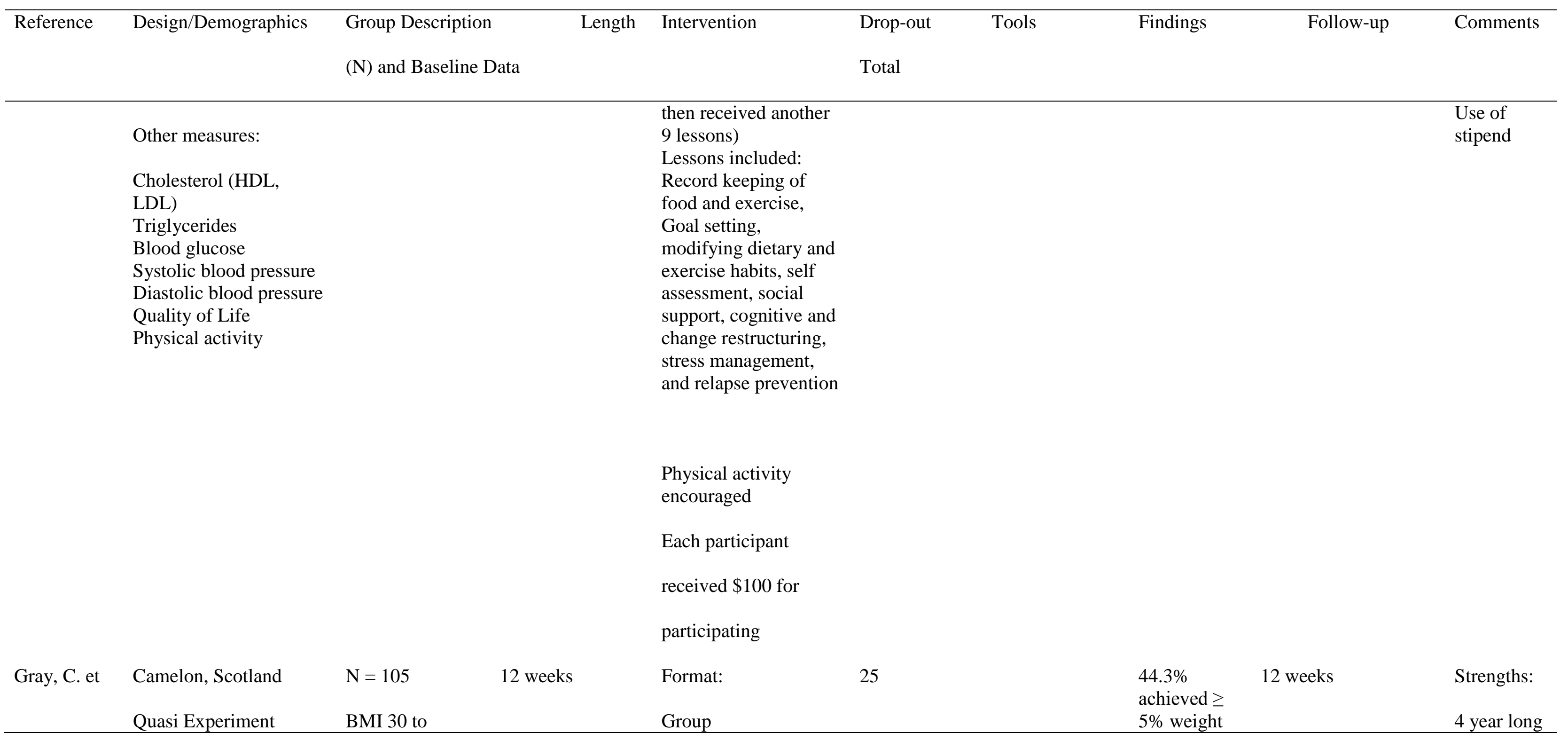


Appendix A Evidence Tables

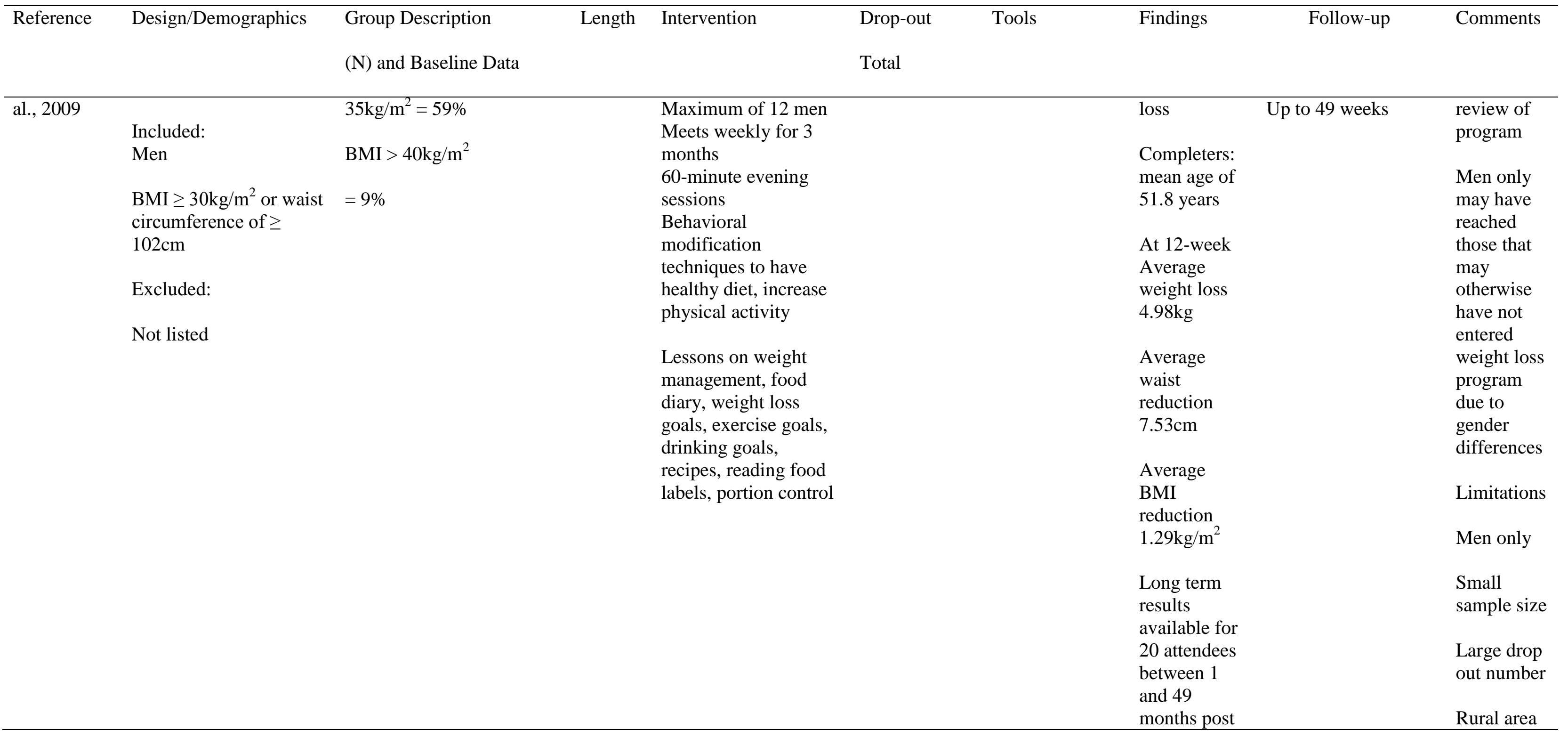


Appendix A Evidence Tables

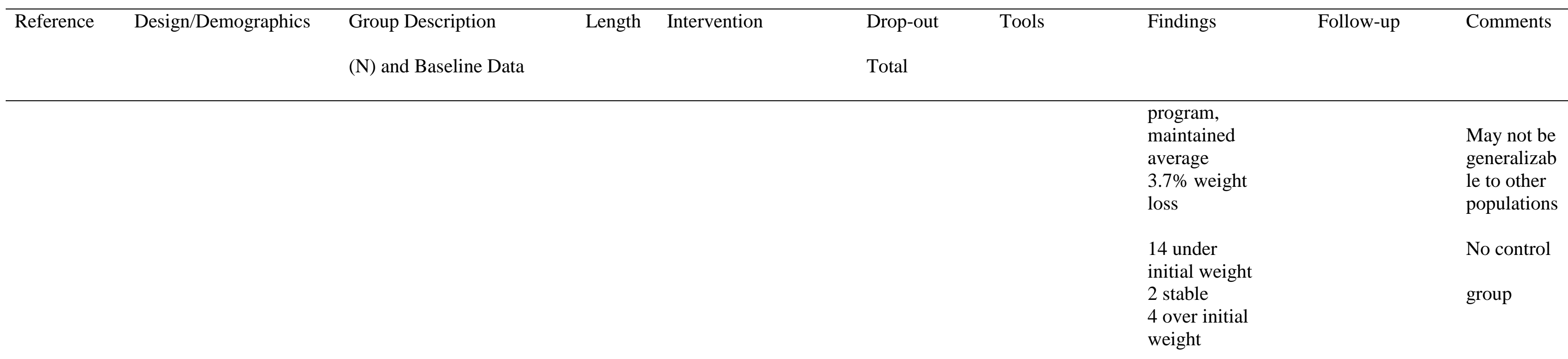


Appendix B MOVE! Lesson Plans found at: http://www.move.va.gov/GrpSessions.asp

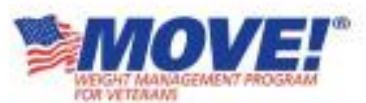

\section{Introduction to Group Sessions for Leaders}

\section{General guidelines for leading group sessions}

The following is a list of tasks and responsibilities in planning for and running a group.

\section{Planning}

- Take the MOVE! online training (currently under revision).

- Review the MOVE! Group Sessions.

- Clarify your facility's process for ordering pedometers.

- Room size - should be appropriate to size of group.

- Room location - provide signage and directions.

- Room set-up - arrange seating in a circle if possible.

- Have a scheduling process.

- Have a check-in process.

- Chairs - appropriate for overweight/obese veterans.

- Materials:

- Arrange a pocket-folio for each patient.

- Order pedometers and photocopy Food and Physical Activity Diaries for the orientation session.

- Photocopy handouts and worksheets for each session.

- Arrange Pens/pencils and extra paper.

- Organize flip chart and/or dry erase board with markers.

- Acquire any props needed.

\section{General format}

- Plan for each session to last 60-120 minutes.

- The Ideal group size is $12-15$ people.

- Arrange for individual weigh-in in private (be sensitive to patient's concerns about this).

- Review Food and Activity Diaries at each session. Note: Diaries and/or worksheets that have been assigned as homework should be reviewed/discussed early in each session. This will communicate to the veteran the importance of self-monitoring.

- Make each session a healthy meeting by incorporating physical activity (examples are provided in each session plan).

- Each session should include general group discussion, problem-solving, and support.

- Make time for individual consultation if needed. 
Appendix B MOVE! Lesson Plans found at: http://www.move.va.gov/GrpSessions.asp

\section{Group Leader Tasks}

- Establish ground rules.

- Facilitate the group process (See: A Guide to Good facilitation, below).

- Encourage veterans to share solutions.

- Identify and teach behaviors and skills.

- Model and demonstrate the behavior.

- Rehearse the behavior/skill with the participants.

- Help participants plan for self-monitoring in real-life.

- Encourage healthy rewards for achieving goals.

- Assist group in determining next steps.

- Encourage questions.

- Solicit thoughts, feelings, and opinions.

- Write major points on a whiteboard / blackboard.

- Frequently summarize key points.

\section{MOVE! Group Sessions}

The following MOVE! Group Sessions have been developed to help you in your role as leader and facilitator. Suggested MOVE! handouts, worksheets and additional reading information are listed for each group session. The complete list of MOVE! handouts is located at www.move.va.gov/Handouts.asp.

GS00. Introduction to Group Sessions
GS01. Orientation
GS02. Stepping Out With My Pedometer
GS03. What's in Your Food?
GS04. Fit For Life
GS05. Trim the Fat
GS06. Play it Safe
GS07. Tip the Balance
GS08. If at First You Don't Succeed...PLAN
GS09. You are the Boss
GS10. Oops I Did It Again
GS11. Keep it Going
GS12. MOVEing Forward

Only an estimated $20 \%$ of skills required for disease self-management are disease specific. Many of the skills needed are general problem-solving skills, skills for resisting temptation and preventing relapse, self-monitoring strategies, and skills for enhancing general healthy lifestyle patterns and behavior change. Group meetings and group medical visits offer a supportive environment in which new skills can be introduced, practiced and reviewed. In addition, a group format can be used to review patient progress and to set goals. 
Appendix B MOVE! Lesson Plans found at: http://www.move.va.gov/GrpSessions.asp

As group leader your role is primarily to facilitate discussion, not to lecture. For example: Instead of listing the known barriers to physical activity try asking the group to discuss why they, in the past, have had difficulty maintaining physical activity. Solutions and ideas that come from the group are much more powerful than those that are taught. In addition to this primary role as facilitator, some group modules require the knowledge and expertise of the leader to help the group learn and develop new skills.

The MOVE! Group Sessions are designed to facilitate guided discussions but need not be rigidly followed. Groups are like individuals; they often will present with some unique concerns. Be prepared to "go with the flow" and address the unique concerns of the group rather than insisting on a fixed format. Rarely do all participants attend every session; thus, consider scheduling approximately 18-20 participants to ensure a group size of 12-15 for each session.

Have the group establish some ground rules at the onset discussing how everyone should get to participate, how confidentiality should be handled, and how everyone needs to be treated with respect. Remember that MOVE! Group Sessions are not meant to be a therapy group. Getting into personal issues that are not related to weight-management should be avoided unless it seems appropriate at the moment. If a participant appears to need special attention for a non-weight related personal issue, suggest that they speak with you outside of the group format.

A Food and Physical Activity Diary has been developed as a self-management tool for use with the group sessions. The diary is a 12 week log in which the veteran can record each week's food intake on one page and each week's physical activity on another page. There are obvious space limitations to this diary format. For those who would like to provide a detailed daily diary, consider

http://www.shapeup.org/support/maintain/logform1.php or use one of your own. 
Appendix B MOVE! Lesson Plans found at: http://www.move.va.gov/GrpSessions.asp

\section{A Guide to Good Facilitation}

\section{Adapted with permission from: Facilitating Meetings: A guide for Community Planning Groups, Academy for Educational Development Center for Community-Based health Strategies}

Good facilitators possess a variety of qualities and skills. Some of the qualities spring from such innate personality traits as being able to recognize one's own biases while remaining neutral, enjoying interaction with diverse groups, and inspiring trust. Although some people possess a natural talent for facilitation, most develop the skills through experience and with guidance from experienced facilitators. Skills include:

- Making everyone feel comfortable and valued

- Encouraging participation and idea exchange

- Preventing and managing conflict

- Listening and observing

\section{Make everyone feel comfortable and valued:}

Most people will not participate fully in a meeting unless they feel comfortable with other members and believe their opinions will be heard. You, with members' support, must create an environment in which members value the potential contributions of those with different perspectives.

- Use body language: You send messages with your movements as well as your voice, so be aware of what your body language is saying. By using body language to show warmth and acceptance, you encourage others to relax and respond in kind.

- Welcome participants: Take a few moments to welcome participants. Full participation is vital, for each person brings a different perspective that can contribute to the group's success

- Introduce participants and yourself: Introductions help participants feel welcome and remind them who their team members are. Introductions also give you an opportunity to clarify your role as facilitator. Ask everyone to say a few words, even if only, "My name is ....". Once people have heard their voices in a large group, they feel more inclined to speak up again later. If you have limited time or numerous attendees, find ways to ensure that introductions are brief.

- Consider an icebreaker: You may ask people to share their favorite ice cream flavor, their first pet's name, or anything else light and personal but nonthreatening as they introduce themselves.

- Thank participants: By thanking participants, you validate and legitimize their comments and contributions. 
Appendix B MOVE! Lesson Plans found at: http://www.move.va.gov/GrpSessions.asp

\section{Encourage participation and an active exchange of ideas:}

Some members are outspoken and energetic. Others are quiet and reserved. As facilitator, you should balance these extremes so that everyone has an equal opportunity to participate.

- Encourage silent members: If members are silent or disengaged, catch their eye or ask them (or even an individual) to share their experience.

- Use open-ended questions: Ask questions people can't answer with a yes or no. Questions beginning with when, what, or how usually encourage members to provide detailed answers, which can spark additional ideas from other members.

- Consult the group: When a participant addresses a question to you, prompt participation from others by consulting the group. This is also an effective technique for shifting the focus of discussion from one member to the whole group.

- Use visual aids: Most people process information better if they see it, so write it on newsprint, an overhead, handouts, etc.

- Be careful when using "why?": "Why" can imply judgment and cause some participants to become defensive. Instead of saying "why," say,

- "What are some of the reasons ...?"

\section{Prevent and manage conflict:}

One of the best ways to deal with conflict is to prevent it, but some conflict is inevitable and even helpful to the process. Use it to develop options the group would not have considered otherwise.

- Use team-building activities: Help members get to know each other better.

- Set ground rules: Members' agreement on these makes your job easier when conflict arises. Basic ground rules may be that the group will hear all views and no one will make personal attacks.

- Search for agreement: Drawing attention to points that participants agree upon helps create an atmosphere of positive collaboration and forward momentum.

- Agree to disagree: Although you would like to resolve all conflicts, you may not be able to. Urge the group to treat each other with respect even when they disagree.

\section{Listen and observe:}

Throughout a meeting keep your eyes and ears open and stay attuned to the group.

Pay attention not only to the group as a whole but also to individuals.

- Listen actively: Apply the basic skills of one-on-one conversation. Truly listen before speaking.

- Scan the room: While maintaining eye contact with the speaker, note how other members are responding to that person. 
Appendix B MOVE! Lesson Plans found at: http://www.move.va.gov/GrpSessions.asp

\section{Session plan for group leader}

\section{Welcome to MOVE! - Orientation}

About this session:

Welcome to MOVEI is an orientation to facilitate rolling admission into MOVE! group sessions. This session can be provided as often as necessary to allow patients to join the program at any point in time. All group participants should complete an orientation session.

By the end of this session participants will have had the opportunity to:

- Learn about the MOVE! group sessions

- Meet the MOVE! group sessions team

- Discuss self-management

- Set goals for the program

To do before this session:

- Review the Introduction to Group Sessions. This provides an overview of facilitating groups and offers guidance on group size, format etc.

- Organize materials for the session:

- Paper, pens, flip chart/white board

- Pedometers for each patient

- Self-management diaries/logs/charts (available on the www.move.va.gov website)

- Why I have joined the MOVE! Program worksheet

- (GD01) Food and Activity Diary

- MOVE! handouts:

- (M05) 10 Health Gains From a 10\% Weight Loss

- (S10) Change Your Thinking About Food, Exercise and Yourself

- (S02) Set Your Weight Loss Goals

- (P19) When to Stop Exercising

- (S03) A Guide to Using Your Pedometer

- (P28)Wheelchair Odometers

Introduction:

- Conduct individual weigh-in in private (can also be done at the end of the session). 
Appendix B MOVE! Lesson Plans found at: http://www.move.va.gov/GrpSessions.asp

- Welcome everyone to the session.

- Use an ice breaker to have participants introduce themselves.

- The goal of the MOVE! group sessions:

\section{Goal of MOVEI Group Sessions:}

To help patients self-manage their weight loss efforts through learning, discussion, reflection and the support of others. The focus of the sessions is weight management through nutrition, physical activity, and behavior change.

- Describe the purpose of the orientation class and give an overview of the other sessions in the program. Clarify your facility's expectations for group session completion (for example, 10 of 12 sessions or 6 of 8 sessions etc.).

- If possible, introduce the MOVE! team members who will lead other group sessions.

\section{Exercise 1: Ground rules:}

- Describe the purpose and importance of ground rules for group sessions using the information in the Introduction to Group Sessions.

- Ask participants to decide on ground rules for the session.

- Take feedback and display the ground rules where everyone can see them.

\section{Exercise 2: Weight management}

- Use MOVE! handouts (M05) 10 Health Gains From a 10\% Weight Loss and (S10) Change Your Thinking About Food, Exercise and Yourself to facilitate a brief discussion about weight loss and behavior change.

\section{Exercise 3: Self-management}

- Write the following definition on a flipchart or board.

\section{Self-Management Defined:}

Self-management means that patients are partners with their healthcare team in the management and treatment of excess weight.

It means that patients:

- Understand, actively participate and take responsibility for your weight management

- Set your own weight loss goals

- Learn new skills to achieve these goals such as:

- Self Monitoring

- Planning and preparing

- Problem solving 
Appendix B MOVE! Lesson Plans found at: http://www.move.va.gov/GrpSessions.asp

- Ask participants to discuss the definition and answer any questions that arise.

- Explain that skills such as planning and preparing and problem solving with be addressed during later sessions and that the remainder of this session will focus on goal setting and self-monitoring.

\section{Exercise 4: Set your goals}

- Distribute the Why I have joined the MOVE! Program worksheet and ask participants to complete it (be mindful of those who may have literacy problems, give an option to verbally express an answer).

- Ask participants to share their answers and to keep this worksheet as a reminder as to why they are entering the program.

- Use the MOVE! Handout (S02) Set your Weight Loss Goals to discuss the importance of setting short term goals and revising goals at each session. Consider a private weigh-in at this time to help participants set a weight loss goal for the group sessions. Remind participants to set realistic, achievable goals.

\section{Physical activity break}

Incorporating physical activity into the session reinforces the healthy lifestyle message and provides opportunity to demonstrate some simple but effective exercises.

- Ask participants to join you in doing the following flexibility exercise:

OVERHEAD STRETCH: Extend your arms overhead with elbows straight. Interlock fingers if possible. Keep your back and neck straight. Take a deep breath in and then let the breath out slowly. You should feel a stretch in your shoulders and upper back.

\section{Exercise 5: Self-monitoring- Keeping a diary}

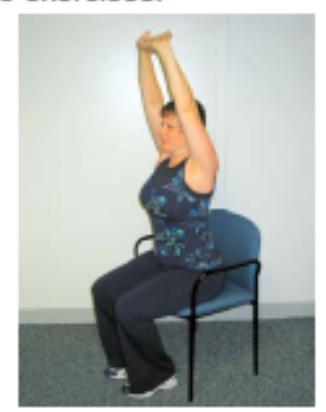

- Discuss how keeping a diary is the single most important thing you can do to change your eating and physical activity behaviors. Ask participants how they feel about keeping a diary and allow the group time to come up with solutions to any difficulties discussed.

- Distribute The MOVE! Program Food and Activity Diary.

- Ask participants to use the diary for the duration of the program. For now, instruct participants to simply write down all food and drinks consumed and any activity taken each day. Explain that the diary will be the focus of discussion at every session. 
Appendix B MOVE! Lesson Plans found at: http://www.move.va.gov/GrpSessions.asp

\section{Exercise 6: Self-monitoring - Recording steps}

- If available, distribute pedometers/odometers. Use MOVE! handout (S03) A Guide to Using Your Pedometer and/or MOVE! handout (P28) Wheelchair Odometers to demonstrate correct use of the device.

- Allow participants to move around to get used to wearing the device. Suggest to participants that they wear their pedometer (for a few days), without making any changes to their normal routine, to establish a baseline number of daily steps.

- Ask participants to start logging steps in their Food and Activity Diary.

- Ask participants to wear their pedometers daily.

- Use MOVE! handout (P19) When to Stop Exercising to briefly discuss safety and explain that safety will come up again in a later session.

- Close the session:

- If participants are entering the group sessions in the middle of a cycle (for example week 4 of a 10 week course) explain that the order in which the sessions are taken is not important.

- Provide whatever information is necessary for attending the next session (date/time/location etc).

- Remind participants to:

- Begin keeping a food and activity diary and bring it to every session,

- Wear their pedometer;

- Begin using the pedometer/odometer to establish a baseline; and

- Bring both the diary and the pedometer to the rest of the sessions. 
Appendix B MOVE! Lesson Plans found at: http://www.move.va.gov/GrpSessions.asp

\title{
Amis: \\ Stepping Out With My Pedometer Session plan for group leader
}

\begin{abstract}
About this session: will have had the opportunity to:

- Discuss walking or wheeling as a physical activity

- Learn how to use a pedometer/odometer

- Develop a walking/wheeling plan

- Practice appropriate stretches for warm-up and cool-down

- Review Food and Activity Diaries

- Set goals for the week
\end{abstract}

This session is designed to promote an exchange of ideas about the benefits of walking or rolling and using a pedometer/odometer. It demonstrates a variety of stretches for the prevention of muscle soreness and injury. By the end of this session participants

You will need to modify the content of this session to meet the needs of wheelchair bound participants.

To do before this session:

- Review the Introduction to Group Sessions. This provides an overview of facilitating groups and offers guidance on group size, format etc.

- Clarify your facility's process for ordering pedometers for MOVEl patients. This is normally done through the Prosthetics Service.

- Organize materials for the session:

- Order a pedometer for each participant

- Paper, pens, flip chart/white board

- MOVEI handouts:

- (P15) Walk

- (S03)A Guide to Using Your Pedometer

- (P28) Wheelchair Odometers

- (P30) Sample Stretches

- (P04)Why Warm-Up, Cool-Down and Stretch?

\section{Introduction (may take 15-20 minutes):}

- Conduct individual weigh-in in private (can also be done at the end of the session).

- Welcome everyone to the class.

- Revisit ground rules for the session.

- Review food and activity diaries, discuss progress/goals, and facilitate problemsolving for barriers. 
Appendix B MOVE! Lesson Plans found at: http://www.move.va.gov/GrpSessions.asp

- Discuss any homework from the last class.

- Discuss the purpose of today's session.

- Encourage questions and comments.

\section{Exercise 1: Walking (modify as necessary for wheelchair users):}

- Ask participants to look at their Food and Activity Diary paying particular attention to the type and amount of physical activity they did over the last week.

- To facilitate a discussion about walking, write "Is walking a good physical activity?" on the board. Ask participants to comment. Provide participants with MOVE! handout (P15) Walk.

- Remind participants of the following:

- Experts estimate that for every one hour of physical activity you may gain two hours of life expectancy.

- The Benefits of Walking for as little as 30 minutes a day include the following:

- Reduces risk of heart disease by improving blood circulation throughout the body

- Keeps weight under control

- Improves blood cholesterol levels

- Prevents and manages high blood pressure

- Prevents bone loss

- Boosts energy levels

- Increases muscle strength, increasing the ability to do other physical activities

- Manages stress

- Releases tension

- Improves the ability to fall asleep quickly and sleep well

- Improves self-image

- Counters anxiety and depression and increases enthusiasm and optimism

- Using their Food and Activity Diary, ask participants to consider and write a walking goal for each day of the coming week. Suggest that at the end of each day, participants note on the diary whether or not they met their goal.

\section{Exercise 2: Using a Pedometer (modify as necessary for wheelchair users):}

- Distribute pedometers to those participants who have not already been provided with one. Use MOVE! handout (S03) A Guide to Using Your Pedometer to demonstrate correct use of the pedometer. Allow participants to get up and move around). Answer any questions.

- Based on exercise 5 of the orientation session, ask participants if they have established their baseline number of steps for each day.

- Once a baseline has been set, suggest to participants that their pedometer can be used to help set walking goals. Remember the following:

- A pedometer is a great motivator to help you meet your physical activity goal.

- For health benefits aim to eventually walk at least 30 minutes per day. 
Appendix B MOVE! Lesson Plans found at: http://www.move.va.gov/GrpSessions.asp

- Walking is an easy, inexpensive physical activity that you can do almost anywhere.

- Ask participants to start logging steps in their Food and Activity Diary.

- Walking as many steps a day as possible is a healthy thing to do.

- Although the goal of 10,000 steps per day has been widely promoted, there is little scientific basis for this specific goal, especially in patients that have health problems.

- Also, setting too high a goal can frustrate patients.

- A good approach is to assist the patient is establishing their normal baseline and then set a goal to increase physical activity. They should periodically (for example, monthly) think about increasing their goal.

- Consider pooling the number of steps completed by a group of patients and mapping how far the group has walked. For many patients, this will be a very rewarding, and everyone's steps will contribute.

\section{Exercise 3: Warm-up and cool-down (modify as necessary for wheelchair users):}

- Use MOVE! handout (P04) Why Warm-Up, Cool-Down and Stretch? to explain the importance of warming-up before and cooling-down after physical activity.

- Explain the benefits of stretching and demonstrate some simple stretches using MOVE! handout (P30) Sample Stretches

- Ask participants to stand and try the stretches. Remind participants to:

- Stretch only as far as is comfortable.

- Hold onto a chair or wall for balance.

- Hold stretches for at least a count of 10 .

- Practice these stretches at home.

- Remember that:

- Warming-up and cooling-down help prevent muscle soreness and injury.

- Stretching is a good way to warm-up and cool-down.

- Warm-up and cool-down could also include simply walking at a low intensity level for 5-10 minutes before increasing the pace to moderate intensity.

\section{Close the session:}

- Remind participants to:

- Maintain their food and activity diaries,

- Wear their pedometers, and

- Bring both the diaries and the pedometers to all of the sessions. 
Appendix B MOVE! Lesson Plans found at: http://www.move.va.gov/GrpSessions.asp

\section{ander \\ What's in Your Food? \\ Session plan for group leader}

\section{About this session:}

What's in Your Food?: This session provides participants with an overview of healthy eating. It explores food composition and dietary guidelines.

By the end of this session participants will have had the opportunity to:

- Learn about food composition

- Discuss healthy food choices

- Review food and activity diaries

- Set goals for the week

\section{To do before this session:}

- Review the Introduction to Group Sessions. This provides an overview of facilitating groups and offers guidance on group size, format, etc.

- Organize materials for the session:

- Paper, pens, flip chart/white board

- MyPyramid mini poster ○ MOVE! handouts:

- S06 Making Healthy Food Choices

- N01 All Foods Can Fit

Introduction (may take 15-20 minutes):

- Conduct individual weigh-in in private (can also be done at the end of the session).

- Welcome everyone to the class.

- Revisit ground rules for the session (set new rules if appropriate)

- Invite participants to discuss their progress/goals since the last class.

- Facilitate problem-solving for barriers.

- Discuss any homework from the last class.

- Discuss the purpose of today's session:

- Learn more about what's in your food

- Discuss healthy food choices

- Discuss using your food diary 
Appendix B MOVE! Lesson Plans found at: http://www.move.va.gov/GrpSessions.asp

- Decide on new goals for the next session

- Encourage questions and comments.

\section{Exercise 1: Food composition and dietary guidelines}

- Write "Why does food choice matter?" on a board and ask for comments.

- Display the MyPyramid mini poster. Use the MyPyramid fact sheets (links provided above) to explain the different food groups. Do not distribute these fact sheets (unless you feel it's appropriate); rather, use them to inform yourself in order to provide participants with basic understanding of the different food groups and their importance. Making this part of the session interactive is challenging because its primary function is to provide information. Try to involve participants by keeping it brief and asking for input and questions. Having just discussed the importance of the food groups MOVE! handout S06 Making Healthy Food Choices

- will make for interesting discussion. Distribute the handout. Ask participants to look at their food diary from the previous week and circle those foods which they think fall under the fats, salt, sugars and alcohol category. Ask if they have lots of circles. Discuss how they might:
- Focus on fruits
- Vary their veggies
- Get calcium rich foods
- Make at least half their grains "whole grains"
- Go lean with protein
- Know their limits on fats, salt, sugars and alcohol

This is particularly useful because it encourages participants to think about dietary guidelines and how they relate to the foods in their individual diets.

- Ask participants to consider which of their circled items they would be willing to cut back on or eliminate.

- Distribute MOVE! handout N01 All Foods Can Fit. Use this handout to summarize and give perspective to the guidelines just discussed.

\section{Physical activity break}

Incorporating physical activity into the session reinforces the healthy lifestyle message and provides opportunity to demonstrate some simple but effective exercises.

- Ask participants to join you in doing the following flexibility exercise:

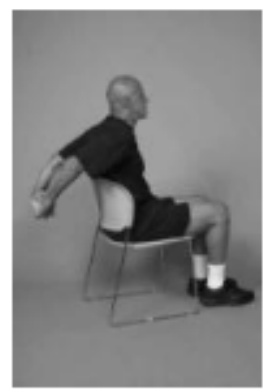

CHEST STRETCH: Extend your arms behind you with elbows straight. Interlock your fingers if possible. Gently lift your elbows upward. You should feel a stretch in your chest. 
Appendix B MOVE! Lesson Plans found at: http://www.move.va.gov/GrpSessions.asp

\section{Exercise 2: Record keeping}

- Ask participants to take out their food and activity diary. Reinforce the message that the diary is a self-management tool, and that keeping track of everything you eat and drink and the amount of physical activity you take is the most important thing you can do to help change eating and physical activity behavior.

- Suggest that participants complete the diary at the end of each day. Even better, suggest that they carry their diary with them and complete it at each meal/snack.

- Explain the diary headings and how best to complete each section.

- Discuss keeping a diary using the following principles:

- Be honest

- Be accurate

- Be complete

- Remind participants that the diary is a personal tool. It's O.K. for a participant to choose not to share his/her information.

- Use the following to explain the hunger/fullness column of the food diary: You should only eat until you are satisfied or full, not too full. In order to manage how much you eat and your weight, you need to listen to your body. Use the scale below to help determine how hungry you are. Stop eating 2 or 3 times during each meal to ask yourself if you are still hungry or starting to feel satisfied. Feelings of satisfaction or fullness do not happen right away so eating slowly can help. After you finish eating. check again to see how full you are. You never want to be too hungry or too full. It is best to stay between 3 and 7 on the scale.

\begin{tabular}{|c|c|}
\hline Rating & Hunger / Fullness Feelings \\
\hline 10 & Uncomfortably full or "sick" - "Thanksgiving full" \\
\hline 9 & Stuffed and uncomfortable \\
\hline 8 & Too full, somewhat uncomfortable \\
\hline 7 & Full, but not yet uncomfortable - hunger is gone \\
\hline 6 & Filling up, but still comfortable - could definitely eat more \\
\hline 5 & Neutral - neither hungry nor full \\
\hline 4 & $\begin{array}{l}\text { Slightly hungry, faint signals that your body needs food, but you can still wait to } \\
\text { eat }\end{array}$ \\
\hline 3 & Hungry, not yet uncomfortable, clear signals that your body needs food \\
\hline 2 & Very hungry, irritable or anxious - you want to eat everything in sight \\
\hline
\end{tabular}


Appendix B MOVE! Lesson Plans found at: http://www.move.va.gov/GrpSessions.asp

$1 \quad$ Starving, feeling weak, lightheaded, dizzy, or other extremely uncomfortable symptoms of hunger

- If they have not already done so, ask participants to start recording a hunger/fullness number before and after each meal. Ask the group to consider their scores and identify where and how they can begin to make changes.

- Plan to review food and activity diaries at each session. The "goal met" section can be used as a quick-check for progress and problem areas.

\section{Exercise 3: Goals for the next session}

- Ask participants to name one or two things that they plan to do for the coming week. Suggest they consider doing something that they learned at today's session. Encourage participants to write their goal/s in their food and activity diary.

\section{Close the session:}

- Remind participants to:

- Maintain their food and activity diaries,

- Wear their pedometers, and

- Bring both the diaries and the pedometers to all of the sessions. 
Appendix B MOVE! Lesson Plans found at: http://www.move.va.gov/GrpSessions.asp

\section{An: \\ Fit for Life \\ Session plan for group leader}

\section{About this session:}

This session generates discussion about the benefits of physical activity. It identifies barriers and helps participants find creative solutions to overcoming these barriers. By the end of this session, participants will have had the opportunity to:

- Reflect on how active they are

- Look at planned versus lifestyle activities

- Develop an activity plan

- Review their Food and Activity Diary

- Set goals for the week

\section{To do before this session:}

- Review the Introduction to Group Sessions. This provides an overview of facilitating groups and offers guidance on group size, format etc.

- Organize materials for the session:

- Paper, pens, flip chart/white board

- Worksheets

- My Physical Activity Worksheet

- MOVE! handouts:

- (P24) Types of Physical Activities

- (P01) Barriers To Physical Activity

- (P02) Benefits of Regular Physical Activity

- (P26) Physical Activity Pyramid

\section{Introduction (may take 15-20 minutes):}

- Conduct individual weigh-in in private (can also be done at the end of the session).

- Welcome everyone to the class.

- Revisit ground rules for the session.

- Review food and activity diaries, discuss progress/goals, and facilitate problemsolving for barriers.

- Discuss any homework from the last class.

- Discuss the purpose of today's session.

- Encourage questions and comments. 
Appendix B MOVE! Lesson Plans found at: http://www.move.va.gov/GrpSessions.asp

\section{Exercise 1: What is physical activity?}

- Use handout (P24) Types of Physical Activity to facilitate discussion. Write "Physical Activity" on a board and make two columns. Ask participants to give examples of physical activities. Without explanation, record the examples provided on the board and separate planned/programmed and lifestyle activities into two columns. Ask participants the difference between the columns and discuss why both planned/programmed and lifestyle activities are important when developing a physical activity plan. The purpose of this discussion is to differentiate between the two types of physical activities and to promote both.

- Use MOVE! handout (P02) Benefits of Regular Physical Activity and the information provided in the MyPyramid fact sheets (links above) to discuss the benefits of physical activity for health and weight loss.

- Distribute MOVEl handouts (P24) Types of Physical Activity and (P02) Benefits of Regular Physical Activity.

\section{Exercise 2: Barriers to physical activity:}

- Ask the question: 'If being active is so good for us, why is it that many of us are not as active as we could be?' To aid the discussion distribute MOVEl handout (P26) Physical Activity Pyramid.

\section{Physical activity break}

Incorporating physical activity into the session reinforces the healthy lifestyle message and provides opportunity to demonstrate some simple but effective exercises.

- Ask participants to join you in doing the following flexibility exercise:

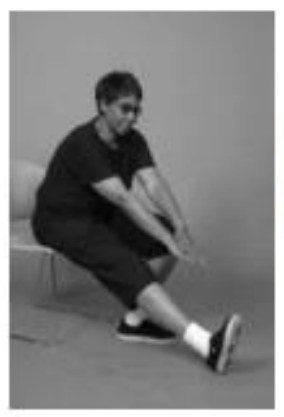

HAMSTRINGS: Sit in chair and extend one leg forward. Keep the knee straight and gently lean forward toward your toes. Repeat the exercise on other leg. You should feel a stretch in the harnstrings. Reduce the stretch or discontinue the stretch if it increases leg pain. 
Appendix B MOVE! Lesson Plans found at: http://www.move.va.gov/GrpSessions.asp

\section{Exercise 3: Develop an Activity Plan}

- Ask participants to review their Food and Activity Diary paying particular attention to the type and amount of physical activity they did over the last week.

- Distribute the My Physical Activity Worksheet to the group. Ask participants to consider their current physical activity levels and allow time for them to complete that side of the worksheet.

- Distribute and discuss MOVE! handout (P26) Physical Activity Pyramid.

- Explain the following recommendations to participants:

- For better health, be active (moderate intensity) for $\mathbf{3 0}$ minutes on most days (5-7 days) of the week.

- Be active for 60-90 minutes on most days (5-7 days) of the week to maintain weight loss.

- Remind participants of the following:

- It's ok to slowly build up to meeting the recommendations.

- Every little increase in physical activity will make you feel better and bring you closer to improved health.

- Every 10 minutes of moderate activity counts towards meeting the recommendations.

- Now ask participants to make a physical activity plan that they would like to work towards by completing the other side of the worksheet. Give opportunity for questions and comments.

- Suggest that participants use their worksheet to help them decide on physical activity goals for their Food and Activity Diary.

\section{Close the session:}

- Remind participants to:

- Maintain their food and activity diaries,

- Wear their pedometers, and

- Bring both the diaries and the pedometers to all of the sessions. 
Appendix B MOVE! Lesson Plans found at: http://www.move.va.gov/GrpSessions.asp

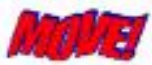 \\ Trim the Fat \\ Session plan for group leader}

\section{About this session:}

The Trim the Fat session promotes discussion of the importance of reducing dietary fat for weight loss as well as for other health benefits. By the end of this session, participants will have had the opportunity to:

- Discover which foods in their diet are high in fat

- Discuss how to eat less fat

- Learn why some fats are better than others

- Review food and activity diaries

- Set goals for the week

\section{To do before this session:}

- Review the Introduction to Group Sessions. This provides an overview of facilitating groups and offers guidance on group size, format etc.

- Organize materials for the session:

- Paper, pens, flip chart/white board

- Worksheets:

- My High Fat Foods

- My Plan to Trim the Fat

- MOVEl handouts:

- (N08) Fat Out... Flavor In

- (N09) What Are The Types of Fat?

- (N15) Sodium

- (B01) Old habits Die Hard

\section{Introduction (may take 15-20 minutes):}

- Conduct individual weigh-in in private (can also be done at the end of the session).

- Welcome everyone to the class.

- Revisit ground rules for the session (set new rules if appropriate)

- Invite participants to discuss their progress/goals since the last class.

- Facilitate problem-solving for barriers.

- Discuss any homework from the last class.

- Discuss the purpose of today's session:

- Encourage questions and comments. 
Appendix B MOVE! Lesson Plans found at: http://www.move.va.gov/GrpSessions.asp

\section{Exercise 1: Finding fatl}

- Write "Are fatty foods more fattening?" on a board and ask participants to comment. Discuss the following answer:

\section{Are fatty foods more fattening?}

Yes. Fat contains more than twice the calories as the same amount of sugar, starch or protein. For example $1 / 4$ cup of peanuts which has $18 \mathrm{~g}$ of fat provides 212 calories, whereas 3 cups (12 times more) of plain, air-popped popcorn containing just 1 gram of fat provides only 92 calories.

- Distribute the "My High Fat Foods" worksheet and ask participants to write the kinds of foods they eat that are high in fat (examples include: fries, chips, milkshakes, desserts, fried foods).

- Ask participants to circle these high-fat foods in their Food and Activity Diary.

Note that much of the fat we eat $(70 \%$ or more) is hidden in foods. Check out food labels.

\section{Physical activity break}

Incorporating physical activity into the session reinforces the healthy lifestyle message and provides opportunity to demonstrate some simple but effective exercises.

- Ask participants to join you in doing the following flexibility exercise:

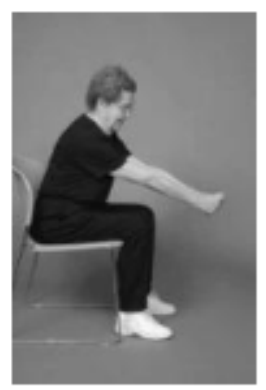

MID BACK STRETCH: Extend your arms in front with elbows straight. Interlock your fingers and gently pull forward, trying to separate your shoulder blades. You should feel a stretch between your shoulders. 
Appendix B MOVE! Lesson Plans found at: http://www.move.va.gov/GrpSessions.asp

\section{Exercise 2: How can I eat less fat?}

- Ask participants for ideas on how to eat less fat. Write the following on the board and use examples generated from the group to explain each:

Three Ways to Trim the Fat

1. Eat high-fat foods less often

2. Eat smaller amounts of high-fat foods

3. Eat lower-fat foods instead

- Distribute the "My Plan to Trim the Fat" worksheet and give participants time to complete it answering any questions that may arise.

- Ask participants what they will need to reach this goal?

- Ask what problems they might have and how they might solve them?

- Distribute MOVEI handouts (B01) Old Habits Die Hard and (N08) Fat Out... Flavor In.

\section{Exercise 3: Are some fats better than others?}

- Write "Are some fats better than others?" on the board and ask for comments.

- Distribute MOVEI handout (N09) What Are The Types of Fat?. Point out that mono- and polyunsaturated fats are healthier fats because they do not raise LDL ('bad' cholesterol). Use the information in the MyPyramid factsheets (links above) for your discussion.

Reducing total fat will help with weight loss. In addition, limiting bad fats will also improve your heart health.

- Discuss with participants that eating the right kind of fats (mono- and polyunsaturated fats) and reducing bad fats (saturated and trans fats) can significantly improve heart health.

- This is also a good opportunity to discuss eating less sodium to improve heart health. Distribute MOVEI handout (N15) Sodium.

\section{Close the session:}

- Remind participants to:

- Maintain their food and activity diaries.

- Wear their pedometers, and

- Bring both the diaries and the pedometers to all of the sessions. 
Appendix B MOVE! Lesson Plans found at: http://www.move.va.gov/GrpSessions.asp

\section{ARTIS \\ Play it Safe \\ Session plan for group leader}

\section{About this session:}

This session provides guidance on safety and physical activity. By the end of this session, participants will have had the opportunity to:

- Discuss when to stop exercising

- Discuss how hard they should exercise

- Consider personal safety including appropriate foot wear and tips for cold and hot weather physical activity

To do before this session:

- Review the Introduction to Group Sessions. This provides an overview of facilitating groups and offers guidance on group size, format etc.

- Organize materials for the session:

- Paper, pens, flip chart/white board

- MOVE! handouts:

- (P19) When to Stop Exercising?

- (S07) F.I.T.T

- (P08) How Hard Should I Exercise

- (P12) Making a Good Fit! Shoes For Active Feet

- (P14) Physical Activity and Your Safety

- (P17) Tips For Cold Weather Physical Activity

- (P18) Warm Weather Exercise Guidelines

\section{Introduction (may take 15-20 minutes):}

- Conduct individual weigh-in in private (can also be done at the end of the session).

- Welcome everyone to the class.

- Revisit ground rules for the session (set new rules if appropriate).

- Invite participants to discuss their progress/goals since the last class.

- Review food and activity diaries and facilitate problem-solving for barriers.

- Discuss any homework from the last class.

- Discuss the purpose of today's session.

- Encourage questions and comments.

\section{Exercise 1: When to stop exercising}

- Distribute MOVE! handout (P19) When to Stop Exercising and discuss.

- Patients who report medical concerns as a result of exercise should be referred to their primary care team for further assessment.

- Remind participants that moderate physical activity is safe for most people. If the veteran is in any doubt regarding safety, have them address this with their PCP. 
Appendix B MOVE! Lesson Plans found at: http://www.move.va.gov/GrpSessions.asp

\section{Exercise 2: How hard should I exercise?}

- Ask participants to describe a physical activity that they found "too hard" to do. Use the examples given to demonstrate that what is easy for one person may be hard for another.

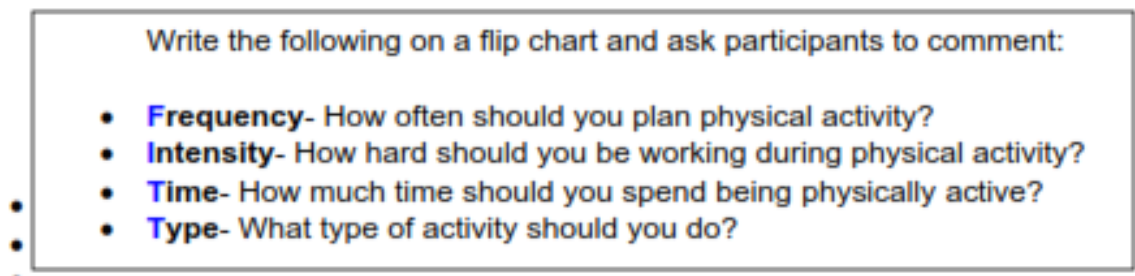

- Ask participants to discuss the F.I.T.T principle based on the activities recorded in their Food and Activity Diary. Use the information in MOVE! handout (S07) F.I.T.T to guide the discussion. Distribute the handout.

- Use the following definitions of intensity for the discussion:

\section{Moderate-Intensity Physical Activity}

Makes you breathe a little harder and sweat slightly. You should be able to carry on a normal conversation. Examples include brisk walking, swimming, slow bicycling, dancing, gardening, yard work, and housework, such as vacuuming.

\section{Vigorous-Intensity Physical Activity}

Makes you breathe hard, makes your heart beat fast and makes you sweat. Examples include jogging/running, lap swimming, bicycling, aerobic classes and racquet sports.

\section{Physical activity break}

Incorporating physical activity into the session reinforces the healthy lifestyle message and provides opportunity to demonstrate some simple but effective exercises.

- Ask participants to join you in doing the following flexibility exercise:

SIDE BENDS: Extend one arm up overhead and gently lean to the opposite side. Hold the stretch a count of 15. Repeat the stretch with the other arm. You should feel a stretch along your side.

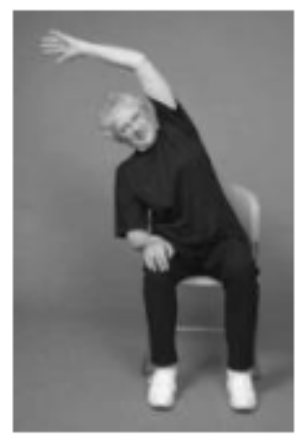


Appendix B MOVE! Lesson Plans found at: http://www.move.va.gov/GrpSessions.asp

\section{Exercise 3: Talk test}

- Use MOVE! handout (P08) How Hard Should I Exercise to describe the 'Talk Test'. If possible give participants the opportunity to determine moderate activity by using the talk test while walking.

- Ask participants to practice using the Talk Test before the next class.

\section{Exercise 4: Be active-be safe}

- Write the following headings on a board and ask participants for their opinion:

- Tips to stay safe while walking or jogging.

- Things to remember before going out for physical activity.

- Things to be careful of while out and about.

- Why are the proper shoes important?

- Use MOVE! handouts (P14) Physical Activity and Your Safety, (P12) Making a Good Fit! Shoes For Active Feet, (P17) Tips For Cold Weather Physical Activity, and (P18) Warm Weather Exercise Guidelines to guide the discussion.

\section{Exercise 4: Goal setting}

- Ask participants to decide on a physical activity goal for the next week and ask that they write it into their Food and Activity Diary.

- Remind participants to use the Talk Test to monitor the intensity of their physical activity during the coming week.

\section{Close the session:}

- Remind participants to:

- Maintain their food and activity diaries,

- Wear their pedometers, and

- Bring both the diaries and the pedometers to all of the sessions. 
Appendix B MOVE! Lesson Plans found at: http://www.move.va.gov/GrpSessions.asp

\section{ands \\ Tip the Balance \\ Session plan for group leader}

\section{About this session:}

This session provides for discussion about energy intake versus energy output. It examines the use of food labels and serving size as a means to monitor food intake and discusses how to tip the balance in favor of weight loss. By the end of this session, participants will have had the opportunity to:

- Discuss how energy intake (food and beverages consumed) and energy output (the amount of energy you use each day) effect weight

- Look at food labels

- Discuss the importance of 'serving size'

- Review Food and Activity Diaries

- Set goals for the week

To do before this session:

- Review the Introduction to Group Sessions. This provides an overview of facilitating groups and offers guidance on group size, format etc.•

- Organize materials for the session:

Paper, pens, flip chart/white

- A selection of empty food products with labels (For

example: food wrappers, boxes, bottles, cans, etc.

- To demonstrate serving size try to bring some of the following to the session: computer mouse, tennis ball, hockey puck, CD, dice, deck of cards

- Worksheets

- Rate Your Plate

- MOVE! handouts:

- (S01) The Basics of Weight Control

- (N10) How to Read A Food Label

- (N21) Serving Sizes

- (N12) Healthy Plate

- (B17) Irrational Ideas About Eating

- (B15) Hungry All the Time 
Appendix B MOVE! Lesson Plans found at: http://www.move.va.gov/GrpSessions.asp

\section{Introduction (may take 15-20 minutes):}

- Conduct individual weigh-in in private (can also be done at the end of the session). .

- Welcome everyone to the class.

- Revisit ground rules for the session (set new rules if appropriate)

- Invite participants to discuss their progress/goals since the last class.

- Review food and activity diaries and facilitate problem-solving for barriers.

- Discuss any homework from the last class.

- Discuss the purpose of today's session:

- Encourage questions and comments.

\section{Exercise 1: How do I lose weight?}

- Ask participants the question - What do you need to do to lose weight? Take feedback on the board. Distribute MOVE! handout (S01) The Basics of Weight Control and discuss the following component:

\section{To lose weight you need to:}

- Eat and drink fewer calories

- Be more physically active

- For best results do both

- Ask participants to discuss why this seemingly simple solution to losing weight is so difficult for so many of us?

- Ask participants to take out their Food and Activity Diary. Then ask the following: "Look at those days when goals were not met. Think about what got in the way". Encourage the group to offer solutions. Take feedback and summarize on the board. This exercise may take some time. Remember to focus on solutions for both healthy eating and physical activity.

- Based on the discussion, distribute appropriate MOVE! handouts from the following:

(B15) Hungry All The Time? (B17) Irrational Ideas About Eating

\section{Exercise 2: Are food labels useful?}

- Pass around sample food products giving participants the opportunity to discuss the pros and cons of the products for the purpose of weight loss and healthy eating. 
Appendix B MOVE! Lesson Plans found at: http://www.move.va.gov/GrpSessions.asp

- Ask participants how they plan to use food labels to tip the balance in favor of weight loss. Distribute MOVE! handout (N10) How to Read a Food label.

\section{Physical activity break}

Incorporating physical activity into the session reinforces the healthy lifestyle message and provides opportunity to demonstrate some simple but effective exercises.

- Ask participants to join you in doing the following flexibility exercise:

TRUNK ROTATION: Sit in chair and gently rotate your trunk and shoulders to one side. Use your arms to help rotate. Repeat in opposite direction. You should feel a stretch in your trunk.

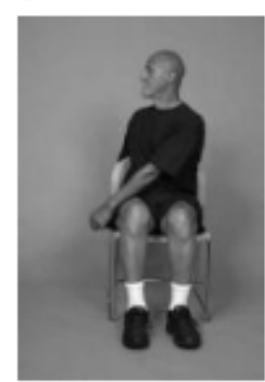

\section{Exercise 3: What is a serving?}

- Distribute the Rate Your Plate Worksheet. Ask participants to draw their last dinner meal on the plate. Remind participants that it is not an art competition and to focus on getting the size of the food correct. For example: If meat took up half the plate, draw a piece of meat on half of the plate. Distribute MOVE! handout N12 Healthy plate and ask participants to compare their plate with the handout.

- Using MOVE! handout (N21) Serving Size and the familiar items you provided for the session, demonstrate recommended serving sizes for common foods.

\section{Exercise 4: How will you tip the balance:}

- Referring to the earlier discussion on "what you need to do to lose weight" ask participants what they have learned from today's session on tipping the balance in favor of weight loss.

- Remind the group that the best way to lose weight is to eat and drink fewer calories but also to be more physically active. Remind participants of the following fact:

\section{1 mile of brisk walking $(15-20$ minutes $)=$ about 100 calories}

- Ask participants to review their Food and Activity diary and to write a goal for the next week.

\section{Close the session:}

- Remind participants to:

- Maintain their food and activity diaries,

- Wear their pedometers, and

- Bring both the diaries and the pedometers to all of the sessions. 
Appendix B MOVE! Lesson Plans found at: http://www.move.va.gov/GrpSessions.asp

\section{and \\ If at First You Don't Succeed... PLAN Session plan for group leader}

\section{About this session:}

This session provides for discussion on the importance and benefits of 'Planning' for successful weight management. By the end of this session, participants will have had the opportunity to:

- Discuss how to eat healthy and be more physically active by planning ahead

- Discuss healthy eating at home and when dining out

- Consider how to make time for physical activity

- Review Food and Activity Diary

- Set goals for the week

\section{To do before this session:}

- Review the Introduction to Group Sessions. This provides an overview of facilitating groups and offers guidance on group size, format etc.

- Organize materials for the session:

- Paper, pens, flip chart/white board

- MOVE! handouts:

- (B20) Lose Weight by Planning Ahead

- (N05) Eating at Home

- (N06) Eating Well On A Budget

- (N07) Fast Food Alternatives

- (N25) Restaurant Tips

- (P23) Activities to Fit Your Lifestyle

- Worksheets

- Planning Ahead Worksheet

- Physical Activity Recall Worksheet

\section{Introduction (may take 15-20 minutes):}

- Conduct individual weigh-in in private (can also be done at the end of the session).

- Welcome everyone to the class.

- Revisit ground rules for the session (set new rules if appropriate)

- Invite participants to discuss their progress/goals since the last class.

- Review food and activity diaries and facilitate problem-solving for barriers.

- Discuss any homework from the last class.

- Discuss the purpose of today's session.

- Encourage questions and comments.

\section{Exercise 1: Plan Ahead}

- Write "Why Plan?" on the board and ask for comments. Use MOVEI handout (B20) Lose Weight by Planning Ahead to develop the discussion. 
Appendix B MOVE! Lesson Plans found at: http://www.move.va.gov/GrpSessions.asp

- Ask the group to consider the following:

- Times when they normally overeat

- Times when they make poor dietary choices

- Reasons why they are not more physically active

- Ask how planning ahead might help. Give the group time to complete the Planning Ahead Worksheet.

- As an optional exercise, discuss how healthy eating can be less expensive by planning. Use MOVEI handout (N06) Eating Well on a Budget. This may be appropriate for a group which raises the issue of expense.

\section{Exercise 2: Healthy eating at home and when dining out}

- Remind participants that a healthy lifestyle involves making healthy choices both at home and when dining out. Give the group opportunity to discuss the difficulties of eating healthy at home and when dining out. Make a list on the board of the main difficulties discussed and solicit solutions.

- Distribute MOVE! handouts (N05) Eating at Home, (N07) Fast Food Alternatives and (N25) Restaurant Tips for further discussion.

\section{Physical Activity Break}

Incorporating physical activity into the session reinforces the healthy lifestyle message and provides opportunity to demonstrate some simple but effective exercises.

- Ask participants to join you in doing the following balance exercises:

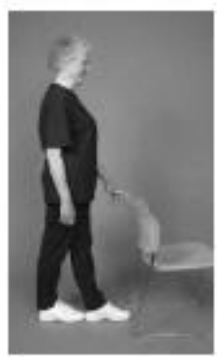

TANDEM STANDING: Place one foot directly in front of the other, touching heel to toe and hold. Repeat with other foot in front. Use a sturdy chair for support as needed.

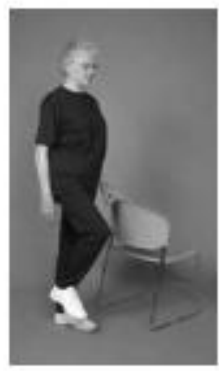

ONE LEG BALANCE: Lift foot to stand on one leg. Repeat the exercise on the other leg. Use a sturdy chair for support as needed. 
Appendix B MOVE! Lesson Plans found at: http://www.move.va.gov/GrpSessions.asp

\section{Exercise 3: Make Time for Physical Activity}

- Distribute the Physical Activity Recall Worksheet. Explain that the worksheet is a tool to help participants discover when and where they may be able to engage in more physical activity.

- After giving the group time to complete the worksheet, ask participants to consider how they may have been able to add more lifestyle physical activities to their day. Distribute MOVEI handout (P23) Activities to Fit Your Lifestyle to help generate ideas.

\section{Exercise 4: Goal Setting}

- Ask participants to decide on a goal for the next week and ask that they write it into their Food and Activity Diary. Suggest that they use a goal from today's

Planning Ahead Worksheet or from the Make Time for Physical Activity exercise.

\section{Close the session:}

- Remind participants to:

- Maintain their food and activity diaries,

- Wear their pedometers, and

- Bring both the diaries and the pedometers to all of the sessions. 
Appendix B MOVE! Lesson Plans found at: http://www.move.va.gov/GrpSessions.asp

\section{QR7? \\ You are the Boss! Session plan for group leader}

\section{About this session:}

This session looks at how to take charge of your surroundings to make healthier food choices and be more physically active. Participants will have the opportunity to:

- Examine the environmental influences affecting food and activity

- Discuss how to take charge of situations so as to make healthier choices

- Learn new techniques to help prevent overeating

- Review Food and Activity Diaries

- Set goals for the week

To do before this session:

- Review the Introduction to Group Sessions. This provides an overview of facilitating groups and offers guidance on group size, format etc.

- Organize materials for the session:

- Paper, pens, flip chart/white board

- MOVE! handouts:

- (B34) Eating With Others

- (B24) Control Yourself!

- Worksheets

- Changing The Things Around You worksheet

\section{Introduction (may take 15-20 minutes):}

- Conduct individual weigh-in in private (can also be done at the end of the session). .

- Welcome everyone to the class.

- Revisit ground rules for the session (set new rules if appropriate)

- Invite participants to discuss their progress/goals since the last class.

- Review food and activity diaries and facilitate problem-solving for barriers.

- Discuss any homework from the last class.

- Discuss the purpose of today's session.

- Encourage questions and comments.

\section{Exercise 1: Changing the things around you}

- Write "what in your everyday life triggers you to overeat or be less active?" on a board. If necessary give some examples to start the discussion such as:

- What you're feeing

- What someone says

- What you see

- Certain places, activities or events (for example, movies, TV, special occasions, vacations etc.) 
Appendix B MOVE! Lesson Plans found at: http://www.move.va.gov/GrpSessions.asp

Suggest that to change a problem or habit, you need to:

Stay away from the problem (or keep it out of sight)

OR

Build a new healthier habit.

- Explain to the group that you are going to do a visual exercise to examine things at home that may trigger them to overeat or make poor food choices. Distribute the Changing the Things Around You worksheet.

- Ask the group to imagine the following: You have just opened your front door. You have a video camera and are taking a video of what's in the room. Which room are you in? Do you see any food in the room? Do you see anything that might make you think about eating, Ilke a comfortable chair or a TV? Write one thing in your worksheet that you could change to make it easier for you not to overeat in this room. Move from room to room. Are there other rooms that cause problems for you? For each problem that you see write down how you might solve it by either putting it out of sight, avoiding it, or changing it so it becomes a healthier habit. Imagine the kitchen once again. Open the cabinets and the fridge. Do you see any foods that you know are not part of a healthy diet? List these on your worksheet. As the boss, what could you do about these unhealthy foods?

- Ask the group to choose one or two things from their worksheet that they would like to do over the next week. Ask them to write this in their Food and Activity Diary as a goal for the next week.

\section{Physical activity break}

Incorporating physical activity into the session reinforces the healthy lifestyle message and provides opportunity to demonstrate some simple but effective exercises.

- Ask participants to join you in doing the following balance exercises:

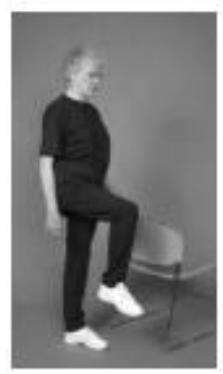

STANDING HIP RAISE: Lift the hip and knee. Repeat on other leg. Use a sturdy chair for support as needed. 
Appendix B MOVE! Lesson Plans found at: http://www.move.va.gov/GrpSessions.asp

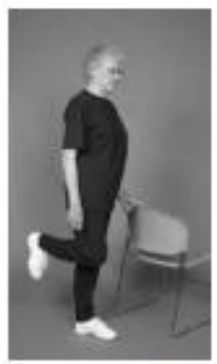

STANDING KNEE BEND: Bend the knee, pulling the heel upward. Repeat on other leg. Use a sturdy chair for support as needed.

\section{Exercise 2: Taking charge of situations}

- Ask the following question: How does what other people say and do affect your eating and physical activity choices (positively or negatively)? Make a list of both positive and negative examples. Invite participants to come up with solutions to some of the problems discussed. Take feedback and use MOVE! handouts (B34) Eating With Others and (B24) Control Yourself!

- Remind participants to review the goals they set earlier in the session. Answer any questions.

\section{Close the session:}

- Remind participants to:

- Maintain their food and activity diaries,

- Wear their pedometers, and

- Bring both the diaries and the pedometers to all of the sessions. 
Appendix B MOVE! Lesson Plans found at: http://www.move.va.gov/GrpSessions.asp

\section{A7072 \\ Oops, I Did It Again! \\ Coping With Slips \\ Session plan for group leader}

\section{About this session:}

This session discusses slips - why they occur and how best to deal with them. By the end of the session, participants will have had the opportunity to:

- Identify some things that cause them to have slips in their weight loss effort

- Practice problem solving and making a plan for dealing with slips

- Review their Food and Activity Diary

- Set goals for the week

To do before this session:

- Review the Introduction to Group Sessions. This provides an overview of facilitating groups and offers guidance on group size, format etc.

- Organize materials for the session:

- Paper, pens, flip chart/white board

- MOVE! handouts:

Worksheets

- (B29) Take Control of Your Thoughts, Feelings and Behavior

- My Problem Solving Worksheet

\section{Introduction:}

- Conduct individual weigh-in in private (can also be done at the end of the session).

- Welcome everyone to the class.

- Revisit ground rules for the session (set new rules if appropriate).

- Invite participants to discuss their progress/goals since the last class.

- Review food and activity diaries and facilitate problem-solving for barriers.

- Discuss any homework from the last class.

- Discuss the purpose of today's session.

- Encourage questions and comments.

\section{Exercise 1: Identifying the cause of slips}

- Ask the group to define a slip.

- Write the following information on a board and discuss with the group:

- Slips are normal and to be expected.

- The problem is not the slip but rather how you choose to deal with the slip. 
Appendix B MOVE! Lesson Plans found at: http://www.move.va.gov/GrpSessions.asp

- Ask participants to list things that cause them to have slips. Any strong emotion positive or negative may trigger a slip. For example:

- Some people overeat when they are happy (family celebrations, holidays, promotions etc.).

- Some people overeat when they are sad or upset (bad day at work, argument with spouse etc.).

- Take feedback from the group writing triggers for common slips on the board. Ask how past slips affected their weight loss efforts?

- One episode of overeating or not being active will not ruin everything.

- One slip can trigger a chain of slips. It is this chain of slips that can lead to a major sense of failure.

- Remember to "draw a box" around the slip (keep it in perspective).

- Explain that the next exercise (problem solving) describes how to manage slips by describing the problem that triggered the slip and making a plan to get back on track.

\section{Exercise 2: Problem solving}

- Distribute the My Problem Solving Worksheet. Ask participants to consider a slip they have had while trying to lose weight. Ask them to describe the problem in detail by writing down the chain of events leading up to the problem. For example:

- Got up late and skipped breakfast

- Missed an appointment

- Felt stressed

- Came home

- Went straight to the kitchen

- Saw leftover fried chicken from the grandchildren's visit

- Ate the chicken 
Appendix B MOVE! Lesson Plans found at: http://www.move.va.gov/GrpSessions.asp

- Ask the group to brainstorm their options by considering what they could have done at each stage of the action chain. For example:

\begin{tabular}{|c|c|}
\hline Find the chain of events & Brainstorm your options \\
\hline - Got up late and skipped breakfast & Pack a snack to have on the go \\
\hline $\begin{array}{l}\text { - Missed an appointment } \\
\text { - Felt stressed }\end{array}$ & $\begin{array}{l}\text { Take some deep breaths and re- } \\
\text { schedule the appointment }\end{array}$ \\
\hline $\begin{array}{l}\text { - Came home } \\
\text { - Went straight to the kitchen }\end{array}$ & $\begin{array}{l}\text { Go for a walk until I am no longer } \\
\text { stressed and likely to overeat } \\
\text { Go to another room, not the kitchen }\end{array}$ \\
\hline $\begin{array}{l}\text { - Saw leftover fried chicken from the } \\
\text { grandchildren's visit } \\
\text { - Ate the chicken }\end{array}$ & $\begin{array}{l}\text { Throw out all leftover food from others. } \\
\text { Always keep some healthy snacks on } \\
\text { the counter-top where I can easily } \\
\text { access them }\end{array}$ \\
\hline
\end{tabular}

- Explain that a chain of events can be broken by choosing any one or more of the brainstorming options. This prevents the slip from ever occurring.

- Ask participants to complete the worksheet by deciding where they would have broken the chain and why.

- Discuss the exercise and how it might be used to solve all sorts of problems.

\section{Physical activity break}

Incorporating physical activity into the session reinforces a healthy lifestyle message and provides opportunity to demonstrate some simple but effective exercises.

- Ask participants to join you in doing the following balance exercises:

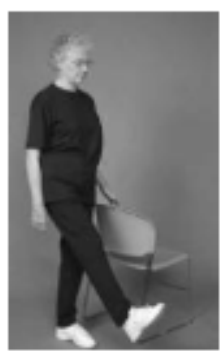

STANDING KICK: Extend the knee and kick forward. Repeat on other leg. Use a sturdy chair for support as needed. 
Appendix B MOVE! Lesson Plans found at: http://www.move.va.gov/GrpSessions.asp

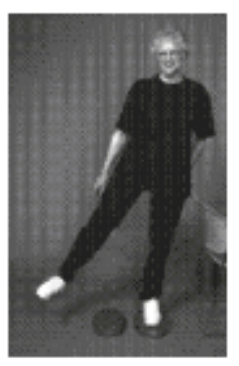

STANDING SIDE KICK: Extend the knee and kick out to the side. Repeat on other leg. Use a sturdy chair for support as needed.

\section{Exercise 3: Take control with positive thinking}

- Distribute MOVE! handout (B29) Take Control of Your Thoughts, Feelings and Behavior. Talk the group through the exercise and suggest they practice the technique during the week.

\section{Exercise 4: Goal setting}

- Ask participants to decide on a goal for the next week and ask that they write it into their Food and Activity Diary.

\section{Close the session:}

- Remind participants to:

- Maintain their food and activity diaries,

- Wear their pedometers, and

- Bring both the diaries and the pedometers to all of the sessions. 
Appendix B MOVE! Lesson Plans found at: http://www.move.va.gov/GrpSessions.asp

\section{COATS \\ Keep it Going \\ Session plan for group leader}

\section{About this session:}

This session addresses maintenance issues. It is unlikely that any participant will have reached his/her total weight loss goal by the end of the group sessions. Remember that the overall focus of MOVE! is to assist the patient in making lifelong healthy lifestyle changes. By the end of the session, participants will have had the opportunity to:

- Review progress

- Consider how to deal with weight plateaus

- Discuss how to stay motivated and deal with boredom

- Discuss maintaining weight management outside of the group setting

\section{To do before this session:}

- Review the Introduction to Group Sessions. This provides an overview of facilitating groups and offers guidance on group size, format etc.

- Organize materials for the session:

- Paper, pens, flip chart/white board

- Tennis ball

- MOVE! handouts:

- (B06) Yes! You Can Keep That Weight Off!

- (M02) Handling Weight Plateaus

- (B19) Dealing With Boredom

- Worksheets

- Progress Review Worksheet

- Why I am Going to MOVE! worksheet (completed from the orientation session)

\section{Introduction (may take 15-20 minutes):}

- Conduct individual weigh-in in private (can also be done at the end of the session).

- Welcome everyone to the class.

- Revisit ground rules for the session (set new rules if appropriate)

- Invite participants to discuss their progress/goals since the last class.

- Review food and activity diaries and facilitate problem-solving for barriers.

- Discuss any homework from the last class.

- Discuss the purpose of today's session.

- Encourage questions and comments.

\section{Exercise 1: Review your progress}

- Remind the group that it is very beneficial to review progress regularly. Setting short term goals is essential for successful weight management but reviewing the overall goal can be a great motivator. Ask participants to look at their Why I Am 
Appendix B MOVE! Lesson Plans found at: http://www.move.va.gov/GrpSessions.asp

Going to MOVE! Worksheet, completed during the orientation session. Ask how they now feel about their overall goals for the program?

- Distribute the Progress Review Worksheet. Ask participants to carefully consider changes they have made to be more active and to make healthy food choices. Ask that they complete the worksheet and to revisit it regularly. Consider providing each participant with additional copies of this worksheet. Suggest that they use it as a self-management tool after the group sessions.

\section{Exercise 2: Coping with weight plateaus}

\section{Weight Loss Plateaus:}

There is no official definition of a weight plateau, but many define the weight loss plateau as a failure to lose weight or inches for at least four weeks.

- Discuss this definition with the group. Ask participants to talk about their experiences with weight plateaus and solicit possible solutions. Take feedback on the board.

- Use MOVE! handout (M02) Handling Weight Plateaus to generate more solutions and consider the following points for discussion.

- Is this really a weight plateau or have you somehow slipped in your weight loss efforts. Review your Food and Activity Diary to see if you can find where you may have slipped.

- Keeping track of everything you eat and drink and your physical activity. This will help you kick start your weight loss efforts.

- Consider shifting your focus a little. For example, if you have been working hard on reducing foods high in fat, try cutting down on carbohydrates. If you have been doing lots of strength exercises, try increasing your aerobic activity.

- If you have been on a low calorie diet, consider mixing it up a little. Sometimes the body thinks it's in starvation mode and reduces its metabolism as a coping mechanism. By temporarily increasing the number of calories you eat in a day, you may actually be able to kick-start your metabolism again. 
Appendix B MOVE! Lesson Plans found at: http://www.move.va.gov/GrpSessions.asp

\section{Physical activity break}

Incorporating physical activity into the session reinforces the healthy lifestyle message and provides opportunity to demonstrate some simple but effective exercises.

- Ask participants to join you in doing the following flexibility exercise:

LEG EXTENSIONS: Sitting up very tall with feet flat on the floor, knees together, straighten the right leg as much as you can while keeping your foot flexed. Bend the knee and lower the foot back down. Touch the heel lightly to the floor (don't rest all the way down) and repeat the leg extension for 16 reps. Switch to the other leg. Make sure your knees stay at the same level (i.e., don't let the knee of the working leg drift up or down).

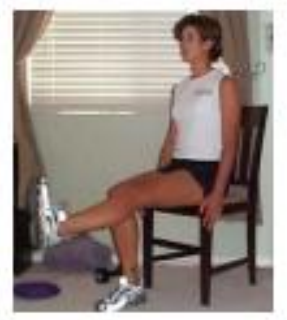

\section{Exercise 3: Stay Motivated}

- Ask the group to discuss ways to stay motivated using the headings listed in the box below. Take feedback on the board and summarize.

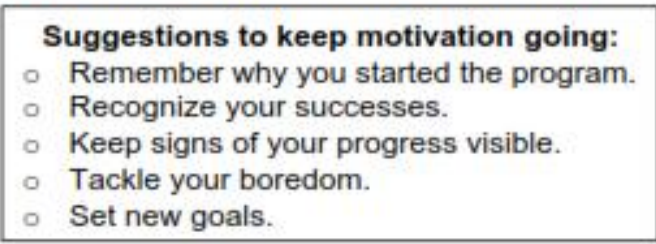

- Remind the group that tracking food and activity in the Food and Activity Diary is a powerful motivator and a great visible sign of progress.

- Distribute MOVE! handout (B19) Dealing With Boredom.

\section{Exercise 4: Maintaining weight management efforts after the group sessions}

- Ask participants to list one thing they have learned that will help them to maintain their weight loss effort after the group sessions. Make a list. Distribute MOVE! handout (B06) Yes! You Can Keep That Weight Off! for further discussion.

\section{Exercise 5: Continuing self-management}

- Ask the group to make a plan for continuing self-management outside of the group setting.

- Things to consider:

- Continue to record food intake and physical activity.

- Check weight on a periodic basis.

- Figure out an amount of weight gain that prompts an action.

- Specify the action plan to get back on the program. 
Appendix B MOVE! Lesson Plans found at: http://www.move.va.gov/GrpSessions.asp

Determine when to contact the MOVE! Team if self-management is not enough.

\section{Exercise 6: Closing the group sessions}

By the end of the group sessions participants have formed a cohesive supportive unit and some may have concerns about "going it alone". Reassure the group that this is a normal response. Explain that while the group sessions are at an end, the MOVE! multidisciplinary team is there to support them in self-managing their weight. Some facilities may offer an ongoing support group. If so, provide the necessary information. This is also a good time to remind the group of the many skills they have acquired during the sessions, as well as the things they have learned.

\begin{tabular}{|l|l|}
\hline \multicolumn{1}{|c|}{ Skills } & \multicolumn{1}{c|}{ Knowledge } \\
\hline - Self-monitoring (record keeping) & - What's in your food \\
- Planning and preparing & - Healthy food choices \\
- Problem solving & - How to recognize fats \\
- Goal setting & - Types of physical activities \\
- Tecord keeping & - How to warm-up and cool-down \\
- Taking charge of what's around you & - Understanding energy intake versus \\
- Managing slips and plateaus & - energy output \\
- Positive thinking & - Understanding serving size \\
& - Knderstanding food labels \\
& \\
\hline
\end{tabular}

- Tell the group how far you think they have come and how proud you are of their progress.

- Discuss how follow-up will be handled (e.g., return to MOVE! Level 1 Selfmanagement support).

- Consider a novel approach to closing the group. For example, ask participants the following:

"If I bump into you a year from now and I ask you how your weight management is going, what would you like to say to me?"

Allow the group to spontaneously respond to the question and then encourage those who have been quiet to comment. 
Appendix B MOVE! Lesson Plans found at: http://www.move.va.gov/GrpSessions.asp

\section{ARDIS \\ MOVEing Forward Session plan for group leader}

\section{About this session:}

This session plan provides a general outline for ongoing group support. This is to facilitate those who run weekly/monthly support groups for veterans who have been through the standard group sessions but show interest in meeting regularly to help maintain weight management. Consider the following when planning ongoing sessions.

- Participants are familiar with the group format and may feel comfortable contributing ideas on how the group should be run.

- Participants may like to take an active roll in leading portions of certain sessions.

- The group may decide on discussion topics for the sessions.

- Consider incorporating physical activity (for example, stretches) into the sessions.

\section{Introduction:}

- Welcome everyone to the class.

- Revisit ground rules for the session (set new rules if appropriate).

\section{Exercise 1: Review your progress}

- Distribute the Progress Review Worksheet. Ask participants to carefully consider changes they have made to be more active and to make healthy food choices. Ask that they complete the worksheet.

\section{Exercise 2: Review}

- Review food and activity diaries and facilitate problem-solving.

\section{Exercise 3: Topic}

- Consider choosing a specific topic from the MOVE! Group Modules (Version 1.0) as material for these sessions.

\section{Close the session}




\section{The Basics of Weight Control}

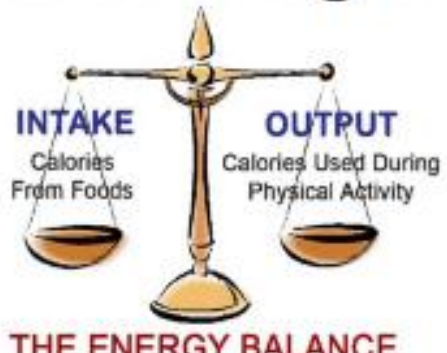

THE ENERGY BALANCE

Your weight is controlled by a number of things, including family history, what you eat and drink (energy intake), and the energy you use to live and be active (energy output).

\section{To lose weight you need to:}

- Eat and drink fewer calories

- Become more physically active

- For best results, do both

The food you eat and the beverages you drink provide energy and nutrients. The basic required nutrients are: water, carbohydrate, protein, fat, dietary fiber, vitamins, and minerals. Three of these nutrients (carbohydrate, protein and fat) along with alcohol provide energy in the form of calories.

\section{When you take in more calories than you use, you gain weight.}

Most of the calories you do not use are stored as body fat. This is true regardless of whether this energy came from fat, carbohydrate, protein or alcohol. You can use more calories by being more active. You can manage your weight by keeping a balance between what you eat and drink and how active you are. 
Appendix C MOVE! Handouts

\section{How do I lose weight?}

- Set your daily target calorie goal using this chart.

\begin{tabular}{|c|c|}
\hline Current Weight & Daily Calorie Goal \\
\hline Under $200 \mathrm{lbs}$. & $1200-1500$ calories/day \\
\hline $200-225 \mathrm{lbs}$. & $1500-1800$ calories/day \\
\hline $226-250 \mathrm{lbs}$. & $1800-2000$ calories/day \\
\hline $251-300 \mathrm{lbs}$. & $2000-2200$ calories/day \\
\hline $300-350 \mathrm{lbs}$. & $2500-3000$ calories/day \\
\hline Over $350 \mathrm{lbs}$. & See a MOVE! Dietitian \\
\hline
\end{tabular}

- Find your current weight in the left column. Your daily target calorie goal for that weight range is listed in the right column. These calorie goals are designed to help you lose about $1 / 2$ to 2 pounds per week.

- Expect better results if you use the lower number for the daily calorie goal.

- Use one of the online services or a simple calorie counter book so you can log your calories accurately. Record in your Food and Physical Activity Diary on a daily basis.

- When you make it to the next weight range (for instance, you start off at 280 pounds, and you now weigh 245 pounds), you will need to reduce your daily calorie goal to that lower level.

- If you weigh over 350 pounds or have diet concerns, talk with the dietitian to help set your daily calorie goal.

- Review your Food and Physical Activity Diary. Celebrate successful days. On days when goals were not met, think about what got in the way and consider solutions.

- Remember, to lose weight, make sure you have clear, daily calorie and physical activity goals. 


\section{Change Your Thinking about Food, Exercise, and Yourself}

What you think drives what you do. You can change your thinking. Here are some tips:

- Make a firm decision to get serious.

- Make your weight management program one of your top priorities.

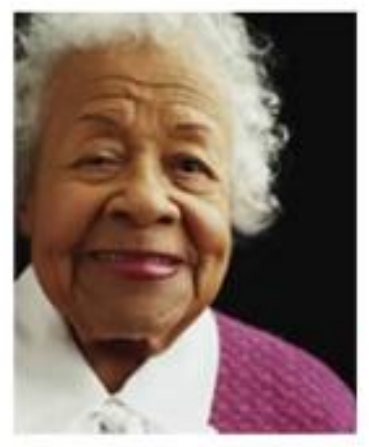

- Realize that you have control over your weight.

- Eating and other lifestyle behaviors have been learned; therefore, they can be replaced or changed.

- Think positively!

- Tell yourself you're worth the effort!

- Think about exercise and physical fitness as increasing your energy, vitality and well-being.

- Think of eating and physical activity as needing a balance. You have the power to tip the scales.

- Think about weight management as a life-long effort and a way to be good to yourself. 


\section{Set Your Weight Loss Goals}

Putting goals on paper helps keep you on track. You can revise or add to your goals at any time.

1. Set a goal for weight loss.

Start with a goal of no more than $10 \%$ of your current weight.

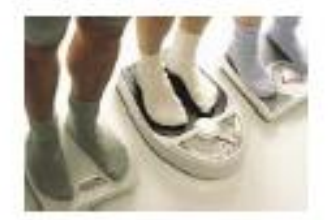

I currently weigh pounds. My initial goal is to lose ___ pounds.

Example: If you weigh 250 pounds, your goal might be to lose 25 pounds, or you could decide to make 10 pound goals. When you lose 10 pounds, set a new 10 pound goal. Choose a realistic, achievable goal.

\section{Decide on 1 or $\mathbf{2}$ food/beverage choice changes.}

What can you do to take in fewer calories and less fat? Example:

"I will have low-fat milk with my cereal every day this week."

Write them down:

1.

2.

\section{Decide on $\mathbf{1}$ or $\mathbf{2}$ ways to increase your activity level.}

Make them simple and realistic. As your fitness improves, add to these goals. Example: "I will take the stairs to the second floor at work this week." Write them down:

1.

2.

4. Weigh yourself at least once a week.

Signature:

Date: 


\section{When to Stop Exercising}

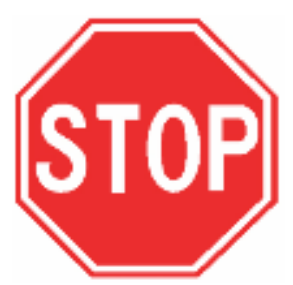

Physical activity is usually safe. Stop exercising right away if you have any of these symptoms:

- Pain, tightness, pressure, or discomfort in your chest, neck, shoulder, arm, back, or jaw

- Severe shortness of breath

- Cold sweats

- Severe nausea or vomiting

- Muscle cramps

- Sudden weakness or changes in feeling in your arms and/or legs

- Trouble swallowing, talking, or seeing

- Severe headache, dizziness, or lightheadedness

- Joint pain

If symptoms don't go away after a few minutes, call 911 or go to the nearest emergency room. If the symptoms go away but return each time you exercise, see your primary care provider.

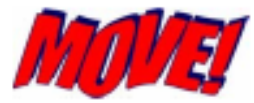




\section{A Guide to Using Your Pedometer}

Walking is a great way to help you lose weight, keep the weight off and improve your health.

\section{What is a Pedometer?}

- A pedometer is a tool to measure how many steps you take.

- A pedometer gives you feedback about your activity.

- Use it to plan, track and reach your physical activity goals.

\section{How to Wear Your Pedometer:}

- Clip it to your clothing, or place it in a pocket or a bag that you carry or wear.

- Use the leash and clip to keep from dropping or losing your pedometer.

- Do not get the pedometer wet.

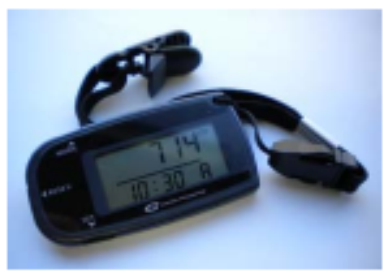

\section{Pedometers do not measure:}

- Walking for less than 10 steps or 10 seconds at a time.

- Cycling, swimming, some dancing, basketball and tennis.

- Distances covered while using a manual wheelchair -- this requires an odometer/cyclometer.

\section{Getting Started:}

- Wear your pedometer every day for one week.

- The pedometer will count your steps each day and then begin counting steps for the next day at midnight.

- Record your steps daily on your Activity/Pedometer Log.

- For the first week, just record how many steps you take.

- At the end of one week, add up your daily steps to find out your daily average (total steps $\div$ number of days).

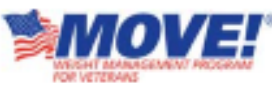


Appendix C MOVE! Handouts

\section{Increasing Your Steps:}

- Starting with the second week, set a goal to increase your steps (Example: average of 3000 steps in first week, may set a goal to increase to 3500 steps per day the next week).

- Start at a comfortable level and gradually increase steps.

- Create a weekly walking plan/schedule.

- Record your steps every day.

- Set goals that you can reach.

- Update your goals every week.

- Choose an activity and a setting that you enjoy: outside, at a mall, at a gym.

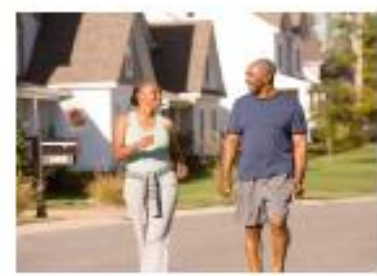

\section{Ways to Add Walking to Your Lifestyle:}

- Take a 10-minute walk whenever you can.

- Take the stairs (up or down) instead of the elevator.

- Take 10-minute walks during lunch and breaks at work.

- Park farther away and walk.

- Get off the bus one stop early and walk the rest of the way.

- Step in place while watching television.

- Walk your dog (or borrow a friend's dog).

- Mow your lawn with a push mower or do other yard work.

- For short distances, walk instead of driving your car.

- Take the long way when walking to meetings.

- Find a regular walking partner.

\section{Other Important Facts:}

- For health benefits, aim for walking or other physical activity at least 2.5 hours per week, in periods of at least 10 minutes.

- To help you lose weight, walk or be physically active more than 2.5 hours per week.

- Walking and wheeling are easy, inexpensive and you can do them almost anywhere. 
Appendix C MOVE! Handouts

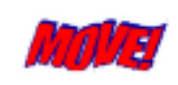

Why I have joined the MOVE! Program

I have joined the MOVE! group sessions because:

As a result of coming to the group sessions I hope to:

Changing my eating habits and becoming more active will help me to: 
Appendix C MOVE! Handouts

\section{Walk}

Walking is a great way to be more physically active. It's free, fun, and you can do it almost anywhere.

\section{Here are 6 reasons to get up and walk:}

1. Regular walking burns calories, which in addition to a healthy diet can help you to manage your weight.

2. More than half the body's muscles are designed for walking; it is a natural movement that is almost injury-free.

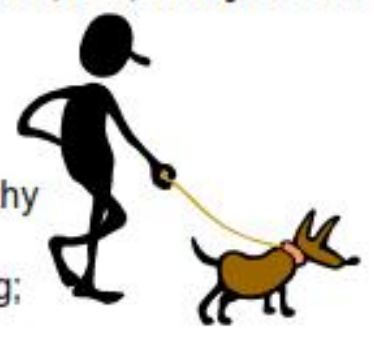

3. Regular brisk walking has many health benefits.

4. Brisk walking is an aerobic activity. It makes your heart, lungs, and muscles stronger.

5. Walking refreshes the mind, reduces fatigue, increases energy, and improves sleep.

6. Walking can be a great time for sharing and socializing with friends and family.

\section{Getting started:}

- A little walking everyday is better than an occasional weekend bout of activity. Start with short walks and build from there.

- Consider using a pedometer to measure the number of steps you walk.

- Warm-up before and cool-down after activity (see MOVE! handout P04).

- Choose routes that are interesting, safe and convenient. Avoid heavy traffic, loose dogs, and rough ground. Remember hills are more difficult.

- Walking with others can help motivate you.

- Be safe. Take a friend when it is dark outside. Tell someone where you are going, and bring a cell phone if you can.

- When it is very hot, walk during the coolest hours, choose a shady route, and walk a little slower.

- When it is cold, avoid icy surfaces.

- Dress in loose, comfortable clothing. In cold weather, dress in layers and wear mittens and a hat.

- Wear comfortable, appropriate shoes.

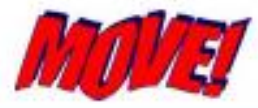


Sample 10-Week Walking Plans to get you started:

This plan is for those who are not used to physical activity.

\begin{tabular}{|l|c|c|c|c|c|c|c|c|c|c|}
\hline Week & 1 & 2 & 3 & 4 & 5 & 6 & 7 & 8 & 9 & 10 \\
\hline Minutes walking & 10 & 10 & 15 & 18 & 20 & 20 & 25 & 30 & 32 & 35 \\
\hline Walks per week & 2 & 3 & 3 & 3 & $3-4$ & 4 & 4 & 4 & 4 & 4 \\
\hline
\end{tabular}

This plan is for those who are already physically active.

\begin{tabular}{|l|l|l|l|l|l|l|l|l|l|l|}
\hline Week & 1 & 2 & 3 & 4 & 5 & 6 & 7 & 8 & 9 & 10 \\
\hline Minutes walking & 20 & 22 & 25 & 30 & 30 & 35 & 35 & 40 & 42 & 45 \\
\hline Walks per week & 3 & 3 & 3 & 3 & 4 & 4 & $4-5$ & $4-5$ & $4-5$ & $4-5$ \\
\hline
\end{tabular}

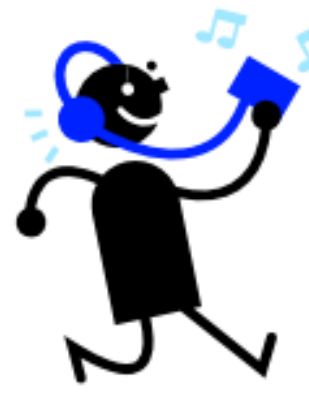

Page 2 of 2

P15 Version 3.0 


\section{Wheelchair Odometers}

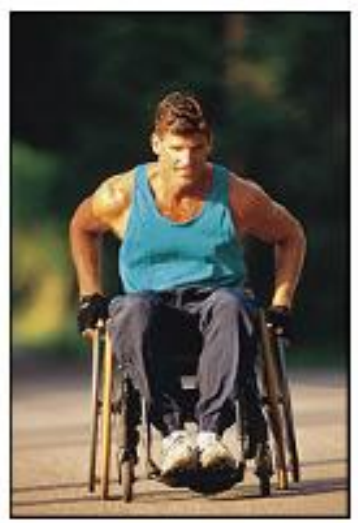

Monitoring your physical activity with a wheelchair odometer is useful for setting your personal physical activity goals. Similar to pedometers used by walkers, an odometer measures the distance covered while manually pushing yourself in a wheelchair.

\section{Installation Tips:}

- Basic digital odometers designed for bicycles can be used on wheelchairs.

- Select a "wired" as opposed to a "wireless" model. The battery will last longer.

- Follow the general instructions for bicycle mounting, but adapt them as necessary for your

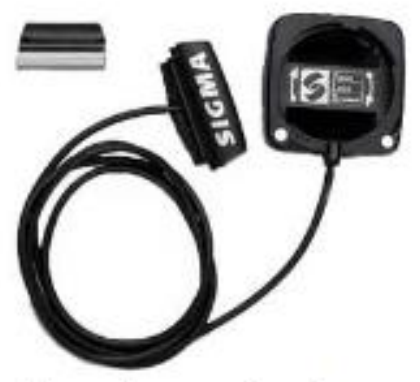
chair. For example, mount the sensor attached to the wire on the frame under the seat and run the wire along the frame to the front uprights where the display can be mounted and accessed. Most bicycle shops can help with mounting if you have difficulty.

- Before first use, all odometers should be calibrated to tire size. Follow the instructions that come with the odometer to do this. The standard wheelchair tire diameter is 24 inches. Measure your tires to be sure you enter the correct size into the odometer.

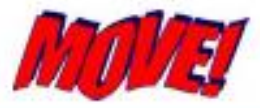


Appendix C MOVE! Handouts

\section{Using the Odometer to Track Physical Activity Progress:}

- Use the odometer every day for a week.

- At the end of each day, record your mileage covered.

- At the end of the week, total your mileage and divide by the number of days recorded. This will give you a daily average.

- You don't need to increase your activity level this first week. Simply observe how much distance you cover.

- Each week try to increase your mileage by $1 / 4$ to $1 / 2$ mile per day. For example, if you average 2 miles per day, set a goal to increase to $2 \frac{1}{2}$ miles per day the next week and 3 miles per day the week after that.

- Set realistic goals.

- Record your mileage covered each day on your Activity Log.

- 5 miles pushed in a wheelchair is approximately equal to 10,000 steps per day walking and is a great long-term goal to work towards.

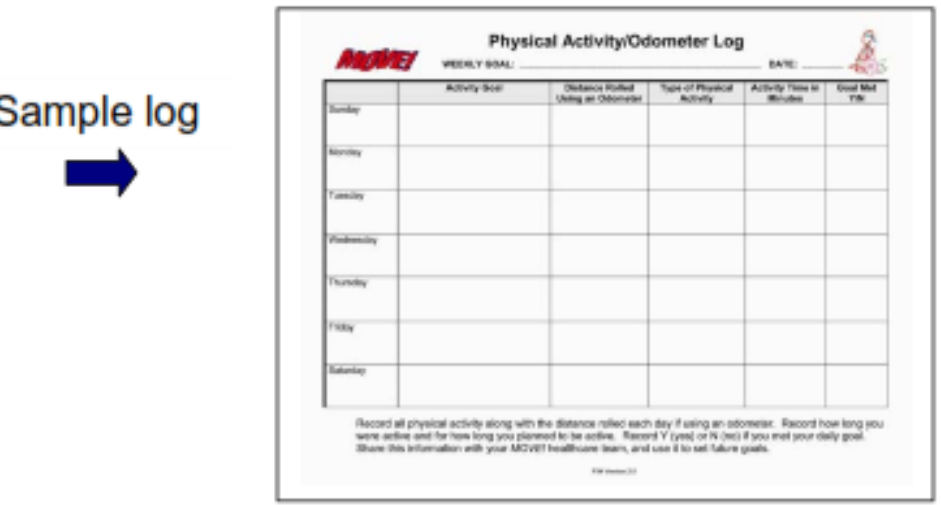




\section{Sample Stretches}

\section{Calf and hamstring stretch:}

Stand a little away from a wall or other structure and lean on it with your head on your hands as shown. Bend one leg and place your foot on the ground in front of you, with the other leg straight behind. Slowly move your hips forward, keeping your lower back flat. Keep the heel of the straight leg on the ground, with toes pointing straight ahead or slightly in. Hold the stretch for 10-30 seconds. Do not bounce. Repeat 3-5 times. Now, stretch the other leg.

\section{Ankle and Achilles tendon stretch:}

Place your left foot against a wall, with your ankle flexed and toes up as shown. Move your body forward until you feel a mild stretch in the Achilles tendon area (see arrow on picture). Hold for 8-10 seconds. This also stretches the bottom of your foot and toes. Now, stretch the other foot.

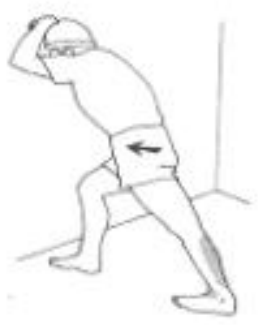

\section{Thigh stretch:}

Start with your feet a little more than shoulder-width apart. Bend your right knee slightly and move your left hip downward toward the right knee. This stretches your left inner thigh. Hold for 10-30 seconds. Repeat 3-5 times. Now, stretch the other thigh.

\section{Alternate thigh muscles stretch:}

Standing close to a wall or a chair, place one hand on the wall and with the other hand reach back and slowly pull your foot up to touch your buttocks. Hold for 10-30 seconds. Relax back to your starting position. Repeat 3-5 times. Now, stretch the other leg.
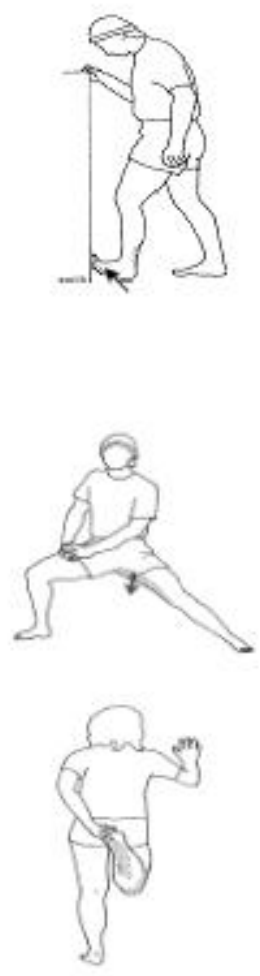
Appendix C MOVE! Handouts

\section{Lower back, hips, groin, and hamstring stretch:}

Start in a standing position with feet about shoulder-width apart and pointed straight ahead. Slowly bend forward from the hips. Keep your knees slightly bent. Let your neck and arms relax. Go to the point where you feel a slight stretch in the back of your legs. Hold this stretch for 10-30 seconds. Slowly come back to a standing position with knees bent all of the time. Repeat 3-5 times.
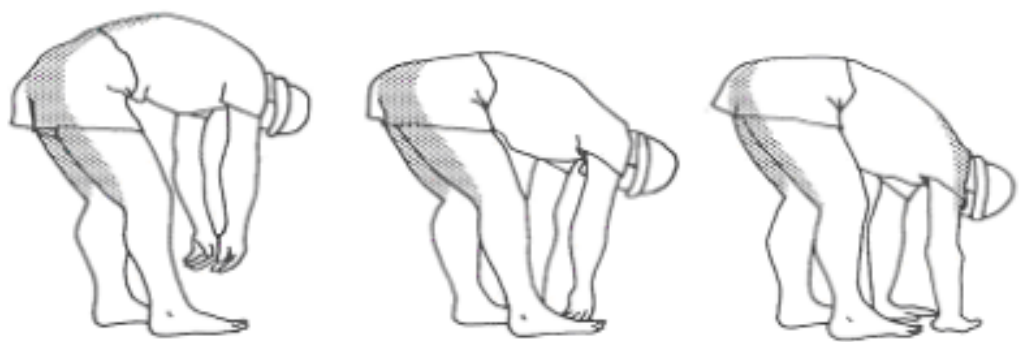

\section{Shoulder and neck stretch:}

Raise the top of your shoulders toward your ears until you feel a slight tension in your neck and shoulders. Hold for 5 seconds. Then, relax your shoulders downwards.

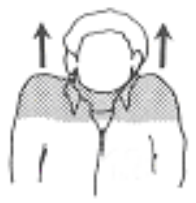

\section{Arm and side stretch:}

From a standing position, bend your knees slightly. Gently pull your elbow behind your head as you bend from your hips to the side. Hold a mild stretch for 10-30 seconds. Repeat 3-5 times. Now, stretch the other side.

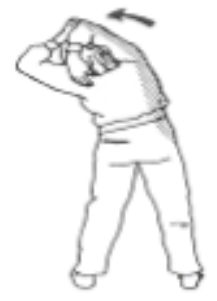

*Excerpted from Stretching, (c) 2000 by Bob Anderson. Shelter Publications, Bolinas, CA. Reprinted by permission

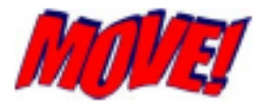




\section{Why Warm-Up, Cool-Down and Stretch?}

You can help prevent injury and reduce muscle soreness if you warm-up before and cool-down after physical activity. Warming-up prepares your muscles and heart for activity. Cooling-down slows your heart rate gradually and helps prepare your muscles for the next time you're active.

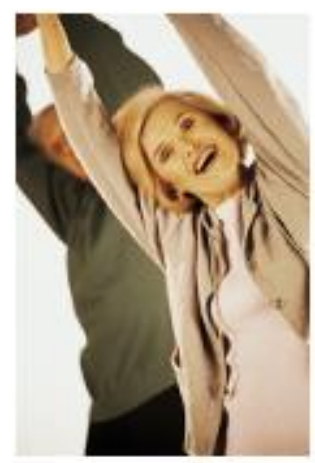

Warm-up: Warm-ups take $\mathbf{5}$ to $\mathbf{1 5}$ minutes.

1. Do your planned activity, such as walking, but at a lower intensity (slower pace) for a brief time. This may mean walking slowly for a few minutes before speeding up.

2. Do a few minutes of mild stretching if you plan to do something more vigorous than walking.

Cool-down: Cool-downs take $\mathbf{5}$ to $\mathbf{1 5}$ minutes.

1. To cool-down, continue your activity but slow down the pace for a brief time.

2. Do a few minutes of mild stretching for all activities including walking.

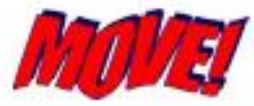


Appendix C MOVE! Handouts

\section{Stretch:}

Stretching is important for a good warm-up and cool-down and is one of the best ways to prevent and avoid muscle soreness, cramps and injury.

Here are some helpful tips on how to stretch properly:

- Do a short warm-up before stretching such as walking.

- Stretch in both directions (i.e., if you stretch to the left don't forget to stretch to the right).

- Avoid fast, jerky movements. Stretch slowly and smoothly.

- Stretch to a point where you place a mild- but not painful-stretch on the muscles. When you repeat the stretch, you should be able to stretch a little further without pain.

- Hold each stretch for 10-30 seconds. Do Not Bounce.

- Repeat each stretch 3-5 times.

- Breathe slowly in and out. Do not hold your breath.

- Relax, enjoy, and feel good about yourself.

- Stretch often, if possible every day.

Important: Never stretch if you have severe pain. If a stretch causes much pain, stop doing it, or do it more gently. Listen to your body! Sample stretches are available from your MOVE! healthcare team. 
Appendix C MOVE! Handouts

\section{Make at least half your grains "whole grains"}

- Eat at least 3 ounces of whole grains everyday.

- One ounce is 1 slice of bread, 1 cup of breakfast cereal, or $1 / 2$ cup of cooked rice or pasta.

- Look to see that grains such as wheat, rice, oats, or corn are referred to as "whole" in the list of ingredients.

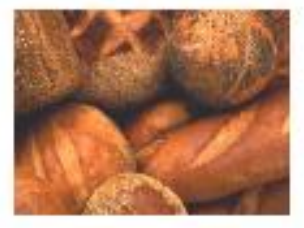

Go lean with protein

- Choose lean meats and poultry.

- Bake, broil or grill meat, poultry and fish.

- Vary your protein choices - with fish, beans, peas, nuts, and seeds.

- One serving of meat, poultry or seafood is 2-3 ounces, about the size of a deck of cards. For beans or peas, $1 / 2$ cup is a serving, and for

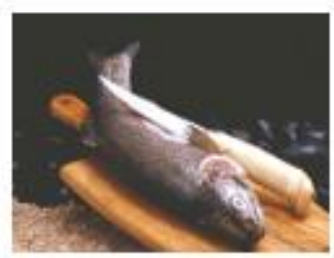
nuts and seeds, $1 / 4$ cup is a serving.

Know the limits on fats, salt, sugars, and alcohol

- Read the Nutrition Facts label on foods.

- Look for foods low in saturated fats and trans fats.

- Choose and prepare foods and beverages with little salt (sodium) and/or added sugars (caloric sweeteners like sucrose or high fructose cornsyrup).

- Limit alcohol. It just adds empty calories.

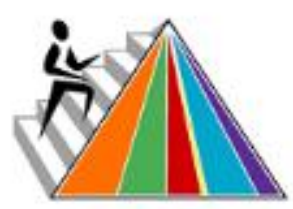

- All foods can be enjoyed in moderation once you know the limits.

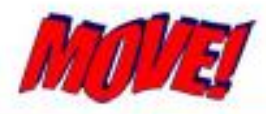




\section{All Foods Can Fit}

There are no good and bad foods. All foods can fit.

No foods are off limits.

\section{Moderation}

Eat until you are satisfied, not stuffed. Watch out for extra helpings, splurging, and "all you can eat" places.

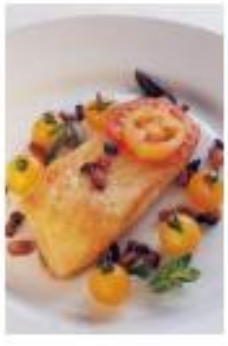

\section{Balance}

To manage your weight, balance what you eat and drink with how active you are. You should also balance foods higher in calories, fat, and sugar with choices that are lower in calories, fat, and sugar.

\section{Variety}

Choose a wide variety of foods: vegetables, fruits, whole grains, meats, poultry, seafood, eggs, beans, peas, nuts, seeds, and dairy. This helps you to get all the nutrients (vitamins, minerals, etc.) that you need. Use the following tips:

- Vary the color - aim for more than one color on your plate

- Vary the flavor - sour, sweet, bitter and salty

- Vary the texture - crunchy, soft, smooth...

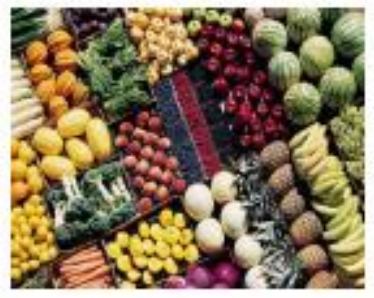

\section{Take time to enjoy what you eat!}


Appendix C MOVE! Handouts

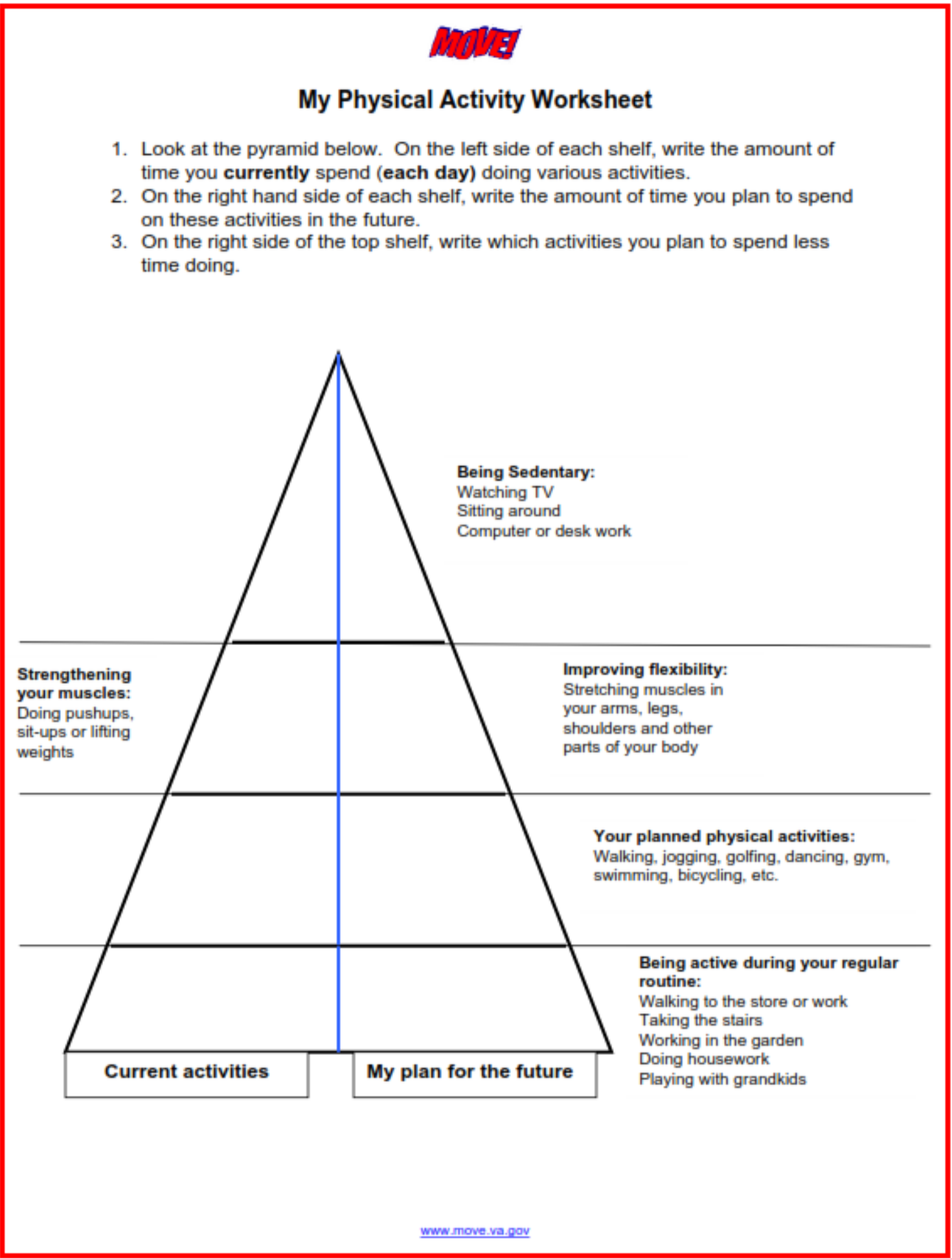


Appendix C MOVE! Handouts

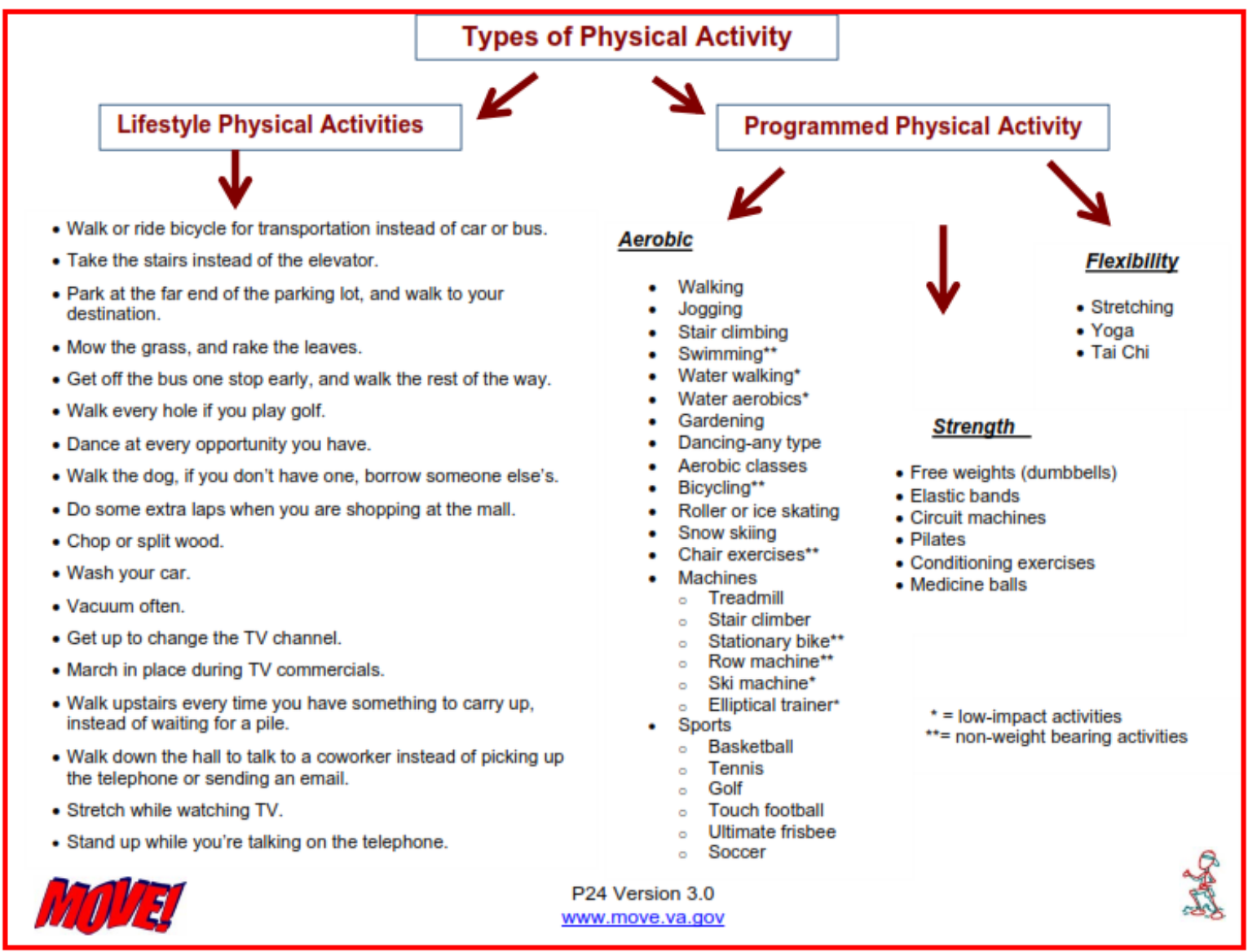


Appendix C MOVE! Handouts

\section{Barriers to Physical Activity}

Ever feel like something always gets in the way of doing physical activity? Here is a list of the more common barriers to physical activity along with ideas on how to overcome them.

Do you feel self-conscious about your weight and being seen by others? Being physically active makes you feel healthy and good about yourself almost immediately. Once you feel good, it's easy not to worry so much about how you look. You'll be surprised how supportive people will be.

Have you had little practice or a bad experience with physical activity in the past? Start slowly with something that you might like. If you joined a gym before and hated it, then try something totally different like walking with a friend or taking dance classes.

Not in the mood to exercise or have little motivation? When you exercise your mood almost always improves. Once you start moving you usually become motivated to do more because it makes you feel so good. Next time you're not in the mood, try some physical activity and you'll be amazed!

Does the hot and/or cold weather stop you from being physically active? You don't have to exercise outdoors. There are lots of activities you can do inside. You could walk the mall; get an exercise tape from the local library; use items around the house for strength training such as canned foods; join the local YMCA or other health facility; or put on some music and dance.

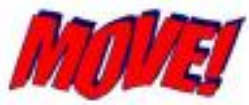


Appendix C MOVE! Handouts

\section{Do you have difficulty finding the time to be more physically active?}

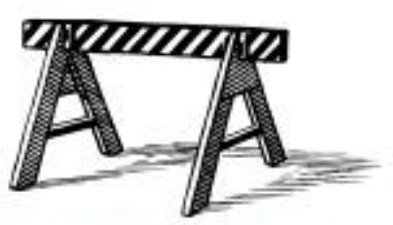

Every bit of activity helps. Spreading exercise over the day in several 10-minute bouts works just as well as exercising all at once. Add physical activity to other daily routines (for example: walk to the store, take the stairs, park farther away and walk, exercise at your desk or while watching TV).

Aren't physical activities expensive? There are lots of physical activities you can do at little or no cost. (Examples: walking, using household items for weights, working in the yard, free or low-cost community events).

Think physical activity will make your pain worse? In most cases, regular physical activity reduces pain over time.

Are you afraid of getting hurt? Learn how to warm up and cool down to prevent injury. Choose activities that have minimal risk such as walking. Consult your doctor if pain is severe or persistent.

Feel like you have no support? Ask for help from family and friends. Find a physical activity buddy.

Does stress get in the way of physical activity? This does not have to stop you from being physically active. Get help. Ask your primary care provider. 


\section{Benefits of Regular Physical Activity}

- Helps you manage your weight

- Reduces your risk of coronary heart disease

- Reduces your risk of stroke

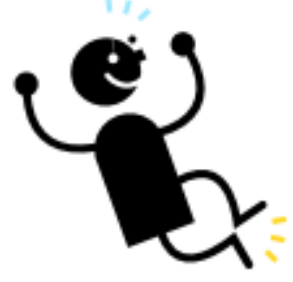

- Decreases blood pressure

- Reduces your risk of colon cancer

- Helps prevent and control diabetes

- May decrease "bad" (LDL) cholesterol and raise "good" (HDL) cholesterol

- Helps you sleep better

- Strengthens bones and helps prevent injury

- Increases muscular strength and endurance

- Increases flexibility and range of motion

- Improves your mood

- Helps with stress and depression

- Improves self-esteem

- Makes you feel better 


\section{Physical Activity Pyramid}

\section{Be creative in finding ways to stay active!}

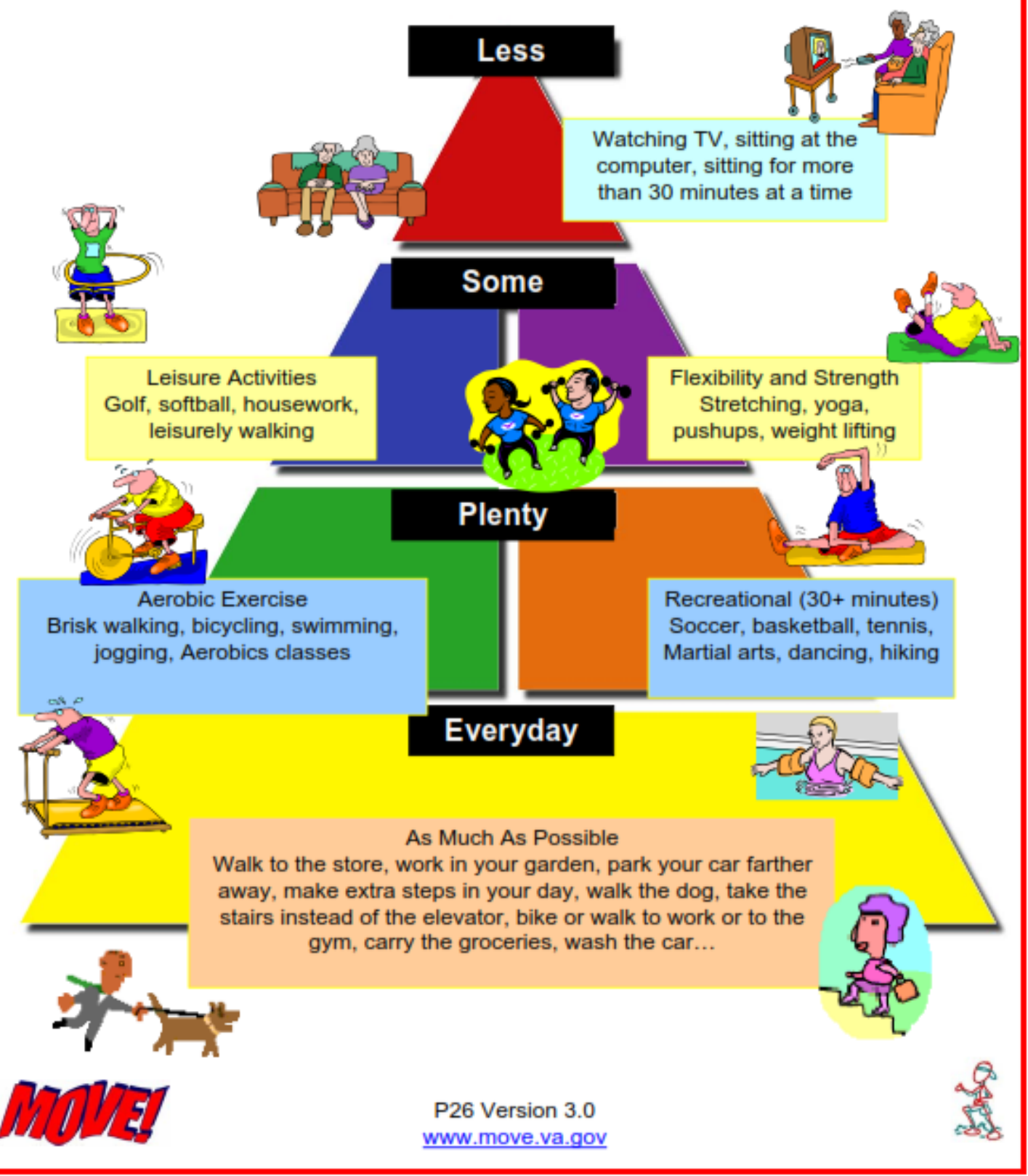


Appendix C MOVE! Handouts

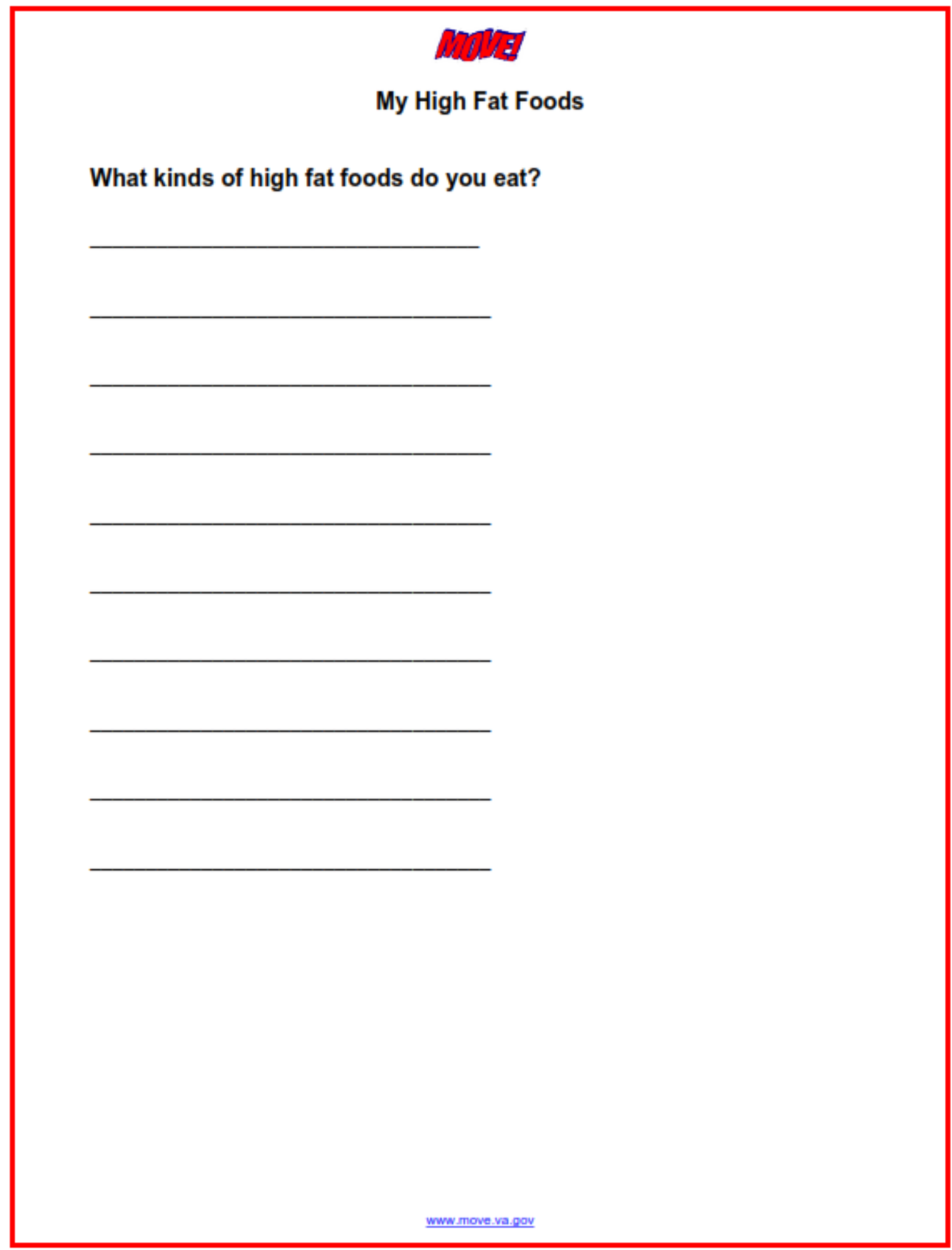


Appendix C MOVE! Handouts

\section{ander}

\section{My Plan to Trim the Fat}

- Write down your top 5 high fat foods

- Complete the table

- Circle one food and one of the three ways to eat less fat from that food

- Make this a goal for the next week

\begin{tabular}{|l|l|l|l|}
\hline $\begin{array}{l}\text { My top } 5 \text { high-fat } \\
\text { foods }\end{array}$ & $\begin{array}{l}\text { Choose one of the three ways to trim the fat for } \\
\text { each of your high fat foods }\end{array}$ \\
\hline & $\begin{array}{l}\text { I will eat this food } \\
\text { less often: } \\
\text { (Set a limit) }\end{array}$ & $\begin{array}{l}\text { I will eat less of this } \\
\text { food: } \\
\text { (Set an amount) }\end{array}$ & $\begin{array}{l}\text { I will eat this food } \\
\text { instead: }\end{array}$ \\
\hline & & & \\
\hline & & & \\
\hline & & & \\
\hline & & & \\
\hline
\end{tabular}




\section{Fat Out..... Flavor In}

A little fat goes a long way. One teaspoon of butter or oil has $\mathbf{5}$ grams of fat and about $\mathbf{4 5}$ calories. Check out these tips to cut fat and add flavor:

- When eating out, ask for the topping or sauce to be put on the side. Ask for lower fat options like salsa, mustard, or ketchup.

- With salads, choose fat free/reduced fat dressings, flavored vinegar, or lemon juice. Ask for the dressing to be served on the side.

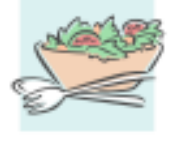

- Pick lean cuts of meats, poultry, and seafood. Trim away any fat or skin.

- Cook foods without adding fat. Use nonstick cooking spray instead of butter, margarine, or oil when grilling, frying, or sautéing. Use non-stick cookware. You can sauté in a small amount of broth. If you do add fat, use a small amount of olive or canola oil.

- Choose to bake, roast, grill, steam, poach, or pan sauté instead of frying. If roasting or baking in the oven, use a rack to raise the food up off the bottom of the pan to allow the fat to drip away.

- Instead of using ham hock or fatback to season vegetables, use lean ham or broth to get the meat flavor.

- Use napkins or paper towels to blot out extra fat from foods. This helps with pizza or fried foods.

- Taste your food before spreading on butter or margarine. Choose another topping. Try using fruit butter or low sugar spreadable fruit on toast.

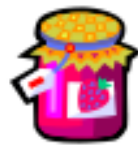

The MOVE! handouts, "Spice It Up" and "Recipe Smart Substitutions", will give you more ideas on how to cut fat and add flavor. 


\section{What Are The Types Of Fat?}

Limiting your fat intake is key to losing weight. Healthy eating includes small amounts of fats, but some fats are much healthier than others. Eating monounsaturated or polyunsaturated fats instead of saturated or trans fats may help improve your blood cholesterol.

\section{Good Fats}

Monounsaturated:

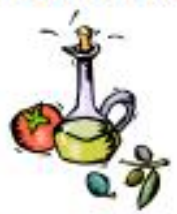

Polyunsaturated:

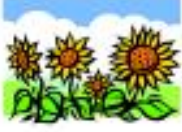

\section{Bad Fats}

Saturated:
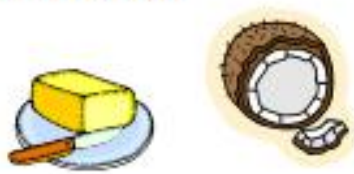

Hydrogenated:
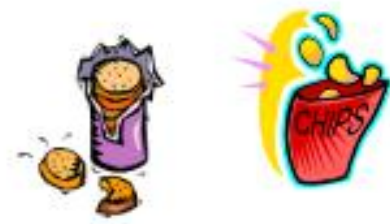

Canola, olive, nut and peanut oils (use these fats for cooking); peanuts; nuts; avocado; olives

Most vegetable oils (corn, cottonseed, flaxseed, safflower, sesame, soybean, sunflower), nuts, seeds, peanuts, fish

Animal sources such as meat, poultry, butter, lard, whole and reduced fat dairy products; tropical oils - coconut, palm and palm kernel Saturated fats are solid at room temperature

Many fats used in processed foods, snack foods, stick margarine, vegetable shortening; Read the ingredients list for shortening, "partially hydrogenated vegetable oil" (A liquid vegetable oil is changed to a solid fat by a chemical process.) *May be labeled as trans fat 


\section{Sodium}

What is sodium? It is a mineral found naturally in food.

Why do we need it? Our bodies need sodium to maintain fluid balance, control blood pressure, keep our nerves working, and help our muscles relax.

\section{How much do we need?}

- 500 milligrams $(\mathrm{mg})$ of sodium ( $1 / 4$ teaspoon of salt) per day

- 1 teaspoon of salt has $2,000 \mathrm{mg}$ of sodium

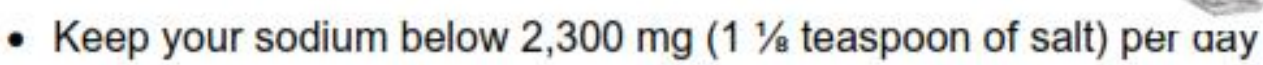

\section{How can you control your sodium intake?}

- Read the Nutrition Facts Label to look for sodium.

- Food that is pre-packaged or processed (food that comes in cans, boxes, or packages) is higher in sodium. Try to buy foods lower in sodium or that have "No Added Salt".

- Try to avoid adding salt while cooking and at the table.

- Always taste your food before adding salt.

- Season your food with herbs, spices, salt-free seasoning, vinegar, or lemon juice instead of salt.

Some people are very sensitive to sodium; their

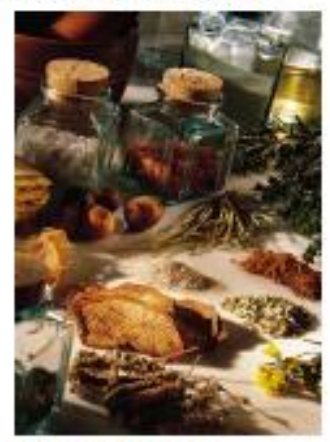
blood pressure may go up with added salt and salty foods. These individuals should be careful not to have too much sodium.

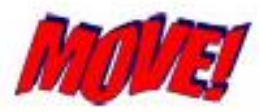




\section{Old Habits Die Hard}

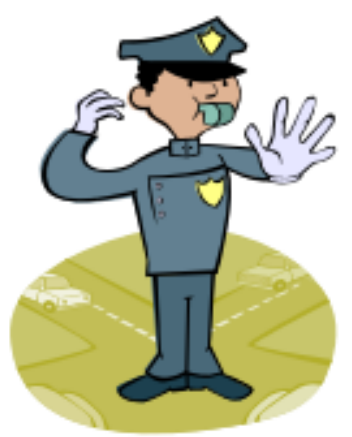

You can bury bad habits. Replace old bad habits with new, healthy habits. Here are some tips:

- Become aware of your actions. When you realize what you are doing, you can change it.

- Keep a record of what you want to change. If you write it down, you are more likely to change it. If your new plan does not work, try something else.

- Avoid situations that trigger bad habits, such as eating in front of the TV.

- Post reminders about healthy habits where you will notice them...on the refrigerator, on the table, in your car, on the bed, wherever.

- Practice makes permanent.

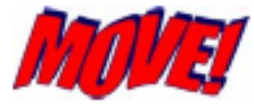


Appendix C MOVE! Handouts

\section{F.I.T.T - Frequency, Intensity, Time, and Type of Activity}

When you put all that effort into increasing physical activity you want results. By following the FITT idea you can be sure that you are working towards managing your weight and improving your health.

\begin{tabular}{|c|c|}
\hline $\begin{array}{l}\text { Frequency } \\
\text { How often you are } \\
\text { active }\end{array}$ & $\begin{array}{l}\text { - Increase frequency slowly. } \\
\text { - Build to being active } 5 \text { or more days of the week. }\end{array}$ \\
\hline $\begin{array}{l}\text { Intensity } \\
\text { How hard your heart } \\
\text { and muscles are } \\
\text { working during activity }\end{array}$ & $\begin{array}{l}\text { - Be active at a moderate intensity similar to a brisk } \\
\text { walk. } \\
\text { - Be active at a rate that allows for talking. } \\
\text { - Slow down if you have trouble breathing or feel you } \\
\text { can't catch your breath. }\end{array}$ \\
\hline $\begin{array}{l}\text { Time } \\
\text { How long you are active }\end{array}$ & $\begin{array}{l}\text { - Try to stay active for at least } 10 \text { minutes without } \\
\text { stopping. } \\
\text { - Aim for at least } 30 \text { minutes of activity throughout the } \\
\text { day. } \\
\text { - Set a goal for the week based on total minutes of } \\
\text { physical activity. } \\
\text { - Increase the length of time you are active before } \\
\text { increasing the intensity of the activity. }\end{array}$ \\
\hline Type of activity & $\begin{array}{l}\text { - Unless you have been instructed otherwise, do } \\
\text { aerobic activities (these make your heart beat faster - } \\
\text { walk briskly, bike, swim, dance). } \\
\text { - Use large muscle groups (such as legs and arms). } \\
\text { - Always warm-up, cool-down and stretch. } \\
\text { - Try to also include strength and flexibility activities. }\end{array}$ \\
\hline & $\begin{array}{c}\text { S07 Version } 3.0 \\
\text { www.move.va.gov } \\
\end{array}$ \\
\hline
\end{tabular}




\section{How Hard Should I Exercise?}

Increasing physical activity improves health and fitness. It is also a key to success with weight management. What is easy for one person is hard for another. Listen to your body. You are the best judge of how hard you should exercise. Start slowly with easy activities and build to those that are harder. Here are some terms you are likely to hear.

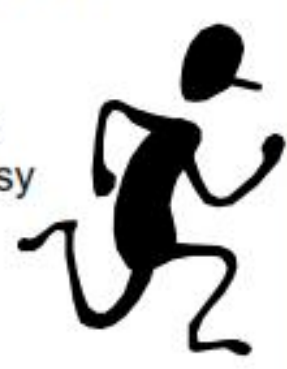

\section{Moderate-Intensity Physical Activity}

- This is how hard you need to exercise for health benefits.

- Physical activities that make you breathe a little harder and make you sweat lightly.

- Activities you feel you could do for up to 45 minutes. This does not mean that you have to do the activity for this long - just that you feel you could.

- Examples might be brisk walking, slow cycling, dancing, and hard house/yard work.

\section{Vigorous-Intensity Physical Activity}

- Physical activities that make you breathe hard, make your heart beat fast, and make you sweat.

- Examples include running, aerobics classes, swimming laps and racquet sports. 
Appendix C MOVE! Handouts

\section{Use the following "Talk Test" or the "Borg Scale" to help you decide if you are exercising at the right intensity:}

Talk Test: If you are exercising at a moderate intensity, you should be able to carry on a conversation comfortably while still exercising. If you cannot carry on a conversation comfortably, you are exercising at a vigorous intensity. If you are just starting to exercise, begin with moderateintensity activities.

Borg Scale: Use this scale to rate how hard you are exercising. Aerobic activities, like walking and cycling should be done at level 13 (somewhat hard). Strength activities, like lifting dumbbells and pushups should be done at levels 15-17 (hard to very hard). You can gradually make activities harder as you become more fit. Activities that used to be hard will become easier over time and earn a lower score compared to when you first started. For example, slow walking on level ground may be a level 13 effort for you in the beginning. As your fitness improves, it may take brisk walking up a slight hill to get to that same level 13 effort.

\begin{tabular}{|c|c|c|}
\hline \multicolumn{3}{|c|}{ The Borg Category Rating Scale } \\
\hline \multicolumn{3}{|c|}{ Least Effort } \\
\hline 6 & \multirow{3}{*}{ very, very light } & \\
\hline 7 & & \\
\hline 8 & & \\
\hline 9 & \multirow[t]{2}{*}{ very light } & \\
\hline \multicolumn{2}{|l|}{10} & \\
\hline 11 & \multirow{4}{*}{$\begin{array}{l}\text { fairly light } \\
\text { somewhat hard }\end{array}$} & 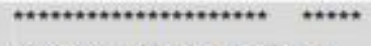 \\
\hline 12 & & \multirow{3}{*}{ Aerobic Training Zone } \\
\hline 13 & & \\
\hline 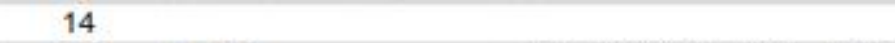 & & \\
\hline 15 & \multirow[t]{2}{*}{ hard } & 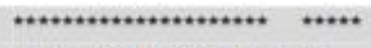 \\
\hline 16 & & Strength Training Zone \\
\hline 17 & \multirow[t]{2}{*}{ very hard } & 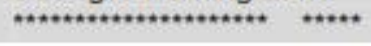 \\
\hline 18 & & \\
\hline 19 & \multicolumn{2}{|l|}{ very, very hard } \\
\hline \multicolumn{3}{|l|}{20} \\
\hline Maximu & & \\
\hline
\end{tabular}




\section{Making a Good Fit! Shoes for Active Feet}

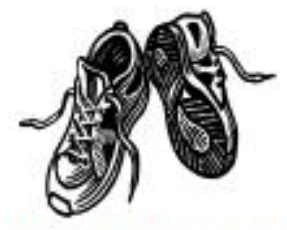

Whatever the activity, wearing the right kind of shoe is very important for your comfort and safety. Here are some helpful tips:

- Shop around for various styles and brands. Ask the salesperson to assist you in choosing the shoe best suited for your specific activity.

- When trying on new shoes, wear the kind of socks you will wear when you are active. Wear cotton socks or athletic socks. Discard worn out socks to prevent blisters.

- Your feet swell slightly during activity. So, when shopping for new shoes, go right after you have been active.

- Try new shoes on and walk around. They should feel comfortable right away.

- There should be one thumb's width of space between your longest toe and the end of the shoe.

- The heel should not pinch or slip when you walk.

- The shoes should bend easily at the ball of your feet just behind your toes.

- After exercising look at your feet to be sure you do not have any sores, cuts, or blisters. Tell your primary care provider about any cuts, sores, or blisters that don't heal.

- Replace shoes when soles (bottom) are worn or slick. You can replace just the shoe inserts (inside cushions) when worn, if the rest of the shoe is in good shape.

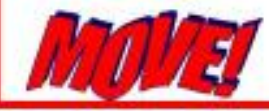




\section{Physical Activity and Your Safety}

If you are diabetic or have heart or lung disease, check with you primary care team before beginning a physical activity program.

\section{General safety tips:}

- Carry identification, emergency contact information and illness information.

- Drink water before, during and after exercise.

- Let someone know where you are going and how long you'll be gone.

- Carry a cell phone if you have one.

- Prepare for the weather.

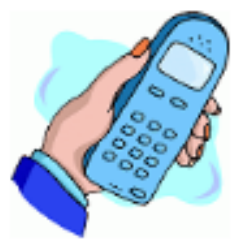

- Wear comfortable, good fitting socks and shoes suitable for physical activity.

- Dress to be seen. Wear bright colored clothing. In poor light, wear safety reflective materials designed for improving your visibility to drivers.

- Use a familiar route.

- Be active in public places.

- Avoid isolated trails, paths and poorly lit areas.

- When approaching another walker or jogger from behind, give a verbal warning before passing them. 


\section{Tips for Cold Weather Physical Activity}

Cold weather doesn't have to slow you down. To stay safe in the cold, keep the following in mind:

\section{Dress Properly}

The layered look

- Start with a synthetic material like polypropylene against your skin. This will draw the sweat away from your body and dry quickly.

- The second layer should be wool or cotton to soak up moisture.

- The third layer should be chosen for its ability to keep the cold air and rain out, if necessary -- something lightweight and artificial, such as Gore -Tex ${ }^{\mathrm{TM}}$ material.

\section{Don't lose your head}

- You can lose a tremendous amount of heat through your uncovered head, so always wear a hat or cap.

- Your feet get cold first. Insulate them with warm socks and keep them dry.

- Choose mittens over gloves because the fingers can warm each other.

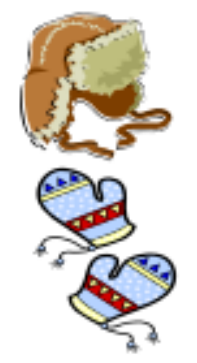

Drink Up - You can become dehydrated in the cold

- Drink before you feel thirsty. By the time you feel thirsty, you're already dehydrated.

- Water is easily available, inexpensive, and exactly what your body needs.

- Drink water before you go out and bring some with you.

\section{Don't Overdo It}

- Cold is a stress on the body. So is exercise. Together they may be too much. Start slowly and don't overdo it.

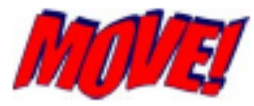




\section{Warm Weather Exercise Guidelines}

You should take extra care when exercising in warm weather. The following tips will keep you safe in the heat:

- Exercise in the early morning or after the sun sets. Avoid mid-day.

- Take frequent rest and water breaks.

- Drink water before you feel thirsty. By the time you feel thirsty, you are already dehydrated. This is especially true as you get older.

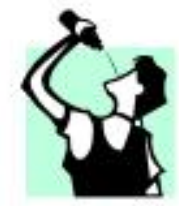

- Avoid beverages with alcohol and caffeine because these can cause dehydration.

- Drink fluids before, during, and after exercise.

- Choose water or a low calorie sports drink.

- Wear light, loose fitting clothing, made of breathable fabric in light colors.

- Reduce speed or distance as needed.

- Exercise indoors during ozone alerts, extreme heat, and very high humidity.

- Listen to your body...Stop if you feel chest pain, short of breath, dizzy, lightheaded, weak, very fatigued, nauseated, or that your heart is pounding.

- Use sunscreen, hats, and sunglasses. 
Appendix C MOVE! Handouts

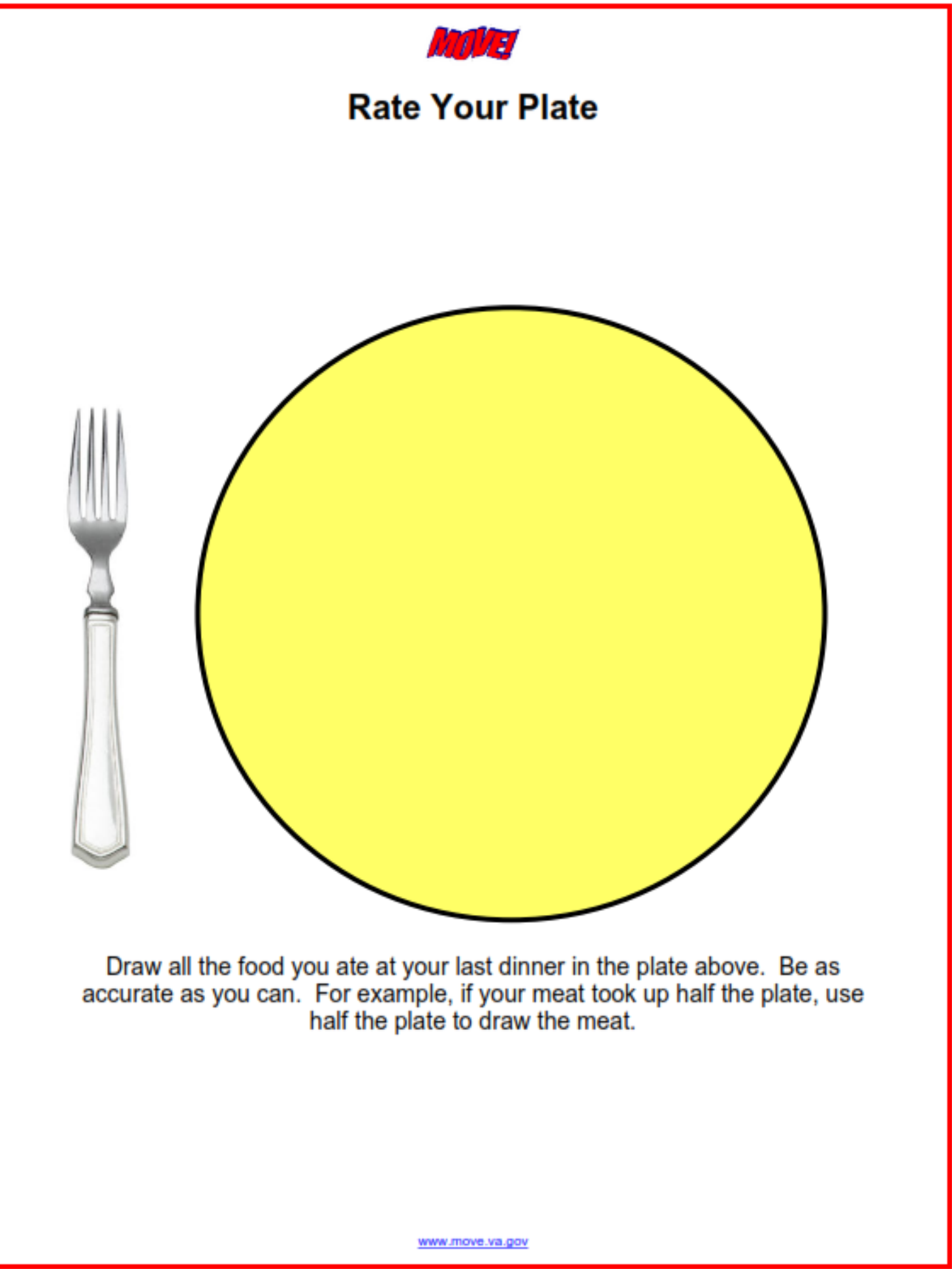




\section{How to Read a Food Label}

Reading the label will help you make smart food choices and get the most nutrition out of calories in order to reach your goals!

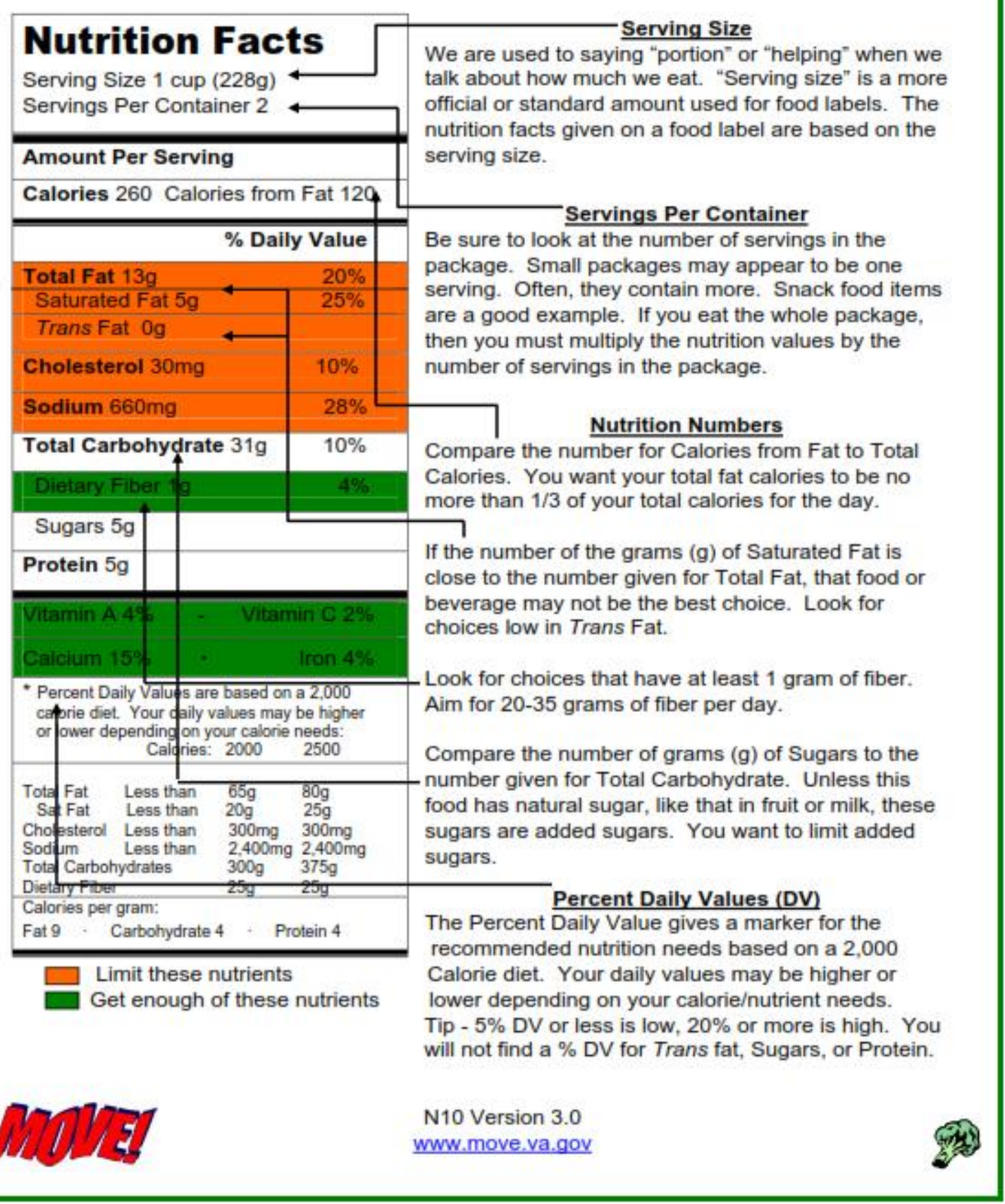




\section{Serving Sizes}

\section{Use familiar objects to judge a single serving size.}

$1 / 2$ cup vegetable

$1 / 2$ cup cooked pasta

$1 / 2$ cup of beans

1 small baked potato

1 medium piece of fruit

1 cup of raw vegetables

1 cup dry cereal

1 cup of lowfat yogurt or milk

1 small bagel

1 small (4-4 1/2 inch) pancake

2 ounces of cheese

2-3 ounces of meat, poultry or fish
Computer mouse

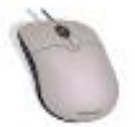

Tennis ball

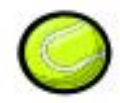

Baseball or your fist

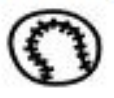

Hockey puck
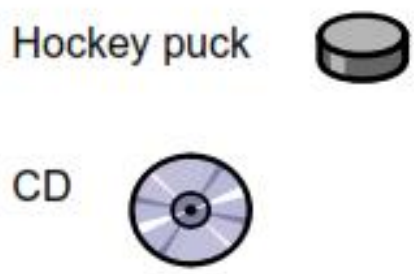

2 Pair of dice

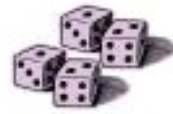

Deck of cards or the palm of your hand

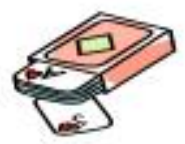




\section{Healthy Plate}

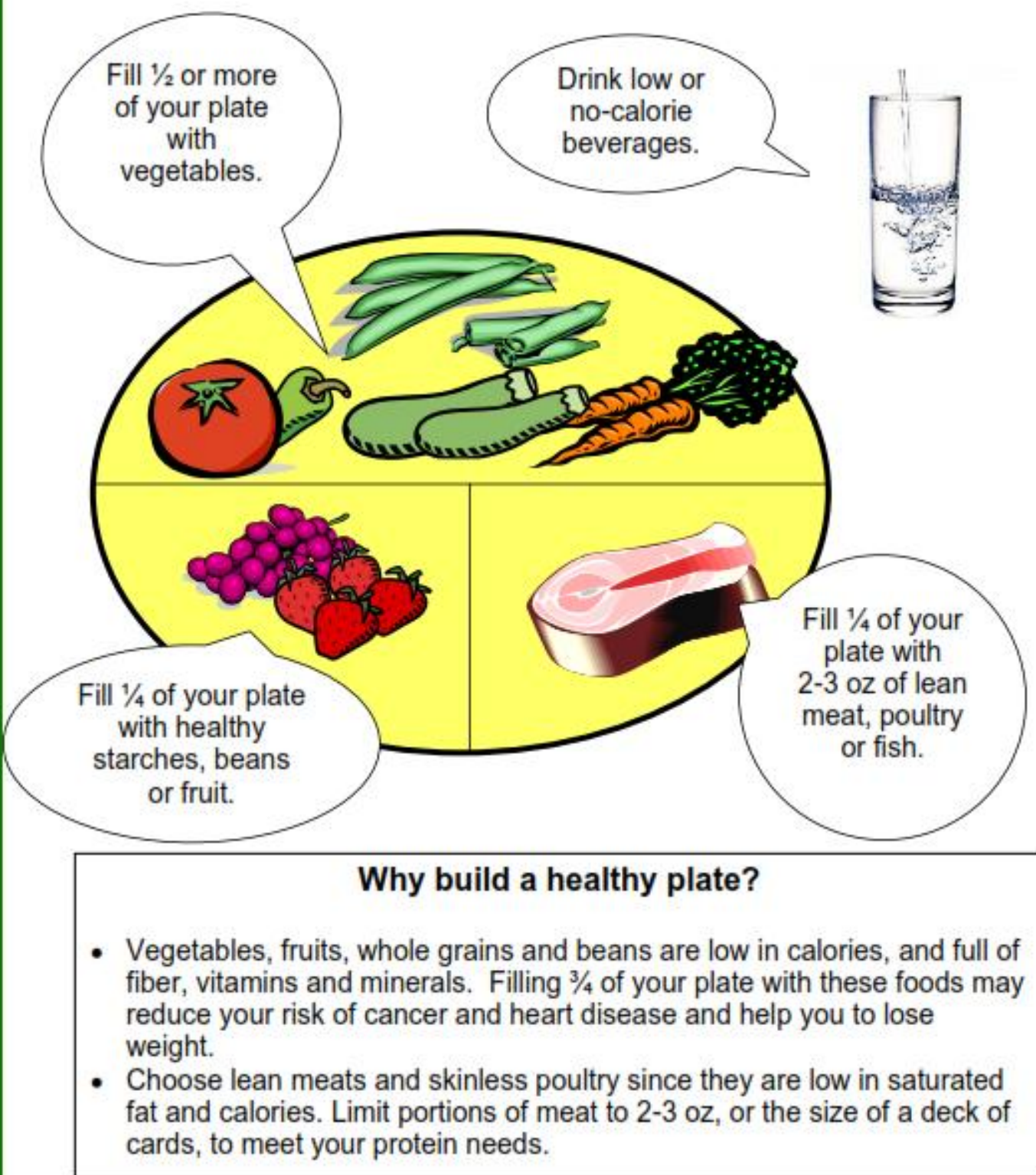




\section{Irrational Ideas About Eating}

There are many myths about eating and food. Sometimes, these strongly held beliefs get in the way of changing your eating.

\section{Here are a few myths:}

1. I MUST eat everything on my plate.

2. I MUST eat when it is time for breakfast, lunch, or dinner.

3. I MUST eat a big dinner in the evening.

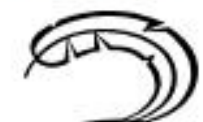

4. I MUST have 3 meals a day.

5. I MUST eat until I am very full or else I will not be OK.

6. I MUST have something to eat to feel better emotionally.

7. I MUST eat it all quickly or I will starve.

8. I MUST have meat at every meal, or at least every day! "Where's the BEEF?"

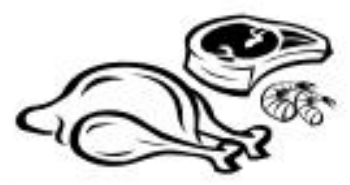

9. I MUST eat when others are eating.

10. I MUST eat the food that somebody has fixed for me or else they will think I don't like them any more. 


\section{Lose Weight By... Planning Ahead!!!}

- Set your physical activity and eating goals in advance.

- Plan your menu for the week.

- Go to the grocery store with a list. Stick to the list!

- Eat before going to the grocery store.

- Fix your plate in the kitchen and bring it to the table to eat. Leave the serving bowls in the kitchen.

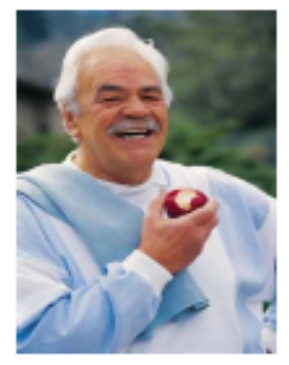

- Plan to drink plenty of low calorie fluids with your meals and throughout the day.

- Choose restaurants with healthy options.

- Don't go to a social event on an empty stomach.

- Pack a healthy meal and/or snacks for work or travel.

- Make time for physical activity. Ten-minute blocks make a difference.

- Plan a physical activity that you are likely to enjoy.

- Look for a physical activity class or group you can join.

- Find out about and join in local physical activity events in your community.

- Consider activities you can do throughout the day ... take the stairs, park farther away, walk to the store, or clean your home. 


\section{Eating at Home}

- Take charge. Plan for healthy meals and snacks.

- Never eat out of boxes, cartons, or bags unless they are single-serving packages.

- Put food on a plate or in a bowl. Then, you can see how much you are eating.

- Use smaller plates, bowls, or glasses.

- Be careful of tasting or nibbling while you cook.

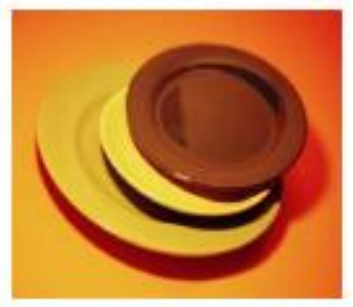

- Sit at the table to eat.

- Fix your plate in the kitchen and bring it to the table to eat. Leave the serving bowls, pots, or containers in the kitchen so you won't be tempted to eat more.

- Let leftovers be leftovers.

- Eating while watching television, working on the computer, or talking on the phone may cause you to overeat.

- Take time to relax and enjoy your food! You can find pleasure from both preparing and eating.
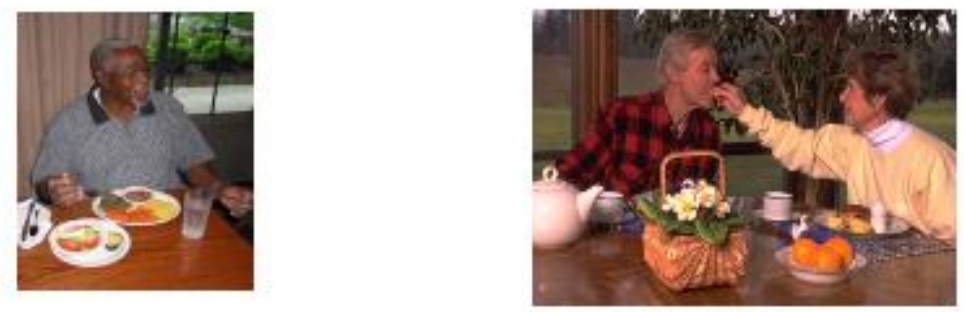
Appendix C MOVE! Handouts

\section{Eating Well on a Budget}

\section{Healthy eating does not have to be expensive. Here are some tips for keeping your calories and budget in balance:}

- Plan your weekly menu in advance. Make a grocery list and stick to it.

- Checkout the weekly ads for the supermarkets with the best sales.

- Clip coupons. Choose only ones that you will use and are a real

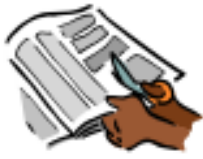
cost-saver.

- Try not to shop when you are hungry.

- Compare store and generic brands for the best buy.

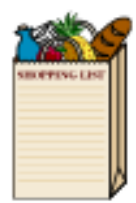

- Take advantage of sales. Cook in bulk and freeze or use leftovers for future meals.

- Stretch costly meals (like meat dishes) by adding lots of vegetables.

- Read food labels to get the best nutrition and the most value for your money.

- Choose fresh fruit and vegetables that are in season. Visit your local farmers market for produce.

- Fruit and vegetables are canned or frozen at the peak of freshness. Choose fruit that is frozen, unsweetened or canned in its own juice.

- Beans, peas, eggs, canned tuna (packed in water) and peanut butter are good sources of protein and good buys.

- Grow your own vegetables, fruit or herbs.

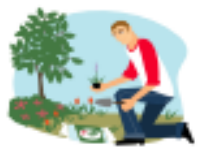




\section{Fast-Food Alternatives}

Instead of these:

Choose these:

\begin{tabular}{|c|c|}
\hline $\begin{array}{l}\text { French fries or curly fries } \\
\text { Potato wedges } \\
\text { Hash browns or tater tots } \\
\text { Onion rings }\end{array}$ & $\begin{array}{l}\text { Baked potato } \\
\text { Salads with fat free } \\
\text { or lowfat dressing } \\
\text { Fresh fruit }\end{array}$ \\
\hline $\begin{array}{l}\text { Large hamburgers with all the 'fixins' } \\
\text { Cheeseburgers } \\
\text { Hotdogs or sausages } \\
\text { Bologna, pastrami } \\
\text { Fried meat sandwich } \\
\text { Pork barbecue sandwich with slaw } \\
\text { Chicken, tuna or egg salad sandwiches }\end{array}$ & $\begin{array}{l}\text { Turkey, roast beef or lean ham } \\
\text { sandwich } \\
\text { Grilled chicken sandwich } \\
\text { Chicken tacos }\end{array}$ \\
\hline $\begin{array}{l}\text { Fried chicken } \\
\text { Breaded chicken strips } \\
\text { Fried chicken wings }\end{array}$ & $\begin{array}{l}\text { Grilled, roasted or smoked } \\
\text { poultry (white meat, no skin) }\end{array}$ \\
\hline $\begin{array}{l}\text { Fried fish sandwich } \\
\text { Fried fish nuggets } \\
\text { Fried clam strips }\end{array}$ & $\begin{array}{l}\text { Broiled seafood platter } \\
\text { Boiled shrimp }\end{array}$ \\
\hline $\begin{array}{l}\text { Sundaes, Banana splits } \\
\text { Cakes } \\
\text { Brownies } \\
\text { Pies }\end{array}$ & $\begin{array}{l}\text { Soft serve ice cream cone } \\
\text { Lowfat frozen yogurt }\end{array}$ \\
\hline $\begin{array}{l}\text { Regular soda } \\
\text { Whole milk } \\
\text { Sweet tea } \\
\text { Fruit punch, lemonade }\end{array}$ & $\begin{array}{l}\text { Water } \\
\text { Diet soda and unsweetened tea } \\
\text { Lowfat or fat free milk } \\
100 \% \text { juice }\end{array}$ \\
\hline
\end{tabular}

Tips for ordering:

- Leave off the cheese and hold the mayo

- Don't super-size

- Say "No" to "Would you like fries with that?"

- Choose baked, broiled, or grilled options rather than fried

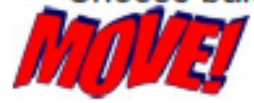




\section{Restaurant Tips}

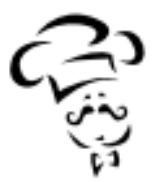

- Choose restaurants you know will have healthy options. Many restaurants have websites. Check out menus in advance.

- You don't have to eat it all - ask for part of your meal to be packaged to go.

\section{Food preparation}

- Don't be afraid to ask how items are prepared.

- Ask for lowfat cooking spray or little or no butter or oil to be used.

- Look for choices that are roasted, poached, steamed, baked, and grilled rather than sautéed, deep fried, or pan fried. If it is sautéed, ask for wine or lemon juice to be used. If you do eat fried foods, remove any breading and skin.

- Ask for sauces on the side.

\section{Appetizers - Choose Soup or Salad}

- Choose clear broth soups or tomato-based soups.

- Avoid cream-based choices such as a bisque, chowder or cheese soup.

- Avoid salads that contain fried foods. Ask for poultry, meat, or seafood to be grilled.

- Ask for fat free or lowfat dressing. Always ask for the dressing to be put on the side, not tossed in the salad. Try vinegar or lemon juice on your salad.

- Leave off extras like croutons, cheese, egg, nuts, fried noodle strips, etc.

\section{Entrée}

- When choosing vegetarian choices, avoid cheese, cream, etc.

- Select skinless poultry, preferably white meat, and lean cuts of beef and pork such as tenderloin, London broil or filet mignon. Avoid ribs, prime rib, and other marbled meats.

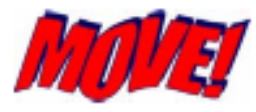


Appendix C MOVE! Handouts

Sides

- Choose colorful vegetables.

- Skip the creamed vegetables or those that have cheese.

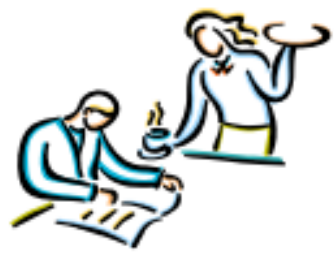

- Be adventurous. Try something new instead of the old stand-by of French fries.

- Choose fresh fruit or a tossed salad over potato salad, coleslaw, macaroni salad, etc.

\section{Beverages}

- Drink plenty of water or low calorie sugar-free beverages with your meal.

- Consider lowfat or skim milk.

\section{Dessert}

- Order fresh fruit.

- Choose a small bowl of lowfat ice cream, sorbet, sherbet, gelatin or a piece of angel food cake.

- If you order dessert, split it with someone else.

\section{Bread}

- If bread is too tempting for you, ask your server not to bring the basket to your table.

- Limit bread to 1-2 slices per meal. Choose baked bread, rolls, and saltine crackers instead of croissants, biscuits, and cornbread.

- Leave off butter or margarine. For toast, ask for it 'dry'.

Eat slowly. Take plenty of time to savor the food's flavor. Enjoy yourself!

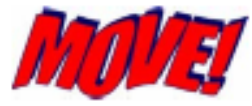




\section{Activities to Fit Your Lifestyle}

Exercise does not have to be planned. Think of all the ways you can be active during your day.

-Walk or ride a bike for transportation.

- Take the stairs instead of the elevator.

- Park at the far end of the parking lot and walk.

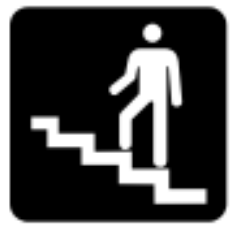

- Get off the bus one stop early and walk the rest of the way.

-Walk your dog, or borrow someone else's dog.

- Take a brisk walk while you are shopping at the mall.

-Walk to your mailbox.

-Mow the grass. Rake the leaves. Weed the garden.

-Dance whenever you can.

-Wash your car.

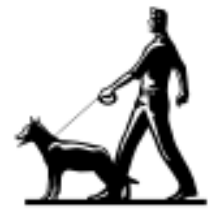

-Vacuum or sweep the floor often.

- Get up to change the TV channel, don't use the remote.

- March in place during TV commercials.

- Stretch or do chair exercises while watching TV.

-Stand up and step in place while using the phone.

-Walk down the hall to talk to a coworker instead of using the phone or sending an email.

- On work breaks, take a 5-10 minute walk.

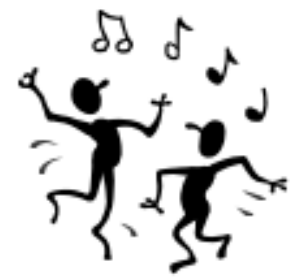

- If you play golf, walk every hole. 
Appendix C MOVE! Handouts

\section{ARDIS \\ Planning Ahead Worksheet}

List 5 ways you can plan ahead to help reach your weight loss goals:

1.

2.

3.

4.

5.

Identify a healthy weekly reward for achieving these goals: 
Appendix C MOVE! Handouts

\section{navg}

\section{Physical Activity Recall Worksheet}

Write down everything you did yesterday (for example: times of the day you spent watching TV, eating, walking, shopping, sitting, exercising, sleeping etc.).

\begin{tabular}{|l|l|}
\hline Time & \multicolumn{1}{c|}{ Activity } \\
\hline & Got out of bed \\
\hline & \\
\hline & \\
\hline & \\
\hline & \\
\hline & \\
\hline & \\
\hline & \\
\hline & \\
\hline & \\
\hline & \\
\hline & \\
\hline & \\
\hline & \\
\hline & \\
\hline & \\
\hline
\end{tabular}




\section{Eating With Others}

Eating healthy with others can sometimes be difficult. Here are some tips:

- Concentrate on the conversation and the company of the people you are with. Tell yourself that you are there because of the company, not just the food.

- Take your time eating your food. Enjoy the TASTE, and savor every bite.

- Put your fork down in between every bite.

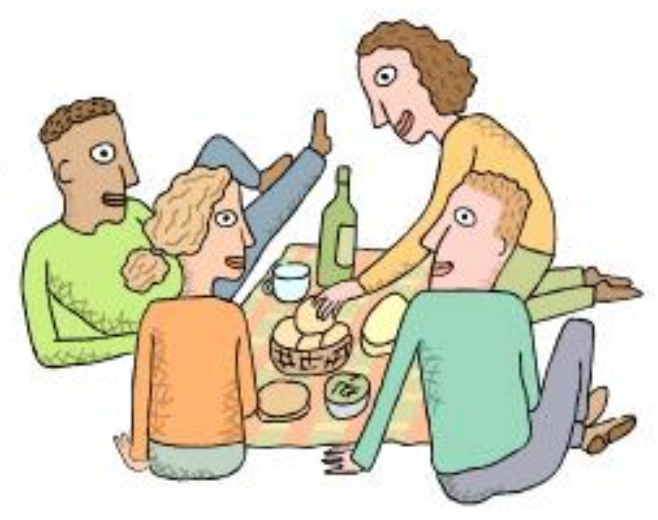

- Spend more time talking than eating.

- Drink lots of water or another calorie-free beverage with your meal.

- Let others know you are eating healthier. Ask for their support.

- Try eating a small healthy snack before dining with other people so that you are not tempted to overeat.

- Always remember that you have ultimate control over what you eat. 
Appendix C MOVE! Handouts

\section{Control Yourself!}

You CAN learn to control your urges to overeat. Here are some suggestions:

- Plan ahead, have a solution ready for difficult situations.

- Distract yourself - immediately find something else to do.

- Take a BIG drink of water, diet soda, tea, or other calorie-free beverages.

- Put something in your mouth like gum, a Tic Tac ${ }^{\otimes}$ mint, toothpick, straw, cinnamon stick, etc.

- Do some exercise - make yourself move!

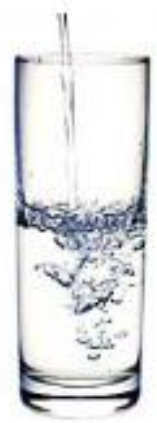

- LEAVE! - just get away from the situation.

- Call someone to get some support and encouragement.

- Learn how to relax yourself. Take a few slow, deep breaths. Tighten your muscles for a moment, and then let go.

- Come up with a "guiding thought" which will make you stop. Say it to yourself over and over and over again.

- Dream up some pleasant imagery of yourself being healthier, proud, more energetic, and happy.

- Think hard about all the benefits you have already gotten from losing weight.

- Pop yourself on the wrist with a rubber band. Gives you something else to think about! 
Appendix C MOVE! Handouts

\section{and}

Changing the Things around You Worksheet

\begin{tabular}{|l|l|}
\hline $\begin{array}{l}\text { Things in my home that trigger } \\
\text { me to overeat or be less active }\end{array}$ & I could fix this problem by: \\
\hline & \\
\hline & \\
\hline & \\
\hline & \\
\hline & \\
\hline & \\
\hline
\end{tabular}

Foods in my home that are not part of a healthy diet

\begin{tabular}{|l|}
\hline Foods in my home that are not part of a healthy diet \\
\hline \\
\hline \\
\hline \\
\hline \\
\hline
\end{tabular}




\section{Take Control of Your Thoughts, Feelings and Behavior}

Your thoughts drive your feelings and actions. In most situations or events, if your thoughts are negative, your feelings will be negative, and you may act negatively.

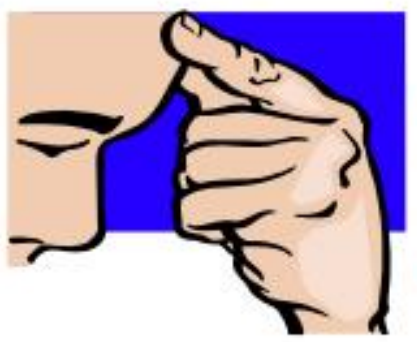

When you catch yourself feeling bad (stressed, angry, hurt, frightened, anxious, sad, depressed, etc.), stop right then and ask yourself what is behind these feelings:

1. What have I been thinking or telling myself? For example: "I will never be able to lose weight."

2. Is this thought sensible, realistic, or am I making something out of nothing? Is there real evidence for thinking this way? For example: "Is it really true that I can never lose weight?"

3. Is it helpful or healthy for me to be thinking this way? For example: "Is it helpful for me to think, I can never lose weight?"

4. What positive thoughts can I use to replace my negative thinking?

For example: "The MOVE! healthcare team will help me to lose weight." 
Appendix C MOVE! Handouts

\section{ander}

My Problem Solving Worksheet

1. Describe the problem in detail:

2. Write down the chain of events leading up to the problem and brainstorm options by considering what else you could have done at each event.

\begin{tabular}{|l|l|}
\hline \multicolumn{1}{|c|}{ Chain of events } & \multicolumn{1}{c|}{ My options } \\
\hline 1. & \\
\hline 2. & \\
\hline 3. & \\
\hline 4. & \\
\hline 5. & \\
\hline 6. & \\
\hline 7. \\
\hline
\end{tabular}

3. Which option would you have picked to break the chain and why? 


\section{Yes! You Can Keep That Weight Off!}

You have been managing your weight successfully for a long time. GREAT!!

Here are some tips to help you keep going:

- Now that you know what works for you keep it up!

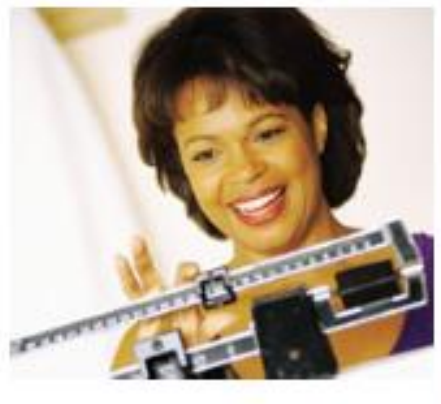

- Write down all the reasons you wanted to lose extra weight in the first place. Look at these carefully, and think about how far you have come.

- Take credit for your success and hard work. Continue to reward yourself often!

- Plan for people, places, and events that might trip you up.

- Keep your thinking POSITIVE.

- Maintain your network of family and friends to provide encouragement and support. Let them know how much their ongoing support is helping you.

- Plan ways in advance for you to deal with difficult situations.

- Find new ways to cope with stress.

- If you do "slip-up", get right back with your program. Give yourself lots of praise for doing that. 


\section{Handling Weight Plateaus}

When losing weight, it is common to have plateaus or times when you can't seem to lose any more weight. Research suggests that our bodies will try to maintain a specific weight or "set-point". This set-point can make getting over a plateau difficult.

\begin{tabular}{|lcll|}
\hline \multicolumn{4}{c|}{ My Weight Log (lbs) } \\
Week 1 & $\frac{285}{285}$ & Week 8 & $\underline{274}$ \\
Week 2 & $\frac{283}{272}$ & Week 9 & $\underline{272}$ \\
Week 3 & $\underline{282}$ & Week 10 & $\underline{268}$ \\
Week 4 & $\underline{280}$ & Week 11 & $\underline{267}$ \\
Week 5 & $\underline{278}$ & Week 12 & $\underline{267}$ \\
Week 6 & $\underline{277}$ & Week 13 & $\underline{267}$ \\
Week 7 & $\underline{276}$ & Week 14 & $\underline{267}$ \\
& & &
\end{tabular}

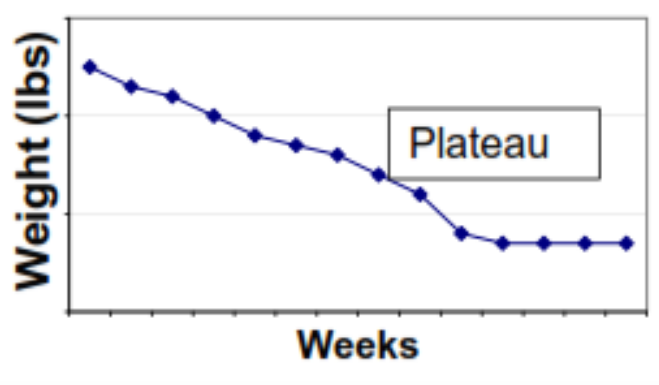

Here are tips that can help with managing plateaus and resetting your set-point:

- $\quad$ Plateaus are often temporary. Stay with your program and you should start losing again.

- Try increasing your physical activity. Adding a few additional minutes or a different kind of physical activity to what you are already doing can get you going again.

- If you haven't been writing down what you eat for a while, start again. You may discover that extra calories have crept into your diet plan.

- $\quad$ Plateaus make you feel like giving up. Remember how hard you have already worked and how far you have come. Don't lose ground, and push a little harder to keep moving past the plateau.

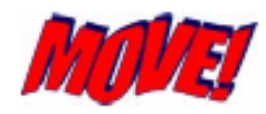




\section{Dealing With Boredom}

Boredom can often lead to overeating. Here are tips:

\section{Get Active}

- $\quad$ Go for a walk.

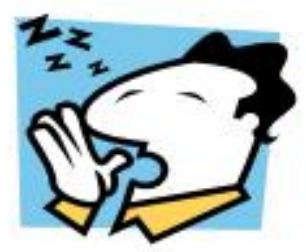

- Put on some fun music and dance.

- Put on an exercise tape and move!

- Walk the dog.

- Mow your lawn.

Occupy Your Mind

- Read a good book.

- Do a crossword puzzle.

- Call an old friend for a chat.

\section{Learn Something New}

- Take up a hobby.

- Do something you have always wanted to do.

- Take a community class.

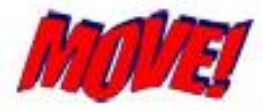


Appendix C MOVE! Handouts

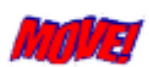

\section{Progress Review Worksheet}

What changes have you made to be more active?

What changes have you made to make healthy food choices?

Have you been reaching your weekly food and activity goals? Yes $\square \quad$ No $\square$

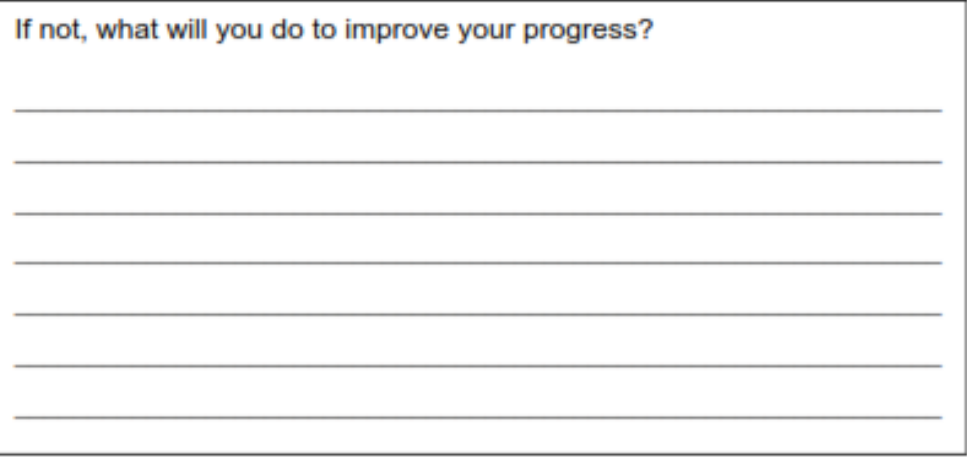


Appendix C MOVE! Handout

\section{MOVE! 23 (MOVE! Questionnaire) \\ Paper and pencil version}

Please print.

NAME:

DATE:

SSN: (Please give all nine digits.)

Height: (feet) (inches)

Weight:

(Please enter measured height and today's weight - Your Body Mass Index or BMI will be calculated from this measurement. Height should be measured without shoes.)

Date of Birth: Month /Day Year

Male or Female (Circle one.)

Ethnicity

Do you consider yourself to be Hispanic or Latino? Select one.

․ Hispanic or Latino A person of Mexican, Puerto Rican, Cuban, South or Central American, or other Spanish culture or origin, regardless of race

ㄴ Not Hispanic or Latino

$\square \quad$ I do not wish to provide this information. 
Appendix C MOVE! Handout

Race

What race do you consider yourself to be? Select one or more of the following.

- American Indian or Alaskan Native A person having origins in any of the original peoples of North, Central or South America, and who maintains tribal affiliation or community attachment

口 Asian

A person having origins in any of the original peoples of the Far East, Southeast Asia, or the Indian subcontinent, including, for example, Cambodia, China, India, Japan, Korea, Malaysia, Pakistan, the Philippine Islands, Thailand, and Vietnam

ㅁ Black or African American

A person having origins in any of the black racial groups of Africa

Native Hawailan or Other Pacific Islander A person having origins in any of the original peoples of Hawaii, Guam, Samoa, or other Pacific Islands

$\square \quad$ White A person having origins in any of the original peoples of Europe, the Middle East, or North Africa

I do not wish to provide this information. 
Appendix C MOVE! Handout

Please complete the following questionnaire.

(All information is confidential and subject to applicable laws regarding privacy of patient records.)

1. I consider myself to be (check one):

a. __ Underweight for my height and age

b. __ Normal weight for my height and age

c. _ Overweight for my height and age

2. In general, would you say that your health is (check one):

a. Excellent

b. Very Good

c. $\longrightarrow$ Good

d. Fair

e. Poor

3. Please indicate (with a check mark to the left) any of the following that apply to you:

Shortness of breath at rest

Chest pains not previously evaluated by your physician

Active infection of any kind

Hernia in the groin or belly area

Retinal hemorrhage (bleeding in the back of the eye)

Loss of balance because of dizziness or passing out

Any chronic medical problem that has recently been out-of-control, unstable or flared up

Arthritis or joint pain

Back pain or spinal disc disease

Osteoporosis or bone disease

Amputation

Spinal cord injury

Lung disease such as emphysema, COPD, or asthma

- Heart disease such as heart failure, heart attack or angina, heart surgery

or angioplasty, irregular heartbeat, implanted defibrillator or pacemaker, heart valve problems

Poor blood circulation in the legs

Stroke or TIAs (mini-strokes) or carotid artery surgery in the neck

Diabetes - even if controlled by medication or diet

High blood pressure - even if controlled by medication or diet

High blood cholesterol - even if controlled by medication or diet

Someone in your immediate family with heart problems at an age younger than 50

None of the above 
Appendix C MOVE! Handout

Please indicate any of the following that apply to you:

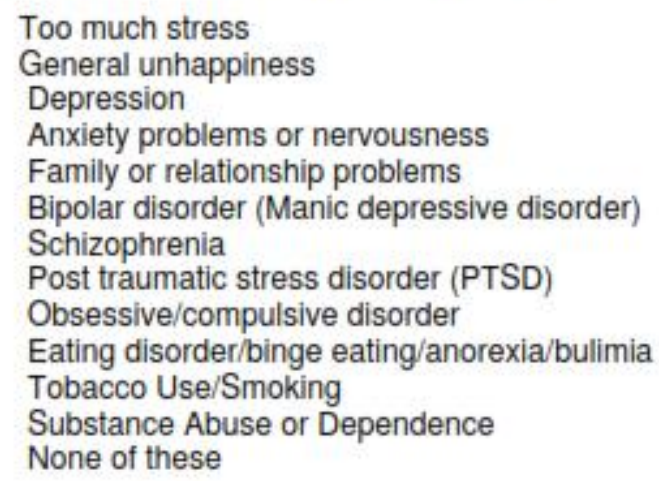

4. Have you tried to lose weight in the past? (Circle one.) Yes No

If so, what of the following options have you tried in order to lose weight? Check all that apply.
a. Some form of dieting, that is eating differently from the way you usually eat for the sake of losing weight
b. Avoiding particular foods or food groups
c. _ Physical exercise, such as walking, swimming or calisthenics
d. Prepackaged meals
e. Meal replacements in bar, powder, liquid, tablet/pill or water form
f. Fasting for 24 hours or longer
g. Skipping meals
h. Hypnosis
i. Comprehensive weight loss program with dietary changes, physical activity, and behavioral counseling
j. __ Any other kind of weight loss program that does NOT provide comprehensive treatment (dietary changes, physical activity, and behavioral counseling)
k. K__ Keeping a log or journal for eating or exercise
l. __ Causing yourself to vomit after you eat
m. Cosmetic procedure such as liposuction or other
n. Weight loss medical procedure such as gastric bypass, gastric banding, wiring of your jaw or other
o. Taking a prescription medication to lose weight
p. ___ Taking an over the counter (OTC) medication; vitamin, mineral, or nutrient supplement; herbal supplement; naturopathic or alternative medicine preparation or supplement to lose weight
q. Smoking to control weight
r. Other 
Appendix C MOVE! Handout

5. Are you trying to lose weight now? (Circle one.) Yes No

If so, what does your current weight loss plan include? Check all that apply.
a. Some form of dieting, that is eating differently from the way you usually eat for the sake of losing weight
b. Avoiding particular foods or food groups
c. Physical exercise, such as walking, swimming or calisthenics
d. Prepackaged meals
e. __ Meal replacements in bar, powder, liquid, tablet/pill or water form
f. ___ Fasting for 24 hours or longer
g. __ Skipping meals
h. Hypnosis
i. _ Comprehensive weight loss program with dietary changes, physical activity, and behavioral counseling
j. ___ Any other kind of weight loss program that does NOT provide comprehensive treatment (dietary changes, physical activity, and behavioral counseling)
k. Keeping a log or journal for eating or exercise
l. Causing yourself to vomit after you eat
m. Cosmetic procedure such as liposuction or other
n. W Weight loss medical procedure such as gastric bypass, gastric banding, wiring of your jaw or other
o. ___ Taking a prescription medication to lose weight
p. _ Taking an over the counter (OTC) medication; vitamin, mineral, or nutrient supplement; herbal supplement; naturopathic or alternative medicine preparation or supplement to lose weight
q. Smoking to control weight
r. Other

6. Select the answer that best describes your rate of weight gain over the years.
a. I I have been overweight since childhood (before age 18).
b. I I have gained weight gradually over the years.
c. I I have gained most of my excess weight in a short period of time.
d. I I have gained and lost weight many times over the years ("yo-yo").

7. Select the answer that best describes your family:

a. _ As a group, my family is not overweight or obese.

b. - As a group, some members of my family are overweight or obese.

c. — As a group, most members of my family are overweight or obese. 
Appendix C MOVE! Handout

8. How much can you rely on family or friends for support and encouragement? (Check one.)
a. A lot
b. $\quad$ Somewhat
c. $\quad$ Not at all

9. How important is controlling your weight to you personally? Please circle the number that applies. Please do not place a circle in the space between numbers.

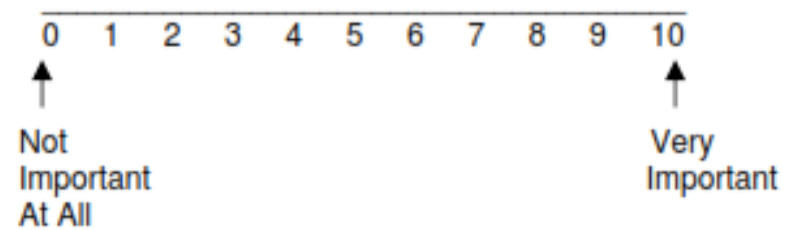

10. How confident are you that you can successfully change your eating and physical activity to control your weight? Please circle the number that applies. Please do not place a circle in the space between numbers.

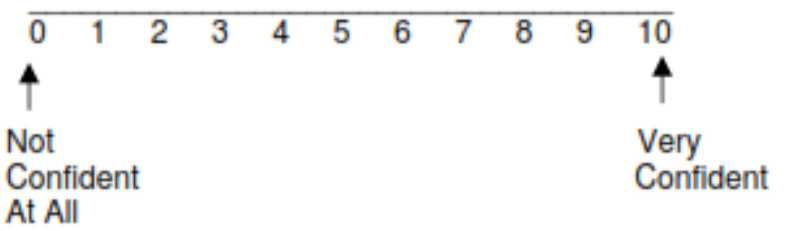

11. Check the statement that most closely applies to you:
a. I I am not considering trying to control my weight at this time.
b. I am considering trying to control my weight sometime within the next six months.
c. I I am ready to make some changes to control my weight.
d. — I am actively working on controlling my weight at this time.

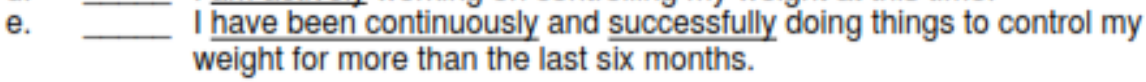


Appendix C MOVE! Handout

12. How much weight do you think you realistically could lose in one year? (Check one.)
a. $10 \mathrm{lbs}$ or less
b. $11-25 \mathrm{lbs}$
c. $\quad 26-50 \mathrm{lbs}$
d. $51-100 \mathrm{lbs}$
e. more than $100 \mathrm{lbs}$

13. How satisfied are you with the appearance of your body? (Check one.)
a. _ Very satisfied
b. Moderately satisfied
c. Neither satisfied or dissatisfied
d. Moderately dissatisfied
e. Very dissatisfied

14. Do any of the following have anything to do with your being overweight? Check all that apply to you.
a. Eating because of emotions or stress
b. — Family or relationship problems
c. Boredom
d. Loneliness or Loss of loved one
e. Eating too much
f. Poor food choices or habits
g. _ Not getting enough physical activity
h. Difficulty with self control
i. Hungry all the time
j. __ Feeling bad about myself
k. Love to eat
l. _uitting tobacco use
m. Pregnancy/Childbirth
n. IIIness or injury
o. __ Medications led to weight gain
p. Other
q. _ None of the above 
Appendix C MOVE! Handout

15. What do you think may get in the way of changing your eating habits? Check all that apply to you.

a. Eating food from restaurants, fast food places, convenience stores, vending machines

b. Person who prepares my food is uncooperative or unsupportive

c. __ Too much high calorie food available at home or work

d. Too little time to prepare and eat healthy food

e. Too little money to buy healthy food

f. —— Feeling hungry much of the time

g. __ Used to eating a certain way

h. _ Difficulties such as stress or depression

i. __ Being with others who overeat

j. Don't know how

k. Other

I. __ Nothing should get in the way

16. How many times a day do you typically eat, including snacks? (Check one.)
a. 1 time a day
b. 2 times a day
c. 3 times a day
d. $\quad 4$ times a day
e. $\quad 5$ or more times each day

17. How many times per week do you eat at restaurants or buy 'take out' food?

Please indicate on the line below the number of times between 0 and 21 . Consider breakfast, lunch and supper 7 days a week for a total of 21 meals for which restaurant or take out food could be eaten.

When you eat out, do you find that you overeat or eat higher calorie foods?
a. Yes
b. No

18. How much juice (including juice-drinks) or sugar-sweetened soda, tea or other beverages do you drink most days? (Check one option below.)

a. I don't drink juice; juice-drinks; or sugar-sweetened soda, tea or other beverages.

b. _ $1-2$ cups, cans, small bottles or drink boxes per day

c. $\quad 3$ or more cups, cans, small bottles or drink boxes per day 
Appendix C MOVE! Handout

19. Do you drink alcoholic beverages (such as beer, malt liquor, wine, wine coolers, hard/distilled liquor)? (Check one.)
a.
Yes

b.

No

20. How fast do you usually eat? (Check one.)
a. I eat slowly.
b. I I eat at a moderate pace.
c. I eat fast.

21. On average, how often have you eaten extremely large amounts of food at one time and felt that your eating was out of control at that time? (Check one.)
a. Never
b. Less than 1 time per week
c. 1 time per week
d. 2 to 4 times a week
e. 5 or more times a week 
Appendix C MOVE! Handout

22. What do you think may get in the way of changing your physical activity habits? Check all that apply to you.
a. _ Too little time
b. $\longrightarrow$ Too little money
c. Safety concerns
d. No place to walk or be active
e. No transportation
f. Lack of support or encouragement from others
g. Difficulties such as stress, depression, etc.
h. Do not like to exercise
i. Daily habits or routines that do not include exercise
j. Pain
k. Amputation
L. $\square$ Back problems
m. Arthritis
n. Muscular problems
o. — Heart or lung disease
p. _ Joint problems
q. — Spinal cord injury
r. $\longrightarrow$ Too tired
s. Job or work schedule
t. Other
u. —— Nothing should get in the way

23. This next question asks about your physical activity habits. There are two types of activity to consider:

- Moderate physical activities cause light sweating and a slight to moderate increase in breathing or heart rate. Examples include brisk walking, bicycling, vacuuming, gardening, and golfing without a cart.

Vigorous activities cause heavy sweating and large increases in breathing or heart rate. Examples include running, aerobic classes, heavy yard work, and briskly swimming laps.

a. How many days per week do you do moderate activities for at least 10 minutes at a time? Please circle the appropriate number. Please do not place a circle in the space between numbers.

$\begin{array}{llllllll}0 & 1 & 2 & 3 & 4 & 5 & 6 & 7\end{array}$


Appendix C MOVE! Handout

b. On days when you do moderate activities for at least 10 minutes at a time, how much total time per day do you spend doing these activities? (Select one choice below.)
a. 10-19 minutes
b. 20-29 minutes
c. $30-59$ minutes
d. $>=60$ minutes

c. How many days per week do you do vigorous activities for at least 10 minutes at a time? Please circle the appropriate number. Please do not place a circle in the space between numbers.

$\begin{array}{llllllll}0 & 1 & 2 & 3 & 4 & 5 & 6 & 7\end{array}$

d. On days when you do vigorous activities for at least 10 minutes at a time, how much total time per day do you spend doing these activities? (Select one choice below.)
a. 10-19 minutes
b. 20-29 minutes
c. 30-59 minutes
d. $\longrightarrow>60$ minutes 
Appendix E

\section{DATA COLLECTION SHEET}

\section{SUBJECT \#:}

AGE:

SEX:

RACE:

MARITAL STATUS:

DATE OF INITIAL VISIT:

INITIAL B/P:

INITIAL WEIGHT:

BMI:

INITIAL HEIGHT:

GOAL WEIGHT:

INITIALSTEPS/DAY:

COMORBIDITIES:

GOALS SET:

GOALS ACHIEVED:

SUBSEQUENT VISIT INFORMATION:

\begin{tabular}{|l|l|l|l|l|l|}
\hline DATE & WEIGHT & BMI & BLOOD PRESSURE & AVERAGE STEPS/DAY & COMMENTS \\
\hline & & & & & \\
\hline & & & & & \\
\hline & & & & & \\
\hline & & & & & \\
\hline \\
\hline
\end{tabular}


Appendix F Food and Activity Logs

\section{MOVE! Group Sessions \\ Food and Physical Activity Diary}

www.move.va.gov

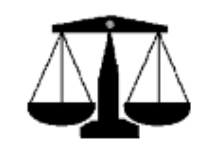


Appendix F Food and Activity Logs

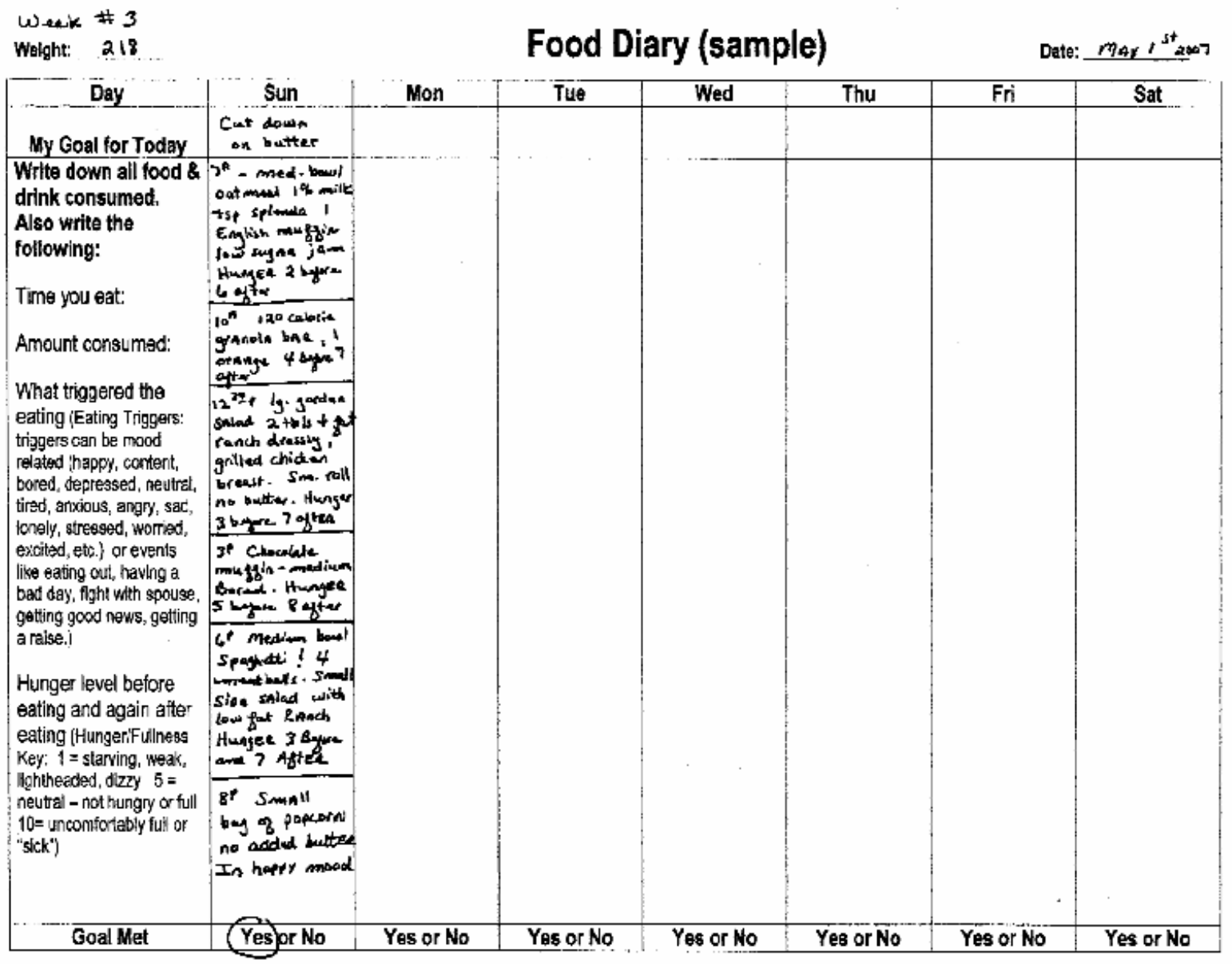


Appendix F Food and Activity Logs

\begin{tabular}{|c|c|c|c|c|c|c|c|}
\hline Weight: 218 & Phys & sical Activit & $\begin{array}{r}\text { and } P_{\epsilon} \\
\text { (sa }\end{array}$ & $\begin{array}{l}\text { meter/ } \\
\text { le) }\end{array}$ & meter & & $m_{A Y} 1^{54} 2007$ \\
\hline Day & Sun & Mon & Tue & Wed & Thu & Fri & Sat \\
\hline $\begin{array}{l}\text { My activity } \\
\text { goal for today }\end{array}$ & $\begin{array}{l}\text { Walk } \\
30 \text { minute } \\
\text { todny at } \\
\text { one time }\end{array}$ & $\begin{array}{l}\text { Do } \\
\text { fleribility } \\
\text { expercises }\end{array}$ & & & & & \\
\hline \multirow[t]{4}{*}{$\begin{array}{l}\text { Physical } \\
\text { activity I did } \\
\text { today }\end{array}$} & \multirow{4}{*}{$\begin{array}{l}\text { Walked to } \\
\text { grocery stare } \\
\text { (10 min) } \\
\text { Took at } \\
20 \text { minute } \\
\text { nonstop walk }\end{array}$} & $\begin{array}{l}\text { Walked } 10 \\
\text { min utes white } \\
\text { waitig for } \\
\text { mous! meas th to } \\
\text { brgin }\end{array}$ & & & & & \\
\hline & & $\begin{array}{l}\text { Mowed } \\
\text { lawn for } \\
30 \text { min }\end{array}$ & & & & & \\
\hline & & $\begin{array}{l}\text { Dio move! } \\
\text { Handont stretches } \\
\text { yor } 10 \text { min. }\end{array}$ & & & & & \\
\hline & & $\begin{array}{l}\text { Walked is min. } \\
\text { at lunch }\end{array}$ & & & & & \\
\hline $\begin{array}{l}\text { Minutes of } \\
\text { activity }\end{array}$ & $30 \mathrm{~min}$. & 65 mis. & & & & & \\
\hline $\begin{array}{l}\text { Pedometer } \\
\text { steps or } \\
\text { odometer } \\
\text { distance }\end{array}$ & $\begin{array}{l}3500 \\
\text { staps }\end{array}$ & $\begin{array}{l}7800 \\
\text { Steeps }\end{array}$ & & & & & \\
\hline Goal Met & Yes or(No) & Yessor No & Yes or No & Yes or No & Yes or No & Yes or No & Yes or No \\
\hline
\end{tabular}


Appendix F Food and Activity Logs

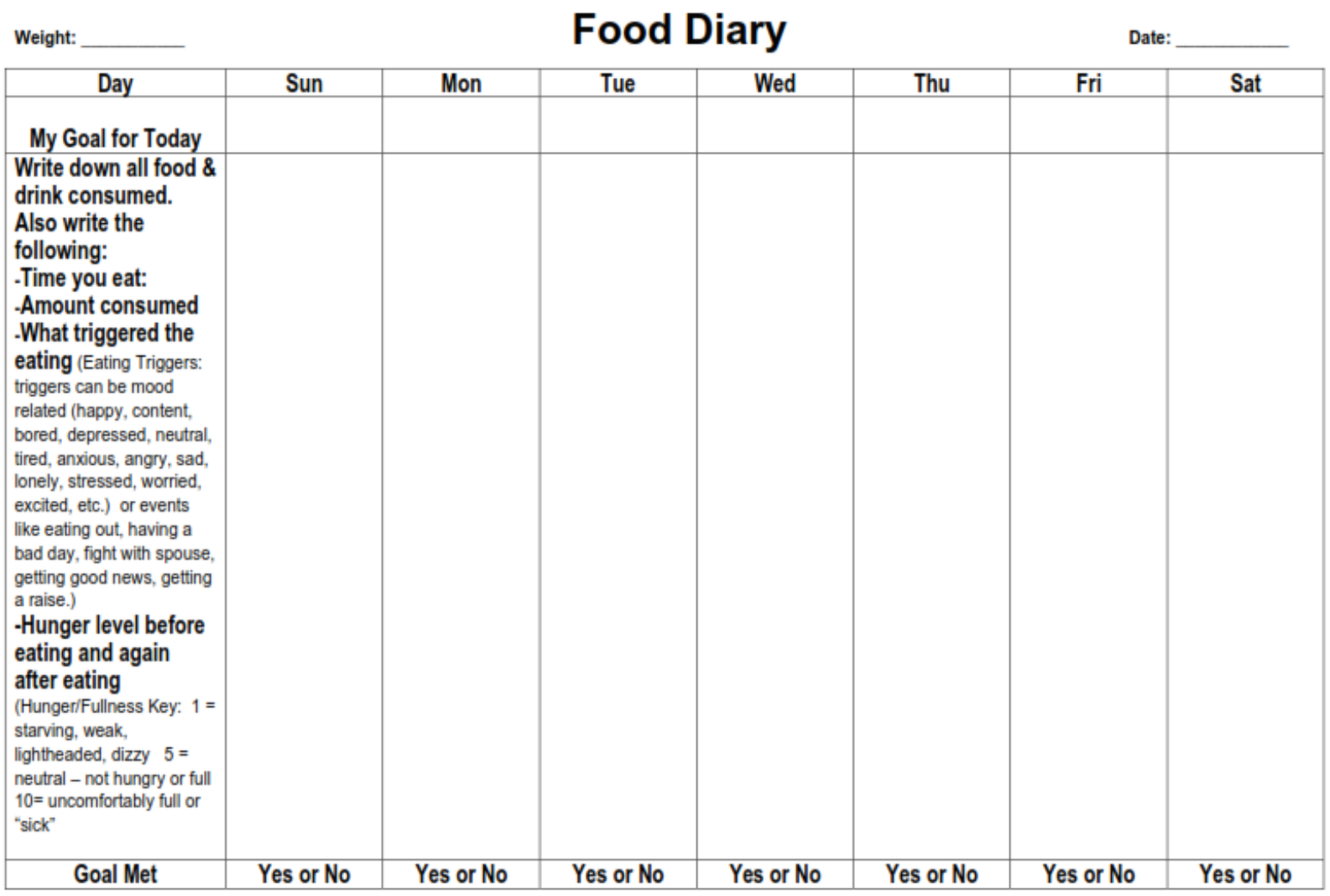


Appendix F Food and Activity Logs

\begin{tabular}{|c|c|c|c|c|c|c|c|}
\hline \multirow{2}{*}{$\begin{array}{l}\text { Weight: } \\
\text { Day }\end{array}$} & \multicolumn{6}{|c|}{ Physical Activity and Pedometer/Odometer Diary } & Date: \\
\hline & Sun & Mon & Tue & Wed & Thu & Fri & Sat \\
\hline $\begin{array}{l}\text { My activity } \\
\text { goal for tod }\end{array}$ & & & & & & & \\
\hline $\begin{array}{l}\text { Physical } \\
\text { activity I dic } \\
\text { today }\end{array}$ & & & & & & & \\
\hline $\begin{array}{l}\text { Minutes of } \\
\text { activity }\end{array}$ & & & & & & & \\
\hline $\begin{array}{l}\text { Pedometer } \\
\text { steps or } \\
\text { odometer } \\
\text { distance }\end{array}$ & & & & & & & \\
\hline Goal Met & Yes or No & Yes or No & Yes or No & Yes or No & Yes or No & Yes or No & Yes or No \\
\hline
\end{tabular}


Appendix G Budget

Capstone Budget- Estimated for three months

\section{EXPENSES}

Salaries

Nurse Practitioner 10 hours monthly @ \$40.00/hour

Medical Assistant 5 hours monthly@ @12.00/hour

Registration Clerk 3 hours monthly @ 10.00/hour

Scheduling Clerk 5 hours monthly @ \$8.00/hour

Rent/Utilities/Office Equipment

Copying Fees

Total

$\begin{array}{lr}\begin{array}{l}\text { Month } \\ \$ 400.00\end{array} & \begin{array}{c}\text { Three Months } \\ \$ 1200.00\end{array} \\ \$ 60.00 & \$ 180.00 \\ \$ 30.00 & \$ 90.00 \\ \$ 40.00 & \$ 120.00\end{array}$

$\$ 166.67$

$\$ 1650.00$

$\$ 2346.67$ 
Appendix H WLC Letter of Support

\title{
Weight Center \\ AFFILIATED WITH \\ C) Charleston Area \\ Mic Medical Center
}

600 Tracy Way

Charleston, WV 25311

Phone: (304) 388-4965

Fax: (304) 343-4850

October 1, 2012

\author{
Kimberly A. Bird, APRN, FNP, Student DNP \\ Nurse Practitioner \\ Charleston Area Medical Center, Inc. \\ Outpatient Care Center \\ 3200 MacCorkle Avenue, SE \\ Charleston, WV 25304
}

Dear Mrs. Bird:

Charleston Area Medical Center Health System, Inc., Weight Loss Center is pleased to support your Capstone Proposal: The Effectiveness of Group Education Weight Loss Sessions with Overweight or Obese Adults. Given the increasing epidemic of obesity and its' co-morbidities, we would welcome the opportunity to assist you in this project.

Please let me know how the clinic staff and/or management staff can assist you in this very important project.

Sincerely,

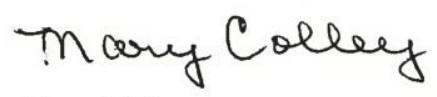

Mary Colley

Practice Administrator

Weight Loss Center

Medical Weight Loss

Comprehensive; Multidisciplinary (Medical Providers, Psychologist, Dietitian, Exercise Physiologist, Exercise Facility
Laparoscopic Surgery

Gastro-Intestinal (Esophagus, Stomach, Small Intestine, Colon, Rectum); Hepato-Biliary (Liver, Gallbladder, Common Bile Duct); Solid Organs (Adrenal Glands, Spleen, Pancreas); Hernias (Para-esophagea//Hiatal, Diaphragmatic, Incisional, Ventral, Inguinal); Anti-Reflex Surgery (Nissen Fundoplication, Toupal Fundoplication) 


\section{Appendix I HR Letter of Support}

\section{Q Charleston Area Medical Center}

HUMAN RESOURCES

PO Box 1547

Charleston, WV 25326

April 23, 2013

Kimberly, A. Bird, MSN, FNP-BC, GNP, BC

Nurse Practitioner

Charleston Area Medical Center, Inc.

Outpatient Care Center

3200 MacCorkle Avenue, SE

Charleston, WV 25304

Dear Mrs. Bird:

Charleston Area Medical Center, Inc., Human Resources Department is pleased to support your Capstone Proposal: Implementation of the MOVE! Program at Medical Weight Loss Center. Given the increasing epidemic of obesity and its' co-morbidities, we would welcome the opportunity to assist you in this project.

Please let me know how the Human Resources staff can assist you in this very important project.

Sincerely,

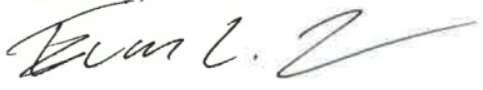

Evan L. Thoman MS, CSCS

Health and Wellness Coordinator

Charleston Area Medical Center, [nc

O: 304-388-7593

evan.thoman@camc.org 
